\title{
An Investigation of Sites, Uses and Practices for Literacy in the Lives of Pasifika Students
}

\begin{abstract}
John G. Dickie
This thesis is submitted in fulfilment of the requirements of the degree of Doctor of Philosophy in Education, Victoria University of Wellington.
\end{abstract}

January 2008 


\section{Abstract \\ An investigation of sites, uses and practices for literacy in the lives of Pasifika students}

Lower test scores on school measures of literacy for Pasifika students than for the majority of students in New Zealand are a cause for concern. As part of a wider attempt to address this problem the Ministry of Education has argued that teachers need to be better informed of out-of-school literacy practices. This thesis considers what can be learned when this guidance is followed and it investigates students' social and cultural uses of literacy in family and community settings. It explores the argument that knowledge of these out-of-school literacies will inform teachers and through incorporation (McNaughton, 2002) teachers may be able to make effective connections for students to school literacy.

A sociocultural perspective is used to investigate the social and cultural practices of the students while the study also uses Cremin's (1976) concept of configurations of sites to consider how learning is mediated for students in different settings. Rogoff's (1995) three planes of analysis provide a tool to examine students' practices at the community, interpersonal, and personal levels.

The investigation sought the students' own perspective of how they appropriate knowledge about literacy as they collected information with cameras and journals on their own practices. The participants were 14 Pasifika students aged 11 and 12 years (mostly Samoan) as well as three adult Samoan church representatives and teachers from the students' school. Students' photos were used to elicit rich description in semi-structured interviews and interview schedules were also used with students and adult participants.

The findings illustrate how the students were socialised into particular practices that are contextualised in the sites of family, church and neighbourhood. They reveal that for the students there was both overlapping of values and conflict between their sites of literacy practice. The complementarities occurred most strongly between family and church and a valued feature of the students' practice was the use of Samoan language. The most common conflicts were those related to popular culture and they occurred between the sites of family, church and school on the one hand and neighbourhood sites on the other as well as within family sites. The thesis argues that 
awareness of the complementary and conflicting features is essential for teachers in understanding the complexity the students face in choosing their paths among two cultures. This knowledge enables teachers to incorporate aspects of out-of-school literacy into school practice and to draw on those in the students' backgrounds who may facilitate students' literacy acquisition. 


\section{Acknowledgements}

I would like to express my thanks to the following people who assisted me with this project:

The year 7 and 8 students who agreed to participate in the study as my junior ethnographers and who contributed by recording and sharing their own experiences of literacy practices.

The principal and teachers of the students' school who were generous with their time and who provided assistance with the investigation in many ways. Thank you for welcoming me into your school as a colleague.

The three church representatives who were interviewed.

My supervisors, Professor Janice Wearmouth, Dr Robert Strathdee, Barbara Craig, Dr Keith Sullivan and Dr Geraldine McDonald. Each has contributed in a valuable way to inform this project and to guide me as a researcher. I must acknowledge and thank Janice for her considerable contribution, particularly in guiding the analysis of data. Both Janice and Rob have been extremely generous with their time in critiquing and supporting the many drafts leading up to submission of the thesis.

I owe a special thanks to Geraldine who has been my supervisor, mentor and friend. She has followed this project from the beginning with great interest and has encouraged me with stimulating readings, challenging questions, and fresh ideas.

My special thanks go to Doreen O'Sullivan, Pele Tui and Sherryn Stuart who provided invaluable advice and support for the project. Their help made this study possible.

Feaua'i Burgess, Tolo Pereira, Fuapepe Rimoni, Galu Hunkin-Tuiletufuga and Sam Lees who advised on Samoan and Pasifika aspects of the study and who assisted me with advice, encouragement and resources. 
The librarians in the Victoria University College of Education library who have been so helpful in many ways. I am especially grateful to Elizabeth Clark for her guidance in literature searches, and also to Linnea Dale and Rebecca Lythe.

Other College of Education colleagues including Jan Baynes, Margaret Gleeson, Gin Weston, and Karen Coulton.

Susan Kaiser for her assistance with formatting and proofreading the thesis.

My nephews Edmund and Karim and my niece Charmian for trialling the initial idea with a camera, and Edmund for his tuition on computer games.

I would also like to thank the management of the Faculty of Education, Victoria University of Wellington for supporting this study through provision of scholarships.

\section{Dedication}

I dedicate this thesis to my parents, Alec and Eve 


\section{TABLE OF CONTENTS}

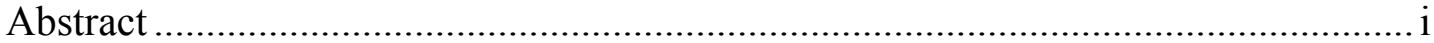

Acknowledgements ............................................................................................ii

Chapter 1 Introduction And Positioning ………………………………….... 1

Rationale for the investigation .......................................................................... 1

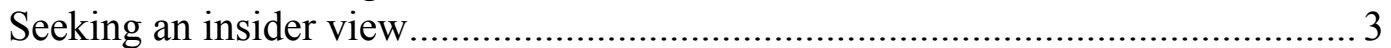

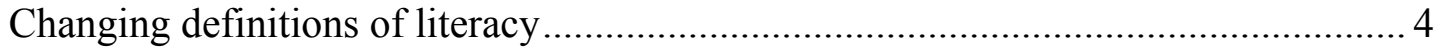

Pasifika students in New Zealand ......................................................................... 6

Pasifika student achievement ....................................................................... 7

Ministry of Education initiatives for Pasifika students ......................................... 8

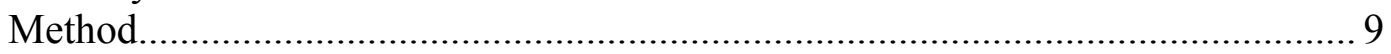

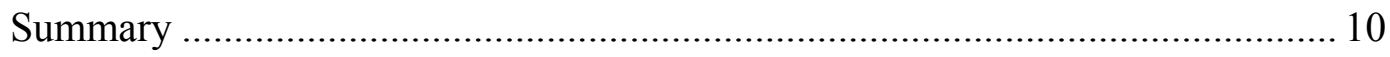

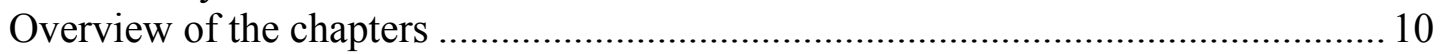

Chapter 2 Literacy As Social Practice: Past To Present ........................................ 13

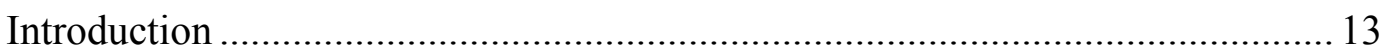

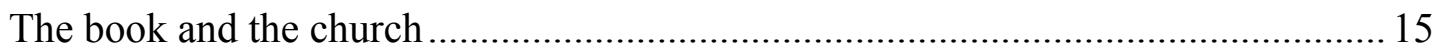

Beginnings of universal literacy: hegemony not liberation ........................................ 16

Literacy introduced to New Zealand ............................................................. 18

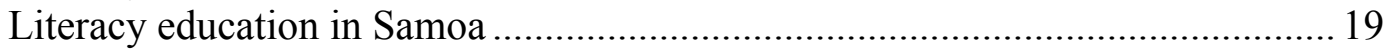

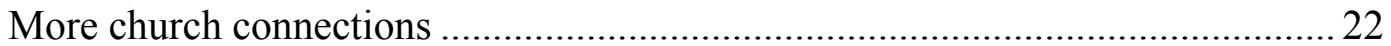

Family literacy defined as social and cultural practice ........................................ 22

Literacy to maintain hegemony and as a means to enlightenment................................2 23

Development of literacy as popular culture ……………………………………..... 25

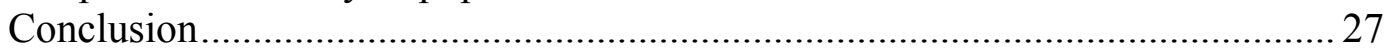

Chapter 3 A Theoretical Framework and Review of the Literature................... 28

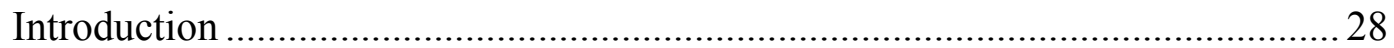

Part One: The theoretical perspective ………………………………………….... 29

Cremin's multiplicity of institutions that educate..................................................... 29

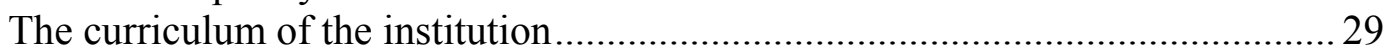

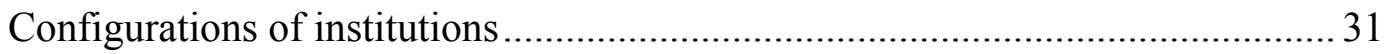

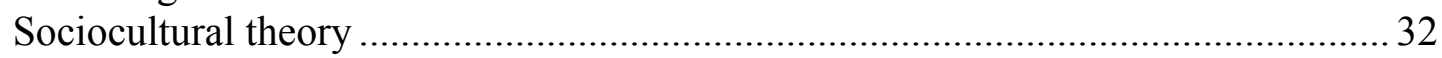

Rogoff's three planes of analysis ............................................................................ 35

Part Two: The Studies of Literacy as Social Practice ……………………………........ 39

A sociocultural perspective on "literacy" ............................................................. 39

Introducing Street's autonomous paradigm ........................................................ 40

Street's ideological model of literacy ................................................................ 42

Heath's study of literacy in three culturally different communities ........................... 44

Patterns of language: socialisation for success or failure at school ....................... 45

One community's patterns for success in literacy at school ................................... 46

Scribner and Cole's investigation into Vai literacy .................................................... 48

Literacy practices and literacy events ..................................................................5 50

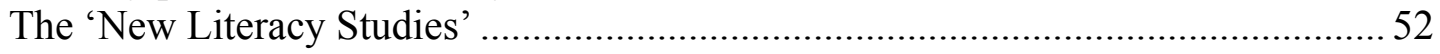

The concept of multiple literacies and multiple sites .............................................5

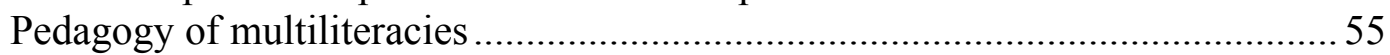

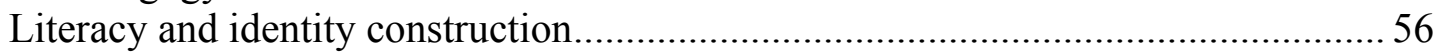

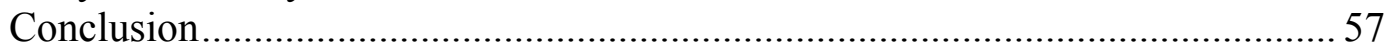


Chapter 4 Curriculum Critique

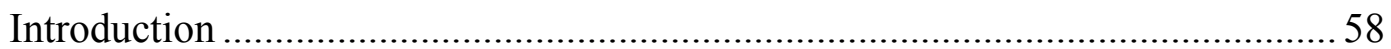

Part One: The official requirements for literacy in New Zealand schools................59

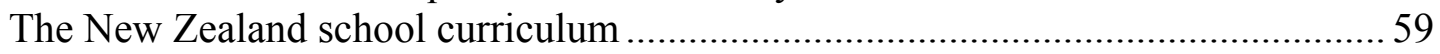

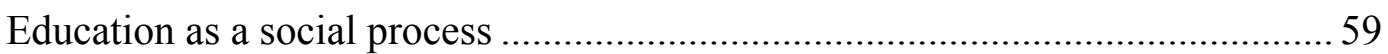

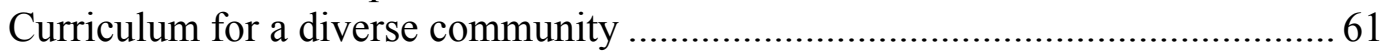

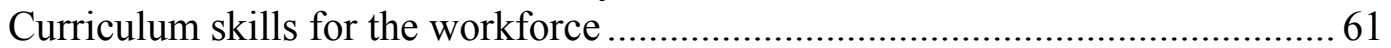

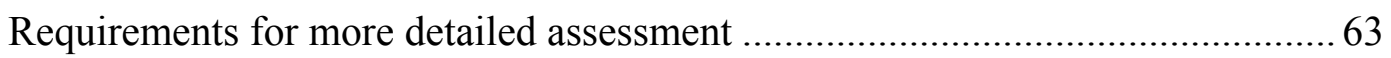

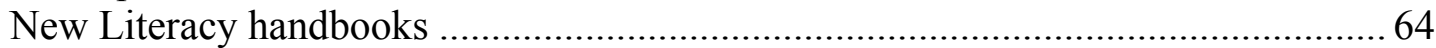

Increasing recognition of students' cultural backgrounds...................................6 67

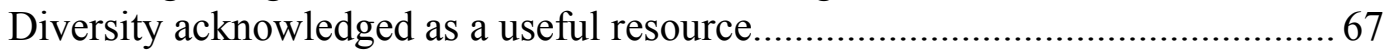

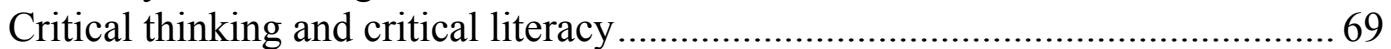

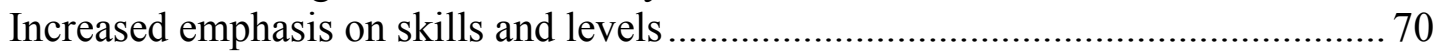

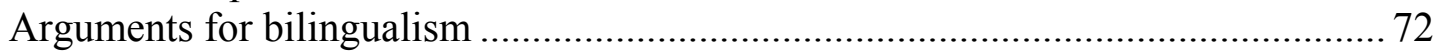

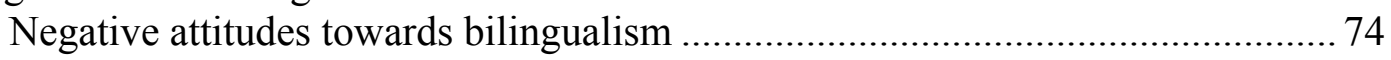

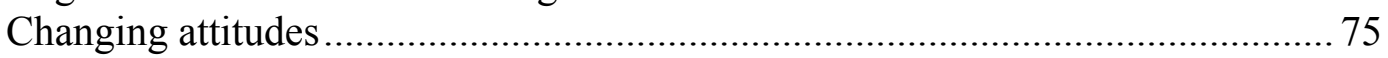

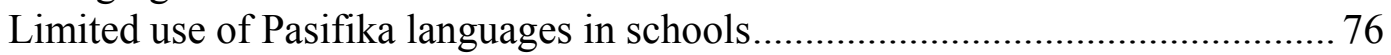

Part Two: Making connections between out-of-school practice and the curriculum ..... 77

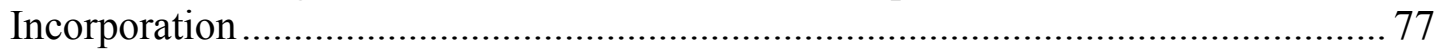

Making the unfamiliar familiar for Samoan students......................................... 78

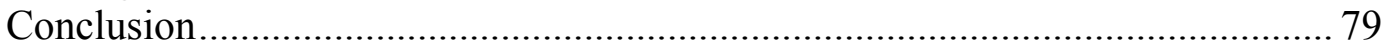

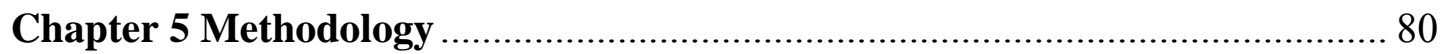

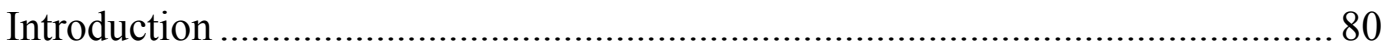

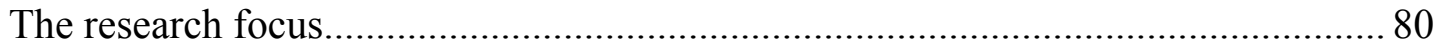

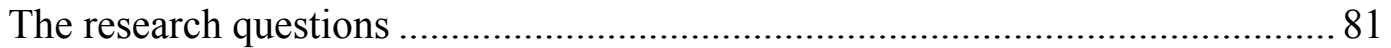

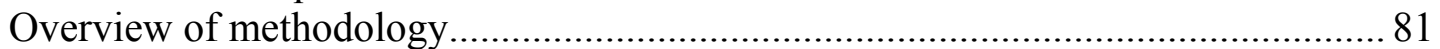

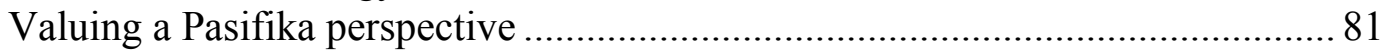

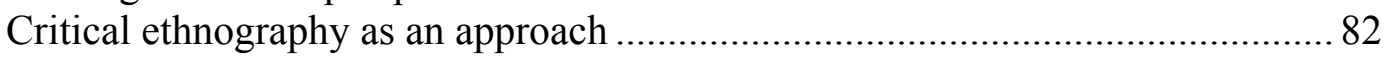

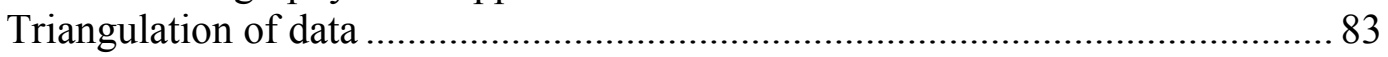

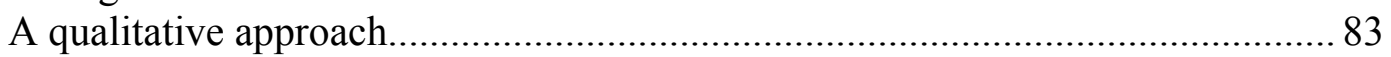

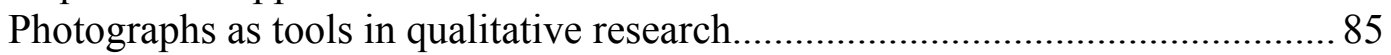

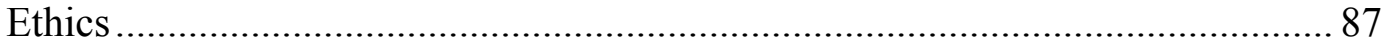

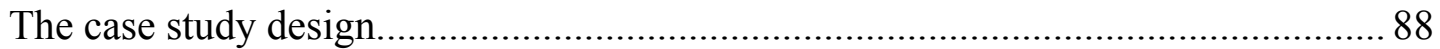

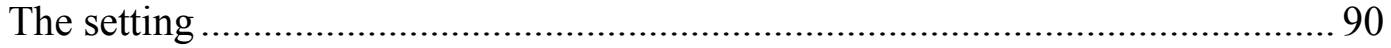

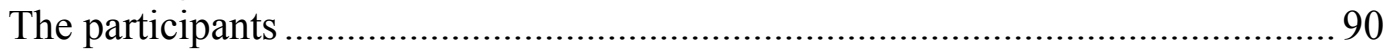

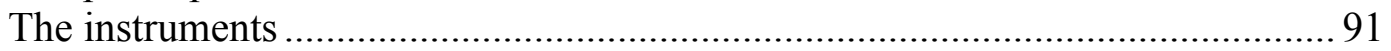

Instruments for data gathering from adult participants ...................................... 93

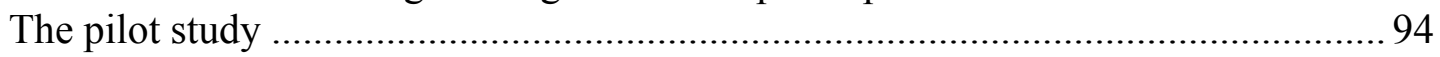

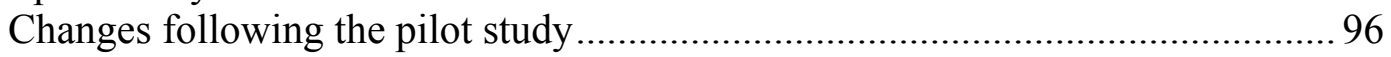

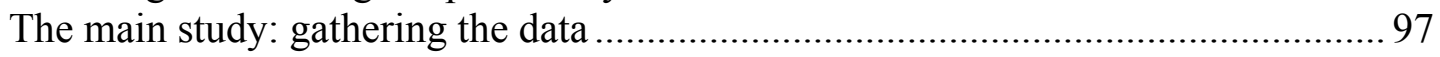

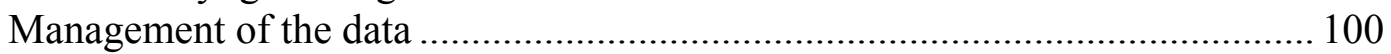

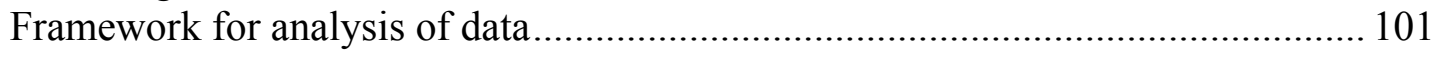

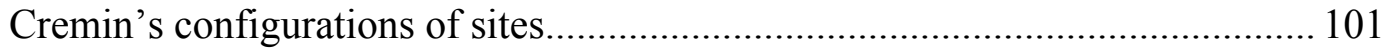

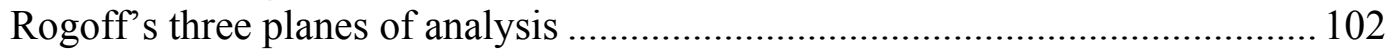

Contextual Background to the School Community .................................................... 110

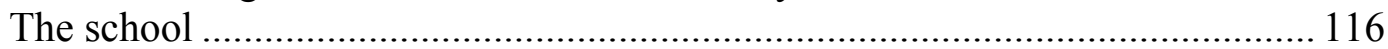

Ethnic composition of the student roll …...................................................... 116 
Chapter 6 Family Sites for Literacy …………………………………………. 119

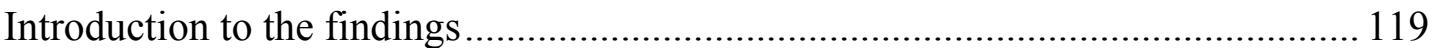

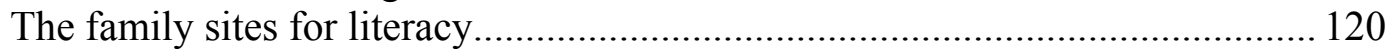

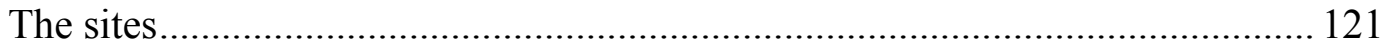

Teachers and curriculum of the family.............................................................. 123

1/ Maintenance of the Samoan language and culture among family members ....... 125

Students' own ratings of speaking, reading and writing in Samoan .................... 126

Using Samoan language for family communication ............................................ 127

2/ Students nurturing school-type reading skills with younger children in the family. 130

3/ Supporting school literacy............................................................................ 133

4/ Literacy for entertainment and pleasure including the fields of popular culture of computer games, music, books and magazines............................................. 135

Literacy for entertainment and pleasure (i) Computer games ............................... 136

Conflict with other agencies (family and religion) …………………………...... 140

Literacy for entertainment and pleasure (ii) Music ............................................ 142

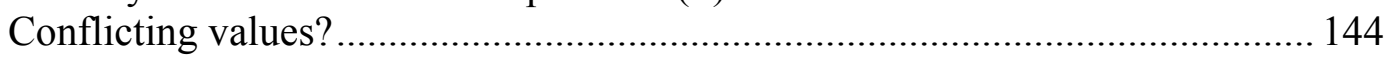

Literacy for entertainment and pleasure (iii) Books and magazines .................... 147

5/ Reading and writing to help organise students' lives ......................................... 150

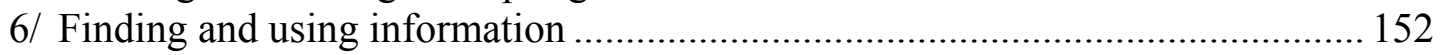

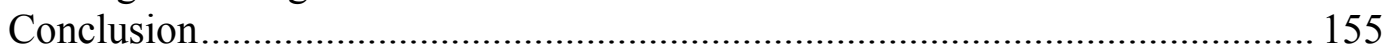

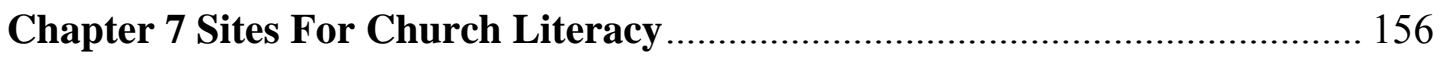

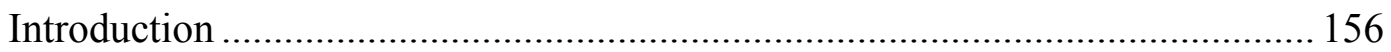

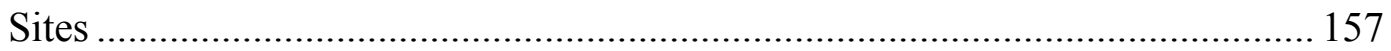

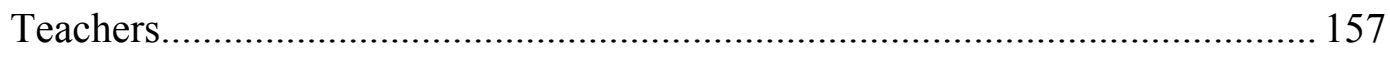

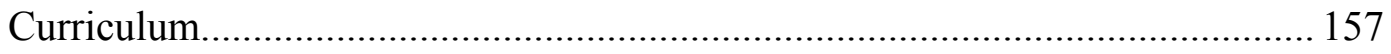

Examples of reading in church sites.................................................................. 159

Examples of writing in church sites .................................................................. 160

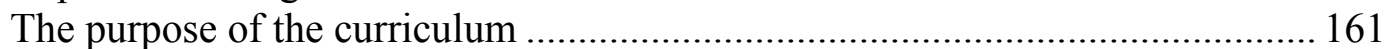

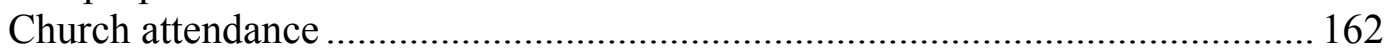

Literacy practices related to the Bible ............................................................. 164

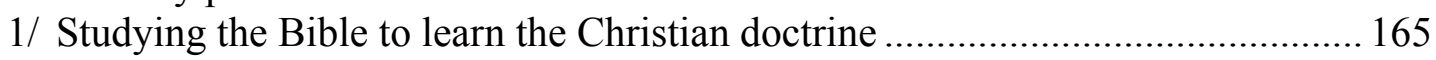

Guided participation in Bible reading and family prayers ................................... 166

Sharing the community's values ........................................................................ 167

2/ Accurate oral reading of the Bible for an audience.............................................. 169

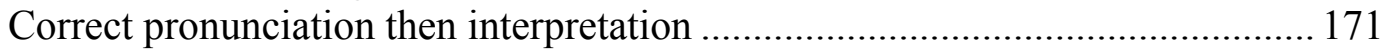

Comprehension is taught ......................................................................... 172

3/ Reading passages of the Bible to memorise and recite them to an audience:

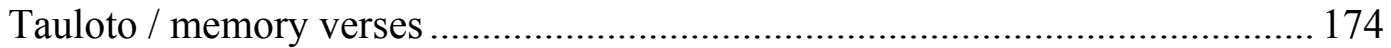

Guided participation in learning tauloto............................................................ 176

Tauloto as part of the community's curriculum .................................................. 177

4/ Maintenance of the Samoan language through religious practices ......................... 179

Maintaining traditional community values........................................................ 181

Christian doctrine taught in Samoan and English ............................................... 182

5/ Assessment of church curriculum through Sunday school tests and exams ....... 183

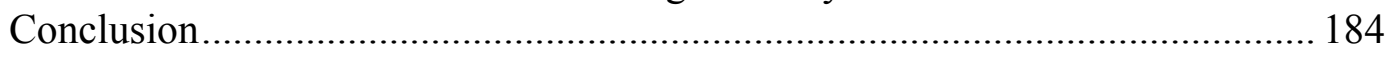


Chapter 8 Neighbourhood Sites for Literacy …............................................ 186

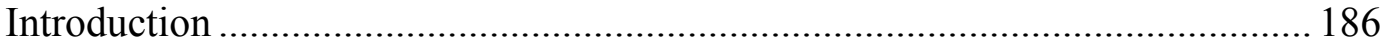

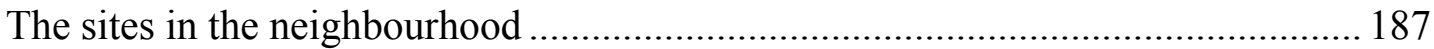

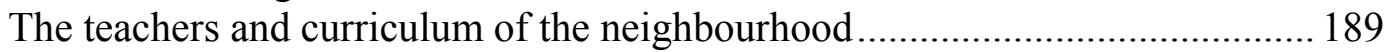

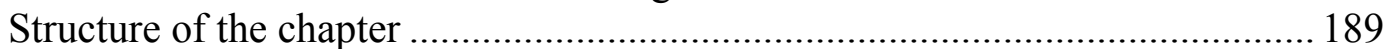

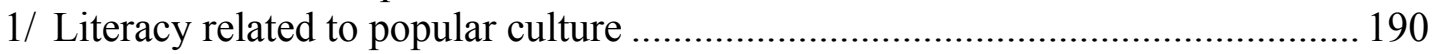

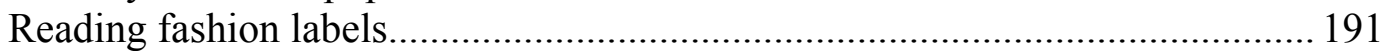

Identifying with the most popular brand: Chuck Taylor shoes .......................... 194

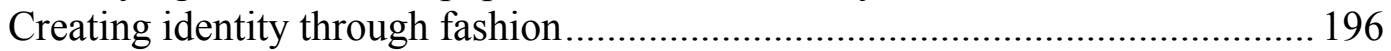

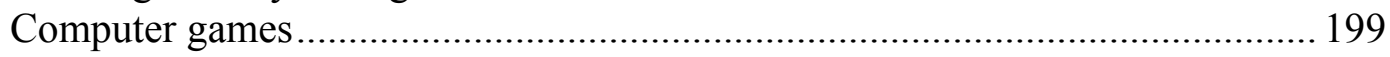

Popular culture texts in the community library .............................................. 201

Values of popular culture may clash with those of family and school............... 202

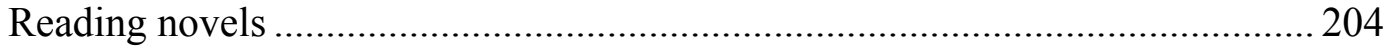

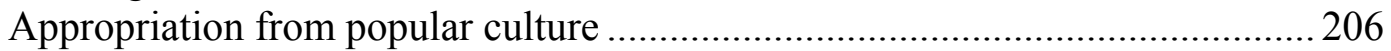

2/ Support for "school-type" literacy in the neighbourhood site of the library....... 208

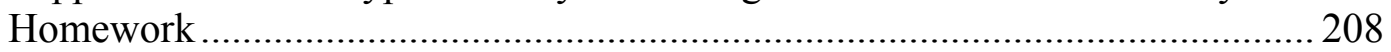

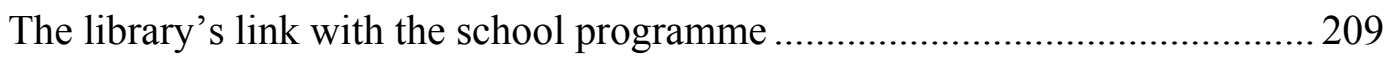

The library as a site for socialisation as well as homework ............................. 210

3/ Literacy for finding and purchasing goods and services ................................. 211

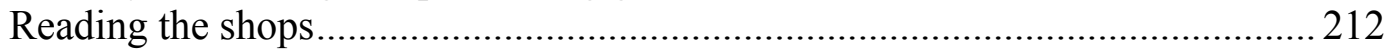

4/ Literacy for navigating one's way in the neighbourhood................................ 216

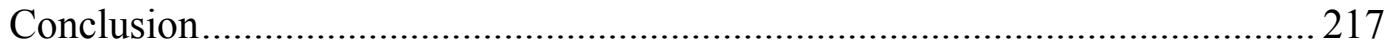

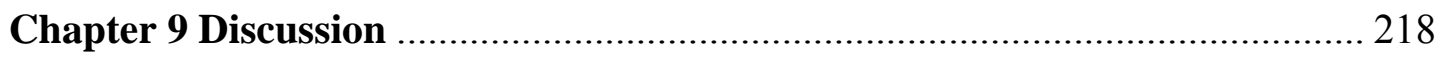

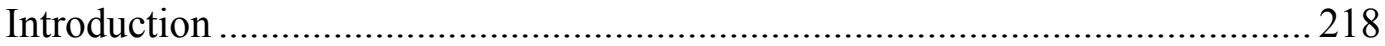

Part One: The configurations with the consonant and dissonant features of sites... 222

Section A: The complementary relationships: The overlaps between sites............ 223

The configuration of family with other sites .................................................. 223

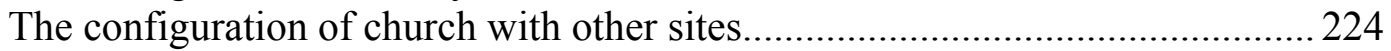

The configuration of the neighbourhood with other sites ................................. 225

Section B: Contradictory values: The conflicts between sites .............................. 227

Cultural and social perspectives on popular culture......................................... 227

Cultural perspectives on reading ................................................................... 229

Cultural and social uses of language: Mother tongue or dominant language ..... 235

Part Two: Implications for classroom practice ................................................... 238

Section A: Discussion of complementary and conflicting values and aims ........... 238

Complementary values, aims, curriculum and pedagogy................................ 238

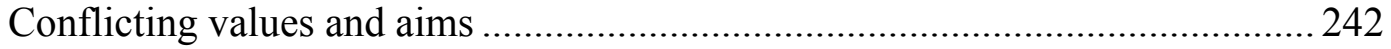

Section B: Incorporation of out-of-school literacy practices to enhance school

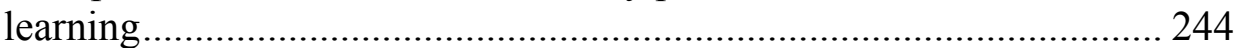

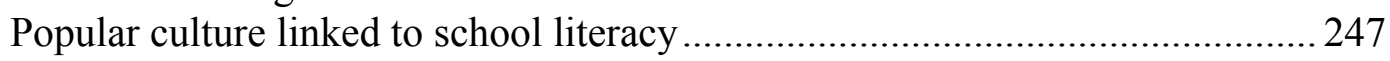

Matching family and school practices: words and books................................ 256

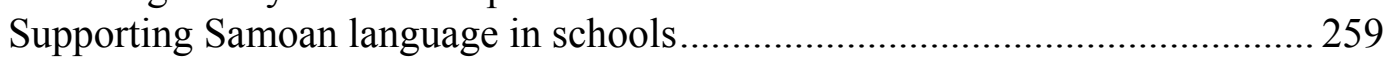

Need for flexibility in assessing and teaching.............................................. 262

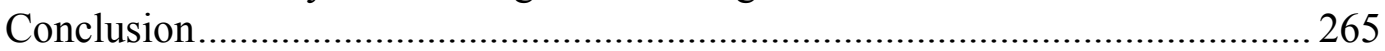




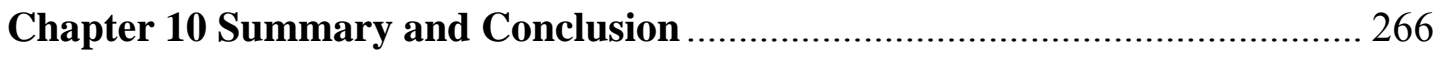

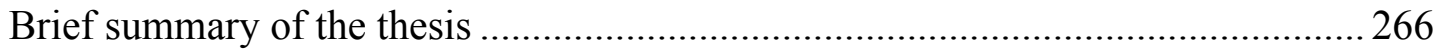

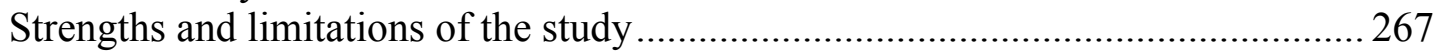

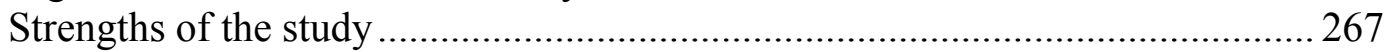

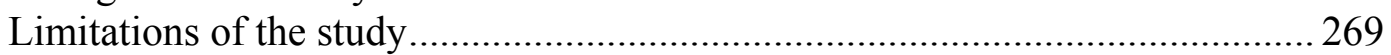

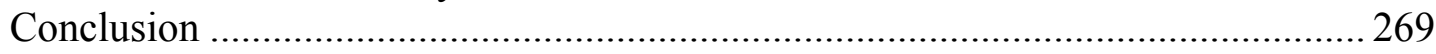

The implications for practice in schools....................................................... 269

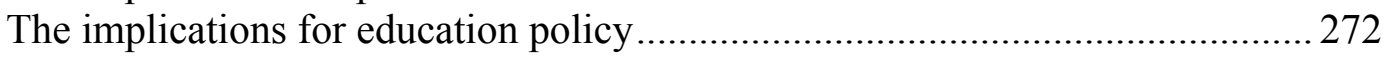

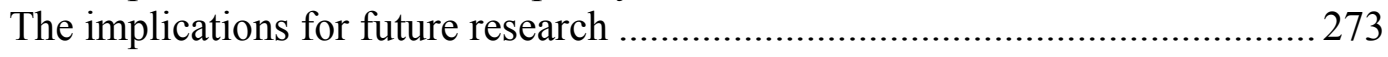

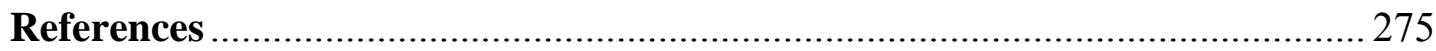

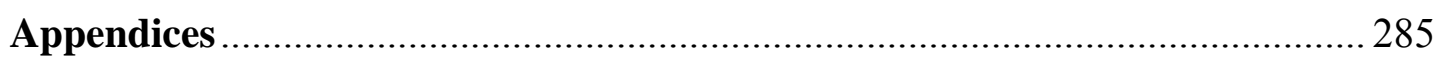

Appendix A: Interview schedule for meeting one with Year 7 and 8 students...... 286

Appendix B: Discussion guide for meeting two with Year 7 and 8 students ........ 289

Appendix C: Interview schedule for Church representatives ................................ 290

Appendix D: Information sheet for principals, teachers, parents/caregivers and

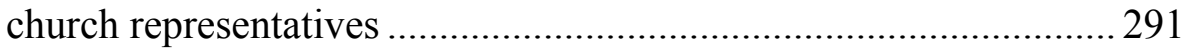

Appendix E: Consent form for Church representatives...................................... 292

Appendix F: Consent form for principals of participating schools ...................... 293

Appendix G: Parents/Caregivers consent form for their child ...............................295

Appendix H: Parents'/Caregivers' consent form for their child ............................ 296

Appendix I: Meeting three interview schedule for students ............................... 297

Appendix J: Discussion guide for meeting with school staff .............................. 299

Appendix K: Consent form for using photographs in the thesis ............................ 301 


\section{List of Figures}

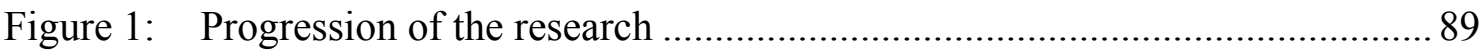

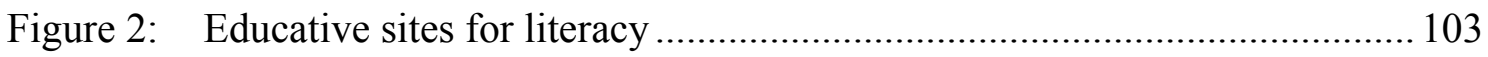

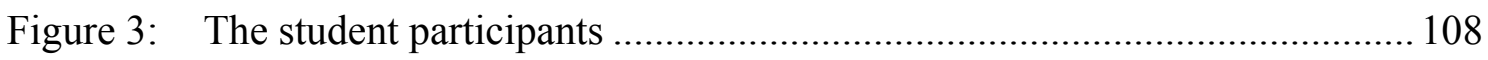

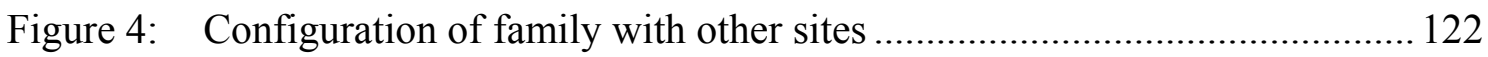

Figure 5: Eseta reading the Samoan language newspaper with her grandfather as

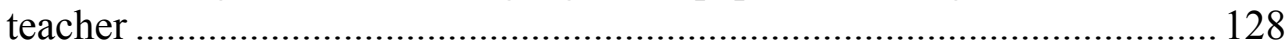

Figure 6: Repeka sharing a picture book with her one year old brother.................... 132

Figure 7: Elisapeta assisting her six year old brother with his spelling homework... 134

Figure 8: Reading for pleasure at home; Elisapeta's older sister reads a book cover in the living room ................................................................... 149

Figure 9: Reading for information in the home; Elisapeta's older sister reads an advertising brochure for Mothers' Day

Figure 10: Eseta listens as her six year old brother reads a favourite story from the children's version of the Bible

Figure 11: Repeka's photo of her Samoan Bible, taken to represent how she practices memory verses every day for the Sunday school exams

Figure 12: Configuration of neighbourhood with other sites

Figure 13: Isaako's photo of his friend's Canterbury school bag, showing the logo that he valued

Figure 14: Local shops photographed by Isaako to represent his community and his culture

Figure 15: More shops photographed by Isaako to represent his community and his culture

Figure 16: Cultural and social perspectives on popular culture. Conflicts between sites and within family sites

Figure 17: Differing cultural perspectives on reading: the need for reconciliation of values.

Figure 18: Cultural and social uses of language: Mother tongue or dominant language? 


\section{CHAPTER 1}

\section{Introduction and Positioning}

\section{Rationale for the investigation}

This study focuses on an increasingly significant issue for New Zealand educators and the wider community, that of literacy achievement of primary school students who come from a Pasifika background. Although New Zealand students in the compulsory education sector perform well in comparison with their peers in other countries, lower test scores for Pasifika and Māori students have been a cause for concern (Crooks \& Flockton, 2005; Flockton \& Crooks, 2003; Sturrock \& May, 2002).

This indicates a need to investigate ways in which literacy learning might be supported for these students in classrooms of the New Zealand education system. The thesis explores the Ministry of Education's (2003a, 2006a) argument that one way to raise the achievement of Pasifika students is first to understand their out-of-school literacies. This involves examining how and where students use literacy in meaningful contexts as well as considering the curriculum and teachers in the various sites. Understanding and valuing these could enable teachers to make relevant connections between out-ofschool literacies and the school curriculum. This would not only be achieved through understanding the students' own literacies, but also through knowledge of how to support students by drawing on the people who are involved and the appropriate texts to be used. It remains unclear whether or not Pasifika students' own skills, understandings and practices of literacy are understood and valued by schools.

The study draws on the work of the American historian Cremin (1976) who argues that education takes place in many institutions in different sites which do not exist in isolation from each other but which operate in configurations. This concept provides a framework to explore the complementary and conflicting features of the relationships that may exist for students between the sites in which their learning is mediated. The study also incorporates a sociocultural ${ }^{1}$ perspective (Tharp \& Gallimore, 1990; Vygotsky, 1978; Wertsch, 1998; Wertsch, del Rio \& Alvarez,

There are overarching difficulties in choosing terms to describe all the people who are working in the social ontology area. 'Sociocultural' refers to neo-Vygotskian theory but in this thesis it is used to cover a range of theorists who may not all be owing to Vygotsky. 
1995) which considers that literacy is always embedded within social and cultural practices and has different meanings for different groups of people in society. In addition, Rogoff's (1995) three planes of analysis, as discussed in Chapter 5, provide a tool to look closely at individuals as they acquire literacy through their participation in social and cultural activities. Rogoff explains that the three planes of analysis correspond to community, interpersonal, and personal processes, and she refers to the "developmental processes corresponding with these three planes of analysis as apprenticeship, guided participation, and participatory appropriation" (p.139).

The sociocultural perspective, Cremin's concept of sites and Rogoff's planes of analysis offer opportunities to determine the uses, examine the sites, and therefore explore the social and cultural practices of literacy for Pasifika students in out-ofschool settings. In turn, this enables a focus on the meaning given to literacy by these students in order to identify their strengths, and the curriculum and teachers in the many sites for literacy.

The procedures used to gather the primary data in the study were consistent with the Pasifika Education Research Guidelines (Anae, Coxon, Mara, Wendt-Samu \& Finau, 2001) in emphasising consultation and building rapport with participants. The Ministry of Education's Pasifika Education Plan (Ministry of Education, 2006c) has a goal of increasing the effectiveness of teaching for Pasifika students in order to raise student achievement. The Ministry's literacy handbooks for primary teachers advocate that teachers should be better informed of out-of-school literacy practices which are situated in family and community, particularly for students from diverse backgrounds (Ministry of Education, 2003a, 2006a). Knowledge of these practices, it is argued, can inform teachers to enable them to make connections between students' out-of-school practices and school literacy and thus improve learning for these students. This can be achieved through what McNaughton (2002) describes as "incorporation":

Effective connections for the learner happen when the activities in an (often unfamiliar) instructional programme incorporate features of some familiar expertise that up until then have been situated in out-of-school activities. Transfer of learning occurs as a result of this incorporation. (p.27) 
Knowledge of out-of-school practices may also enable teachers to link to people in the students' community groups who have understandings of the students' out-ofschool strengths and who can support learning in school. Teachers may then be able to incorporate aspects of the out-of-school literacy into the school curriculum with the aim of raising student achievement in literacy.

\section{Seeking an insider view}

The study involves a sample of fourteen year 7 and 8 Pasifika students (aged 11 and 12) who attend a Catholic school attached to a church which has a Sunday school. The students were in the final two years of the sector in education where teachers focus most strongly on teaching reading and writing. This is an important group to explore as more information is needed about the literacy practices of students of this age. Therefore it is important for teachers in the sector to know about children's backgrounds to be able to make links to students' out-of-school practices. The knowledge needs to be in primary schools to give students the best chance of acquiring literacy to the highest standard possible before they go to secondary school where conventionally there is a lot less focus on literacy acquisition. The sample offers the students' own perspectives of the complexity of how young people operate in different sites which may have different values. In order to achieve this, year 7 and 8 students were trained as ethnographers to gather information with cameras and journals on their own literacy practices in out-of-school settings. The intention of this was to seek an "insider view" of the students' literacy acquisition and use so they could illustrate how they make sense for themselves of the literacy learning that goes on within the sites they chose to represent. The study seeks to show the "appropriation" of knowledge about literacy practices (Rogoff, 1995) through the students' own eyes. The students made their own decisions about what they valued and how they would represent their literacies. The researcher aimed to generate data with the participants through discussion of the data they gathered. The study shows how the students construct their own literacy practices which are linked to their identities as adolescents.

This approach considers the concept that literacy is a powerful tool of cultural hegemony (Laqueur, 1976) and is about cultural knowledge and social power (Luke, 1994). Literacy has for a long time been a hegemonic tool and used to promote the values of church and state (Gee, 1996; Graff, 1987b). This piece of research is a case study of the views of a group of Pasifika students living in one area in New Zealand. 
The study seeks the views from the year 7 and 8 students and the adult participants of whether literacy is seen in New Zealand as a papalagi ${ }^{2}$ value. This leads to ask whose literacy and whose curriculum is taught in New Zealand classrooms and how is literacy measured.

\section{Changing definitions of literacy}

In a study that investigates literacy practices, it is necessary to define the term "literacy" as the term has been interpreted widely and definitions have changed considerably in recent decades. It is important to understand that the definitions and demands of literacy are becoming more complex as those who are critical of literacy standards may have simplistic ideas of what literacy is all about. It is also useful to define literacy in this study as the students are involved in literacy practices in their Samoan cultural background and the mainstream school where there may be different understandings and values. It is interesting to note how changing definitions of literacy appear to have moved from the simple skill of writing one's name to complex social practices that are seen as essential for participation in many aspects of life. This section of Chapter 1 explains how the term has evolved, how it is now interpreted, and how it will be interpreted in this study as practices related to written language. The term literacy is contested and its social and political implications are discussed in the following three chapters. Over the past two to three decades there has been a shift from what Gee (1996) describes as a traditional view of literacy based on psychological approaches which tended to focus more on the technical skills of literacy, to an anthropological approach which explores literacy as social practice. This definition is relevant to the current study as it includes the values associated with literacy and the ways in which people interact with others as they acquire and use literacy. Barton (1994) writes that literacy is a fairly recent English word and comments that it is interesting in that it derived from its opposite. The word "illiteracy" is found in Walker's Critical Pronouncing Dictionary of 1839, but the word "literacy" only appears in a dictionary in 1913. Barton states that the word illiterate dates from 1556 and illiteracy from 1660. The word literacy appears in 1883 in the New England Journal of Education. However, the word literate, to mean being able to read and write, does not appear until 1894.

\footnotetext{
${ }^{2}$ Papalagi is defined in the Samoan dictionary as European, white man (Milner, 1993).
} 
The Literacy Dictionary (Harris \& Hodges, 1995) records that in 1951 literacy was defined as "the ability of a person "who can with understanding both read and write a short simple statement on his everyday life"” (p.140). The Literacy Dictionary offers a definition of literacy for the present day. Venezky, (cited in Harris \& Hodges, 1995) writes "literacy is a minimal ability to read and write in a designated language, as well as a mindset or way of thinking about the use of reading and writing in everyday life" (p.142). It involves more than simple reading and writing as it "requires active, autonomous engagement with print and stresses the role of the individual in generating as well as receiving and assigning independent interpretations to messages" (p.142).

In the $20^{\text {th }}$ century the meaning of the word literacy was extended as a metaphor, to mean competent and knowledgeable in specialised fields such as economic literacy, (recorded in the Oxford English Dictionary in 1943 according to Barton, 1994) and more recently terms such as computer literacy. An interesting analogy that helps to explain the popular use of this word is made by Collins and Blot (2003) who describe the variety of terms for other kinds of literacy than reading and writing in the $21 \mathrm{st}$ century such as "cultural literacy" and even "moral literacy" and offer the view "that 'literacy,' as a key word in our culture, has a status in the current era rather like that of 'science' in the nineteenth [century]: it refers loosely to any body of systematic useful knowledge" (p.3). They write that this is countered by pressure to determine what constitutes "real literacy". Barton and Hamilton (2000) argue that literacy is best understood as a set of social practices that are observed in events which are mediated by written texts. These definitions for literacy which changed through the twentieth century and at the beginning of the twenty first, will be discussed in the following chapters in relation to the theories of literacy.

Traditionally reading and writing have been understood as discrete cognitive skills which, in Street's (1984) words, are the autonomous view of literacy. These skills have been measured by schools and they are considered to be the property of the individual who can transfer them to many new situations where they can be used. An apt metaphorical description of the skills interpretation is the banking concept of education knowledge described by Freire (2000). Here the students are described as receptacles to be filled by the teacher whose action is to deposit while the students' only action is to receive, file and store the deposits. Freire notes that the more 
students work at storing their deposits, "the less they develop the critical consciousness which would result from their interventions in the world as transformers of that world" (p.73). However, the view of literacy as a set of skills has been challenged by the broader and more complex view of literacy as social practice (for example, Barton, 1994; Gee, 1996; Street, 1984). According to this view, the uses of literacy differ depending on the sites in which it is situated and its social settings. This is a major theme of this thesis. This investigation explores literacy as cultural and social practice and introduces the idea of literacy which is not only learned at school but in the home, community and workplace.

With a definition of literacy which situates it in sites in addition to school, the sites of home and community may provide literacy activities where children develop strengths in reading and writing that may not be assessed by the official school literacy measures which are often administered as formal tests. It can be questioned whether the school assessment tasks in literacy adequately reflect the students' understandings of literacy. As an example, the traditional Samoan literacy practices of the pastors' schools with their emphasis on oral reading and memorisation (Thomas, 1984) are continued in New Zealand for some students as the later chapters describe and these skills are seen by their communities as strengths. However, they will not necessarily be recognised as strengths by school measures. In considering the apparent underachievement in literacy of Pasifika students in New Zealand it can be asked whose knowledge is represented.

\section{Pasifika students in New Zealand}

As outlined at the beginning of the chapter, this thesis investigates Pasifika students' out-of-school literacy practices and conceptualisations of literacy. In this thesis the term "Pasifika" will be used to include all groups of Pacific peoples in New Zealand. The changes in nomenclature for this section of the New Zealand population who were born in their Pacific homelands or in New Zealand are described by Coxon, Anae, Mara, Wendt-Samu and Finau (2002). In the early 1980s they were referred to as "Pacific Islanders". This was followed by the term "Pacific Islands," and in more recent years "Pacific Nations", "Pacific Peoples", and "Pasifika" or "Pasefika". Although a collective term is used for this ethnic group, it is important to remember that it is made up of people from island nations that have their own distinctive 
languages and cultures. The number of Pasifika people born in New Zealand has increased significantly in the past two decades and they represented 6.9 percent of the total population in 2006 .

The majority of Pasifika people in New Zealand are concentrated in Auckland where 66.7 percent of the total number live, and in Wellington where 13.9 percent live. In these areas there are large concentrations of Pasifika students in some schools (Statistics New Zealand, 2002) and so it is essential teachers are well informed of their needs. The Pasifika population is a young one, having the highest proportion of children aged 0 to 14 years of all the major ethnic groups (Statistics New Zealand, 2007). The largest groups consisted of Samoan (3.25 percent), Cook Island Māori (1.44 percent), Tongan (1.25 percent), Niuean (0.55 percent), Fijian (0.24 percent) and Tokelauan (0.16 percent) (Percentages calculated by the researcher from Statistics New Zealand, 2006). Pasifika students represent a growing diversity of ethnicity in New Zealand schools, making up 9.1 percent of the primary and secondary population in New Zealand in 2006. Pākehā ${ }^{3}$ students make up 59 percent, Māori students 21.6 percent, Asian students 8.2 percent and students from other ethnic groups make up 2 percent (Education Counts, 2007).

\section{Pasifika student achievement}

The results from the Programme for International Student Assessment (PISA 2000) (Sturrock \& May, 2002) that examined the literacy skills of 15-year-old students show that students from a Pasifika background achieved lower scores than Pākehā, Asian and Māori students on assessment tasks for retrieving information, interpreting texts, reflection and evaluation, and on combined reading literacy (Sturrock \& May, 2002). Examples of the text types that were assessed included narrative, descriptive and expository prose as well as tables, graphs and diagrams. They represented the text types that students would use at school as well as those encountered outside the school for personal use (such as letters, novels), and texts such as newspaper articles, and documents. The authors state that a substantial proportion of Pasifika students were born outside New Zealand and routinely spoke a language other than English at home. The National Education Monitoring Project (NEMP) Reading and Speaking Assessment Results for the year 2004 (Crooks \& Flockton, 2005) showed lower scores in reading

\footnotetext{
${ }^{3}$ In New Zealand a person of European descent
} 
tasks for year 4 and year 8 students from a Pasifika background than for mainstream students. The Writing Assessment Results 2002 (Flockton \& Crooks, 2003) show that Pasifika students at years 4 and 8 performed less well than other students in 25 percent of the assessments. As a consequence, over the last few years the Ministry of Education has been implementing initiatives that are designed to improve literacy teaching and learning for Pacific people. The students in this study identified largely as Samoan and represent a range of attainment on the school measures used for reading assessment.

\section{Ministry of Education initiatives for Pasifika students}

In 1997 a plan (Ko e Ako 'a e Kakai Pasifika) was launched by the Ministry of Education (1996a) to increase participation and achievement by Pasifika peoples in early childhood, compulsory schooling, and at the tertiary level. This plan emphasised involving the Pasifika community in the initiatives, such as the Pacific Islands School Parent Community Liaison Project. The Pasifika Education Plan (Ministry of Education, 2001) included educational initiatives for early childhood, tertiary education and the compulsory education sector where it focuses on increasing achievement in literacy and numeracy, attainment of school qualifications and reducing at-risk factors. The plan aimed to achieve this by promoting education with Pasifika students, families and communities, promoting effective teaching and school initiatives, and developing a profile of students based on the NEMP results. The Pasifika Education Plan 2006-2010 (Ministry of Education, 2006c) states that since the release of the first plan in 2001, participation in early childhood and tertiary education has increased considerably for Pasifika people and more students are leaving school with qualifications. It acknowledges that in many schools Pasifika students are achieving more highly in reading and that Pasifika communities are finding that the education system is engaging more effectively with them.

The Ministry of Education and the Education Review Office require teachers to gather large amounts of information about students' uses of literacy in the school. An example of this is the use of the writing and other exemplars (Ministry of Education, 2003b) to illustrate what the criteria for assessment mean in practice. The exemplars are taken from students' own work in schools and represent teachers' views of what students should be achieving at particular levels. For example, the exemplars for written language represent the work of children at all levels of the primary school and include several genres with explanatory notes of how the writing was achieved. When students' skills 
and understandings about literacy are considered, the instruments measure the "school" uses of reading and writing but there is no information about the students' uses and practices in literacy in sites outside the school. The data on school literacy that are gathered by teachers and researchers are collected by quantitative measures which although useful, may not show some of the important and useful literacy skills and understandings of the students. This thesis argues that qualitative information is needed to explore the students' sites, cultural and social uses of literacy and knowing this may contribute to improved learning.

\section{Method}

This study did not test children's competencies in reading and writing. It is an ethnographic case study of situated literacy in which the unit of analysis is the sites for literacy. This leads to a study of the students' interpretations of literacy which reveal their literacy uses and practices within those sites. It also reveals the relationships between the sites with common values and conflicts. The uses of literacy are seen in the literacy events, which are shaped by the practices and the value systems located in the home and community rather than in the classroom. The main method of gathering data in this investigation was to train year 7 and 8 students as junior ethnographers; this was important in empowering them to make their own choices to define and to document their own literacies outside the school. They used disposable cameras to take photographs of their uses and sites of literacy in the home and community settings, kept a journal of reading and writing in these settings, and subsequently discussed the photographs in interviews. The study also involved several representatives from churches that have Pasifika congregations associated with the school that the students attend. Cremin (1976), Graff (1987b) McKenzie (1985) and Zinsser (1985) write of the church as a site for literacy as social practice, and the adult Pasifika participants interviewed in the researcher's Masters thesis (Dickie, 2000), as well as a number of his current students in pre-service teacher training, have discussed the strong influence of the church in the lives of Pasifika people in New Zealand.

A qualitative approach was particularly suitable for this study which adopts a sociocultural stance to explore situated literacy practices where the students as ethnographers are being asked to define their own literacies. Denzin and Lincoln (2000) write that the detailed interviewing and observations in a qualitative study 
allow the researcher to capture the participants' perspectives and the rich descriptions of the social world. They describe the role of the qualitative researcher as at times like a bricoleur or maker of quilts, in putting together many pieces of a complex puzzle. The information from the interviews with the church representatives was compared with the information from the students. The analysis of the students' interviews was essentially qualitative but there were some quantitative data as well. The responses were collated and data sorted according to the sites of practice. The analysis explored how these Pasifika students gave meaning to literacy through their social and cultural practices in sites outside the school and this was compared with the autonomous view of Pasifika achievement.

\section{Summary}

This chapter has introduced the key themes of the thesis. Sociocultural theory offers explanations for social and cultural practices of literacy and the multiple sites for literacy. The thesis argues strongly that this theory is appropriate to use to investigate and explain Pasifika students' strengths in out-of-school literacies which may not be assessed by the official school measures. The chapter introduces the idea that qualitative data is the key to explore the students' cultural and social uses of literacy in various sites. Using quantitative data alone has limitations and will not help to address the gap in our knowledge about the literacy practices of these students. Another key idea of the thesis is that literacy has been, and is still, closely linked with politics and hegemonic practices of states in their bureaucracies as well as with the church and trade. These themes are developed in the following chapters as indicated by the overview.

\section{Overview of the chapters}

\section{Chapter 2: Literacy as social practice: Past to present}

This chapter provides an historical background to the study by adopting sociocultural theory as an explanation for literacy acquisition and use as it gives an historical view of literacy as social practice. It argues that literacy has not generally been learned through formal schooling alone but has been learned and practised in many sites, with the church being a major site since literacy's beginnings. The chapter explores the themes of literacy as social practice, literacy being taught by many institutions which have their own curricula and values, and literacy being concerned with cultural knowledge and social power. 


\section{Chapter 3: A theoretical framework: Review of the literature}

This provides the main theoretical framework for the thesis. It builds on Chapter 1's introduction of literacy as social practice by exploring sociocultural theory and the work of Cremin (1976) and Rogoff $(1995,2003)$. These theories together provide background for the framework of analysis which is outlined in Chapter 5. They provide lenses through which learning is viewed not as separate from the individual's environment but as situated within the environment and both interactive with and influenced by it. Learners are immersed in many educative sites with their own curriculum and values while learning is mediated by many teachers. The chapter includes an explanation of influential studies that explore literacy that is situated in the community as social practice and it introduces the New Literacy Studies (NLS).

\section{Chapter 4: Curriculum Critique}

This chapter outlines the development of the New Zealand English curriculum and the Ministry of Education's literacy handbooks and support material for teachers. It considers whether the Ministry of Education's definition is sufficiently broad to include the interpretations of literacy as social practice as described in Chapters 2 and 3. It then introduces the concept of "incorporation" as a means for teachers to make connections for students between out-of-school practice and the curriculum requirements of school.

\section{Chapter 5: Methodology}

Chapter 5 explains and justifies the methodology of the study. The research can be described as an ethnographic case study which is concerned with the cultural context of particular sites and uses of literacy. It investigates a small sample, seeking rich description through qualitative data. To gain an insider view and to help address the power imbalance the students were trained as junior ethnographers to document their own literacy practices through taking photos and keeping journals. Data were gathered in semi-structured interviews with students and adult church representatives.

\section{Chapter 6: Family sites for literacy}

This is the first of three interconnected chapters that illustrate how the students' literacy learning is mediated in different communities of practice and how multiple identities are constructed in different sites. The family emerged as a significant site for teaching and using literacy for the Pasifika students. The family uses of literacy illustrate that sites do not exist in isolation, but work in a network with others to 
mediate the life of the students. Family practices overlap with those of religion, the neighbourhood and school. There were mutually supportive values and pedagogies between family and religion, and family and school.

\section{Chapter 7: Sites for church literacy}

The church is a significant mediator of literacy for people in this Pasifika community with strong connections to the sites of family and school. The data reveal the significance to the participants of the Bible (both Samoan and the English versions) and their community's literacy practices which are linked to the Bible.

\section{Chapter 8: Neighbourhood sites for literacy}

This chapter discusses the students' descriptions of their literacy uses in the various sites in the community and helps to build a more complete picture of their out-ofschool literacies. The major literacy practices that emerged were those relating to popular culture and this adds to our understanding in the previous two chapters of the configurations between sites for literacy and the development of students' identities.

\section{Chapter 9: Discussion}

Part One discusses the configurations of students' sites for literacy learning that have emerged in the study and describes the overlap of values, curriculum and pedagogy between the sites and where there may be conflict between sites. Part Two discusses the implications for school practice in a response to the demand outlined in Chapter 1 for teachers to have a better understanding of students' out-of-school literacy practices and cultural backgrounds in order for them to achieve success in school literacy. It discusses issues related to the conflicts and complementarities in literacy practices and how out-of-school practices and expertise can be linked to school practice to enhance students' learning through incorporation where the teacher or student build on the familiar or unlock what is unfamiliar.

\section{Chapter 10: Summary and conclusion}

The final chapter offers a brief summary, an outline of the strengths and limitations of this study and then discusses the implications of this study for practice in schools, for education policy, and for future research. 


\section{CHAPTER 2}

\section{Literacy as Social Practice: Past to Present}

\section{Introduction}

As Chapter 1 outlined, the predominant interpretation of literacy used in this thesis is one of literacy as social practice (Gee, 1996; Street, 1984) and this chapter provides examples of social practice through an historical exploration of uses of literacy in various sites. It provides background to the two traditions of literacy that the students participate in, namely the European (or Western) and the Samoan. The chapter outlines the history of literacy as social practice from a European perspective and gives a brief outline of literacy as social practice in Samoa. There is much less literature on the development of Samoan literacy and much appears to be written from a papalagi perspective. The researcher is writing from the point of view of a papalagi who is not immersed in the culture but it appears that there are links between the Samoan social practices as described in the literature and the practices of the students in the current study.

Literacy is situated in many distinct domains which include the home, community and the church as well as school settings, and these domains may each have their own distinctive literacy practices. The chapter offers a view of how literacy learning takes place in many sites with each site having its own requirements of technical and social skills for participating in these situated practices. A sociocultural perspective enables exploration of social and cultural influences on reading and writing and considers how the individual's learning is mediated through initiation into cultural practices of literacy. This interpretation recognises that in addition to learning skills, people's interactions with others and their values are crucial aspects of literacy learning. The types of texts that are read and written are also crucially important. Cremin (1976) describes many institutions which are situated in various sites that educate in literacy. These institutions have their own curricula and teachers, values and pedagogies. While each institution has its own curriculum of technical skills, individuals must also learn the social skills that are required to carry out the literacy activities. This chapter also helps to illustrate the pluralist functions of literacy in society. The concept of social and cultural hegemony is described by Graff (1987b) as providing the most useful approach to understand the uses and patterns of literacy. Almost since its beginnings, literacy has been a tool of cultural hegemony; it is to do with cultural knowledge and 
social power (Luke, 1994). As an example, the church may use literacy for spreading piety and faith and fear of God, and thus as a way to control the social behaviour of the population. However, individuals may see other purposes such as enhancing personal freedom, employment, and entertainment. A theme discussed in Chapter 2 is the connection of literacy with hegemonic practice of both the state and the church.

To provide background to this study it is useful to explore these themes in relation to how people have used literacy in various sites and cultural settings over time. In this study, two traditions of literacy must be considered as the Pasifika students' learning is acquired in each. One tradition reflects the European perspective which is represented by the schools and the majority culture in New Zealand. The other tradition reflects the Samoan perspective of literacy which is maintained by the students' families and community in New Zealand. Chapter 2 offers an overview of the development of a system of (Western) writing and how literacy has changed from being restricted to use by an elite class to being used by the masses. The chapter also offers a brief overview of literacy education in Samoa. One interesting fact that emerges from the historical perspective of literacy is that in both the European and Samoan traditions the oral aspects were valued to a greater extent than by the "official" literacy of today. This has significance for the Pasifika students and church representatives in this study as their church literacy still values the oral aspect very highly. This chapter reveals that through much of history literacy has not been learned through formal schooling but through other sites, particularly religious sites. Almost since the beginnings of literacy, religion and "the church" in its many forms has played a significant role in the acquisition and uses of literacy. Literacy has been integral to the social and cultural practices of the church. The Christian church's significant historical role in these literacy practices is described here.

The idea that schools are the sole determinants of literacy is a modern one and a consequence of the introduction of mass schooling in the $19^{\text {th }}$ century (McDonald, 1995). If individuals live in a society which possesses a written script, then they can acquire literacy whether or not they receive instruction from a school. McDonald writes "literacy is first and foremost the property of a society" (p.6). The idea of ownership of literacy in a society that has a written script is described by McDonald (1987) using the metaphor of the sharemarket. The technology of writing is described as the stock which is owned collectively by society. Individuals in that 
society can only take out shares in literacy with some having greater portfolios than others. Some groups in society may corner the market in literacy and keep it from others. Individuals may use their shares as an investment in their careers (McDonald, 1987, pp. 1-2).

\section{The book and the church}

Through history there have been significant links between literacy and religion and to an extent these remain to the present day. The link between the church and literacy goes back to the early civilisations of Babylonia and Egypt where literacy was restricted to the elite, firstly to priests and expanding later to the ruling and property owning classes. When the codex form of book was developed towards the end of the Roman Republic it was accepted in Egypt and Europe, with this form of book being readily adapted by Christians but slowly taken up for secular use. These codices were used for early versions of the Old and New Testaments. The historical background illustrates how the curriculum and values of the church were promulgated and it also illustrates the hegemonic practice of the church serving to emphasise the significant role of the Christian church as an institution for teaching (Western) literacy. Graff (1987b) writes that from earliest times literacy "was a tool, useful firstly for the needs of state and bureaucracy, church, and trade" (p.5). What Graff describes as "the religious impulse for reading for the propagation of piety and faith" (1987a, p. 29) goes a long way back in time and is tied closely to the history of Western Christianity. Religions such as Christianity which have a "Book" are able to record the Word of God. Graff (1987b) writes that the Jewish tradition provided a model for Christianity in that writings "attracted fascination as the vital, living monument to the spoken word of the Creator and the Savior. They took on the power and mass appeal of magical sacred texts" (pp.29-30). This idea has relevance today as in this study the utmost importance of accurate and clear oral reading was stressed by student participants, and the church representatives, to ensure that the Word of God was communicated correctly from the book to the reader and to the congregation. In 311 A.D. Christianity became the official religion of the Roman Empire. With the revealed Word of God presented in a book, the Bible and related works, and the desire to spread the Word, Christianity had the need for copyists (Gaur, 1984). As the Roman Empire collapsed the need for common literacy decreased but the Christian church was expanding and it spread literacy along the old 
Roman lines of communication with the Bible, the vellum codex and the quill pen (Gaur, 1984. p. 157). As in the past, the role of the scribe became important. The large monasteries of Ireland, Britain and Europe had their scriptoria where monks worked as scribes, illuminators and bookbinders to spread the Christian message.

However, in the Middle Ages, with economic and political life becoming more complex, there developed the need for a wider use of literacy than was practised within the church. Gaur writes that the church monopoly of scholarship and learning declined with the gradual secularisation of society as independent universities and schools were founded. The importance of the church as a site for literacy learning is emphasised by Graff (1987b) who writes that from the $10^{\text {th }}$ to the $13^{\text {th }}$ centuries lay controlled schools were established but most institutions that transmitted literacy were part of the church. The teachers who taught in the lay schools were mostly church educated clerics. Only a minority of children could attend these schools and nunneries were the most important source of literacy learning for girls and women.

When the norm of mass literacy in $21^{\text {st }}$ century society is considered, it is interesting to consider that historically the Bible was propagated mainly by oral preaching and teaching. What this meant was that the written, then printed, word was spread far more widely through oral processes than purely literate means would allow. Graff (1987b) stresses that for a long time reading was itself an oral activity which was often collective and not the silent individual activity of today. This provides a perspective to consider the relative values placed on oral and written forms of language then and now. Chapter 7 describes how for the participants in this study there was a strong emphasis on oral language in church and Sunday school practices.

\section{Beginnings of universal literacy: hegemony not liberation}

A key concept introduced in Chapter 1 was that literacy is a powerful tool of cultural hegemony. Hegemony is a term coined by Gramsci, a Marxist in Fascist Italy, who used it to describe how one class dominates another through the consent of the dominated group. Abercrombie, Hill and Turner (1994) explain that although political force is important, the role of ideology in winning the consent of the dominated classes may be more significant. This winning of consent by ideological 
domination is achieved by, for example, the family, the church, and trade unions. Graff writes (1987b, p.12):

Literacy is not a likely technique for domination or coercion; for hegemony, however, it has proved a much more viable option and often a successful tool. 'Schooling' in common values, attitudes, and norms as well as in skills and common languages, has long been grasped as especially useful.

Several writers describe a link between hegemony and the development of mass literacy (for example Freire, 2000; Graff, 1987b; Laqueur 1976). The social historian Graff (1987b) has an interesting perspective on the development of mass literacy in European countries and its connection with the church and this is outlined in the following sections of this chapter. The ideas in the following section can be linked to the discussion in Chapter 4 which critiques the New Zealand curriculum and links to literacy as "political practice", in other words literacy as a tool of hegemony in the New Zealand context. A strong argument is advanced by Graff (1987b) that there is an intrinsic relationship between hegemony and literacy and he describes the concept of social and cultural hegemony as the most useful approach to understanding the many uses and patterns of literacy. Hegemony is not domination by force but derives from consent. Graff writes:

\footnotetext{
Hegemonic relationships have historically involved processes of group and class formation, recruitment, indoctrination, and maintenance at all levels of society. For most of literacy's history, these have centered upon elite groups and their cohesion and power. For them, the uses of literacy have been diverse but have included common education, culture, and language (such as Latin); shared interests and activities; control of scarce commodities, such as wealth, power, and even literacy... . (1987b, p.12)
}

Through the history of alphabetic literacy, Graff writes "literacy and schooling have been seized increasingly as a tool for establishing and maintaining social and cultural hegemony" (p.12). He writes that since the Reformation, schooling has sought to develop assimilation and control of the population. It has sought to secure the consent of the masses. The work of Graff (1987b) describes the development of mass literacy in Europe which occurred without formal schooling, with the Protestant church in particular promoting social morality and the values of state religion. 


\section{Literacy introduced to New Zealand}

The church played a significant role in spreading literacy in Europe and as had been the situation in so many other societies, religion was the motivating force when literacy was first taught in New Zealand during the European settlement in the early $19^{\text {th }}$ century. In New Zealand literacy was introduced to the indigenous people through the church as it was in Samoa (described in the following section). In his work Oral culture, literacy and print in early New Zealand: The Treaty of Waitangi, McKenzie (1985) records that between 1815 and 1830 the British missionaries made a start to teaching reading and writing to the indigenous Māori people to enable them to be participants in Christian worship. The missionaries thought that restricting the Māori people to the Māori language would keep them away from the imported European evils that were emerging in New Zealand, and they restricted their reading to Biblical texts. By 1827 the Gospels had been translated into Māori and Simon (2000) records that the curriculum for the mission schools around Paihia consisted of reading, writing, arithmetic and catechism. McKenzie notes that the first items ever printed in New Zealand were produced in 1830 when Yate printed off hymns, and in 1836 Colenso printed the complete New Testament in the Māori language. Simon writes that Māori displayed an enthusiasm for literacy which rose from their perception that it was of relevance and value to their own lives. Thanks to the British and Foreign Bible Society's printing of New Testaments, it was estimated that by 1845 there was at least one Māori Testament for every two Māori people in New Zealand (Jackson, 1975, cited in Simon, 2000). McKenzie (1985) records that the missionaries reported that the mission schools were effective in teaching the Māori reading and writing in their own language, that many Māori had a great desire for literacy, and that there were villages where the schools were set up and run by Māori.

McKenzie describes the Treaty of Waitangi ${ }^{4}$ as a remarkable moment in the contact between a literate European culture and a wholly oral indigenous one. He suggests that it offers an example of the European assumptions about the comprehension, status and the binding power of written statements against the flexible accommodation of oral consensus. A shift to a 'literate mentality' when the Normans introduced literacy to medieval England is described by Clanchy (1979,

4 The Treaty of Waitangi which was signed by Māori chiefs and representatives of the British Crown in 1840, made New Zealand a British colony and is regarded as the founding document of New Zealand. 
cited in Street, 1995, p.31). This was a shift involving a way of thinking and an ideology rather than simply a change in technological processes involving skills and knowledge. People came to share new assumptions about the status of the written word. According to Street, this shift involved profound changes in people's identity and what they took as a basis of knowledge.

\section{Literacy education in Samoa}

In comparison with what is known about the development of written literacy in the European context, little has been written about it in Samoa. Samoa had an oral culture with no written literacy until the arrival of the European Christian missionaries in the 1830s. It appears that with their introduction of text-based literacy a strong oral tradition continued in Samoan literacy practice. The oral culture and traditional education of Samoa before the arrival of the missionaries are described by Thomas (1984). He writes that when the missionaries arrived they found that the people taught each new generation without written language or formal schools and the content of Samoan education was "everyday village life" (p.206). The principal institutions for acquiring the cultural knowledge were the family and village while "the main methods of study were the child's observing the activities of community members and his participating in daily life" (p.206).

In the 1830s the London Missionary Society established itself in Samoa, creating a Samoan orthography, and translated the Bible into Samoan (Thomas, 1984) with the first books being printed in the Samoan language in 1834 (Tuafuti, 2000). Within a few decades of the arrival of the missionaries all Samoans belonged to a Christian congregation. Thomas writes that by the end of the $19^{\text {th }}$ century there were about 200 London Missionary Society churches as well as Methodist and Catholic churches and by the early $20^{\text {th }}$ century the churches were controlled by the local people. The rapid spread of Christianity was due to the missionaries establishing educational institutions that reached every age level in the community, the main sites being the village church, the home of the pastor or missionary, homes of church members and seminaries for teacher training (Thomas, 1984). An important development in Samoan literacy was the establishment and growth of the pastors' schools (Duranti \& Ochs, 1993; Tagoilelagi, 1995; Thomas, 1984; Tuafuti, 2000). The distinctive cultural practices of literacy in these schools are of relevance to this study in that they are continued in the New Zealand setting. These schools were important sites 
for learning, with Thomas describing them as next in educational importance to the Sunday church services. He describes them as day schools which were held by the pastor throughout the week in the church or in the pastor's home. Thomas writes that the financial support of the village pastor, who serves with his wife as the teacher in day school and Sunday services, comes from the villagers. The literacy practices of the pastors' schools illustrate the incorporation of a strong oral tradition which might be interpreted as a mingling of the old (oral) ways of learning with the new written ways. The emphasis on oral language is seen in the degree to which memorisation and performance are valued as being integral to literacy practice. This continues to the present day.

The type of literacy instruction in the pastor's school is described by Tagoilelagi (1995). She writes that children from 1 to 5 years old are given exercises such as the Pi Tautau (alphabet) chart to read and memorise. The children in these classes give only verbal responses as "the teachings concentrate on performance, where the child is required to orally respond and often imitate what the teacher is saying aloud" (p.8). The children are given a phrase or sentence from the Bible to memorise and they develop a strong sense of memory. Duranti and Ochs (1993) describe the older children reading orally from the Bible and interpreting Bible passages, with the pastor questioning each child on the passage they read. They write that many children will attend the pastor's school until their early teens. However, while the pastors' schools emphasise literacy that is related to the Bible, they teach other subjects as well. Although the pastors' schools in the past taught the literacy required to read the Bible, according to Barradale (1907, cited in Thomas, 1984) children also learned reading and writing, addition and multiplication, and other subjects including geography. Writing more recently, Tuafuti (2000) describes the emphasis in the schools being on reading the Bible, writing stories that were dictated from the Bible as well as basic mathematics and problem solving.

The oral pattern of learning is used in both the pastors' schools and Sunday schools. Tagoilelagi explains the tauloto routine (performance routine) as consisting of a model from the teacher or other adult which is followed by a response or imitation from the child. She writes that it is clear from the language practices in the pastors' schools and Sunday school that the pedagogical patterns used during literacy activities are similar and they complement the socialisation in the home. Both schools emphasise the 
oral patterns using the same procedures to teach tauloto, hymns, plays and Bible reading. The valuing of oral language is also illustrated by the example from Duranti and Ochs (1993) who write that by three and a half to four years of age a child will be asked to transmit orally lengthy messages to adults. This will involve competence in politeness conventions and in using the correct respect vocabulary that is appropriate to the addressee. In describing the present time, Tuafuti (2000) states that the family and church are two important institutions in the Samoan community and "therefore, the uses and functions of Samoan literacy are interwoven with cultural behaviour, traditions, and family and church expectations" (p.11). She states that these are totally different from those of English language programmes in New Zealand schools.

Thomas writes that after World War 1 when New Zealand exercised a trusteeship over Western Samoa, the upper levels of the pastors' schools became public secular schools while the lower levels remained under the pastors' control. As well as the public schools, many schools were sponsored by Christian missions. The curriculum was strongly influenced by New Zealand and after independence in 1962 the official language of instruction continued to be English with Thomas noting that "teachers were permitted at all grade levels to use Samoan whenever it seemed appropriate to make concepts clear to the pupils" (p.227). Thomas writes that the intention is to produce students who are fluent in both Samoan and English. According to Tuafuti (2000), most children are literate in the Samoan language before they start at state schools and from the age of eight or nine years, students are introduced to English.

An interesting example from New Zealand that illustrates how literacy practices are informed by cultural knowledge and associated with social power is described by Tagoilelagi. She offers a Samoan perspective of the cultural and social uses of literacy in New Zealand including the role of the Samoan culture $\left(\mathrm{Fa}^{\text {'a-Samoa }}{ }^{5}\right)$ in the development of its children's literacy skills. The Samoan families she studied in New Zealand maintained their cultural practices in acquiring literacy, rather than being transformed by the dominant culture. Tagoilelagi describes the church related methodologies of teaching and learning as influential and explains how children are socialised within literacy activities in their families. The reading of the Bible is the most

\footnotetext{
${ }^{5}$ Fa'a-Sāmoa (noun) Samoan custom, ways and traditions (Milner, 1993).
} 
popular reading activity in Samoan families and creates a significant channel for socialization during the evening lotu (devotion) and sometimes in the morning. Memorisation and performance are described as an important aspect of literacy learning. It seems as if Samoan children are apprenticed into a model of learning which emphasises observation and listening. This is referred to by Amituanai-Toloa (2005) in Chapter 9 who recommends that in relation to improving students' reading comprehension, teachers should build on student strength in observation and listening by using the teaching strategy of demonstration.

\section{More church connections}

This chapter has illustrated how historically the church has been an important site for literacy acquisition and practice. The church for literacy, and the home as a site for church related literacy practices, are also described by Heath (1983) and the church is also the site for literacy acquisition by pre-school children in a study by Zinsser (1985) who describes how fundamentalist Christian churches in the United States were a site for the acquisition of specific Bible literacy for four and five-year-old children who had not yet been "officially" taught to read and write. The skills of listening, memorising and repeating were emphasised and the children learned what Zinsser describes as an important message about literacy that the text (the Bible) has

an authority of its own. She notes that whether the skills they have learned in acquiring Bible literacy and the "skills of pedagogical discourse" will be helpful in their future schooling will depend on the type of school they attend. If they attend public schools where divergent and critical thinking are encouraged, then these children would need to learn the new rules of classroom behaviour.

\section{Family literacy defined as social and cultural practice}

A number of writers describe social practices in the family site for literacy (Cairney, 2003; Gregory, 2004, 2005; Heath, 1983; Luke, 1994; McNaughton, 1995, 2002; Taylor, 1983) and literacy in the family site is particularly important for this study which explores students' out-of-school literacies. The term 'family literacy' was introduced by Taylor (1983) in her ethnographic study of young children becoming literate within their families in the United States. Cairney (2003) defines family literacy as "social and cultural practices associated with written text" (p.85) and discusses how literacy is constructed and developed, valued and defined in families. Heath's (1983) study also describes how children of different communities were 
socialised into literacy practices within their families. Luke (1994) describes the family as a site for literacy as social practices. McNaughton (2002) explains how children are socialised into family literacy practices through joint, personal and ambient activities and he links this to Rogoff's (1990) concept of guided participation. He writes (McNaughton, 1995) that families provide occasions for young children to learn about written language and these reflect and construct important social and cultural messages for the children. It is from these messages that children develop ideas and values about literacy and about their personal and cultural identity. Gregory's (2004) study of practices in Bangladeshi families in East London shows that family and community members other than parents play a crucial role in assisting young children with literacy in out-of-school settings. She writes that siblings were found to be efficient teachers of the literacy practices of school. The family emerges as an important site for literacy in this study and this is discussed in Chapter 6.

Another example of New Zealand families as sites for literacy acquisition is Smith's (2004) study which explored children's acquisition of literacy within their family social and cultural practices before they started school at the age of five. Smith found that the parents from different cultural backgrounds helped their children to become literate by the children's involvement with, and observation of, the family and community uses of literacy. The majority of parents who were interviewed mentioned reading the Bible or other religious texts. An interesting finding was that while the Pākehā parents' main purpose in reading or telling stories to their children was for pleasure, the Indian, Tongan and Sri Lankan parents in this small sample did this "to transmit cultural values, to give examples of good behaviour, for religious reasons, to hear their own languages, or to gain proficiency in English" (Smith, 2004, p.88).

\section{Literacy to maintain hegemony and as a means to enlightenment}

When considering the pluralist functions of literacy in society it is necessary to discuss not only its role in hegemonic practices, but also its emancipatory role. Gee (1996) describes literacy as "a socially contested term" (p.22). He explains "literacy as "the ability to write and read' and situates literacy in the individual person, rather than in society and as such it obscures the multiple ways in which literacy interrelates with the workings of power" (p.22). He argues that "any view of literacy is inherently political, in the sense of involving relations of power among people" (p.22). Throughout the 
centuries literacy has been used as an instrument to establish and maintain cultural and social hegemony for both state and religion. With the introduction of mass literacy (as in Sweden) and the introduction of compulsory schooling it was not the intention of those in power that the people would be emancipated through becoming literate. Neither political nor church leaders wished for interpretation of texts. However, others saw the possibilities for change. Becoming literate can contribute to emancipation. Literacy is integral to the rise of the working classes in gaining access to political power and it can be a defence against oppression (Laqueur, 1976).

The interpretation of literacy as a way to enlightenment is also demonstrated by Freire (2000) who worked on adult literacy programmes in Brazil and Chile in the 1950s and 1960s and whose influential text Pedagogy of the oppressed was first published in 1970. Freire did not teach the decontextualised skills of reading and writing to the peasants but presented these skills as a way to enable them to participate in political processes. He was exiled from his homeland, Brazil, in 1964 for his work in emancipating the rural poor through these educational programmes. According to his definition, literacy is situated in, and is meaningful to, the learners' lives. This conception of literacy of Freire and Macedo (1987) which argues that literacy cannot be reduced to the mechanical treatment of words and letters, supports Street's (1984) ideological interpretation of literacy.

\footnotetext{
Reading the world always precedes reading the word, and reading the word implies continually reading the world...this movement from the word to the world is always present; even the spoken word flows from our reading of the world...I have always insisted that words used in organising a literacy program come from what I call the 'word universe' of people who are learning, expressing their actual language, their anxieties, fears, demands and dreams. Words should be laden with the meaning of the people's existential experience, and not of the teacher's experience. (p.35)
}

They write that it is necessary to go beyond a limiting and rigid understanding and see literacy as the relationship of learners to the world. From their perception that democracy was in crisis as they saw it, a campaign of critical literacy must occur to free the oppressed. They argue that the campaign must transcend the debate that recycles the old ideas that literacy is a mechanical process that overemphasises the technical aspects of reading and writing skills. They call for a view of literacy as a form of cultural politics that can either empower or disempower people. They 
planned to analyse literacy "according to whether it serves to reproduce existing social formation or serves as a set of cultural practices that promotes democratic and emancipatory change" (p.viii). Several writers argue that critical literacy has a place in school literacy programmes (for example Au, 1995; Au \& Raphael, 2000; Lankshear, 1997, cited in Lankshear, Gee, Knobel \& Searle, 1987; Luke, 1997; Marsh \& Millard, 2000; Morrell, 2002) and this is discussed in Chapter 4 in relation to the New Zealand curriculum and in Chapter 9 in relation to school practices.

\section{Development of literacy as popular culture}

One of the aims of this chapter is to illustrate the pluralist functions of literacy in society and while the chapter has focused heavily on the church and functional uses of literacy, literacy has also been used for pleasure as noted by Laqueur's (1976) and Graff's (1987b) accounts of ownership of books. The concept of mass literacy has evolved to include a modern interpretation of social and cultural practice in popular culture. A perspective of popular culture is provided by the work of Luke (1997), Marsh and Millard (2000), Morrell (2002) and by Hoggart (1957) who investigated the literacy practices of working class people in Britain in the first half of the $20^{\text {th }}$ century in relation to popular publications. What has been termed "popular culture" forms an interesting contrast to other factors that mediate culture such as the family, church and community influences, and values that relate to literacy uses and help to shape the individual's identity. Literacy learning that is related to popular culture is mediated in many sites including the family and neighbourhood, and forms part of the curriculum of these sites. As with the other examples of literacy uses described in this chapter, literacy associated with popular culture involves distinctive technical skills as well as social skills. It is also an example of literacy for pleasure.

Marsh and Millard (2000) describe children's popular culture as overlapping that of adults in the broad fields such as music, sport, computer software, books magazines and film. They point out that children's popular culture also includes many diverse artifacts such as toys, games, comics, cards, clothing, sports accessories, and food and drink, and these cultural forms are constantly emerging and disappearing. Carmen Luke (1997) describes children's popular culture as television, video games, comics, and the toys associated with television and movies. She writes that from these texts of popular culture children develop from the time they are infants their understandings of such 
things as good versus evil, heroes, gender, race and social power in society. Just as the concept of culture can be interpreted widely, so can children's popular culture. Marsh and Millard caution that there is not only one set of values, beliefs and practices which could be described as children's popular culture, and in any school community there will be different groups each with their own popular cultural practices. This example is useful to illustrate that rather than the property of the individual, literacy belongs to the diverse groups in the community to which the individual belongs and there can be many different interpretations.

Appropriation by children of their own popular culture interests into the school site is described by Dyson (2003) who explains how young African American children drew upon their knowledge of popular culture to help them to relate to school literacy when they began school. According to Dyson, these children appropriated out-of-school topics they were familiar with such as music and cartoons, and they recontextualised them into the school setting to help make school literacy meaningful to them. This is a useful example as the children themselves had some control over making the connection from their own cultural experiences to the school curriculum, and were encouraged to do so.

An opportunity to incorporate aspects of literacy into school through children's popular culture is provided by children's interests in music such as rap. Rap music is originally an African American popular music genre being a branch of hip hop culture with thematic associations of "race, life in the urban ghetto, survival and black politics" (Zemke-White, 2001, p.231). Rap music is well established in New Zealand with many Māori and Pasifika artists "...whose Polynesian identities form an integral part of their image, ideology, lyrics and iconography" (p.235). Zemke-White writes how these are relevant to young New Zealanders as "their raps embrace politically charged messages about 'keeping your culture', nuclear testing, and immigration issues”' (p.235).

In the past there has been criticism of the literacy associated with popular culture (see, for example, Hoggart, 1957) and teachers have expressed unease about the use of comics and certain authors being read in schools and libraries. However, there is a growing recognition that these interpretations are narrow and reading these texts of popular culture is not going to prevent students from reading other "quality" texts but may in fact encourage them to do so. Marsh and Millard (2000) argue against a narrow view of what "quality" literature should be taught in schools. They describe 
teachers' unease about including popular culture in the school curriculum with one reason being that they are more transient than what is considered to be more literary. Marsh and Millard (2000) describe how using popular cultural texts can motivate students in literacy programmes in the classroom. According to Morrell (2002), popular culture as expressed for example through music, film, mass media, customs and values can provide for some students a connection between their lived experiences and school culture. The idea that perceptions of literacy need to change for the classroom is supported by Luke (1997) who describes how there has been a shift from static notions of culture to the present day "global, corporate, and electronic culture that is in a constant state of renewal and reinvention" (p.23). Individuals can continuously reinvent themselves "through increasingly globalized and standardized media messages", all of which contribute towards the individual gaining status as part of the "in-group" (p.24).

\section{Conclusion}

This chapter has provided an historical perspective of literacy as social and cultural practice that is situated in many sites. It has illustrated that through history literacy has been learned through many sites other than those of formal schooling and the church has played a significant role in literacy acquisition and practice. Chapter 2 introducd the two traditions of literacy that the Pasifika students participate in, namely the European tradition from mainstream society and school and the Samoan tradition from their family and community. The chapter has introduced the concept of literacy having many functions. These include that of hegemonic practice where an "official" view of literacy as promulgated by the state and the church may serve to minimize other forms of literacy. The functions also include literacy as a way to enhance personal freedom and as a means to pleasure. The following chapter builds on these concepts of situated literacy by exploring sociocultural and other theories as a framework for this study. 


\section{CHAPTER 3}

\section{A Theoretical Framework and Review of the Literature}

\section{Introduction}

To provide background to this study, Chapter 2 introduced through an historical perspective the themes that literacy is social practice, literacy is taught by many institutions with their own curricula and values, and literacy is concerned with cultural knowledge and social power. Chapter 3 builds on this by exploring sociocultural and other theories that provide a suitable framework for exploring these themes. The key idea is that the learner is viewed not as an individual separate from his or her environment but as situated within the environment and both interactive with, and influenced by, it. Learners are immersed in many educative sites and their learning is mediated by many teachers. An analytical framework was required that revealed the mediation of the individual's literacy learning in different sites and the possible connections and conflicts arising from this.

Part One of the chapter introduces the work of Cremin (1976), then sociocultural theory and Rogoff $(1995,2003)$ which together provide background for the framework of analysis which is outlined in Chapter 5. These theories provide lenses to explore literacy within the social and cultural practices of participants in various sites.

Part Two begins with a sociocultural perspective of literacy followed by examples of influential studies which explore literacy that is situated in the community as social practice (Barton \& Hamilton, 1998; Heath, 1983; Scribner \& Cole, 1981; Street, 1984). This is followed by an explanation of literacy practices and events, the NLS and multiliteracies, and the relationship of identity construction to literacy. All of these add depth to an understanding of the theories outlined in Part One which form the basis for the analytical framework. 


\section{PART ONE: THE THEORETICAL PERSPECTIVE}

\section{Cremin's multiplicity of institutions that educate}

A major aim of the analytical framework is to show that children as learners are not operating in isolation but their learning is constantly mediated by their social and cultural environment. The way that the environment mediates learning will vary greatly for each child as they make their own sense of their world. The work of the American historian Cremin $(1976,1977)$ provides a framework for exploring the different institutions for education, using the term "educative agency" (1977, p.107) and the configurations or connections between the institutions in their various sites. Cremin describes "an ecological approach to education, one that views educational institutions and configurations in relation to one another and to the larger society that sustains them and is in turn affected by them" $(1976$, p.36). The point of this model is to reveal the scope and the complexity of education and he cautions that to be concerned only with schools "is to have a kind of fortress mentality" as "education must be looked at whole, across the entire life span, and in all the situations and institutions in which it occurs" (1976, p.59). He refers to the major educative agencies as the family, religious organisations, television broadcasters, schools and employers, and at times he describes them as institutions (1976, p.23). He describes a "multiplicity of institutions that educate." and names libraries and museums among these. Cremin stresses the point that the institutions for education do not exist in isolation from each other, writing "The relationships among the institutions constituting a configuration of education may be complementary or contradictory, consonant or dissonant" (p.31). Cremin (1977) uses the term "educative setting" (p.102) and in this study this is interpreted as "site".

\section{The curriculum of the institution}

According to Cremin (1976) every family, church and employer has a curriculum which is taught "...deliberately and systematically over time" (p.22). He argues that the curriculum includes not only the technical skills of the institution but also social skills of carrying out the activities with others according to the expectations and routines of the institution. The term "curriculum" can be defined in several ways. Marshall (1998) describes it as the subjects and courses taught in any educational institution and a formal statement of what is to be learned, as in The New Zealand Curriculum Framework (Ministry of Education, 1993) and English in the New 
Zealand Curriculum (Ministry of Education, 1992b). This study considers the "official" school curriculum but as it views curriculum through a sociocultural lens it also requires a wider interpretation of curriculum that takes into account the view that learning, rather than being an individual process that is separated from the rest of the learner's activities, places learning “...in the context of our lived experience of participation in the world" (Wenger, 2006, p.3). Everybody belongs to what Wenger describes as "communities of practice" (p.6) in their homes, work, school and other places and these communities each have their own values and requirements. This view fits with Cremin's concept of curriculum. Wenger argues that families, for example, "...develop their own practices, routines, rituals, artifacts, symbols, conventions, stories, and histories" (p.6). The required learning to become a member of a community of practice takes place not so much through what he terms "reification" of a curriculum but through the participation by new members in the practice of the community. ${ }^{6}$

In writing of communities of practice Wenger (2006) argues that there is a profound connection between identity and practice. Being a member of a community and participating in its practice requires negotiation of ways of working in that practice. However people negotiate this, they engage in action with one another and relate to one another, meaning that "the formation of a community of practice is also the negotiation of identities" (p.149).

People belong to many communities of practice, in what Wenger refers to a "nexus of multimembership" (p.158), with some of these being central to the individual's identity and some being more incidental. Many young children are active members of different cultural and linguistic groups and acquire membership of these communities simultaneously (Gregory, 2005). Gregory writes that this means that they "syncretise the languages, literacies, narrative styles and role relationships appropriate to each group and then go on to transform the languages and cultures they use to create new forms relevant to the purposes needed" (p.225). She cites Drury's (2004) study of bilingual children of preschool age who blend the languages

6 Wenger (2006) explains reification as treating something abstract as existing or "making into a thing" (p. 58) and gives the example from education of codifying knowledge into "reified subject matter" such as a textbook or curriculum. 
of family and school sites. Although this thesis study did not reveal this type of complementary relationship between sites, it would be an interesting topic to investigate for a future study.

\section{Configurations of institutions}

Cremin (1976) explains that school is one of several institutions for literacy education and in any individual's life several institutions may work together in a network to support literacy. He explains that the white Protestant family, the white Protestant church, and the white Protestant Sunday school as well as the common school are a configuration where the values and pedagogies are mutually supportive and contribute to the success of American public schools. Other configurations may have internal conflict if they are not committed to similar values. Cremin writes that the relationships that may exist among the institutions in a configuration are complex and may be political, pedagogical, or personal relationships. Pedagogical influences may extend from one institution to another within the configuration and he gives the example of movie and television entertainment styles being used in churches and other institutions such as colleges. Cremin (1988) explains configurations of agencies in New York where "many churches, synagogues, temples and mosques brought together clusters of ethnoreligious families joined together for the preservation of a particular way of life ..." (p.576). These formed configurations with other agencies that were dedicated to similar goals. He writes that as well as becoming central social institutions of these neighbourhoods, "those configurations became the teaching arms of the several immigrant communities, seeking to preserve particular traditions at the same time that they mediated the influence of the dominant American culture" (pp.576-7). Cremin argues against concerning ourselves only with schools when considering education and suggests that education occurs through many institutions such as the family and the church. He agrees with the point made by Dewey (1941) that schools are an important means of transmitting culture but only one means, and a comparatively superficial means. Cremin acknowledges that education occurs through many individuals and institutions including families, churches, libraries and museums as well as through schools. 


\section{Sociocultural theory}

As Tharp and Gallimore (1990) write, the theory underlying much sociocultural research in literacy is that of Lev Vygotsky (1978). Our current conceptualisations of sociocultural theory draw on the work of this influential Russian psychologist (1896 to1934) and his colleagues in the early $20^{\text {th }}$ century as well as later writers such as Wertsch (1998) and Cole (2000). Vygotsky (1978) describes the sociocultural origins of cognitive development and emphasises the relationships between people, contexts and communities. His works describe how the social, cultural and historical background and experiences shape children's developing cognition (Vygotsky, 1978). Vygotsky emphasises the social nature of children's learning and explains that ways of thinking are acquired through interactions with others and are then gradually internalised by the individual. Vygotsky argues that a child's learning and development occur within a sociohistorical and sociocultural context.

Rogoff (2003) comments that this contrasts with theories of development that focus on individuals and their social and cultural contexts as separate entities, as "...the cultural-historical approach assumes that individual development must be understood in, and cannot be separated from, its social and cultural-historical context" (Rogoff, 2003, p.50). Vygotsky argues strongly that the child and environment interact to mould cognition in ways that reflect the culture and this is evident in the themes of his work. These include the sociocultural and sociohistorical origins of cognitive development and language as a mental tool. They also include the role of private speech and the zone of proximal development (Krause, Bochner \& Duchesne, 2006). Vygotsky (1978) explains the zone of proximal development as “... the distance between the actual developmental level as determined by independent problem solving and the level of potential development as determined through problem solving under adult guidance or in collaboration with more capable peers" (p.86). This is where children learn to use their culture's tools for thinking through their interactions with more skilled partners. The cultural tools which include various ways of using language mediate the child's learning.

Wertsch (1998) agrees that the sociocultural context should not be separated from the action of individuals, arguing that to try to analyse human action by focusing just on the individual is too limiting. He writes "the task of a sociocultural approach is to 
explicate the relationships between human action, on the one hand, and the cultural, institutional, and historical contexts in which this action occurs, on the other" (p.24). Mediated action is a natural unit to be analysed in sociocultural research (Wertsch, 1998). It provides a link between action which is carried out by individuals or groups (including mental action), and the cultural, institutional, and historical contexts in which the action occurs. This is because the means of mediation, which are the cultural tools, are situated culturally, institutionally and historically (Wertsch, 1988; Wertsch et al., 1995). In this study the cultural tools involve uses of literacy. Sociocultural theories of human development draw particularly from the fields of anthropology and psychology. The work of cultural psychologists has added to our understanding of literacy "as a highly social rather than an individual accomplishment" (Razfar \& Gutierrez, 2003, p.35). Studies such as that undertaken by Scribner and Cole (1981) which is described later in this chapter have used social practice as the unit of analysis. Razfar and Gutierrez (2003) explain: "These crosscultural studies linked the literacy of a cultural group to the larger societal values of the community and illustrated the complexity of the literacy practices in which children engaged outside of formal instructional contexts" (p.35).

In Changing Literacies Lankshear et al. (1997) describes the changes in thinking about text-mediated practices that have occurred in recent years. Lankshear comments that notions of reading and writing as cognitive abilities or sets of skills held sway in educational theory and practice until the 1970s but since then some researchers have taken another view and emphasised the social influences on reading and writing. Lankshear writes that these conceptions of reading and writing have stressed "...their inherently social character and embeddedness in larger social practices" (p.2, italics in original). Many studies (which are explored elsewhere in this thesis) have taken this approach and focused on the social and cultural practices of literacy and explored its uses in various sites other than the school (Au \& Raphael, 2000; Barton, 1994; Barton \& Hamilton, 1998; Barton, Hamilton \& Ivanic, 2000; Cairney, 2003; Fleer, 2004; Gee, 1996, 1997, 2000, 2001a, 2001b; Hamilton, 2000; Heath, 1983; Lankshear et al., 1997; Lankshear \& Knobel, 1997; Luke, 1994; Pahl \& Rowsell, 2005; Razfar \& Gutierrez, 2003; Robbins, 2005; Rogoff, 1995, 1998, 2003; Street, 1984, 1993, 1995, 1997; Taylor, 1983; Zinsser, 1985). 
Gee (1996) offers an explanation of how sociocultural approaches to language and literacy emerged from the earlier anthropological approaches to orality and literacy. He explains that orality and literacy disappear as autonomous categories into many social practices which have their own various values. Gee writes that the traditional view of literacy treats it as an asocial cognitive skill with little or nothing to do with human relationships. Gee explains the shift in interpretation of literacy from a largely psychological interpretation to one of social practice: "The traditional view of literacy has defined it in rather simple terms: literacy is the ability to read and (sometimes) to write" (p.39). This involves decoding and encoding and interpretation of the text. Gee writes that for traditionalists the interpretation is largely a psychological matter: "If readers know the language, can decode writing, and have the requisite background 'facts' ... they can construct the 'right' interpretation in their heads. And this 'right' interpretation is roughly the same for all competent readers" (p.39). Questioning of this traditional view in the 1970s and 1980s led to the field of study known as NLS which in some quarters has begun to replace the traditional view of literacy with a sociocultural approach. The NLS and their relevance to this thesis are described in Chapter 3.

Rogoff (1998) writes that while much research in child development focused on the individual as the unit of analysis, Vygotsky (1978) argued that rather than explanations of psychological processes coming from the individual's characteristics as well as secondary social influences, the analysis needs to focus on the social, cultural, and historical processes which influence the individual. She explains that central to Vygotsky's theory is the view that children's participation in cultural activities with the guidance of others, allows them to internalise their community's tools for thinking. Rogoff (1998) writes "Thus, efforts to understand individual cognitive development must consider the social roots of both the tools for thinking that children are learning to use and the social interactions that guide children in their use" (p.682).

Rogoff (1998) describes deep international interest in Soviet cultural/historical theory following the translation of Vygotsky's (1978) work by Cole, Scribner, JohnSteiner and Souberman, writing that a family of sociocultural approaches has been built on cultural/historical theory (for example Heath, 1983; Rogoff, 1990). Another theorist who provides an additional perspective to sociocultural theory, which is 
useful for its emphasis on connections between the settings of the learner's experience, is that of Bronfenbrenner (1979). His theoretical perspective for research in human development draws on the biological analogy of ecology in developing the concept of the individual learner being connected to, and influenced by, his or her cultural and social environment. Bronfenbrenner's theory explores relationships between settings for learning, which Rogoff (2003) acknowledges as a very important point and illustrates with the example of relations between home and school or religious institutions. Rogoff acknowledges the usefulness of Bronfenbrenner's approach, particularly in emphasising the relations between the multiple settings in which children and families are involved and also in examining how they make transitions among their different ecological settings.

\section{Rogoff's three planes of analysis}

A suitable framework for analysis is provided by Rogoff $(1995,2003)$ for a study that seeks to investigate what participants are being guided towards and how they are apprenticed into literacy in the various sites. A sociocultural approach to development which is based on three planes of analysis is outlined by Rogoff who describes these as the personal, the interpersonal, and community/institutional planes. Rogoff (1995) refers to the developmental processes that correspond with these planes as participatory appropriation (at the personal level), guided participation (at the interpersonal level) and apprenticeship (at the community/institutional; level). This approach emphasises the patterns that occur in the organisation of sociocultural activities and focuses on any one of these three planes at one time. Rogoff (1995) writes "these are inseparable, mutually constituting planes comprising activities that can become the focus of analysis at different times, but with the others necessarily remaining in the background of the analysis" (p.139). Looking at the sites and the interpersonal and community planes in particular provides an opportunity to see into what values and practices the learners are being apprenticed into and whether there may be issues of conflict.

Rogoff (2003) illustrates these planes by using a series of images to illustrate an individual child's participation in sociocultural activities, the images allowing the researcher to view the learning situation through a different "lens" for each plane of analysis. The first lens shows the solitary individual, the second shows the social 
influences of other people who are involved in the activity, and the third shows the cultural influences. The personal, interpersonal, and "cultural-institutional" aspects constitute the activity. Rogoff writes that no aspect exists or can be studied in isolation from the others. The analysis of what is happening at the interpersonal level could not take place without the researcher understanding the community processes. These might include, for example, the historical and cultural roles and the practices of schools and families. The researcher also needs to attend to the processes on the personal plane, such as the efforts being made to learn through observation and participation in the activities (Rogoff, 2003, p.58).

Rogoff (1995) stresses that the individual and environment are interdependent and refers to Vygotsky's interest in the mutuality of the individual and the sociocultural environment.

She writes:

\footnotetext{
...the use of "activity" or "event" as the unit of analysis - with active and dynamic contributions from individuals, their social partners, and historical traditions and materials and their transformations - allows a reformulation of the relation between the individual and the social and cultural environments in which each is inherently involved in the others' definition. None exists separately. (p.140)
}

However, Rogoff states that the individual parts that make up a whole activity can be considered separately without the researcher losing track of their interdependence. The three planes of analysis provide the means to achieve this. She writes "foregrounding one plane of focus still involves the participation of the backgrounded planes of focus" (p.140). These planes are neither separate nor hierarchical but involve different focuses on the sociocultural activity. The following section describes what Rogoff refers to as three inseparable concepts each of which reflects one of the three planes of focus in sociocultural analysis, that is the personal, the interpersonal and the community/institutional planes.

Rogoff uses the term participatory appropriation to refer to the personal plane where the researcher examines the process of individuals changing their understandings through participating in particular activities and preparing themselves to engage in similar activities in future. She explains that she uses this term in preference to 
"internalization" (which played a central role in Vygotsky's theory) to show how children gain from involvement in sociocultural activities. Rogoff explains that she emphasises participatory appropriation rather than internalization in order to distinguish between two theoretical perspectives: "The appropriation perspective views development as a dynamic, active, mutual process involved in people's participation in cultural activities; the internalization perspective views development in terms of a static, bounded 'acquisition' or 'transmission' of pieces of knowledge ..." (p.153). The questions about how children take information from external events and accumulate knowledge are less relevant ways to study their development when this sociocultural approach is used. Instead, the researcher explores the processes of children's participation with other people in cultural activities and the ways they transform their participation.

\begin{abstract}
Rather than searching for the nature of internalization as a conduit from external bits of knowledge or skill to an internal repository, we look directly at the efforts of individuals, their companions, and the institutions they constitute and build upon to see development as grounded in the specifics and commonalities of those efforts, opportunities, constraints, and changes. (p.159)
\end{abstract}

Guided participation is the term that Rogoff applies to the interpersonal plane of sociocultural analysis. Rogoff (1990) writes that she developed "the concept of guided participation to suggest that both guidance and participation in culturally valued activities are essential to children's apprenticeship in thinking" (p.8, italics in original). She writes that "it stresses the mutual involvement of individuals and their social partners, communicating and coordinating their involvement as they participate in socioculturally structured collective activity" (p.146).

Rogoff, 1990) defines this term:

\footnotetext{
Guided participation involves children and their caregivers and companions in the collaborative processes of (1) building bridges from children's present understanding and skills to reach new understanding and skills, and (2) arranging and structuring children's participation in activities, with dynamic shifts over development in children's responsibilities. Children use social resources for guidance - both support and challenge in assuming increasingly skilled roles in the activities of their community. (p.8)
}

Guided participation consists of the events of everyday life as people engage with each other and materials that are managed collaboratively by themselves and others. 
It may involve direct action with other people or distant and unknown people. To illustrate this Rogoff gives the example of a child working alone on a report who is participating in a cultural activity which is guided by interactions from "the teacher, classmates, family members, librarian, and authors, and the publishing industry" (p.147). The interactions with these people help to set the task and guide the materials and approach the child will use. Communication and coordination occur as people participate in what Rogoff refers to as "shared endeavors" as they attempt to accomplish something (p.148). Rogoff explains that understanding the purposes of these shared endeavours is essential when analysing guided participation.

Rogoff (1995) uses the metaphor of apprenticeship to describe the learner's activity in the community or institution. She writes: "In apprenticeship, newcomers to a community of practice advance their skill and understanding through participation with others in culturally organized activities" (p.143). The metaphor of apprenticeship focuses on the active roles of those who support the developing participation and on cultural and institutional practices.

While apprenticeship may involve peers in expert/novice dyads, it goes far beyond this. It is a system of interpersonal arrangements where people are involved in culturally organised activities where the apprentice becomes a more responsible participant (p.143). Using the community plane for research may involve the researcher in looking at the institutional structures as well as cultural constraints and values of the community.

The concept of children as active participants in their own learning is also clarified by Gregory (2004). Children are seen as apprentices learning within their community alongside a more experienced member of their culture. Gregory writes that crucial to a sociocultural approach “... is the role of the mediator (a teacher, adult or more knowledgeable sibling or peer) in initiating children into new cultural practices or guiding them in the learning of new skills" (p.98). She comments that early studies into Vygotsky's (1978) zone of proximal development showed how caregivers scaffolded the child's expertise but more recent interpretations, although recognising the importance of the mediator's role, give the child a more active role in their learning, which is seen for example in Rogoff's guided participation. 


\section{Part Two: The Studies of Literacy as Social Practice}

This thesis argues that to understand people's literacy practices and conceptualisations of literacy it is necessary to explore literacy as social and cultural practice. Part Two begins with an explanation of how definitions of literacy have changed to reflect more of a sociocultural perspective and then discusses the work of Street (1984), Heath (1983), Scribner and Cole (1981) and Barton and Hamilton (1998) who explored literacy as social practice situated in the community and whose work illustrates how social processes connect people with shared values and beliefs. This is followed by an explanation of literacy practices and literacy events, then a brief explanation of the new interdisciplinary field of study known as the NLS which questions the more traditional views of literacy and offers a fresh view on the social, cultural, and political contexts of the users rather than on the technical skills of reading and writing.

\section{A sociocultural perspective on "literacy"}

As part of this exploration to interpret literacy, it is worth noting that over the last two or three decades there has been a change in perception about definitions of "reading". Before then the term 'literacy' was hardly used in educational discourse as the focus was on 'reading'. Understandings about reading were grounded mainly in psychology and they emphasised instruction on teaching young children how to decode text and encode text. In the 1970s "literacy" became the major focus and three reasons for this are suggested by Lankshear and Knobel (2003). The first is the work of Paulo Freire (briefly described in Chapter 2) in the late 1960s and 1970s where learning to read and write was an integral part of learning to understand how the world works socially and culturally to produce inequalities for different peoples. The second is the claim that there was a problem of widespread illiteracy in the workforce of the United States, then in other countries as the economies of these countries were restructured. The third reason Lankshear and Knobel suggest is the development and growing popularity of a sociocultural perspective in research studies. These include a number of the studies outlined in this and the previous chapter, namely those of Hoggart (1957), Graff (1987b), Scribner and Cole (1981), Heath (1983) and Street (1984). These and other studies provided a base which was informed by research that challenged the traditional approaches to teaching reading and writing in schools and the demand for a return to literacy basics which was fuelled by the alleged literacy crisis (Lankshear \& Knobel, 2003, p.7). The writers claim that although the word literacy replaced 'reading' in many 
professional journals and in school timetables, people still carried on with what they had been doing as teachers or researchers of reading. The change to the term "literacy" was not because of an altered understanding towards a sociocultural perspective, but essentially because of the need for a term that included writing. The new English Curriculum introduced in New Zealand in 1992 (Ministry of Education, 1992b) was interpreted by teachers as giving more weight than previously to writing (as well as to oral and visual language). Lankshear and Knobel (2003) write “... whereas 'reading' has traditionally been conceived in psychological terms, 'literacy' has always been much more a sociological concept. For example, 'illiteracy' and 'illiterate' usually carried social class or social group connotations" (p.8. Italics in original).

A result of changing perceptions and perhaps an overuse of the term "literacy" is that the term becomes so widely used that it is often used merely as a metaphor for skill. Barton (1994), Street (1995), Barton and Hamilton (2000) and Lankshear and Knobel (2003) are all critical of this usage. Lankshear and Knobel (2003, p. 14) offer the examples of "computer literate", "maths literate" and "politically literate" as metaphors for competence or efficiency. Street is also critical of the wide uses of the terms such as emotional literacy and film literacy and he warns that "the further these usages get away from the social practices of reading and writing, the more evident it is that the term 'literacy' is being used in a narrow, moral and functional sense to mean cultural competence or skills" $(1995, \mathrm{p} .135)$. He cautions that there is a danger when trying to compare the literacy practices of different groups that it becomes easy to impose particular cultural meanings on to the practices of other people for whom it may be inappropriate. In this study literacy does not include these metaphors for skill. It refers essentially to the practices of reading and writing in society and the oral and visual aspects of language that are associated with these.

\section{Introducing Street's autonomous paradigm}

Street writes (1984, 1993, 1995, 1997, 2003) that many representations of literacy assume it is a neutral technology that can be detached from specific social contexts and it matches the view of literacy as a set of skills that are culture free. Street calls this the autonomous model and explains that this view has the assumption that literacy in itself (autonomously) will have effects on the social and cognitive practices of the users. The autonomous model focuses on technical skills. Street 
writes that this theory of the technical and autonomous qualities of literacy is seen when examining the claims for the cognitive consequences of literacy, for example, that literacy affects cognitive processes including abstract context-free thought, rationality, critical thought, detachment and logical processes. The view that a skills interpretation of literacy is too narrow is supported by other writers, for example Heath (1983), Barton (1994), Luke (1994) and Lankshear and Knobel (2003). The idea of skills as a way to measure comes from psychology and today it is applied to many forms of learning, fitting well with what Barton (1994) describes as general cultural moves towards measuring and monitoring human activities. According to Barton, when applied to reading this interpretation suggests "that reading is a set of skills that can be broken apart and taught and tested" (p.162). In criticising this emphasis on the mechanics of learning to read Barton writes:

\footnotetext{
One of the most powerful metaphors for literacy in public discussions of reading and writing is that of literacy as a set of skills. It underpins the way politicians and the media discuss literacy issues. Behind discussions and headlines on falling standards, the need to improve the teaching of reading and the 'problem' of adult literacy, there is often the metaphor of skills. (p.162)
}

The skills required for literacy should not be seen as isolated from people's uses of literacy. Lankshear and Knobel (2003) write that people read and write differently out of different social practices and their different ways with words are part of being different persons with different ways of life. The important implication of this is that from a socio-cultural perspective, it is not possible to separate out the 'bits' concerned with reading and writing from text-mediated social practices.

The following section discusses three influential studies which add support to the interpretations of literacy as social and cultural practice. These are in turn, Street (1984), Heath (1983) and Scribner and Cole (1981).

Cremin's (1976) concept of many sites and many literacies is supported by these studies and also by Barton and Hamilton (1998). These studies examine the varied sites in which people use literacy in the community and social and cultural practices of literacy within meaningful contexts. They strengthen the argument that what is important is not the decontextualised skills of literacy but the practices to which people put these skills. Each of these studies adds to our knowledge about the social 
factors that shape the uses of literacy for individuals in what Wenger (2006) describes as their various communities of practice. They provide a useful background to this study which explores how literacy as social practice connects people with shared values and beliefs and how the participants make their way as they deal with differing values in their communities of practice.

\section{Street's ideological model of literacy}

Street's $(1984,1995)$ study was grounded in anthropology and his interpretation concentrates on the specific social practices of reading and writing, recognising the ideological and, therefore, culturally embedded nature of these. This model stresses the significance of social processes in the construction of meaning, and is therefore concerned with all the social institutions through which this takes place, not just the "educational" ones. This emphasis on social and cultural influences on literacy acquisition has parallels with the work of the American historian Lawrence Cremin (1976) and the philosopher John Dewey $(1941,1966)$.

The significance of the social setting for literacy practices and how this influences people's uses of literacy is described by Street (1984) in the context of his anthropological fieldwork in northeast Iran in the 1970s. Street offers an example of his ideological model of literacy in describing the development of a commercial literacy as the villagers of the fruitgrowing villages in the mountains were able to take advantage of an economic boom and they were assisted by the literacy practices that they had previously learned in the traditional religious Maktab schools. At this time the Maktab schools still dominated village social life and institutions. The knowledge imparted in the Maktab was mainly that of the Koran, and this may have involved learning to recite whole passages by rote often without reading in the sense of cracking the phonemic code. Street records that despite the appearance of only rote learning and memorisation, people who attended the Maktab school learnt more than this.

Street claims that the basic skills which were learned in Maktab literacy facilitated the development of a commercial literacy practice and associated skills amongst the villagers, and that this commercial literacy enabled economic growth to occur. The tajers (village entrepreneurs who bought and sold the fruit) developed commercial literacy practices from their basic knowledge of literacy which they had acquired in the 
Maktab schools. These practices were associated with the fruit distribution and exchange in the villages, and the skills included signing cheques, writing out bills, labelling boxes of goods and maintaining books of records. The villagers needed to use lists, tables, and columns, and use was made of the "hidden" literacy skills within Maktab literacy. These skills included understanding layout and format and thumbing through text to skim read in order to retrieve information. Their understanding of the text was not just to do with the words but with such features as the position on the page as had been seen in the religious texts through the use of categories, headings and page numbers. Street argues that these skills in isolation had no significance, but when they were developed by a specific group of people to enhance commercial enterprise, they were crucial. Street (1984) asserts that "the 'tajers' were able to expand their power base precisely because a significant number of people had also acquired the literacy practice in which they had expertise" (p.176). Those who had more expertise had the power. Street observes that many western observers assume that literacy is a single thing that can be applied to any context once it is learnt, but Street's emphasis is on the importance of the social setting for skill use. The literacy skills were not just techniques to be easily acquired but "part of a complex ideology, a set of specific practices constructed within a specific infrastructure and able to be learnt and assimilated only in relation to that ideology and infrastructure: the acquisition of literacy is, in fact, a socialisation process rather than a technical process" (p.180). The implication for this study is that for teachers to be successful in incorporating students' out-of-school literacies into school literacy they need to be aware not only of the skills that are used but also of the social settings in which the students use them.

Street explains that the autonomous and ideological models do not necessarily set up a dichotomy and he suggests that in fact all models of literacy can be understood within an ideological framework. From his view, the autonomous model could therefore be seen as a subset within the ideological framework. This means that an ideological interpretation does not exclude the teaching of skills. Street states that those who subscribe to the ideological view do not deny the importance of the technical aspects of reading and writing and difficulties in reading:

...rather they argue that these features of literacy are always embedded in particular social practices: the socialization process through which reading and writing are acquired and the power relations between groups engaged in differing literacy practices are central to the understanding of specific issues and 'problems'. (1984, p.151) 
Rather than denying the technical skills or cognitive aspects of reading and writing, "it understands them as they are encapsulated within cultural wholes and within structures of power" (p.161). In that way, Street claims, the ideological model subsumes rather than excludes the work of the autonomous model.

An understanding of practices is necessary to interpret how literacy may be a tool of social and cultural hegemony, a topic which is explored in Chapter 4. As with Graff's (1987b) and Scribner and Cole's (1981) explanations of literacy, Street's (1984) definition is also shaped by its sites and the uses to which literacy is put. He writes "I shall contend that what the particular practices and concepts of reading and writing are for a given society depends upon the context; that they are already embedded in an ideology and cannot be isolated or treated as 'neutral' or merely 'technical "' (p.1). Street argues strongly that literacy is not a neutral technology that can be detached from specific social contexts. Street's interpretations of literacy have influenced many other writers, for example, Au and Raphael (2000) who suggest that Street's (1995) ideas have important implications for researchers and educators in the literacy education of students of diverse backgrounds. They note that changing definitions of literacy (including changes in literature and styles of instruction) appear to offer great promise for helping students of diverse backgrounds to higher levels of literacy. Students of diverse backgrounds often have literacy skills that are different from those of the school. Au and Raphael explain that "the ideological model reminds us that the literacy measured by achievement tests is but one among several literacies that students are learning. Students of diverse backgrounds often appear highly literate and accomplished when literacies other than those of the school are considered" (p.173).

\section{Heath's study of literacy in three culturally different communities}

An innovative and influential study that strongly supports a sociocultural interpretation of literacy is that of Shirley Brice Heath (Heath, 1983). Her research is particularly pertinent to this study as she describes how young children are apprenticed into the social practices of their families and communities, with Heath noting the considerable differences between the practices of the communities as they prepare their children for school. One community had similar values, curriculum and pedagogy to the school 
and the apprenticeship of the children in that community matched more closely the practices of the school resulting in success in literacy for these children.

Heath rejects the interpretation of literacy as solely technical skills and examines in detail her participants' social and cultural practices of literacy. Heath illustrates the value of an ethnographic approach in her study of the relationship between home and school methods of imparting the skills of literacy in culturally different communities. She conducted her ethnographic study over a decade at a time of desegregation of schools in the United States in the 1970s, exploring how children in culturally different communities in the Piedmont Carolinas learned to use language at home and in the community and how these different ways of using language influenced their success at school. Heath did not see literacy as restricted to the learned skills of reading and writing. Children were seen as acquiring language and literacy practices from their cultures and what the cultures considered correct in regard to social use, religious use, and the valuing of language.

\section{Patterns of language: socialisation for success or failure at school}

The three communities that she studied Heath named Roadville (a small white working class community), Trackton (a small black working class community), and Townspeople (mainstream middle class black and white). Heath observed that the different types of uses of reading and writing in Roadville and Trackton prepared the children in different ways "for negotiating the meaning of the printed word and the production of a written text" (p.348). Heath suggests that although readers may tend to assume that the differences were due to race (between Trackton and Roadville), this was not really so as the blacks and whites who were Townspeople had far more in common with each other than with the people of Roadville or Trackton. She reports that the significance of the different patterns of language socialization for success at school soon became clear. After some initial years of success the Roadville children fell behind and by junior high most were waiting to leave school while the Trackton students fell quickly into a pattern of failure. Heath writes that the place of language in the cultural life of each social group in her study is interdependent with the habits and values of that group so the community contrasts were not explained by race. The central point of Heath's study as it relates to this thesis is the focus on culture as learned behaviour and language habits as part of the shared learning of the group. 


\section{One community's patterns for success in literacy at school}

Heath describes the social and cultural practices learned in their homes and community that enabled the Mainstream children to succeed at school. This explanation of school success offers an insight into possible reasons for the success of "Mainstream" children in New Zealand schools and stimulates the reader to question what is needed to ensure similar success for children who are not from this community. Heath writes that one way the pre-school children in the Mainstream families learnt was through bedtime stories. The pedagogical practices and cultural assumptions of their homes matched those they later found at school; "As Heath argues, the 'literacy events' to which people are exposed and the meanings they 'take' from them 'require a broad framework of socio-cultural analysis' for sense to be made of them" (Heath, cited in Street, 1984, p.124). She recorded how the Townspeople prepared their children for school and how they stressed the value of individual achievement at school. They taught their children to label items and events, how to describe their features, and they read books to them. They immersed the children in repetitive and redundant narratives on items and events. They linked items from setting to setting, pointing out similarities between them. They linked school activities with the activities of home and with their voluntary association networks. There were ritualised uses of language by Mainstream people such as assigning labels to objects with the child responding to a question where it was obvious that the questioner knew the answer.

Street (1984) compares these Mainstream children in Heath's study to the adult participants in his study who were learning skills in the Maktab schools and then applied these to their daily lives and nonliteracy experience. The Townspeople made links between the literacy artefacts at home and those at school and work. For example, a child's cloth book which had single items out of context was similar in format and labelling to the parts identification chart for a new lawnmower or the manual for new equipment in the factory. "As the children of Townspeople learn the distinctions between contextualized first-hand experiences and decontextualized representations of experience, they come to act like literates before they can read" (Heath, 1983, p.256). This was seen in the type of talk associated with written materials and negotiation of meaning. Many examples of writing were seen in their homes. In their jobs the adults expanded the routines and habits of using the oral and written language that they practised at home with their children. Heath writes that 
this group carried the values and ideas about literacy as they constructed their self identity too. They learned the rules for talking about books and writing tasks. When they went to school they saw the continuity of the patterns of using oral and written language and this continued in the workforce. A motivation in the family site for language socialisation of children is to support the common idea of links between the home and the school, the usual idea being that the more parents talk to their children the more likely they are to succeed at school. Yet this did not apply to the Trackton and Roadville children. Trackton children heard and took part in more talk around them than the others, yet more talk did not mean a "positive transfer value" to the practices of the school. It was clear in Heath's study that the children's out-of-school literacies were important to their success in school literacy. It was the type rather than the amount of talk that helped the Townspeople's children to succeed in school.

Heath claims that school is not a neutral objective place. She explains that some people such as the Townspeople bring linguistic and cultural capital which has been accumulated through many occasions of practising the skills and espousing the values of the school:

Long before reaching school, children of the townspeople have made the transition from home to the larger societal institutions which share the values, skills, and knowledge bases of the school. Their eventual positions of power in the school and the workplace are foredestined in the conceptual structures which they have learned at home and which are reinforced in school and numerous other associations. Long before school, their language and culture at home has structured for them the meanings which will give shape to their experiences in classrooms and beyond....Their socially determined habits and values have created for them an ideology in which all that they do makes sense to their current identity and their preparation for the achievements which will frame their future. (Heath, 1983, p. 368)

Thus, success at school for the children in Heath's study involved much more than learning sets of reading and writing skills. Heath rejected the concept of reading as a technical skill and describes reading as "a way of taking" meaning from the environment (1983, p.49). In emphasising the social practices of literacy, Luke (1994, p.6) describes competence in literacy requiring not only skill to read and write: "the reading and writing of texts makes use of linguistic and symbolic codes shared by communities of readers and writers. The technology of writing makes possible the representation and reiteration, interpretation and transformation of 
cultural patterns, knowledges and practices" (p.6). The apprenticeship of the children in Heath's Mainstream community ensured that the children entered school with the knowledge to succeed. Luke (1994)argues that "literacy is about cultural knowledge and social power" (p.6) and Heath's (1983) study illustrates that this was achieved by the Mainstream community. Heath's work is of particular relevance to this study as she provides an explanantion of how communities apprentice their young people into their distinctive social practices of literacy and when the children from different communities enter the same school system the values, curriculum and pedagogy of their community may not match those of the school. In discussing Samoan students, Tagoilelagi (1995) describes a mismatch in New Zealand between school and home practice. She also relates to Heath's (1983) study by drawing a parallel between the way families in Samoa and those in Heath's Trackton socialised their children into literacy practices.

\section{Scribner and Cole's investigation into Vai literacy}

Scribner and Cole's (1981) study is useful in illustrating how people have very specific uses for literacy in socially organised practices. As outlined earlier in this chapter, the cognitive claims and others for the powers of literacy have been challenged by anthropologists including Brian Street (1984) and social historian Harvey Graff (1987b). Gee (1996) is also critical of this view. He writes that while it has long been assumed that literacy gives rise to higher-order cognitive abilities to equip people in literate cultures with more analytic and logical thought than people on oral cultures might possess, this view was challenged by psychologists Scribner and Cole's (1981) influential study into literacy practices amongst the Vai. This famous study adds to our knowledge of literacy as social practice through providing insights into the sites and practices of literacy of the Vai people of Liberia in West Africa. The researchers adopted a psychological approach to investigating literacy practices during their five years of field work from 1973 to 1978 in an attempt to find out if literacy learning produces cognitive changes. One of the goals of the research "was to gain evidence for or against the proposition that literacy is the crucial learning that goes on in school from the point of view of cognitive consequences" (Scribner \& Cole, 1981, p.252). They wanted to explore whether mastery of a written language affected the processes of thinking. 
The Vai people had developed their own unique written script which was based on syllabification. It was thought that groups of Vai men in the early $19^{\text {th }}$ century had developed a graphic system using consistent phonetic rules and created this written language. Scribner and Cole were drawn to Vai society because they hoped that the existence of an indigenous script, which was transmitted outside of an institutional setting and having no connection with a Western-style school, would make it possible for them to isolate the effects of literacy from the effects of schooling. The Vai script was used to write letters, mostly to friends and relatives, for record keeping of family events and town matters, to write plans for visits, and for financial matters. The people used this script which was learned in out-of-school community and family settings mainly for secular tasks, while Arabic was used mainly for liturgical and religious practices, reading and studying the Qur'an (Koran). The English language was taught in formal school settings and was associated with matters of government and with education. As they had three forms of literacy to study, Scribner and Cole were able to disentangle the effects of literacy from the effects of formal schooling which was used for teaching English only. The reasoning was that if literacy affected the learners' mental abilities, then those who were literate in English, Vai or Arabic should show these effects.

In order to ascertain if this Vai literacy which was acquired without formal schooling influenced cognitive changes in its users, Scribner and Cole formed a framework for interpreting their findings to help them to understand how socially organised activities might have consequences for human thought. They explain:

This notion of practice guides the way we seek to understand literacy. Instead of focusing exclusively on the technology of a writing system and its reputed consequences ('alphabetic literacy fosters abstraction' for example), we approach literacy as a set of socially organised practices which make use of a symbol system and a technology for producing and disseminating it. Literacy is not simply knowing how to read and write a particular script but applying this knowledge for specific purposes in specific contexts of use. (p. 236)

The authors developed an understanding of the socially organised practices of writing in trade and agriculture. What was acquired in literacy was closely related to the practice of that literacy. In answering their question (whether literacy substitutes for schooling), Scribner and Cole disagreed with the claims that there were great 
psychological differences between populations that were literate and those that were non-literate. They concluded that literacy learning itself did not promote the development of abstract and logical thinking. An important aspect of this study was for the researchers to develop an understanding of the social system that generates certain practices. Scribner and Cole's inquiries into the cognitive consequences of literacy were seen as inquiries into the impact of socially organised practices in domains such as trade and agriculture on literacy uses that involved writing (such as keeping lists of sales or exchanging goods by letter). The implications of Scribner and Cole's research for this study are as Gee (1996) describes; it clearly indicates that what matters is not literacy as a decontextualised ability to read or write but the social practices into which people are apprenticed as part of a social group.

\section{Literacy practices and literacy events}

A further study that draws on the work of the previous writers to explore literacy as social practice was conducted by Barton and Hamilton (1998). This study of the uses of reading and writing was conducted in the community of Lancaster in England in the 1990s. Barton and Hamilton acknowledge the studies of Heath (1983), Street (1984) and Scribner and Cole (1981) as the starting points for their study into community literacy with the two terms literacy practices and literacy events originating from these previous studies. They describe these studies as coming from three traditions: Heath from sociolinguistics and education, Street from social anthropology, and Scribner and Cole from cross-cultural psychology. Barton and Hamilton write that while literacy events are empirical and observable, literacy practices are more abstract and therefore are inferred from events and other cultural information. Their account of social practices is often at odds with the public image of literacy as it is described in the media and policy discourse in relation to skills. They define and describe dominant literacies and draw attention to vernacular literacies which are described by the authors as often hidden literacies which are devalued and overlooked.

Their following comments on shared beliefs and social connectedness have some similarity to Heath's conclusion. For the three groups in her own study, the contrasts between the community's understandings and practices of literacy were explained through culture as learned behaviour and the shared learning of each group. Barton and Hamilton (1998) explain the social practice of literacy: 
This includes people's awareness of literacy, constructions of literacy and discourses of literacy, how people talk about and make sense of literacy. These are processes internal to the individual; at the same time, practices are the social processes which connect people with one another, and they include shared cognitions represented in ideologies and social identities. (pp.6-7)

They also write ... "literacy practices are more usefully understood as existing in the relationships between people, within groups and communities, rather than as a set of properties residing in individuals" (p.7).

The term "literacy practices" is explained by Street (1995) as a development from Heath's concept of "literacy events" and he writes that a literacy event as defined by Heath (1983) is "any occasion in which a piece of writing is integral to the nature of the participants' interactions and their interpretative processes" (cited in Street, 1995, p.2). Street (1984) uses the phrase "literacy practices" as a way to focus on "social practices and conceptions of reading and writing" (p.1) and writes that he later elaborated on this term to take into account "events" in Heath's sense as well as the social models of literacy that people bring to bear on those events and that give meaning to the events (Street, 2003). He writes:

Literacy practices, then, refer to the broader cultural conception of particular ways of thinking about and doing reading and writing in cultural contexts. A key issue, at both a methodological and an empirical level, then, is how we can characterize the shift from observing literacy events to conceptualizing literacy practices. (2003, p.2)

By literacy practices Street (1995) means not just the observable behaviours (what Heath describes as literacy events) but also the concepts and meanings brought to the events which give them meaning. He gives the example that the three literacies of Heath and his own in Iran are best described as literacy practices.

Street (1995) writes that "literacy practices" is at a higher level of abstraction, referring to behaviour as well as social and cultural conceptualisations that give meaning to the uses of reading and/or or writing. "Literacy practices incorporate not only 'literacy events', as empirical occasions to which literacy is integral, but also folk models of those events and the ideological preconceptions that underpin them" (p.2). Barton (1991, cited in Street, 1995) compares Street's usage with that of 
Scribner and Cole (1981) who, as psychologists, created a "practice account" of literacy. Scribner and Cole believed that skills are located within practices and the practices determine the skills. Barton (1991) argues for a combination of these two meanings and continuation of both concepts. Barton (1991, cited in Street 1995, p.5, Italics in original) writes that "literacy events are the particular activities in which literacy has a role: they may be regular repeated activities. Literacy practices are the general cultural ways of utilizing literacy that people draw upon in a literacy event."

Further clarification of the terms literacy events and practices is provided by Pahl and Rowsell (2005). They explain that an event may be connected to a classroom setting by a teacher but practice is often connected to out-of-school settings. An important characteristic of practices is that they are iterative, that is they occur over and over again. Examples of literacy practices might be the prayers said in a church and other things that a family may do on a regular basis such as sending birthday cards and writing thank you letters. Pahl and Rowsell write "we can hold a literacy practice in our heads from one day to the next" $(2005, \mathrm{p} .21)$. This means that these memories can be drawn on to enable repetition of the practices. Literacy practices are explained also by Barton and Hamilton (2000) as the general cultural ways of using written language that people draw upon in their lives. They state that practices are not observable units of behaviour as they also involve values, attitudes, feelings and social relationships. They describe literacy events as activities where literacy has a role. Written text is usually central to the activity and the events are observable episodes that arise from practices and are shaped by them. Barton and Hamilton write that the notion of events stresses the situated nature of literacy in that it exists in a social context: "These three components, practices, events and texts, provide the first proposition of a social theory of literacy, that: literacy is best understood as a set of social practices; these are observable in events which are mediated by written texts" (p.9. Italics in original).

\section{The 'New Literacy Studies'}

A new body of work has begun to replace traditional views of literacy which emphasise the acquisition of skills, with a sociocultural approach which looks at literacy from the point of social practice. Gee (1996) writes that in the 1970s and 1980s a group of scholars began to question the traditional views of literacy and 
developed a new interdisciplinary field of study which was referred to as the NLS. Gee refers to a number of sources which include Heath (1983), Gee (1992), Street (1984, 1993) and Barton (1994). This NLS approach which was strongly influenced by the early work of Heath (1983) and Street (1984) focuses on the social, cultural, and political contexts of the users rather than on the technical skills of reading and writing. Literacy is seen as "multiple" and reading and writing are differently shaped and transformed in different sociocultural practices. (Gee, 1999) writes:

\footnotetext{
...these sociocultural practices always have inherent and value-laden, but often different, implications about what count as 'acceptable' identities, actions, and ways of knowing. They are in this sense deeply 'political'. Furthermore, these practices always fully integrate language, both oral and written, with non-language 'stuff,' that is, with ways of acting, interacting, feeling, valuing, thinking, and believing, as well as with various sorts of nonverbal symbols, sites, tools, objects and technologies. Thus, the NLS seek, as well, always to study literacy and literacy learning as they are integrated with oral language, social activities, material settings, and distinctively cultural forms of thinking, knowing, valuing and believing. (p. 356)
}

The NLS are explained by Lankshear and Knobel (2003) as using a sociocultural approach to understanding and researching literacy. They offer a new paradigm for exploring literacy as opposed to the existing one which was based on psychology which could be described as a psycholinguistic or a technicist paradigm. Lankshear and Knobel (2003) write that the sociocultural approach to literacy rejects the idea that textual practices are largely or solely processes that go on in the head or are communication from one head to another by means of graphic signs. A sociocultural perspective focuses on social practices. The NLS reveal that as children are socialised into particular practices of literacy, they are at the same time socialised into discourses that position them ideologically within the larger social and cultural environment (Razfar \& Gutierrez, 2003). In adopting a sociocultural approach it is necessary to look at context, relationships, culture and the activities in which the participants are involved as well as the tools and artefacts they use (Robbins, 2005). In this study, the Pasifika students are revealed through their literacy practices as individuals positioned ideologically within their social and cultural environment where sometimes the values between sites are complementary and sometimes conflicting. 
The settings for learning these ways according to Gee (1996) are various social institutions such as schools, churches, banks or government offices or social groups with particular interests such as novels, movies, comics, or politics. Gee argues that people have to be socialised into the groups or institutions to acquire their practices of reading texts in these particular ways. He comments on the embeddedness of literacy as social practice: "You can no more cut the literacy out of the overall social practice, or cut away the non-literacy parts from the literacy parts of the overall practice, than you can subtract the white squares from a chess board and still have a chess board" (p.41).

\section{The concept of multiple literacies and multiple sites}

Street (2003) describes the NLS as a new tradition in considering the nature of literacy, one which focuses not so much on the acquisition of skills but on literacy as a social practice. Street's text Social Literacies (1995) emphasises the social nature of literacy and the multiple nature of literacy practices. Multiple sites (such as the home and church as well as school) means that there are multiple literacies. Street (1995) describes "multiple literacies" as a concept that is crucial in challenging the autonomous model "but which is beginning to be discredited as each observer offers their own criteria for different literacies and as metaphors and extensions of the term move further and further away from the social practices of reading and writing" (p.105). Hull and Schultz (2002) describe the NLS as being characterised by their understanding that there are multiple literacies, that these are situated within social and cultural practices and discourses, and they explore the role of power.

The studies are described by Hull and Schultz as emphasising literacy in out-ofschool contexts and building on the ethnographic tradition of exploring literacy in communities. The NLS are useful in demonstrating that children and adults who may not appear to be particularly literate in a formal educational setting may be very successful in literacy activities outside the classroom. According to Hull and Schultz (2002) perhaps more than any other paradigm, the NLS investigates out-of-school contexts for literacy, and they have "unabashedly" valued these contexts as distinct from those of schools. However, they express concern with a tendency for studies to relegate all good things to out-of-school contexts and everything repressive to school. They argue that rather than setting informal and formal settings against each other there should be a search "for overlap or complementarity or perhaps a 
respectful division of labor" (p.3). They acknowledge that good teaching takes place in schools, and they reject the sweeping claims, for example that school literacy is based on a universal model that reduces other literacies to deficits. However, they also argue reasonably that there is a benefit in that "...the close description of literacy practices in out-of-school contexts and the concurrent focus on how these practices are shaped by power and ideology lead us to look with fresh eyes at what kinds of literacy we teach in school and what we count as literate practices" (p.27).

\section{Pedagogy of multiliteracies}

A group of ten writers (including Cazden, Gee, Kress and Luke) known as the New London Group (1996) presented a theoretical overview of the connections between the changing social environment of today and a new approach to literacy pedagogy that they termed "multiliteracies". They argue for a broader view of literacy than is offered by the traditional language-based approaches. They state that a traditional view of literacy is centred on language only and usually on a national form of language based on rules and delivered by an authoritarian type of pedagogy. The pedagogy of multiliteracies is represented more widely than by language alone and differs according to culture and context. They write of a new world order of liberalism with a reduction in the role of what were "strong centralizing and homogenizing states" (p.68). While schooling played a large part in the old order in imposing standardized national languages and in assimilating immigrants and indigenous peoples to the language of the colonizer, the role of schools has now altered. They argue that this is because cultural and linguistic diversity are critical issues in education and changes have been made in literacy pedagogy. Along with the decline of the dominant monocultural and nationalistic approach, there is a need for students to develop much broader notions of literacy. Because there is "local diversity and global connectedness" there is no longer the standard of the past (p.69). The New London Group writes:

\footnotetext{
the most important skill students need to learn is to negotiate regional, ethnic, or class based dialects; variations in register that occur according to social context; hybrid crosscultural discourses; the code switching often to be found within a text among different languages, dialects, or registers; different visual and iconic meanings; and variations in the gestural relationships among people, language, and material objects. (p.69)
} 
They argue for states and schools not to require one cultural and linguistic standard but to be strong neutral arbiters of differences. Their view that students' cultural and linguistic diversity can be viewed positively as a resource in the classroom is echoed by the two handbooks for primary teachers, Effective Literacy Practice in Years 1 to 4 and Effective Literacy Practice in years 5 to 8 (Ministry of Education, 2003a, 2006a) which are discussed in Chapter 4.

\section{Literacy and identity construction}

This chapter has introduced several theories to explore literacy acquisition of the individual whose learning is situated in different educative sites and mediated by different teachers. These theories have stressed individuals' interactions with other people in their communities of practice. The settings and relationships reveal the significance of the identities that people construct as they operate in different sites each of which may have its own values. Several writers have linked literacy practices to identity (for example Heath, 1983; Pahl \& Rowsell, 2005; Street, 1995). Awareness of identity and knowledge of the multiple identities of learners is important in helping researchers to understand the mediation of learners as they participate with others in sites for literacy. This adds to the researchers' understandings as learners are viewed through Rogoff's $(1995,2003)$ planes of analysis. This is particularly important as learners are viewed through the personal plane as they appropriate knowledge and the community/institutional plane as they are apprenticed into the ways of their communities. Pahl and Rowsell (2005) describe literacy as being closely linked to identity, linking people to each other in their communities and to their shared histories: "Whether expressed as a piece of graffiti, a child's letter to a friend or an adult's practice of recording thoughts in a diary, literacy supports identity, and travels through our lives with us" (p.5). The concept of an individual's identity often relates to belonging to various groups in society (Collins \& Blot, 2003; Ferdman, 1990; Gee, 1996; Kenway \& Bullen, 2001) and consequently the individual may have many identities.

Culture influences how the individual constructs his or her identity (See for example, Alton-Lee, 2003; Biddulph, Biddulph \& Biddulph, 2003; Ferdman, 1990; Luke, 1997). 
Ferdman (1990) describes an ethnic group's cultural identity as involving a shared sense of cultural features that define and characterise the group. He suggests that other social categorisations such as gender, race and class also play an important role in linking individuals to groups and help in forming their identities. Ferdman (1990) explains that "cultural identity involves those parts of the self - those behaviors, beliefs, values, and norms that a person considers to define himself or herself socially as a member of a particular ethnic group - and the value placed on those features in relation to those of other groups" (pp.193-194). He argues that literacy is a culturally defined construct and therefore is closely linked to cultural identity. Collins and Blot (2003) write that "identities are built, constructed, with the discursive resources which are our birthright, our 'mother tongues,' but also with other, competing discourses of street, school, and workplace" (p.119).

Awareness of how learners construct their identities is essential in a study such as this that seeks an insider view from participants. An understanding of how participants may have multiple identities in their interactions with others in their different communities of practice informs the research. Pahl and Rowsell (2005) argue that the NLS make educators aware of their learners in relation to their identities. They are makers of texts and they infuse their texts with their sense of identity. The individual may have multiple identities (for example, relating to their age, gender, and ethnicity) and these will affect their uses and practices of literacy. Gee (1999) considers that individuals occupy different or multiple identities in relation to the different communities they operate in as perhaps parents, teachers or musicians and they move between these identities. It must also be considered that different domains where literacy is used such as church, home and school may require different practices and position learners in different ways.

\section{Conclusion}

The theories that have been outlined in Chapter 3 provide appropriate lenses to explore an insider view of the out-of-school social practices of participants in this study of literacy and to consider how their learning is mediated in different sites. They offer a suitable framework to analyse complementary and conflicting values between the various sites for learning. 


\section{CHAPTER 4}

\section{Curriculum Critique}

\section{Introduction}

This thesis aims to investigate the out-of-school literacy practices of students who are enrolled in the compulsory education sector. It is therefore important to include discussion of the official Ministry of Education requirements for literacy to see to what extent these are consistent with the ways people use literacies in of out-ofschool sites. The official requirements for primary school literacy are promulgated by the Ministry of Education through the English curriculum, teacher handbooks and other support materials for teachers. Chapters 2 and 3 argue that literacy is best understood through a sociocultural perspective that explores how people's literacy learning is mediated as they are apprenticed into cultural uses in different communities of practice. These involve social interactions with other people and the values of the various communities of practice or sites. This chapter discusses some of the influences which have informed the development of the literacy curriculum in New Zealand (in English) and critiques the current requirements of the curriculum in relation to literacy as social practice.

The purpose of this chapter is to raise and discuss two issues. The first issue is noted in Part One. This describes the official view of literacy for compulsory schooling in New Zealand and considers whether the Ministry of Education's definition is sufficiently broad to include the interpretations of literacy as social practice as they have been described in Chapters 2 and 3 . It provides an overview of the development of the curriculum and outlines the present situation in relation to issues raised in this thesis. The second issue is considered in Part Two of this chapter. The Ministry of Education (2006c) wants to improve learning for Pasifika students and expects teachers to be able to draw on strengths from students' cultural and linguistic backgrounds. This chapter argues that the concept of "incorporation" has been identified by some researchers as an appropriate means to enable teachers to help students make links between their out-of-school practices and the curriculum requirements of school. 


\section{PART ONE: THE OFFICIAL REQUIREMENTS FOR LITERACY IN NEW ZEALAND SCHOOLS}

\section{The New Zealand school curriculum}

The following section describes the development of the New Zealand school curriculum (in English) and considers to what extent it recognises literacy as social practice. The 1877 Education Act introduced a national system of education at primary school level, which was free, secular and compulsory (Simon, 2000). However, as noted by Codd and Openshaw (2005), education was compulsory only at primary level and it was not compulsory for Māori children. The curriculum subjects that usually took precedence were reading, writing, arithmetic and English grammar and composition. Examinations were conducted by inspectors and the results were published with teachers' jobs depending on good results (Codd \& Openshaw, 2005). Children were graded into six standards which were set out in Department of Education regulations, with "standard" referring to the standard of work that had to be attained before the child could be promoted to a higher class (Price, 2000). Parents were obliged to purchase one reading book for each standard and this single text was the child's reader for the whole year. Price describes how school inspectors carried out an annual inspection of children's mastery of this book and also the class arithmetic book, but there was criticism that children simply learned the book by heart. The rigidity in the school literacy of the era is interesting to consider in this thesis which interprets literacy as social practice as it illustrates how official interpretations have changed. There remains in the present, however, an argument for standards and increasingly detailed assessment and this is discussed later in the chapter.

\section{Education as a social process}

Some of the changes in education introduced many decades ago are interesting in that they seem to set the scene for an interpretation of literacy as social practice rather than as increasing levels of skills to be learned. The ideas discussed earlier in this thesis that learning is a social process and that, for learning to be successful, it needs to be made relevant to the learner can be linked to the ideas of the American philosopher John Dewey who lived from 1859 to 1952. In 1897 he wrote his ideas for a pedagogic creed (see Dewey, 1941) which included his beliefs that the school is primarily a social institution and that education is a social process. His belief was 
that the school must represent life "as real and vital to the child as that which he carries on in the home, in the neighborhood, or on the playground" (Dewey, 1941, p.6). Dewey's ideas can be linked to the argument in this thesis that students' social and cultural uses of literacy in family and community settings are highly relevant to their understandings of literacy in the school site. Dewey criticises traditional schooling because "the centre of gravity is outside the child. It is in the teacher, the text-book, anywhere and everywhere you please except in the immediate instincts and activities of the child himself" (p.30-31). The criticism was that traditional schools can become places for listening and mass instruction and can be divorced from the life experiences of the learner.

By 1935 the election of the first Labour government saw more resources put into education, while teachers were encouraged to interpret the curriculum more creatively and widely. A revision began of each subject in the primary curriculum and this extensive review of the curriculum, its development and implementation took almost fifteen years to complete. From 1940 when Dr Clarence Beeby was appointed Director-General of Education, teachers and students had more freedom to determine their own direction. This was under more of a progressivist model of education, influenced by the writing of Dewey. These changes were setting the scene for later changes which would take into account the out-of-school practices of Pasifika and other students in New Zealand schools and which would acknowledge and value their home languages. In describing Dewey's influence on education in Britain, Darling and Nisbet (2000) stress that in his writings Dewey emphasised activity for the learner rather than a passive acceptance of instruction, and that learning took place as a result of experience in a social context rather than as a result of instruction. This view represents more closely the appropriation of knowledge by the learner as described by Rogoff (1995) rather than a transmission model of learning. Carpenter (2001) writes that for Dewey education was a way of passing on to the young the cultural heritage, initiation into worthwhile ways of thinking and doing, and the training to be a good democratic citizen. The teacher's main function was to interpret the needs and interests of children and to guide them, and according to this philosophy schoolwork should be investigative rather than prescriptive. 


\section{Curriculum for a diverse community}

This section provides background material to the argument later in this thesis for the teaching of Pasifika languages in New Zealand schools. In the 1980s there was government support for teaching Pasifika languages in schools. When the new Labour government was elected in 1984 in New Zealand, it set up a Committee to Review the Curriculum for Schools which considered public submissions and then in 1987 it published The Curriculum Review (Department of Education, 1987). This document included fifteen principles for every school in New Zealand. The second principle stated that the curriculum shall be designed so that it is accessible to every student, regardless of factors such as race, cultural background and gender. This idea was echoed in the thirteenth principle which stated that the curriculum shall be inclusive, taking into account the needs and experiences of all students and the diverse character of the community. It is interesting to note that the eighth principle states that learning must be broad and general rather than "narrowly vocational" (p.11). In its extensive section of recommendations the report called for a national policy on languages to be developed (including Pacific Island languages), and also provision for second language learners (such as Pacific Islanders) to be reviewed and more suitable support and resources provided. It also recommended that resources be developed to assist the maintenance of Pacific Island languages throughout the school system.

\section{Curriculum skills for the workforce}

A feature of the curriculum development was the growing demand for education to meet the skills needs of the workforce. The review of the core curriculum led to the publication in 1991 of the draft of The National Curriculum of New Zealand (Ministry of Education, 1991b). A key purpose of the document was made clear in the foreword by Lockwood Smith, Minister of Education in the National Government, who wrote that the framework "will assist young New Zealanders to achieve success and acquire the essential knowledge, understanding, and skills which will enable them to compete in the modern international economy." He continued that this was essential if New Zealand as a small trading nation was to prosper in the international marketplace. The document listed "essential skills" and placed an emphasis on the need for a highly skilled and adaptable workforce which would meet the needs of a modern competitive economy. 
This draft was followed in 1993 by The New Zealand Curriculum Framework (Ministry of Education, 1993) which again strongly emphasised the need to create a workforce that was highly skilled and adaptable to meet the challenges of a competitive world economy. Although the Framework calls for "a broad and balanced education throughout their years of schooling" (p.6) for New Zealand students, its repetitive emphasis on preparation and adaptation for employment makes it seem a long way from Dr Beeby's vision. The principles of the Framework which give direction to the curriculum continue these themes, but in addition they state that the curriculum must reflect the multicultural nature of New Zealand society with specific reference to Pacific peoples. "It will ensure that the experiences, cultural traditions, histories, and languages of all New Zealanders are recognised and valued. It will acknowledge the place of Pacific Islands communities in New Zealand society ..." (p.7). In addressing the essential learning area titled "Language and languages," the Framework states that students whose mother tongue is a Pacific Islands language or another community language "will have the opportunity to develop and use their own language as an integral part of their schooling” (p.10). This was to be in response to the needs and initiatives taken by local communities. The Literacy Experts Group (Ministry of Education, 1999a) writing six years later also recommended that Pasifika languages be used in schools. They wrote that literacy instruction in years 1 to 4 in a Pasifika language could have benefits for children's learning both their first language and English, as well as helping to maintain and protect minority languages in a dominant English context.

However, the wishes of the people (including the teaching of Pasifika languages) were not necessarily addressed as the education reforms continued and the most powerful groups in New Zealand society were able to maintain their power and privilege. Carpenter (2001) writes "...in the final analysis the input of 'ordinary New Zealanders' was bypassed as the focus of the state from 1987-1990 moved to the restructuring of education" (p.118). Carpenter states that when the Framework was first published in 1993 it seemed to be liberal and permissive. However, since then the curriculum statements and support material have been published and the structures for teachers have become more prescribed and the autonomy of teachers more restricted. Writing earlier, Heath (1984) had also criticised a reduction in teacher autonomy as the curriculum for her American teachers became more prescribed and created an increased emphasis on testing. What the New Zealand 
curriculum now represents seems to be parallel demands. On the one hand there are the skills required to meet the needs of the workforce, and on the other, the need to make effective links to students' social and cultural practice. While these demands may not necessarily exclude each other, achieving the links to out-of-school practices is made more difficult when education is increasingly driven by assessment if the assessment is concerned with school literacy practices only.

In New Zealand the production of supporting handbooks and documents such as the English writing, oral and visual language exemplars mean that teachers are required to teach and assess increasingly complex skills and consequently may have less freedom to teach more learner-centred programmes. The relevance to this study is that the more the official curriculum becomes prescribed as levels and skills, the more difficult it will become for teachers to incorporate students' out-of-school social and cultural uses of literacy from their family and community settings. A debate in the 1990s about whether New Zealand should have national assessment and league tables led to the establishment of the NEMP. The increasing demands on assessment in education are challenged by Carpenter (2001) who suggests that New Zealand is reflecting education systems overseas where global political and economic structures have influenced education systems. She cautions:

Each new publication or idea has the potential to move curriculum further towards rigidity and conformity, using the argument that teachers require or should have imposed on them, 'guidelines'. (p.130)

\section{Requirements for more detailed assessment}

The crucial role of assessment as a driver in education is described by Broadfoot (1996) who writes:

So integral to the mass provision of education has the ideology and the associated practice of formal assessment become that the two would now appear to be inseparable. Any attempt to release education from the constrictions of assessment procedures, whether at individual, institutional or systemic levels, would be likely to result in the collapse of the system itself. (p.8)

Broadfoot argues that the significant role of assessment can be understood through three themes. These are promoting and accrediting competence, competition for 
limited rewards and control of both the individual and the whole education system. Each of these influences the content of education.

In their Report to the Secretary for Education the Literacy Experts Group (Ministry of Education, 1999a) made the recommendation that teachers identify patterns of diverse literacy and language skills to build on children's literacy skills from outside of school. Literacy is recognised as part of one's cultural practices and this means that children can bring very different literacy experiences to reading and writing. However, if it is true as Broadfoot (1996) suggests that there is a "pervasive presence and overwhelming importance of formal assessment procedures in any form of mass education provision" it is difficult to see how teachers can include a very strong focus on literacy as social practice because it cannot be assessed in that way. With this autonomous view of assessment being so important as a driver of education, there is a danger that teachers may focus too much on skills. Schools are now required to provide more detailed information on student achievement to the Ministry of Education with The Education Standards Act of 2001 (Ministry of Education, 2005) expanding the type of information that schools are required to gather to include information on individual, named students, as well as electronic reporting of statistical data from schools. In addition, changes introduced to school charters require goals for improved student achievement and annually updated improvement targets. The influential Report of the Literacy Taskforce (Ministry of Education, 1999b) recommended a description of the knowledge skills and attitudes for nineyear-old children for reading and writing. This led to the detailed indicators of reading and writing skills in the primary teachers' literacy handbook Effective Literacy Practice in Years 1 to 4 (Ministry of Education, 2003a) which show what children might be expected to have acquired after one year and four years at school and the indicators for the end of year 8 in Effective Literacy Practice in Years 5 to 8 (Ministry of Education, 2006a).

\section{New Literacy handbooks}

The two Effective Literacy Practice (ELP) texts have been written to complement but not replace the other literacy handbooks for primary schools, these being the writing text Dancing with the Pen (Ministry of Education, 1992a) and The Learner as a Reader (Ministry of Education, 1996b). In the foreword of Effective Literacy 
Practice in Years 1 to 4 (Ministry of Education, 2003a) Howard Fancy, Secretary for Education, states that the book has been designed as "the key reference for professional development programmes as well as providing a platform for further materials to support literacy teaching and learning in classrooms" (p.6). In contrast to the previously published handbooks, these new handbooks address both reading and writing. For example, the first text briefly mentions oral language, stating that oral underpins written language and the two are closely related, but by far the major emphasis is on written language. Over half of the text is dedicated to reading and writing together and considers them in some respects as reciprocal processes, with the remainder separated into reading information and writing information, with slightly more information on reading. These books are discussed here in some detail as they present a teacher guide to pedagogical practice in literacy.

An obvious change in both handbooks is the greater emphasis on literacy research than has been seen in previous handbooks for teachers, with a strong influence from the research arising out of the initiative to strengthen education in Mangere and Otara that began in 1997 to improve learning for Pasifika and other students in low decile ${ }^{7}$ schools (See Phillips, McNaughton \& MacDonald, 2001). The new handbooks' focus on pedagogy and meeting the needs of students from diverse backgrounds can also be linked to Quality Teaching for Diverse Students in Schooling: Best Evidence Synthesis (Alton-Lee, 2003) and to McNaughton (1995, 2002) and Timperley, Robinson and Bullard (1999). While the Ministry of Education's perspective on literacy teaching now has greater emphasis on skills, it is also giving a clear direction to teachers of the necessity for cultural engagement with students. Alton-Lee (2003) states that one of the ten characteristics generated out of the synthesis reads "effective links are created between school and other cultural contexts in which students are socialised, to facilitate learning." This is followed by the characteristic from the research "quality teaching recognises and builds on students' prior

7 Deciles of schools. In New Zealand the Ministry of Education uses census data to rank schools according to a socio-economic indicator that is influenced by five factors which relate to students' households. These factors include the household income and the percentage of parents who are in the lowest skilled occupational groups. The school attended by the students in this study could be considered typical of those attended by Pasifika students in that it is ranked by the Ministry of Education as decile 2. Decile 1 schools are the ten percent of schools with the highest number of students from low socio-economic communities, while decile 10 schools have the lowest number of these students (From Ministry website www.minedu.nz/print doc (11 July, 2006). The purpose of these rankings is to enable the Ministry to target funding to schools to help overcome barriers faced by students in lower socio-economic areas. 
experiences and knowledge" and "quality teaching respects and affirms cultural identity... and optimises educational opportunities" (p.vii).

Both Effective Literacy Practice texts acknowledge students' out-of-school literacies learned in families and communities. They introduce key concepts as their theoretical basis for effective practice in literacy teaching. These include a developmental perspective that recognises that a child beginning school has learned a great deal already and each student is on a unique pathway of development. Both handbooks emphasise that children have individual pathways of learning and recognition of the uniqueness of each student's needs is particularly important in light of the diverse nature of New Zealand's school populations. For example, Effective Literacy Practice in Years 1 to 4 states that teachers need extensive knowledge of "each child's individual profile of learning and the implications of this for instruction" and "each child's language and literacy practices outside of school as well as in school" (Ministry of Education, 2003, p.13). Both handbooks state that "there is no place for programmes with prescriptive methods and materials or for predetermined, recipe-style literacy activities that claim to fit the needs of all learners. There is no evidence of a single sequence of literacy development. The evidence shows clearly that there are many pathways that lead children to the desired goal of learning to read and write" (Ministry of Education, 2003, p.21). The point is made much more strongly than in previous texts that social and cultural practices are of prime importance in literacy teaching and learning. The handbooks refer to the socialisation model of literacy learning which is built on the idea that the student constructs meaning within social settings: "Social and cultural practices in fact shape all learning, and children's literacy development is shaped by their interactions with those around them" (Ministry of Education, 2003a, p.20). It explains that this model of learning is based on co-construction (see McNaughton, 1995, 2002) in which children construct their understandings through engaging with others in literacy activities in the home, in the community and in the school. The theory and guidelines for teachers contained within the Effective Literacy Practice texts fit a sociocultural model of literacy and through the handbooks is a strong message that being literate involves much more than simply being able to use the technical skills of reading and writing. 


\section{Increasing recognition of students' cultural backgrounds}

It is interesting to see how the successive Ministry of Education handbooks for teachers demonstrate an increasing emphasis on the need for teachers to make effective links to students' cultural backgrounds. This is appropriate considering the growing diversity of student backgrounds in New Zealand classrooms (outlined in Chapter 1). The significant change in recommended pedagogy can be seen when comparing the writing handbook Dancing with the Pen (Ministry of Education, 1992a) which makes only brief reference to the cultural influences on literacy to the later books. The Learner as a Reader (Ministry of Education, 1996b), which was published four years later as the reading handbook for primary teachers, stresses the importance of teachers knowing and being sensitive to students' culture and social backgrounds. Effective Literacy Practice in Years 1 to 4 which was published in 2003 has a very strong emphasis on cultural links, defining culture as the understandings and formal and informal ways of doing things that a student's family and community share, and which are not necessarily related to the student's ethnicity (Ministry of Education, 2003a, p.46). The book refers to the research that shows that some groups of students, including Māori and Pasifika students, have not been well served by the conventional school literacy practices.

\section{Diversity acknowledged as a useful resource}

Teachers may attribute children's low achievement to deficiencies within their families (McNaughton, 2002). Timperley, Phillips and Wiseman (2003) describe the relationship between teacher expectation and children's levels of achievement, with some teachers having "entrenched low expectations of achievement for children from low-income communities" (p.9). Teachers with low expectations may attribute children's failure to family background, including economic and cultural deprivation (McNaughton, 2002). However, the Ministry of Education's literacy handbooks avoid a deficit view of diversity and the message is that diversity in the classroom can be regarded as a rich resource rather than a difficulty.

The handbooks strongly reflect the research from the South Auckland schools (for example Phillips, McNaughton \& MacDonald, 2001) in building on the strengths that children bring from home and from their community literacy practices. They include the examples of students having rich oral language traditions, such as storytelling and reciting passages of scripture. The Ministry of Education (2003a) states "in a 
classroom that is a true community of learners, diversity offers tremendous potential for the learning of both the teacher and all the students" (p. 46). However, there is a caution that students from similar cultural and linguistic backgrounds can differ widely in their knowledge and experience, and generalisations about these students may disadvantage them. Both books refer to the research evidence showing a common pattern in New Zealand schools of teachers having lower expectations for Māori and Pasifika students in low-decile schools and students from a non English speaking background (Ministry of Education, 2006a, p.174).

Each text devotes a chapter to the concept of partnerships and the home-school partnership is emphasised strongly along with in-school partnerships, with the focus being on sharing knowledge of the learner. This emphasis meets a sociocultural view of literacy “....both partners know about and value the learner's background of experience because the family shares information about home and community literacy practices, including the knowledge, expertise, and activities involved" and the result is that the teacher uses the knowledge of these practices in planning school programmes (Ministry of Education, 2003a, p.161). In addressing knowledge of literacy learning both Effective Literacy Practice texts state that teachers need to consider cultural engagement:

Every learner views literacy tasks through a cultural 'lens' because most of the prior knowledge, experiences, and values that a learner brings to literacy activities arise from their cultural background. Culturally based values and knowledge affect each learner's engagement and interest in the learning activity. Ensuring cultural engagement is particularly important in classrooms where the students come from diverse backgrounds, especially where their cultural backgrounds differ from the teacher's. (Ministry of Education, 2003a. p.23)

This emphasis in the Ministry handbooks is important to this thesis as they explain literacy through a sociocultural perspective. However, they do not explain to teachers in any detail how to incorporate out-of-school literacies and they have a strong emphasis on assessment.

Some of the text materials that are provided free to schools in New Zealand are designed so that teachers and students can make connections to students' 
backgrounds. Many of the Ready to Read $\operatorname{series}^{8}$ which are for younger readers (five years to eight years old) and the School Journals for older primary readers (up to twelve years old) have a Pasifika focus. They contain material by, and about, Pasifika peoples living in their Pacific homelands and in New Zealand. As well, there are other Pasifika resources which are described in Chapter 9.

\section{Critical thinking and critical literacy}

Both ELP texts include thinking critically as a core component of the framework for literacy acquisition, and it is given considerably more emphasis in Effective Literacy Practice in Years 5 to 8 where there is a greater focus on teaching comprehension of texts and less on teaching the processes of how to read and write. The book is advocating an approach of critical thinking and encourages students to be aware of cultural and social perspectives. The new draft English curriculum (Ministry of Education, 2006b) addresses a critical literacy perspective, by for example, placing an emphasis on exploring how texts are constructed for different purposes and audiences and identifying points of view and evaluating the reliability of texts.

Teaching a critical literacy perspective to students from diverse backgrounds is particularly important. Freire's concept of reading the world (introduced in Chapter 2 ) is described by Au and Raphael (2000) as a personal stance taken by the reader. The reader's perspectives, background, beliefs and their language all contribute to the way they read the world and this shapes the way they read the written word. $\mathrm{Au}$ and Raphael write that for all students ownership of literacy is the key to attaining the critical literacy that Freire describes and this is especially so for those from diverse backgrounds (See also $\mathrm{Au}, 1995)$. Au and Raphael (2000) are concerned that in schools with large numbers of students from diverse backgrounds, literacy tends to be defined in terms of basic skills rather than higher level thinking. Rickford (1999) writes of African American and minority students being disadvantaged through being taught literal levels of comprehension and factual recall rather than higher level thinking skills, while she argues that her own study found ethnic minority students were better at higher order questions and critical evaluation than the lower order questions. Au and Raphael (2000) comment "opportunities to develop critical literacy are often less available to students of diverse backgrounds than to

\footnotetext{
${ }^{8}$ The Ready to Read series and New Zealand School Journals are published for the Ministry of Education by Learning Media Ltd, Wellington.
} 
mainstream students, and opportunities for thoughtful engagement with the full range of society's literacy artifacts are even more limited" (p.179).

This concept of language and power is described also by Lankshear (in Lankshear, Gee, Knobel \& Searle, 1997) who explains how there have been significant changes in the way many theorists think about literacy from the traditional view of reading and writing as cognitive ability or sets of skill to the view that reading and writing are embedded in social practice. A study of literacy then changes the perspective from mechanical skills and individual cognitive events to meaning being created within a sociocultural context. This lens means that "questions of power and the role of literacies as social practices within social productions and distributions of power have often been foregrounded, and the 'politics of literacy' has emerged as a wellsubscribed focus of theoretical attention" (p.3). Lankshear argues for a critical social literacy to be taught as part of the school curriculum. To support this he argues that language is deeply bound up with producing and maintaining arrangements of power in society which are unequal.

\section{Increased emphasis on skills and levels}

Embedded with the strong demand for culturally aware practice is a move towards a greater emphasis on skills and more detailed and prescribed assessment practice in reading and writing. This is part of an international trend but is more demanding and time-consuming than primary teachers in New Zealand have experienced previously. This interpretation of literacy which has been influenced by the needs of the state and business can be linked to Graff's (1987b) observation (in Chapter 2) that the hegemonic effect of historic uses of literacy are still part of our world in meeting the needs of the state, bureaucracy and trade. This is to exert cultural and political influence over the social and individual functions of literacy and schooling.

An example of this skill emphasis is seen in the Patterns of Progress in the first Effective Literacy Practice text (Ministry of Education, 2003a, pp.70-74) which includes detailed indicators of what children may be expected to know and be able to do after one year of literacy instruction at school and after four years. These indicators for reading and writing are more detailed developments of the descriptors in the Report of the Literacy Taskforce (Ministry of Education, 1999b, pp.32-35). 
The handbook suggests standardised assessment procedures that teachers may use to assess their students in literacy and it suggests the levels where these may be used (for example, School Entry Assessment, running records, The Observation Survey, Assessment Resource Banks, and Progressive Achievement Tests). In the past there has been some debate amongst teachers over expected reading levels for children at particular ages. Teachers are well aware that children enter school with varying degrees of understanding of emergent reading and writing. While schooling in New Zealand is compulsory from the age of six, most children start at the age of five years, and the system needs to be flexible enough to take into consideration their diversity of literacy understandings. The previous handbooks for teachers, Reading in Junior Classes (Ministry of Education, 1995) and The Learner as a Reader (Ministry of Education, 1996b) do not specify reading levels for children of a particular age. The Ready to Read series published for the Ministry of Education forms the basis of reading programmes in New Zealand junior classrooms and a general understanding about it is that it is designed to cover three years of reading level (from 5 to 8 years) although it is expected that some children will progress more quickly through the levels.

For the first time, Effective Literacy Practice in Years 1 to 4 provides a guideline for teacher expectation of reading levels for children at the end of year 1 and year 4 by which time they are expected to be able "to read, comprehend, and respond to texts that are widely agreed to be appropriate at their chronological age" (p.73). In spite of their limitations, "reading ages" are a common measure of a child's capability and one which many parents are concerned about. As there are no specified texts for this assessment, the selection will be made by teachers and whether the texts are appropriate or not for Pasifika children will depend on teachers' knowledge. The handbooks represent what seems to be a parallel demand in the curriculum which may form a dilemma for teachers. These demands are the need for teaching skills and the need to make effective links to students' social and cultural practice.

According to Apple (1999) the public debate on education has shifted greatly to the right. In his chapter about "official knowledge" he backs this claim by describing the proposals for school vouchers, to make schools more like what he describes as the idealized market economy, and the movement by states to raise standards and to mandate competencies for both teachers and students leading to more centralized 
state control of teaching and the curriculum. In New Zealand the National Party has advocated vouchers since the 1980s as a way to improve education. During the 2005 election campaign, leader Don Brash argued in the Dominion Post newspaper for an alternative path to schools for parents to help their children with vouchers for parents of "failing pupils" (Dominion Post, 28.4.05) (Brash, 2005). This was under the heading "A better education for every child" and also argued for school test results to be benchmarked against a set of national standards in literacy and numeracy.

Rather than providing equitable opportunity for all students, schools may be an effective means of perpetuating the existing social patterns and social inequalities from one generation to the next. Bourdieu (1974) writes that a sociological explanation can explain the unequal achievement that is usually imputed to unequal ability. Each family transmits to its children what Bourdieu names cultural capital and an ethos which determines the children's behaviour and attitude at school. By treating all children as equal, instead of taking into account cultural inequalities between children of different social classes, the school continues the inequalities. The cultural capital or habitus of the middle classes is taken by the school as natural as if all children have equal access to it, and the school therefore acts as an agent to reproduce the hierarchy in society. Apple (1990) explains that schools use formal and informal knowledge as a filter to process people, often by class and "different dispositions and values are taught to different school populations, again often by class (and sex and race)" (p.33-34). While Apple (1990) has warned against creating a schooling process that remains unconnected to the lives of so many children, the notion that the sameness of treatment is not the same as educational opportunity is echoed by Gay (1989) who states that a popular interpretation of educational opportunity is access to the same schools by minority culture students as majority culture students. Gay argued that in the American environment, the teacher training, curriculum design and the resources to deliver the curriculum all reflect middle class mainstream values and the mainstream students can connect readily to this.

\section{Arguments for bilingualism}

One way to address equality of opportunity is to follow the Curriculum Framework (Ministry of Education, 1993) and provide education in the home language of the student. Strong arguments have been advanced for the teaching of Pasifika 
languages in New Zealand schools by Irwin (1988), Spolsky (1988), HunkinTuiletufuga (1996, 2001) May, Hill and Tiakiwai, 2004) and Taumoefolau, Starks, Bell and Davis (2004). Writing in relation to the Samoan community in New Zealand Spolsky (1988) states:

\begin{abstract}
It is evident that an immigrant or other minority group that maintains the strength of its traditional cultural, social and religious values is better equipped to meet the major challenges of modernization and immigration. The modernization takes place inside the group as a whole, with provision of mutual support during the difficult transition. The alternative, where the full weight falls on individuals who have lost connections and identity results in anomie and social disharmony. (p.8)
\end{abstract}

Although Spolsky's words are like a warning of what might occur to communities like the one in this study, the data provided more evidence of common values than conflicting values. In this study the students' descriptions of literacy practices in family, church and neighbourhood sites revealed aspects of their individual and group identities. For example, their uses of popular culture and its associated conflicting and consonant relationships within the configuration of sites illustrates the complexity of the paths they choose. In spite of conflicts, the sense of connectedness with the community emerged as a very important one, and the significance of connectedness is stressed by those who write in support of Pasifika languages being taught in schools.

The peoples of the various Pacific nations may be viewed at times by other New Zealanders as one homogeneous group but they each have their own distinctive cultures. This point is stressed by Hunkin-Tuiletufuga (2001) who argues that

\footnotetext{
...each of the Pacific languages has a centrally important role to play in keeping Pacific cultures and associated identities alive, particularly in migrant enclaves such as those in New Zealand. Each language embodies values, knowledge and understandings that give meaning, structure and purpose to the social life of its users... We are able to build a cultural system in our own Pacific language and through which the world is moderated... Our cultural domains, and the value systems that underlie and influence our social systems, are embodied in our languages. (p.197-8)
}

This interpretation seems analogous to Cremin's (1988) theory of education where the major educative agencies perform a mediative role with respect to the others and with respect to society at large. As Cremin says, the family mediates the culture, and 
also mediates the ways in which other institutions mediate the culture for members of the community.

A further argument to support the teaching of these languages is made by HunkinTuiletufuga (2001). Learning these languages strengthens the Pasifika communities through inter-generational communication between family members in New Zealand and also with those in their Pacific homelands. May, Hill and Tiakiwai (2004) write that there are few studies in New Zealand that address Pasifika bilingual education directly. However, Hampton (1992), May (1994) and McCaffrey and Tuafuti (1998) (all cited in May, Hill \& Tiakiwai, 2004) illustrate positive results in English for students involved in bilingual programmes with Pasifika languages. There are cultural and social benefits to learning two languages. May, Hill and Tiakiwai write that bilingual students have certain advantages over monolingual students and give the examples of how bilingual learners tend to develop greater linguistic and syntactic awareness and demonstrate more divergent thinking.

May, Hill and Tiakiwai (2004) advocate for bilingual programmes and suggest that Two-way immersion programmes would be appropriate. They explain that these programmes which are also known as dual medium bilingual immersion, are unlike other immersion programmes in that they include native speakers as well as nonnative speakers of the heritage language in the same classroom in approximately equal numbers. This would allow students who speak a Pasifika language as their first language to be integrated with second and third generation New Zealand born students whose first language is English. They write "the results of Two-way programmes in the US strongly suggest that both groups of students would benefit significantly, particularly given the ongoing overrepresentation of Pasifika students in the lowest quartiles of English literacy performance" even for those whose first language is English (p.98).

\section{Negative attitudes towards bilingualism}

However an obstacle to a bilingual education is that parents' and teachers' attitudes towards it have not always been supportive. Hunkin-Tuiletufuga (2001) describes a negative view held by some Pasifika people that the acquisition of Pasifika languages is not important, a view which he states may remain from a widely promoted belief held from the 1960s to the early 1980s. He refers to this as a misguided belief which 
was encouraged by an educational philosophy that learning the languages of the migrant communities got in the way of learning English which was seen as essential for academic success. This resulted in many first generation New Zealand born Pasifika children growing up knowing little of their Pasifika language which HunkinTuiletufuga (2001) describes as a mistake, citing Spolsky (1988, p.16) who writes "any group that acquires English by giving up its own language runs the serious risk of losing its culture, identity, and traditional values as well" (Hunkin-Tuiletufuga, 2001, p.203). As well as parents, others in the wider community have not sufficiently understood and valued learning two languages. In the past bilingualism has been defined from a deficit perspective (May, Hill \& Tiakiwai, 2004) and because this remains to an extent with teachers, administrators and the public, many bilingual students do not experience their bilingualism, or schooling as a positive experience.

Hunkin-Tuiletufuga (2001) asserts that the education system must acknowledge that "its efforts in the last thirty or so years in educating Pacific peoples in New Zealand have been based on models that are culturally and linguistically inappropriate and unsuitable" (p.204). He writes that a serious mismatch between the cultural capital of home and school is a principal reason for the high failure rate of Pasifika children in schools. He gives the example of children's linguistic strengths not being sufficiently valued and used successfully in children's education beyond the preschool sector. Ideally, for children who leave the A'oga Amata $^{9}$ to enter school, the school programme needs to incorporate their understandings into literacy programmes.

\section{Changing attitudes}

The Ministry of Education commissioned a survey (Market Research Limited, 1995) to discover the attitudes of parents to their children learning in English or Pasifika languages and concluded that Pasifika people had a strong desire for their children to retain the values of their own culture while they succeeded in the English language oriented school system. Ninety seven percent of the parents said that their child was exposed to their own language in the two weeks prior to the interview. This occurred in the sites of their own home (90 percent), a relative's home ( 88 percent) at church (71 percent) and at primary school (34 percent). The survey found that 38 percent of

\footnotetext{
${ }^{9}$ Samoan language early childhood centre
} 
the children had equal ability in their Pasifika language and English while for one quarter, their Pasifika language was better than English. There was strong support from parents for their language to be taught in the school with 43 percent of parents wishing their children to be taught in both their Pasifika language and in English. Only 18 percent wished only English to be used.

The Pasifika communities in New Zealand are minorities in a society dominated by papalagi values and there is a danger perceived by some in the communities that their languages could be lost. While numbers of Pasifika people born in New Zealand have grown considerably, the proportion of these who speak Pasifika languages is decreasing.

\section{Limited use of Pasifika languages in schools}

However, in spite of some support in the community the true situation is that very few students learn in Pasifika languages. At July 2006 a total of 32 primary and secondary schools offered a Pasifika language as the medium of instruction for more than three hours a week, involving a total of 2,513 students (Ministry of Education, Education Counts, 2006). A factor that may make this more difficult to achieve is the small number of teachers who identify as Pasifika. Only three percent of primary teachers and two percent of secondary teachers identify as being Pasifika in comparison with 9.1 percent of students who identify as being from a Pasifika background. Around 400 primary and secondary teachers identified in 2004 that they had taught students in a Pasifika language with nearly three quarters of these teaching in Samoan. [Ministry of Education website 16 May 07, Education Counts]

In a previous study the researcher (Dickie, 2000) interviewed 21 Pasifika students who were enrolled in a degree programme for primary teaching. The majority of these said they wished to teach their Pasifika language in a bilingual or immersion class at some time in the future. Some students related how having knowledge of the language helped them to build rapport with children when they were on teaching experience. One mentioned using her Pasifika cultural capital and another said using the Pasifika language would help her to connect with the Polynesian students she was teaching. 


\section{PART TWO: MAKING CONNECTIONS BETWEEN OUT-OF-SCHOOL PRACTICE AND THE CURRICULUM}

\section{Incorporation}

As this chapter has illustrated the curriculum guidelines as they are explained in the ELP handbooks recommend that teachers make links to students' backgrounds. A strategy that enables transfer of learning between out-of-school and school sites is described by McNaughton (2002) as incorporation, and this section of Chapter 4 explains the concept and gives examples of how the strategy has been used to make meaningful connections for students in widely different settings (Amituanai-Toloa, 2005; Au, 1980; Dyson, 2003; Gregory, 2004; McNaughton, 2002). McNaughton argues that for children from culturally and linguistically diverse backgrounds who are beginning school, the "meeting of minds" (p.14) between teacher and learner is vitally important for effective literacy teaching. This can be achieved through "enhancing the multitude of sites that learners and teachers have available to them in which to make connections" (p.26). He explains that effective connections can be made for the learner when the class programme incorporates features in which the child has developed expertise in out-of-school settings. He writes "transfer of learning occurs as a consequence of this incorporation - bridges between the familiar and the unfamiliar can be made by both the learner and by the teacher" (p.27). However, incorporating out-of-school knowledge and expertise may not match the curriculum or pedagogy of the school. Therefore what McNaughton terms a "discrimination learning" is required (p.28) so children become aware to what extent their out-of-school knowledge is aligned with that of school. As an example McNaughton refers to some children, including Pasifika children, who have considerable experience of recitation of text outside school. He explains that children may draw on this skill in learning simple texts: "Recitation skills incorporated into the activity can aid the learner's attending to relationships between what is said (part-memorised) and what is seen" (p.29). However, he cautions that a reliance on recitation may interfere with the child's development of other reading processes so their use of recitation needs to be guided to help the child to discriminate when it is appropriate.

An example of incorporation of cultural practice is described by Au (1980) who was seeking to improve the academic performance of minority culture children. She 
facilitated improved reading achievement of young Hawaiian children by making links to talk story, a practice with which the children were familiar from their own culture. Another example of successful incorporation is Dyson's study (2003) where a group of young African American children appropriated aspects of popular culture from their out-of-school experiences into their early school experiences of literacy. Both of these works are described in Chapter 9 and relate to the findings of this study.

\section{Making the unfamiliar familiar for Samoan students}

A study that investigates incorporation for Samoan students in New Zealand has been conducted by Amituanai-Toloa (2005) who explored the effects of incorporating students' out-of-school activities in improving comprehension in six Samoan bilingual classrooms in South Auckland. She argues that for teachers to teach more effectively students from diverse backgrounds they need to understand the relevance of students' background knowledge and how to apply it in their teaching. She writes that in understanding the background knowledge of students, teachers can text switch to make the unfamiliar familiar (see McNaughton, 2002) and “incorporate appropriate cultural, procedural, or linguistic knowledge” (p.32). She emphasises the importance of teachers needing to be aware of how students live outof-school and explains that if students already have knowledge grounded in the community and home then effective teaching will elicit these experiences in order to make the connections as described by McNaughton (2002). Amituanai-Toloa stresses that for the Samoan students in her study “...culture and religion play pivotal roles in their prior instruction and background knowledge" and she suggests that these would be predicted to "...exert great influence on cognition in their perception and comprehension of texts" (p.29). She stresses how these are interlinked, writing that "...for Samoan students, culture cannot be addressed without religion just as religion cannot be without culture" (p.29).

Amituanai-Toloa's (2005) study revealed that incorporation was found in the context of students acquiring vocabulary. This involved teachers answering questions about and discussing words that students had difficulty with and it was an influential strategy in improving students' comprehension results. This has an implication for teacher planning as when teachers select the texts that are to be used by students they need to consider where incorporation of students' out-of-school activities can be 
integrated into the lesson. Amituanai-Toloa (2005) writes "in the case of Samoan students, there are explicit and implicit characteristics of fa'aSamoa that form the basis of principles, values and beliefs that influence and control the behaviour of Samoans" (p.35, italics in original). She writes that there are also characteristics of reading practice and therefore reading comprehension that affect students' understanding of texts.

\section{Conclusion}

There is a dual perspective in the Ministry of Education Effective Literacy Practice handbooks and other documents which emphasises the teaching of skills, and also emphasises a sociocultural perspective. This view of literacy as social practice seems highly appropriate in light of the changing demographics of New Zealand schools and the need to address disparities in literacy learning. Reading the handbooks can lead to the interpretation that the Ministry supports recognition of students' own cultural uses of literacy although they do not offer teachers specific information on how to achieve this. There is a need for more information on this and the need for the curriculum to be interpreted in a way that is flexible enough to suit learners from diverse backgrounds. This thesis argues that given the exhortations of the Ministry of Education, there is a need now to follow this guidance, investigate the literacy practices of a group of Pasifika students in detail and see what the evidence this yields tells us about how to support Pasifika students' literacy learning in schools in relation to their out-of-school experiences.

The first four chapters have used a sociocultural perspective to illustrate the complexities of literacy as social and cultural practice and to consider how these literacies can be addressed through the official school curriculum. These chapters have built a case for the appropriate methodology for an ethnographic case study such as this and the methods are explained in the following chapter. In order to show the perspective of this group of Pasifika participants and to help address any power imbalance, the study seeks an insider view. This requires rich qualitative data to explore the complexities of literacy as social practice as the participants make their way in different cultures and their identities are created. 


\section{CHAPTER 5}

\section{Methodology}

\section{Introduction}

The purpose of this chapter is to outline the methodological framework and research methods through which the data for this study are generated, interpreted and evaluated. The first section introduces the research questions followed by a general overview of the methodology that is appropriate to answer these questions. The second section begins with a description of the research design for this case study, including the setting, participants, and instruments for data gathering. This is followed by a description of the pilot study, and then information about the main study including management of data and the framework for analysis. The last section of Chapter 5 is a description of the students' community which provides contextual background to the study.

\section{The research focus}

The Ministry of Education (2003a, 2006a) argues that teachers need to know more about the out-of-school literacies of students from diverse backgrounds, including Pasifika students. In order to improve learning for Pasifika students, teachers need to be better informed of their out-of-school literacy practices with their associated cultural and social values which are situated in family and community. This, it is asserted, would enable teachers to make meaningful links to, and draw on students' backgrounds, and to be aware of possible connections and conflicts between the practices in these different sites (Cremin, 1976). It may also enable teachers to link to people who have understandings of these strengths and who can support learning in school. With this information teachers may be able to incorporate aspects of it into school learning with the aim of raising student achievement in literacy. This study, therefore, sought to empower Pasifika students as ethnographers to let them define their own literacies in order to provide an insider view of their uses of literacy in various sites outside the school. The procedures were consistent with the Pasifika Education Research Guidelines (Anae et al., 2001) which emphasise consultation with people in the community and building rapport with participants. 


\section{The research questions}

In order to investigate this topic the research questions are:

1/ What are the uses of literacy associated with the sites such as family, church, and neighbourhood?

2/ Where and how is the literacy learning of year 7 and 8 Pasifika students mediated in out-of-school sites?

2/ What are the implications of the practices across the configurations of sites for students' literacy learning in school?

\section{Overview of methodology}

\section{Valuing a Pasifika perspective}

The Pasifika Education Research Guidelines (Anae et al., 2001), which explain how to behave in a culturally sensitive manner, were considered when designing and undertaking this study. These aspects related to consultation, using translations, the value of face-to-face meetings and the need to build rapport with participants who are being interviewed. This means that in a sense the data are not being collected but are instead co-authored. These points are significant in an investigation where the researcher, who is papalagi, seeks to gain an insider view from his Pasifika participants. The researcher followed a similar procedure to that in his study of the views of adult Pasifika students in primary teacher training (Dickie, 2000). To help establish rapport between participants and researcher he sought advice on this from Pasifika colleagues. As part of the process of consultation, in the early stages of planning the study, the researcher consulted three experienced teacher educators from a Samoan background who gave advice on the interview questions and the appropriate protocols for the investigation. Their guidance was sought particularly in relation to gathering data about church practices in literacy. These informal meetings and subsequent dialogue informed the type of questions that were asked and how the data were to be gathered. One of the teachers of the students is also Samoan and her knowledge and experience as a member of the Samoan community and as the students' teacher was invaluable to the researcher. There was consultation with her about gaining consent for student participation, and ongoing consultation about engaging the students in the project. 


\section{Critical ethnography as an approach}

This research can be described as an ethnographic case study which is concerned with the cultural context of particular sites and uses of literacy. Therefore, the methodological approach that is required is predominantly qualitative in order to generate detailed data and allow the participants' voices to be heard. The term ethnographic derives from the Greek ethnos meaning people, a race or cultural group, and ethnography refers to a social description of a people and the cultural basis of their peoplehood (Vidich \& Lyman, 2000). Ethnographic methods are descriptive with the analysis reaching across multiple sources of data (Miles \& Huberman, 1994). Exploring a group's literacy practices through their social and cultural perspectives requires detailed description. The term "thick description" as a contrast to "thin description" has been used by Geertz (1973, cited in Bogdan \& Biklen, 1992) to describe the task of ethnography and this detailed description is necessary for the researcher to interpret different cultural perspectives. Bogdan and Biklen write "the ethnographer's goals are to share in the meanings that the cultural participants take for granted and then to depict the new understanding for the reader and for outsiders" (p.39). Interviews are an appropriate means of gathering data in an ethnographic study. The Pasifika Education Research Guidelines (Anae et al., 2001) advise that face-to-face interviews are the most effective type of qualitative interviews for Pacific peoples as they provide opportunities to build familiarity with the interviewer as well as the topic. The guidelines also suggest the value of introductions between interviewers and interviewees in order to establish good rapport. Anae et al. (2001) write "the importance of building rapport with participants cannot be understated, as it is critical to gaining valuable information..." (p.38).

When considering the relationships of power in society, as noted in Chapter 4, a critical ethnographic approach is appropriate (See Carspecken, 1996; Comaroff \& Comaroff, cited in Kincheloe \& McLaren, 2000, p.302) Critical ethnography is also useful in freeing the object of analysis from stereotyping or simplistic interpretations of culture (Kincheloe \& McLaren, 2000, pp.301-2). A qualitative approach that permits the participants' voices to be heard facilitates an insider's perspective of these relationships of power. Carspecken states that "criticalists" are concerned about social inequalities and they direct their work towards positive change. $\mathrm{He}$ writes of generating data with participants rather than recording information about 
them in what is called a "democratisation" of the research process (p.42). When the researcher aims to generate data with participants rather than have the researcher controlling the interpretation, a strategy for interviews that may help to gain an insider view is suggested by Kvale (1988, cited in Miles \& Huberman, 1994, p.35) who describes the researcher in open-ended interviews as occasionally summarising or reflecting on key points, in order to condense and interpret the participants' meaning.

\section{Triangulation of data}

In ethnographic research the strength of fieldwork is in triangulation of data (Wolcott, 2001). Combining the use of two or more methods of data collection can improve the richness of the data that is collected. Using these multiple sources enables the researcher to check the consistency of findings that are gathered by different methods and check the consistency of different data sources within the same method (Burns, 2000). Stake (2000) explains triangulation as having “...been generally considered a process of using multiple perceptions to clarify meaning, verifying the repeatability of an observation or interpretation" (p.443). However, as Stake points out, because no observations or interpretations can be repeated exactly, triangulation is also used to clarify meaning through identifying the different ways the phenomenon is being seen. In this study the data comes from multiple sources including the transcripts of dialogue from interviews, students' journals and their photos. These are compared with data from the interviews with church representatives as well as data from teachers in the school and the community librarians.

\section{A qualitative approach}

A qualitative approach to data collection reflects the sociocultural approach through which participants' perceptions of their social and cultural practices in literacy are explored. A qualitative method is particularly suitable for a study of literacy that is situated in the social settings of the home and the community where individuals tell their own stories about their practices of reading and writing. A qualitative inquiry enables the researcher to interpret authentic situations from the real world. It is "a situated activity that locates the observer in the world. It consists of a set of interpretive, material practices that make the world visible" (Denzin \& Lincoln, 2000, p.3). The qualitative researcher interprets the world through representations in 
such techniques as field notes, interviews, conversations, photographs, recordings and memos. "Qualitative researchers study things in their natural settings, attempting to make sense of, or to interpret, phenomena in terms of the meanings people bring to them" (Denzin \& Lincoln, p. 3). Qualitative researchers go to the setting under study as they assume that human behaviour is significantly influenced by the setting in which it occurs and when possible they go to gather data in that location (Bogdan \& Biklen, 1992, p.30).

Qualitative data are descriptive (Bogdan \& Biklen, 1992) and in the form of words or pictures. Qualitative researchers "try to analyze the data with all of their richness as closely as possible to the form in which they were recorded or transcribed" (Bogdan \& Biklen, 1992, p. 30). Characteristics of qualitative data are "their richness and holism, with strong potential for revealing complexity; such data provide 'thick descriptions' that are vivid, nested in a real context, and have a ring of truth that has strong impact on the reader" (Miles \& Huberman, 1994, p. 10). Patton (2002) also describes "thick, rich description" as essential for qualitative analysis and reporting to take the reader into the setting that is being described (p.437) and this may also include "rich quotations" (p.438). Qualitative data "capture and communicate someone else's experience of the world in his or her own words. Qualitative data tell a story" (Patton, 2002, p.47).

Although a small study such as the present one is not representative of the wider population, its strength can be on authenticity rather than reliability, and on depth. Open-ended questions are often the means to achieve this (Silverman, 2001). The samples in the study are often small and audio recordings are commonly used with transcripts to provide a record of the interaction. "Compared to field notes of observational data, recordings and transcripts can offer a highly reliable record to which researchers can return as they develop new hypotheses" (p.13).

This study is a small case study of a sample of Pasifika students, their families and church representatives. A case study is useful in social research to provide data on a limited and specific sample in depth and has been used in studies of situated literacy (for example, Taylor, 1983). Smaller scale research such as case studies tend to have items for study selected on the basis of their particular characteristics (Denscombe, 2002, p.146) rather than as a random selection or as a quota. Purposive rather than 
random sampling methods are used by many qualitative researchers. "They seek out groups, settings, and individuals where and for whom the processes being studied are most likely to occur" (Denzin \& Lincoln, 2000, p.370).

\section{Photographs as tools in qualitative research}

Photographs are an appropriate research tool in a qualitative investigation into cultural uses of literacy as they:

- enable participants to offer an insider view

- help to address the imbalance of power between participants and researcher

- can elicit rich qualitative data in discussions.

\section{Providing an insider view}

An obvious advantage of using photographs as research tools is that they are able to provide the researcher with an insider view into the lives of the participants. This is particularly important in this study as it seeks a Pasifika perspective on literacy practices to add to what is known already about school literacy. Photography has long been used to document cultural practices in anthropology and ethnography. Flick (1998) writes of Dabbs' (1982) description of people under study who received cameras and were asked to take their own photos or have someone else take photos to tell who they were. A key point of this approach, as in the present investigation, is that the participants make their own decisions about what will be photographed to represent aspects of their lives (in Flick, 1998, p.153). Collier (2001) describes how participants provide an insider's viewpoint of details, places, people and activities, as well as providing their own 'reading' of the photograph and commenting on the researcher's reading. Collier describes photo elicitation where in a direct analysis participants can provide their own open-ended interpretations and make comments on the researcher's interpretations of the photos, thus allowing the participants to provide an inside viewpoint of the topic. Ethnographer Goldman-Segall (1998) adds to this by questioning how the researcher can be an expert on someone else's culture and explains how the use of video cameras and still cameras with grade 7 students allowed children to "become ethnographers of their own culture, crafting artifacts to represent themselves" (p35). 
Helping to address the power imbalance

Researching children's views is different from researching adults as the power imbalance between researcher and participant is even greater. In this study the researcher was in a position of power and seen by the students as a teacher. However, the imbalance of power can be somewhat addressed when children are invited to make their own decisions in selecting their sites and uses of literacy and then to take their own photos and subsequently discuss them. With this method, the researcher can be working with children rather than observing them as an outsider. In a sense, the participants can become ethnographers themselves and offer the insider's view, and this was how the use of photos was explained to the students in this study at meeting one.

Several studies describe children as collectors of data using cameras (Burnett \& Myers, 2002; Clark \& Moss, 2001; Goldman-Segall, 1998; Schratz \& SteinerLoffler, 1998). Using disposable cameras allows children to take control of the process without any worry that expensive equipment might be damaged. As well, the cameras are small and light which makes them easier for children to use and carry about (Clark \& Moss, 2001). The work of Burnett and Myers (2002) with year 3 and 6 children is relevant to this study as it illustrates how children's photos were used as a tool to provide an insider view. Burnett and Myers engaged children as researchers in order to explore what the children themselves considered to be meaningful literacy practices in their own lives through their collection and reflection of their photographs. The photographs were used in semi-structured interviews where the children commented and reflected on their photos, with the writers stating that the photos provided a means of entry into the children's world which would otherwise have been inaccessible to the researchers. They write that this method draws heavily on the work of Barton and Hamilton (1998) in using disposable cameras to record literacy events (See Hamilton, 2000). The emphasis was on research with children so the methodology reflected the children's own ability to investigate and reflect on their own experience. "In this way, our approach accepted the validity of children's voices" (p. 57).

Photo elicitation technique provides rich qualitative data

While photos can by analysed in their own right (Flick, 1988), using them as the basis for discussion in semi-structured interviews provides the opportunity for rich 
qualitative data to emerge (see for example, Barton, 2000; Collier, 2001; Hamilton, 2000; Prosser \& Schwartz, 1998; Schwartz, 1989). The photograph elicitation technique is described by Flick (1998), Prosser and Schwartz (1998), Collier (2001), and Harper (2002). Harper (2002) defines photo elicitation as inserting photographs into research interviews to evoke deeper elements of human consciousness in the participants than would words alone. Harper explains that the term photo elicitation was first used by Collier (1957) who noted that using pictures elicited longer and more comprehensive interviews with participants. In the current study the photographs provide the opportunity to explore literacy through the eyes of 11 and 12-year-old children and enable them to state their identities, providing a perspective the researcher would not be able to obtain by observations and interviews alone. The children are recognised as the experts on their own literacies.

Collier (2001) explains the value of the technique with an example where photographs which had little potential for direct analysis were used in an interview and released vivid memories, feelings and insight: "...a flood of comments, memories and intense emotional statements of identity, relationships to families and tradition, and much more" (p.46). This type of stimulus also occurred in the current study where the photo elicitation discussions produced useful data that had no direct relationship to the photos. The students in this study enjoyed using the cameras and most described it as fun. Question 11 in the meeting three interview schedule for students (Appendix I) asked them how they felt about taking the photos and the positive comments from the boys about using the cameras contrasted with their negative comments about how they felt about writing in their journal, which most boys described as boring.

\section{Ethics}

The ethical procedures of NZARE were followed as well as the Pasifika Education Research Guidelines: Final Report (Anae et al., 2001). The researcher informed the teachers, students, the church representatives and the parents of the students through an introductory letter (Appendix D), which provided an outline of the purposes of the study and its procedures. Informed consent was sought from the church representatives who were invited to be interviewed after being contacted by the school principal (See Appendix E: Consent form for church representatives). Permission was sought from all participants for audio-recordings to be made. 
Consent was sought from the principal of the participating school (Appendix F: Consent form for principals of participating schools) and advice was sought from the school principal on gaining consent from the parents of the year 7 and 8 students. Signed consent was then sought from the parents/caregivers and the students (Appendix G: Parents/Caregivers consent form for their child).

Following the interviews, transcripts of the church representatives' interviews were forwarded to the participants to enable them to check for accuracy. The research data were stored securely in a locked cabinet in an office at Victoria University College of Education and the raw data will be destroyed three years after the completion of the study.

During the analysis of data the researcher, in consultation with his supervisors, decided to seek permission from student participants for some of their photos to be included in the thesis. Copies of the photos were sent to participants with Appendix $\mathrm{K}$ and written permission was obtained. The names of participants were not used but in consultation with the school and a Samoan colleague it was decided to give students names from the Samoan Bible (See Figure 3). Names were supplied by a Samoan colleague in the support group.

The researcher gave an oral presentation of the findings to the school staff. During this meeting more data were produced about the overlap of literacy practices between the home and the school and these were added to the findings. The researcher will offer a brief written summary of the findings to the school.

\section{The case study design}

The following section of Chapter 5 describes the research design for this case study. 


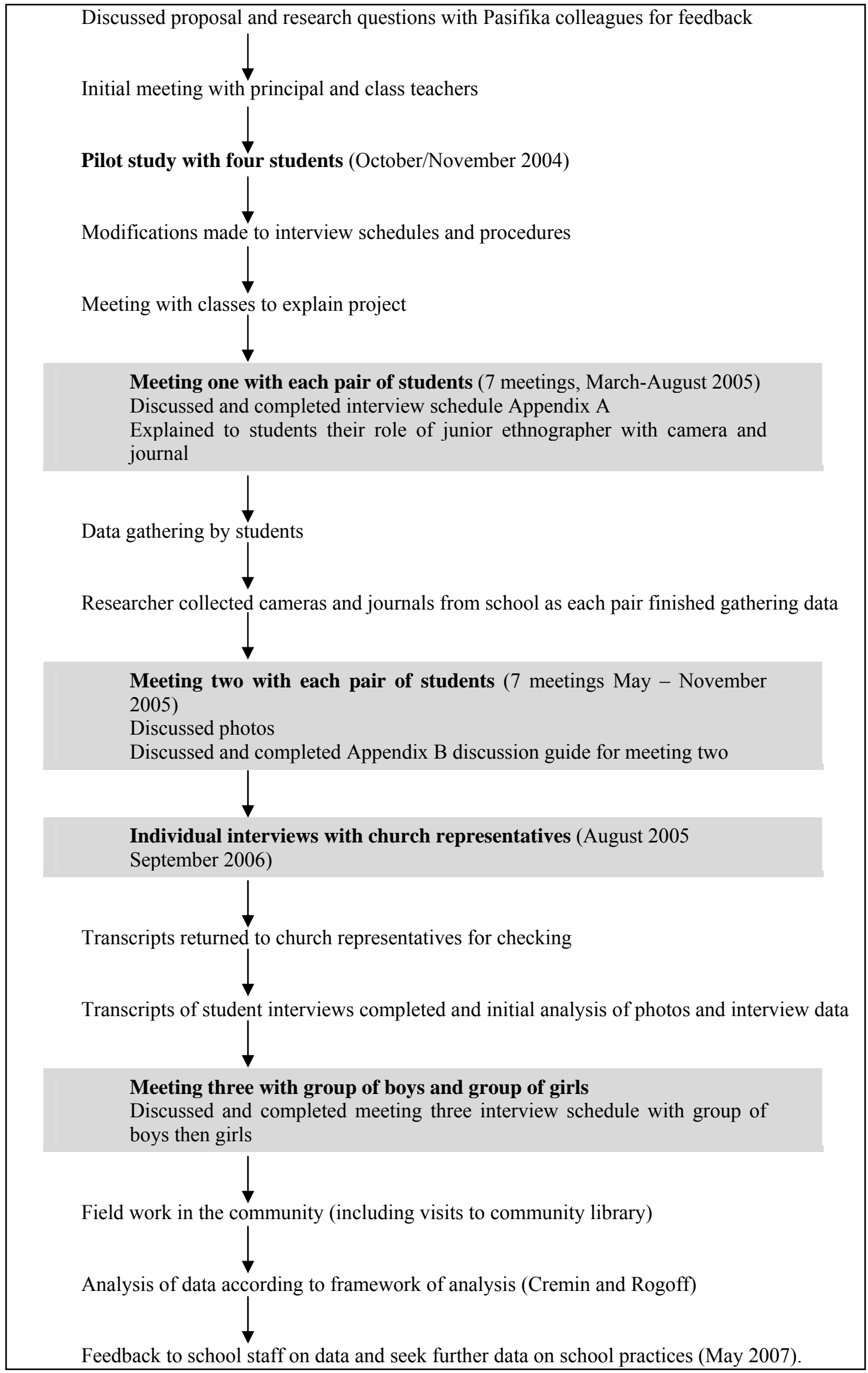

Figure 1 Progression of the research 


\section{The setting}

The setting for this study of out-of-school literacies is a suburb close to the centre of a large New Zealand city. The majority of sites for literacy practice that are described in the study, namely family sites, church, neighbourhood and school, are situated in this suburb. All the student participants attend a decile 2 Catholic school in this suburb and most of them live in the suburb and attend Sunday school there. The final section of the current chapter offers a description of this suburb which provides a contextual background for the findings and discussion chapters.

\section{The participants}

Students: The main sample consisted of fourteen Year 7 and 8 Pasifika students aged 11 and 12 years who had volunteered to assist when the researcher had explained the study. There were two year 7 and five year 8 girls, and five year 7 and two year 8 boys who participated. Equal numbers of boys and girls were sought. The definition of who is a "Pasifika student" was as reported to the schools by parents. Access to the students was granted by the school. Ten of the fourteen students identified as Samoan when they were asked "which Pasifika culture or cultures do you belong to?" (Appendix A) while the other four answered Tongan/Niuean/Samoan, Niuean/Tongan, Samoan/Māori, and Samoan/Tokelauan. This study did not investigate their school literacy but their attainments measured by STAR (Elley, 2001) ${ }^{10}$ a norm referenced test of reading ability which shows a range of levels with stanines indicating five students above average, six at average and three below average on this measure.

Adults from the church: The participants also included three Samoan representatives from the church that has Pasifika congregations associated with the school. These church representatives offered an adult perspective on church literacy practices and this was compared with the perspectives of the students.

Adults from the school: All of the teachers in the school and the principal contributed as participants through a meeting where the researcher sought data on how the curriculum and values of the school were complementary or conflicting with those of the students' out-of-school sites.

10 STAR (Supplementary Test of Achievement in Reading) assesses word recognition, sentence comprehension, paragraph comprehension and vocabulary. 


\section{The instruments}

The main instruments for gathering data were as follows:

(i) the photographs taken by the students as ethnographers of their own literacy practices and which were used to elicit dialogue from the students during meeting one. The photos were also analysed separately as data

(ii) the journals which were kept by the students

(iii) the interview schedule (Appendix A) for meeting one with students, the discussion guide for meeting two with students (Appendix B) and the interview schedule for meeting three with students (Appendix I)

(iv) the interview schedule for the interviews with the church representatives (Appendix C)

(v) the discussion guide for the meeting with school staff (Appendix J).

Instruments for data gathering with student participants

(i) Photographs taken by students with disposable cameras

(ii) Journals

Before the project started the researcher consulted with the students' teachers to ensure that all students would be able to record their thoughts in writing.

A small notebook was given to each student for them to record their uses of reading and writing and to keep notes about the photos they took. This was explained to students during meeting one. The following questions were placed in the back of their journals:

Questions for junior ethnographers.

Where do you use reading (outside the school)?

What is read and who is involved?

Where do you use writing (outside the school)?

What is written and who is involved?

Please record in your journal:

1/ Every time somebody reads something at home.

What was read?

Who read it? 
2/ Every time somebody writes something

What was written?

Who wrote it?

3/ Brief notes about each photograph you take

Where was the photo taken?

What reading or writing was taking place?

Who was doing the reading or writing?

(iii) Interview schedule and discussion guide for meetings with students

The instrument used in meeting one with the students is included in Appendix A: Interview schedule for meeting one with Year 7 and 8 students. This provided useful information about each student's background. Questions 1 to 8 provided demographic information on each student's gender, age, Pasifika background, country of birth, country of schooling and their place in the family. Questions $9-17$ produced quantitative data on the number of students speaking a Pasifika language and where they might read and write this language. These questions include Likert-style and open-ended questions on how often they speak their Pasifika language, whether they read and write in that language and how good they think they are at this. These questions were discussed at the first meeting with the students and the discussion audiorecorded.

During meeting two with students, the instruments used were their photographs and journals and Appendix B: Discussion guide for meeting two with Year 7 and 8 students. The questions in Appendix B sought their views about their conceptualisations of literacy and Pasifika people. These meetings were also audio recorded. When each pair was asked questions from the interview schedule they discussed their ideas and at times the researcher repeated or summarised what he believed they were saying so the students could signal that they agreed with this or clarify it further. Sometimes the researcher had misunderstood what they intended or did not hear them correctly, so this recapping was an important part of the process. It was in a sense a co-authoring of data (Kvale, 1988, cited in Miles \& Huberman, 1994, p.35). 
This approach was used as the interviews were up to an hour in length and the transcripts were correspondingly long and the researcher considered that the students would not be likely to read through them carefully to check for accuracy. On several occasions the researcher went back to an individual student on the next visit to the school to check a detail that had been missed during the interview and checking process.

\section{Instruments for data gathering from adult participants}

(iv) Interview schedule for the interviews with the church representatives (Appendix C)

The instrument for the interviews with the three church representatives was a semi-structured interview schedule with open-ended questions (Appendix C: Interview schedule for church representatives). Questions $1-9$ of Appendix C provided information on the church representatives' view of how the students may experience literacy in the sites of church and Sunday school, and this was compared with the students' own information about these sites and events. The Pasifika Education Research Guidelines (Anae et al., 2001) recommend that consent be sought for audio recording and that participants be sent transcripts to check for accuracy in order to foster confidence in the integrity of the interviewer and in the value of the research project (p.39). This procedure was followed with all the transcripts being returned and one participant making minor changes to correct words which the researcher had not heard correctly and adding in brief comments to clarify the points being made.

(v) Guide for the meeting with school staff (Appendix J).

During the meeting with school staff data were gathered through an informal discussion of the points in Appendix J: Discussion guide for meeting with school staff. The meeting was audio recorded and as a form of member checking, during the meeting the researcher summarised and reflected on key points to ensure that the staff's meaning was captured. 


\section{The pilot study}

The researcher contacted the principal of a school which had a high number of Pasifika students who were mostly from a Samoan background, explained the proposed investigation and asked her if the pilot study might be conducted in that school. She immediately welcomed the research project. Initially there was a meeting with the principal and the class teacher of the majority of the year 7 and 8 students in order to explain the whole investigation and the pilot study. Each was given copies of the research proposal which included all the consent forms. They were both supportive and the principal sought permission from the Board of Trustees.

The purpose of the pilot study was to test the instruments for gathering information from the students in order to answer the research questions. These instruments were the interview schedule and discussion guide (Appendices A and B) which were intended to elicit demographic information and to stimulate open-ended discussions. The pilot was also to test if the concept of students as junior ethnographers taking their own photos and keeping a journal would be suitable for this investigation. It needed to test whether the disposable camera could be used successfully and shared by each pair of students, and whether the photo elicitation technique would be successful in producing appropriate data to answer the research questions.

The pilot study was undertaken in October and November 2004. The researcher explained the project to year 7 and 8 students in one class. Names of volunteers were put in a hat in order to ensure a random representation of students, and names of two boys and two girls were drawn. The researcher explained the letter and consent form to the four students as they might have to explain them to their parents. Both forms were written in English, and the teacher advised that some of the parents would definitely need a Samoan translation for the main study. The researcher's Samoan colleagues also recommended this and the researcher obtained a translation of the letter through a translation service. One of the colleagues then suggested that several alterations be made in order to make the meaning of the letter clearer, and this was done (See Appendix H: Parents'/caregivers' consent form for their child (in Samoan)).

Meeting one with students lasted approximately one hour. The teacher arranged the use of a small, quiet room next to her classroom and this was the room that was used for all the subsequent meetings. The researcher explained the role of junior 
ethnographer which was for students to gather information about their sites and uses of reading and writing outside the school. They would do this by writing information in a journal and by taking photographs of reading and writing activities that they were involved in outside the school setting. Each student was given a notebook into which were pasted some small pictures of possible sites for literacy and they were asked to gather information to answer the questions which were written into the back of the notebooks (See Questions for Junior Ethnographers). The interview schedule for meeting one was trialled (Appendix A). One disposable camera was given to the two boys and one to the two girls and each student was asked to use it for about one week and then hand it to the other student. They were also given lapel badges which read "The Literacy Project" with the researcher's email address on it in case anybody asked them about their data gathering activities.

Meeting two for the pilot study took place three weeks after the first. This timing between meetings proved to be sufficient for the first student to take the photos and hand over the camera to the second student. The researcher collected the cameras and journals from the students' teacher and had two sets of prints made so he could keep a complete set for analysis and give each student their own copies of the photos they had taken. The students were quite excited to see their photos and they were asked to explain the literacy uses and sites they had photographed. Although the researcher had expected that the photos would generate rich discussion, the students were reticent. They whispered amongst themselves (boys to boys and girls to girls as if they did not want the others to hear) but there was very limited information about the photos that was shared amongst the group. At times the students did not respond at all to the researcher's questions and comments.

A discussion guide (Appendix B) with five questions had been prepared for this second meeting but because of the students' reticence in speaking it was decided to ask them to fill it in as a written task. They seemed much more comfortable in writing the answers than in speaking in the group, and their responses provided useful information about their views on reading and writing. At the end of the meeting, the researcher kept two girls back to seek their views on the lack of discussion. One explained that she and the other girl knew each other well but did not know the boys as well. When they were asked a few questions about their photographs they responded with much more information than when the boys had been present. 


\section{Changes following the pilot study}

The pilot study indicated that Appendix A (the interview schedule) and Appendix B, (the discussion guide), the journals with their guidelines for the student ethnographers, the photographs and the discussions produced useful data which allowed examination of the sites and uses of literacy of these students. The pilot study revealed that more consideration to the languages used by the students was required, in other words whether they use Samoan and English. The pilot did show that some modifications were necessary to Appendices A and B and to the procedures. The pilot indicated the need to change the wording slightly to improve the clarity of several questions in Appendix A and some extra questions were added, including one to ask about uses of writing in English at Sunday school.

The experience of the pilot study indicated that meeting the students in groups of four was inhibiting their discussion, so in consultation with the supervisors and the class teacher the researcher decided to meet the students in pairs of girls or boys who agreed they were happy to work together as a pair. This change proved to be very successful as there were several advantages in meeting pairs of students. All the students were now willing to contribute to the discussion. It also meant that more information was elicited from each individual as there were now only two students in each group and the interview time remained at approximately 45 minutes. As Davies (1999) warns, it is difficult when transcribing to identify unambiguously individual voices in groups of any size, and this needs to be approached with great caution. The meetings were audio recorded and the researcher wrote transcripts from the tape but with four voices it was difficult to attribute utterances to particular students when transcribing. With only two students in the group it was simple to separate the voices and in this study it was important to identify the individual voices of the students as they were offering individual insider perspectives of literacy practice.

A further change in procedure was made in an attempt to make the interview less formal in order to promote discussion, and this innovation was also successful. The researcher read out questions 1 to 9 of Appendix A and recorded the students' responses himself. This changed the first part of the interview to an informal discussion rather than a silent writing task for the students. Students then completed the rest of Appendix A as the questions were read out and discussed. One of the supervisors suggested providing drinks and chocolate biscuits for the interviews. As 
the students enjoyed these and it helped to create a friendly atmosphere, this was continued with the other groups. Following the advice of the class teachers, the researcher made informal visits to the students' classrooms during their literacy programme in order to get to know the students and establish a relationship of trust.

\section{The main study: gathering the data}

\section{Meeting one with each pair of students}

The first meeting with students was intended to cover:

- the interview schedule for meeting one (Appendix A)

- how students would collect data with cameras and journals.

The meeting took place in the students' school in the withdrawal room. At this meeting, which lasted approximately 45 minutes, the researcher explained the role of "junior ethnographer" in gathering information about the sites and activities of reading and writing outside the school. The students were then asked to complete the written questions (Appendix A) that provided background information about whether they speak, read and write in a Pasifika language and where they do this. The researcher discussed each question with the pair and clarified issues that were raised by the students as they wrote their answers. The researcher then explained to the students how they would contribute by writing information in a journal and by taking photographs of reading and writing activities they are involved in outside the school setting. The use of the photographs was explained both to the students and their parents in a letter (Appendix D: Information sheet for principals, teachers, parents/caregivers and church representatives).

One disposable camera was given to each pair with 27 exposures and the students were asked to share the camera. The researcher returned to the school within a negotiated time which was generally three to four weeks to collect the camera and have the film developed, then took the photographs to the second meeting with the students.

\section{Data gathering by the student ethnographers}

(as outlined above in the first meeting with students). 


\section{Meeting two with each pair of students}

The second meeting was intended to cover:

- discussion of the students' photos

- the discussion guide for meeting two (Appendix B)

This meeting which lasted approximately one hour with each pair was in two parts. The first part was the discussion elicited from the photos. During the second part of the meeting the students answered questions on the guide (Appendix B: Discussion guide for meeting two with year 7 and 8 students) about their possible future occupations, their ideas about Pasifika people's results in reading and writing in English and whether they think that reading and writing are more of a papalagi thing to do. This meeting was audio recorded and a transcript written from this. The students spoke confidently about their photos and the discussion on literacy uses was not limited to the content of the photos. This discussion meant that there was a degree of member checking as the meeting progressed when the researcher rephrased or summarised the students' ideas to ensure that he had correctly understood their meaning.

The timetable for data gathering and meetings had to be flexible as the students were not always successful in returning the cameras by the agreed date. Whereas students were asked to return their camera after two or three weeks, some students had them for much longer.

\section{Interviews with church representatives}

The in-depth individual interviews with church representatives took place in a site suggested by each participant and used an interview schedule (Appendix C). Each interview, which lasted approximately one hour, was audio-recorded. Face-to-face interviews are described in the Pasifika Education Research Guidelines: Final Report (Anae et al., 2001, p.36) as the most effective type of interviews for gaining qualitative information from Pasifika people. The writers stress the importance of building rapport with the participants. Some issues from the student interviews were discussed with the church representatives, but individual students were not identified. 


\section{Meeting three}

1. all boys together

2. all girls together

The third meeting with students was intended to cover:

- the further interview schedule for students (Appendix I)

Following the analysis of the data from meetings one and two with all the students, the researcher found that it was necessary to seek further information from all the students. For example, some students had indicated how often they attended church and Sunday school but as these sites emerged as being so important for literacy, the researcher needed to find out how often all the students attended. An interview schedule was developed for meeting three (Appendix I) with thirteen questions. It was given to the boys in one meeting, and then the girls (one girl was absent) in a separate meeting.

\section{Field work in the community}

The researcher also visited the streets of the community several times to observe the community sites for literacy which had been described by the students and portrayed in some of their photos. The purpose of these visits was to take observational notes on these sites and the types of writing the students would see there and to observe the neighbourhood as the wider context for the students' learning. The field work included several visits to the community library to speak to librarians about the students' use of the library, and also visits to the downtown arcades and shops which the students had described. Several visits were also made to various libraries to search for information including early photographs that show the historical development of the suburb. This information forms a contextual background which is included at the end of the current chapter as an introduction and setting for the findings related to the students' literacy practices in this community. 


\section{Meeting with school staff to feed back findings and to seek further data on school practices}

This meeting had a twofold purpose. It was part of the process of feeding back information from the findings to the school and to gather further information on the school literacy practices. This was particularly to see where there were overlapping values, curriculum and pedagogy with the students out-of-school sites for literacy. A series of questions was written as a discussion guide for this meeting (See Appendix J).

\section{Management of the data}

At the beginning of the data collection it was essential to establish a clear system for storing and retrieving data. Approximately 180 photos were taken and detailed transcripts of the photo elicitation meetings were written and annotated to the relevant photos. In addition there was the demographic and interview dialogue from the first meeting with students. All the data for each pair of students (photos and journals, interview transcripts and students' written answers) were put in a labelled manila folder while a system of coding enabled quick location of specific information in computer files. During the second meeting each pair of students identified which photos they had taken. Instead of using students' names in recording of data, students were referred to as Student A, B etc and each photo label included the letter for the student who had taken the photo. When the transcript for the meeting was written, the discussion about each photo was coded with the interview number, student's letter and the number of the photo. For example, the transcript was coded 2.8.A for meeting two, photo number 8 and student A. During the analysis it was necessary to return to the data many times to search for patterns and evidence and this computer coding and the manila files systems were simple and successful ways to manage the storage of data.

It was essential that the researcher himself type the meeting transcripts as individual students' responses had to be identified, attributed to the correct student and then connected to specific photos. The photos and dialogue were also linked to the students' journals and at times connections could be made to other photos taken by these or other students. The researcher added in other comments as he reflected on the themes that were emerging. 
Early analysis of data during the early stages of a qualitative study is strongly recommended as it may guide the researcher towards collecting new data to fill in gaps or to test hypotheses that emerge during analysis. (Miles \& Huberman, 1994). It emerged during this study that changes were necessary in the data collection. Eisenhardt (2002) describes how in theory building during case study research there is frequently an overlap of data analysis with data collection. This allows data collection to be flexible. She describes the freedom to make adjustments during data collection as a feature of theory building in case research, such as making changes to questionnaires and adding new data sources such as extra interviews. In this study changes were necessary to both the wording and the administration of the interview schedules and during the analysis an extra set of questions for a further group interview was found to be necessary to fill in gaps in the data.

\section{Framework for analysis of data}

\section{Cremin's configurations of sites}

The framework for analysis of data in this thesis is based upon the work of Cremin (1976) and Rogoff $(1976,1995)$ and is congruent with a sociocultural approach to understanding learning. It uses Cremin's concept that there are many institutions in many sites that educate and that these are related to one another in "configurations of education" (p.30). This concept provides a means to explore the Pasifika students' literacy practices in family, church and neighbourhood sites as they participate in cultural and social practices. Cremin's work allows exploration of the curriculum that is valued and taught in these sites, as well as the uses or purpose of the curriculum. It also includes the teachers who contribute to literacy in these sites and in this study the term "teacher" is used to include both people and other sources of information such as texts.

A further aspect of Cremin's concept that makes it appropriate as an analytical framework for this study is it enables consideration of the configurations of institutions for individual students and the relationships between institutions. A useful feature of this framework is that it reveals where there is overlapping support of the values and pedagogy between the sites and where there is conflict. This informs our understanding of how the students' literacy learning is mediated as they negotiate their individual pathways between cultures, and this provides relevant 
background information for teachers. For example it is useful to consider which institutions are working together with similar values and pedagogies to support the students' acquisition of literacy or the reverse. A further feature of Cremin's concept that makes it suitable for this study is that it acknowledges the variation between individuals as the configurations are different for each person. Cremin writes "individuals come to educational situations with their own temperaments, histories, and purposes, and different individuals will obviously interact with a given configuration of education in different ways and with different outcomes" (1976, p.37). Cremin's concept of sites and configurations in education was developed by McDonald (2006) into a grid to show the sites, the teachers, the curriculum and uses for literacy, and this interpretation is applied to this study (See Figure 2).

\section{Rogoff's three planes of analysis}

In conjunction with the framework derived from Cremin, Rogoff's $(1995,2003)$ analytical framework which explores three planes of analysis provides a useful tool to look closely at the student in literacy acquisition through their participation in social and cultural activities. The student is seen as an active participant on the personal plane, in guided participation with various others as teachers at the interpersonal level, and as apprentice learning the values, expectations and curriculum of the community/institutional level. None of Rogoff's three planes of analysis exists in isolation. No one can be studied in isolation from the other two as the individual and their environment are interdependent (Rogoff, 1995). In this study's analysis and discussion of data the two frameworks (from Cremin, 1976 and Rogoff, 1995) are interconnected in the following way.

Firstly the educational sites for literacy that were identified by students are described in turn, these being the family, the church and the neighbourhood and these three sites form the themes for Chapters 6,7 and 8. An introductory outline is given of each site, its teachers, and its curriculum. The themes of literacy that evolved from each site are then described using Rogoff's three planes of analysis which serve as lenses to view different perspectives of the student's participation in the sociocultural activities of the site. This also includes discussion of the connections within the configurations of sites for literacy learning. These three planes help to provide a more complete picture of the student's learning environment than simply examining activities in the sites. 
Figure 2: Educative Sites for Literacy based on Cremin

\begin{tabular}{|c|c|c|c|c|}
\hline & Church & Family & Neighbourhood & School \\
\hline \multirow[t]{4}{*}{ Sites } & Church & Students' homes & Local shopping centre & School \\
\hline & Sunday School & Relatives' homes & Community libraries & Libraries \\
\hline & Home & Friends' homes & Streets & \\
\hline & School & & Sports clubs & \\
\hline \multirow[t]{18}{*}{ Teachers } & Sunday School teachers & Parents & Peers, siblings and cousins & School teachers \\
\hline & Priests & Grandparents & Libraries & School librarian \\
\hline & Ministers & Uncles, aunts & Librarians & Peers \\
\hline & Parents & Cousins & Shops & Visitors to school \\
\hline & Grandparents & Siblings & Street signs & Books \\
\hline & Other family members & $\begin{array}{l}\text { English and Samoan } \\
\text { dictionaries }\end{array}$ & Advertisements & Internet \\
\hline & Peers & Books & Bus timetables & \\
\hline & Bible & Internet & Sports coaches & \\
\hline & & & Internet & \\
\hline & & & Computer games & \\
\hline & & & Cheats & \\
\hline & & & Radio & \\
\hline & & & DVDs & \\
\hline & & & Television & \\
\hline & & & CDs & \\
\hline & & & Books & \\
\hline & & & Magazines & \\
\hline & & & Comics & \\
\hline
\end{tabular}




\begin{tabular}{|c|c|c|c|c|}
\hline & Church & Family & Neighbourhood & School \\
\hline \multirow[t]{6}{*}{ Curriculum } & $\begin{array}{l}\text { English and } \\
\text { Samoan languages }\end{array}$ & $\begin{array}{l}\text { English and Samoan } \\
\text { languages } \\
\text { Reading the English and } \\
\text { Samoan Bibles }\end{array}$ & $\begin{array}{l}\text { Reading: } \\
\text { - Signs on shops and public } \\
\text { buildings } \\
\text { - Price tags and labels } \\
\text { - Sandwich boards } \\
\text { - Advertisements } \\
\text { - Street signs } \\
\text { - Bus timetables }\end{array}$ & $\begin{array}{l}\text { The New Zealand } \\
\text { curriculum } \\
\text { (English and Samoan } \\
\text { languages) }\end{array}$ \\
\hline & $\begin{array}{l}\text { ( and for some Niuean, } \\
\text { Tongan, Tokelauan) } \\
\text { Reading prayers in } \\
\text { English and Samoan }\end{array}$ & $\begin{array}{l}\text { Reading prayers (family } \\
\text { and individual) }\end{array}$ & $\begin{array}{l}\quad \text { Library: } \\
\text { - Catalogue } \\
\text { - Reading books, magazines, } \\
\text { newspapers, posters } \\
\text { - Researching on Internet } \\
\text { - Doing homework }\end{array}$ & $\begin{array}{l}\text { The Bible } \\
\text { (Reading prayers in } \\
\text { English and Samoan) }\end{array}$ \\
\hline & $\begin{array}{l}\text { English and Samoan } \\
\text { Bibles }\end{array}$ & & & $\begin{array}{l}\text { Writing stories and } \\
\text { articles }\end{array}$ \\
\hline & $\begin{array}{l}\text { Reading Bible stories } \\
\text { Understanding the Bible } \\
\text { passages }\end{array}$ & $\begin{array}{l}\text { Learning songs for } \\
\text { church }\end{array}$ & $\begin{array}{l}\quad \text { Sports clubs: } \\
\text { - Reading information about } \\
\text { training, trips etc } \\
\text { - Reading and writing scores for } \\
\text { games } \\
\text { - Reading draws for games } \\
\text { - Reading and writing emails to } \\
\text { and from team members and } \\
\text { coach } \\
\text { - Reading letters and notices } \\
\text { from coach } \\
\text { - Reading maps to tournament }\end{array}$ & $\begin{array}{l}\text { Writing in school diary } \\
\text { Using Samoan (and } \\
\text { other languages) to } \\
\text { assist peers when the } \\
\text { concept in English } \\
\text { puzzles them. }\end{array}$ \\
\hline & Church support books & $\begin{array}{l}\text { Reading to prepare for } \\
\text { Sunday School exams }\end{array}$ & Writing bank deposit slips & $\begin{array}{l}\text { Reading instructions to } \\
\text { make a circuit }\end{array}$ \\
\hline & $\begin{array}{l}\text { Reading aloud to } \\
\text { audience (Samoan and } \\
\text { English) }\end{array}$ & & & $\begin{array}{l}\text { Reading cue cards for } \\
\text { speech }\end{array}$ \\
\hline
\end{tabular}




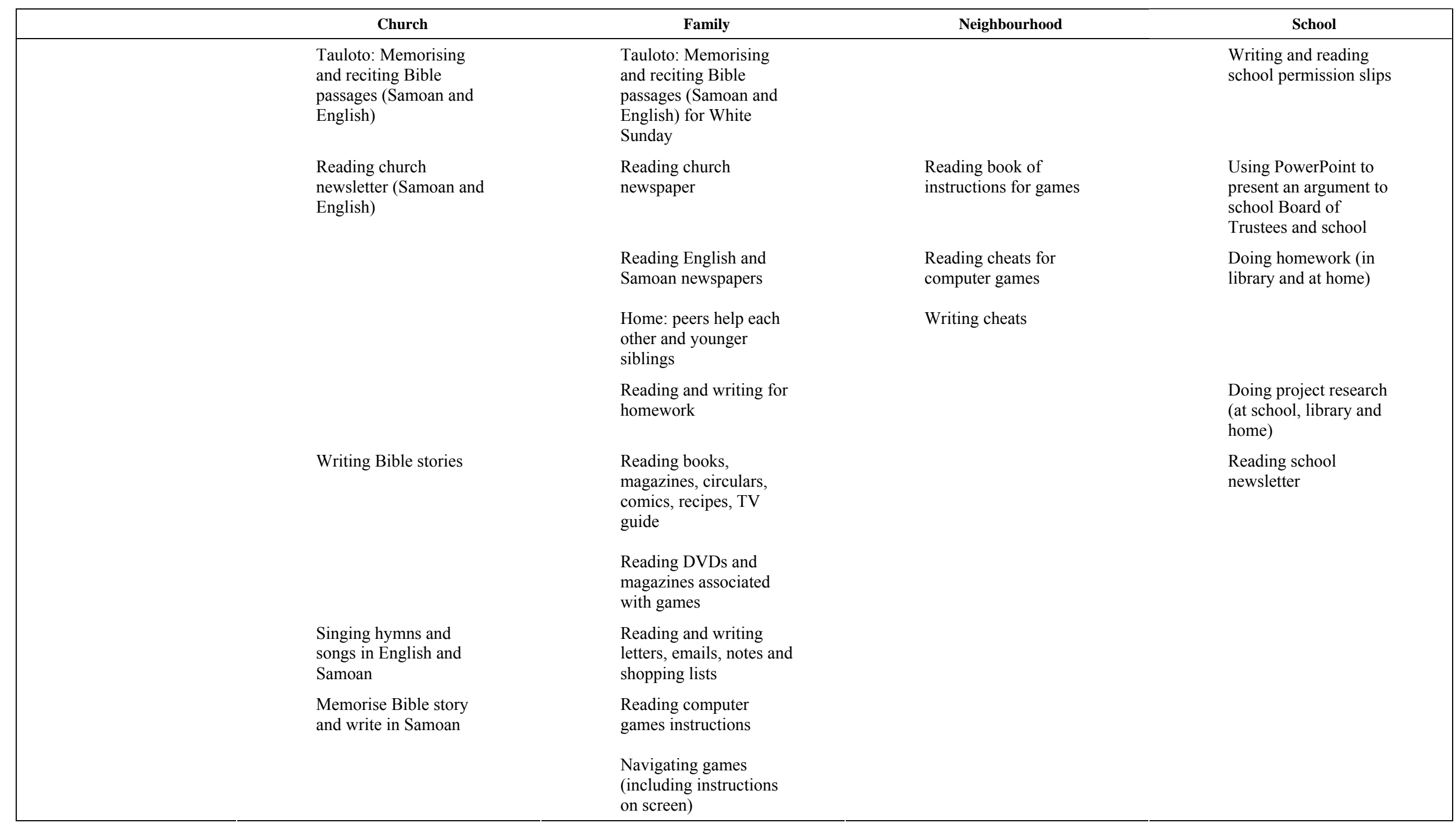




\begin{tabular}{|c|c|c|c|c|}
\hline & Church & Family & Neighbourhood & School \\
\hline & $\begin{array}{l}\text { Writing in Samoan and } \\
\text { English in activity } \\
\text { books }\end{array}$ & $\begin{array}{l}\text { Writing in church } \\
\text { activity book }\end{array}$ & & \\
\hline & Writing a solo & $\begin{array}{l}\text { Reading school } \\
\text { newsletter }\end{array}$ & & \\
\hline & $\begin{array}{l}\text { Writing dictation in } \\
\text { Samoan }\end{array}$ & $\begin{array}{l}\text { Reading ingredients on } \\
\text { food packaging }\end{array}$ & & \\
\hline & $\begin{array}{l}\text { Copying notes from } \\
\text { board }\end{array}$ & Writing personal diary & & \\
\hline & Writing a summary & Writing song lyrics & & \\
\hline & $\begin{array}{l}\text { Writing answers to oral } \\
\text { and written questions }\end{array}$ & Reading fashion labels & & \\
\hline & & $\begin{array}{l}\text { Writing and reading text } \\
\text { messages }\end{array}$ & & \\
\hline \multirow[t]{3}{*}{$\begin{array}{l}\text { Use or } \\
\text { Purpose }\end{array}$} & $\begin{array}{l}\text { To teach Christian } \\
\text { doctrine }\end{array}$ & $\begin{array}{l}\text { To teach and maintain } \\
\text { Samoan language }\end{array}$ & For navigation & $\begin{array}{l}\text { To acquire literacy } \\
\text { skills to enable full } \\
\text { participation in society } \\
\text { and the workforce }\end{array}$ \\
\hline & $\begin{array}{l}\text { To maintain traditional } \\
\text { cultural practices } \\
\text { (tauloto) }\end{array}$ & $\begin{array}{l}\text { To teach and maintain } \\
\text { Christian beliefs and } \\
\text { values }\end{array}$ & $\begin{array}{l}\text { For finding goods and } \\
\text { services and purchasing }\end{array}$ & \\
\hline & $\begin{array}{l}\text { To maintain use of } \\
\text { Samoan language } \\
\text { (reading, writing, } \\
\text { speaking) in worship }\end{array}$ & $\begin{array}{l}\text { To support Sunday } \\
\text { School practices } \\
\text { (tauloto, recitation, } \\
\text { reading as a } \\
\text { performance, } \\
\text { homework) }\end{array}$ & $\begin{array}{l}\text { For information and } \\
\text { pleasure }\end{array}$ & \\
\hline
\end{tabular}




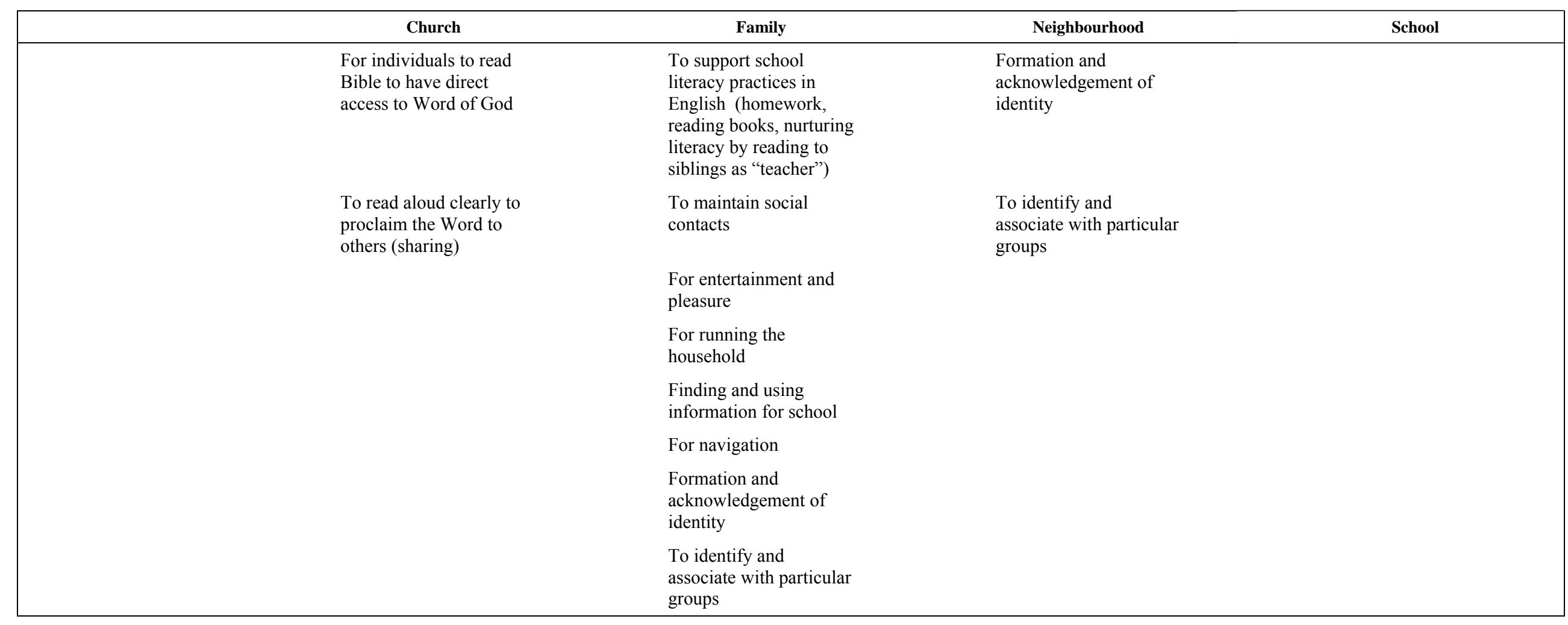




\begin{tabular}{|c|c|c|c|}
\hline $\begin{array}{c}\text { Samoan Bible Names } \\
\text { for participants }\end{array}$ & Age & $\begin{array}{l}\text { Which Pasifika culture or } \\
\text { cultures do you belong to? }\end{array}$ & Pasifika language spoken \\
\hline Isaako (Isaac) & Year 7 & Samoan & Samoan \\
\hline Samasoni (Samson) & Year 7 & Samoan/Tokelauan & No \\
\hline Tavita (David) & Year 7 & Samoan & Samoan \\
\hline Paulo (Paul) & Year8 & Samoan & Samoan \\
\hline Ioane (John) & Year 7 & Samoan & Samoan \\
\hline Iosefa (Joseph) & Year 8 & Samoan & Samoan \\
\hline Mareko (Mark) & Year 7 & Samoan & Samoan \\
\hline Eseta (Esther) & Year 8 & Samoan/Māori & Samoan \\
\hline Apekaila (Abigail) & Year 8 & Samoan & Samoan \\
\hline Maria (Mary) & Year 8 & Samoan & Samoan \\
\hline Elisapeta (Elizabeth) & Year 7 & Tongan/Niuean Samoan & Niuean and Tongan \\
\hline Hana (Hannah) & Year 8 & Niuean/Tongan & Samoan \\
\hline Sara (Sarah) & Year 8 & Samoan & Samoan \\
\hline Repeka (Rebecca) & Year 7 & Samoan & Samoan \\
\hline
\end{tabular}

\section{Figure 3: The student participants}

Using data elicited from interviews the personal plane provides a lens to foreground the individual's construction of literacy practices. This includes their thoughts as they are involved in an active process as a participant in sociocultural activities and provides an "insider view" of their literacy acquisition and use. The analysis looks to see how students make sense for themselves of the literacy learning that goes on within each of these sites. Exploring at the interpersonal level reveals how the student is engaged in guided participation through the mediation of other people in social contexts. This level which considers the learner interacting with others who help to set tasks and provide guidance, is linked to discussion of the sites and teachers (Cremin, 1976). The community/institutional plane of analysis which explores the cultural values and cultural tools of the community (Rogoff, 1995) is linked to discussion of the sites and curriculum of the community (Cremin, 1976). As the findings and discussion chapters reveal, the curriculum reflects the values of the institution or community, and each of Rogoff's planes of analysis is closely linked to the other two.

\section{Reflection on analysis of data}

Data from all sources were examined for patterns of literacy use and practice. These sources included the students' photos, the interviews based on the photos, students' journals, the interview schedules for the three meetings with students, the interview schedules for meeting with church representatives, and the discussion guide used 
with the school staff. The data were sorted into the main sites for literacy use as described by the students (shown in Figure 2) these being the family, church, neighbourhood and school. The data were then examined to reveal the teachers who mediated the learning in each site, the curriculum of each site as well the main uses of literacy in each site.

Data from different sources were checked for validity. For example, in many cases the students' photos, explanations of their photos and their journals provided matching examples of literacy use. The interviews with church representatives provided many examples of literacy use in the Sunday school and church that matched those described by the students, for example practising and reciting tauloto. Comparison of data from student and adult sources provided examples of values that matched and some that conflicted, such as those related to popular culture.

Following an initial analysis it was clear that there were some gaps in the data (for example in the numbers of students who read with younger children) so the researcher decided to seek additional data through a further interview with students. Each of the questions in this interview rose out of the initial analysis of the data. After the initial analysis of data from interviews and photos it was clear that the outof-school uses were connected with the school site, so additional information was sought from the school, for example on Bible related literacy, popular culture and the use of Samoan language.

The photos were a particularly useful data-gathering tool that enabled the students to provide an insider view into their out-of-school uses of literacy. The photos enabled the researcher to see into students' homes and other sites which might not otherwise have been attainable to him. The use of photos and journals also gave some control over the data gathering to the participants so that their views were valued. While it appeared that some of the photos were posed to represent students involved in expected uses of literacy, other photos led to discussions about less conventional uses, such as reading fashion labels. Overall, the methods used were successful in providing a perspective that the researcher could not have otherwise obtained, one that offers a fresh view and which exemplifies and illustrates the students' literacy uses. 


\section{Contextual Background to the School Community}

A characteristic of qualitative research is the natural setting as the direct source of data (Bogdan \& Biklen, 1992). Most of the examples of literacy uses recorded in the photos and described by the students in this study were situated in the community where the students attend school and where the majority live. Knowing the context of the community is essential in order to explore participants' literacy practices through a sociocultural perspective (Bogdan \& Biklen, 1992). The community where the students live, and where they attend school, Sunday school and church is the setting for the literacy uses which they represented in the photos and described in their interviews. Therefore, it is useful to describe briefly the community which is their environment and which provides the context for this study.

Chapter 1 described how the majority of Pasifika people in New Zealand live in two large cities, with concentrations of Pasifika students in some schools in those cities. This study investigates a small part of one Pasifika community in a suburb of one of those cities. This is an older suburb, close to the city centre and possessing some characteristics which add to its richness as an environment and make it interesting to compare with other areas in New Zealand. This area has seen several waves of migration which began in prehistoric times and continue in the present. The ancestors of the Māori, the Polynesian seafarers from tropical islands to the northeast, discovered these islands of New Zealand over a thousand years ago and named the land Aotearoa - the land of the long white cloud. Migration over several centuries occurred and it was to be a thousand years until Europeans rediscovered these islands and began their own migration. Many centuries ago the early Polynesian settlers were the first to arrive in the area that was to become the students' suburb. They established gardens in the more sheltered and fertile areas and grew kumara (sweet potato), caught fish in the sea and the streams and gathered food in the forests. In the surrounding region they established many pa (villages protected by palisades and ditches) and kainga (unfortified villages). The historic migrations to this region from other parts of New Zealand, conquest through battles and more recent migration, has led to a complex mix of Māori peoples living here.

Since the late $19^{\text {th }}$ century this suburb has become home at different times to migrants from Europe, the Pacific Island nations, particularly Samoa, and more recently from Asia. The suburb is very cosmopolitan and over the last half century 
has reflected the immigration patterns of New Zealand although there is a greater concentration of some ethnic groups here than in the country as a whole. It is an example of a New Zealand community with a high concentration of Pasifika people (as described in Chapter 1). Waves of immigrants from the $19^{\text {th }}$ century to the present day have been attracted to this part of the city and adjoining suburbs. These have tended in parts to be working class areas with less expensive housing, close to a large hospital which employs many people and close to factories which also provide employment. In the $19^{\text {th }}$ century immigration began from the United Kingdom and from Ireland. During and after the Second World War more migrants arrived from European countries, while the 1950s saw the beginning of Samoan immigration to the suburb. Smaller numbers of immigrants also arrived from the Cook Islands from the 1940s. In the late 1970s and early 1980s Vietnamese immigrants began to settle in the suburb, many of them refugees. As the numbers of immigrants increased community organisations were established to support the newcomers, with various groups being organised through the churches. A large community centre was established to support the people of one Pasifika group in the wider area of the city and suburbs.

When the Europeans arrived in the mid $19^{\text {th }}$ century the characteristic vegetation of the area had been forest, flax, raupo (bulrush) and tussock, but soon the forests were cleared and swampy areas drained for farms and dwellings. Early photos of the area show muddy unpaved streets with coaches drawn by horses. The main streets were named after the first emigrant ships and important early settlers from England who arrived in the middle years of the $19^{\text {th }}$ century. The first school in this suburb was built in the $1870 \mathrm{~s}$. Later in the $19^{\text {th }}$ century tramlines were laid through the suburb connecting it to the growing city centre, the trams being powered by steam, then by horse. The early years of the twentieth century saw the introduction of electric trams and these encouraged the expansion of the suburb as a working class area. Photographs taken at this time show the dense housing development with many rows of compact one-storey wooden houses with corrugated iron roofs, each on its own small fenced section. The photos show two houses side by side or a row of several, built in identical style. However there has always been a mix of housing types here, and the contrast between the less expensive and more expensive dwellings is still apparent today with a mix of these workingmen's cottages and larger Victorian and Edwardian villas. In many streets elegant two storeyed houses are seen with many 
retaining their original architectural features. The old photos show that the distinctive ridgelines which border the suburb have been cleared of their forest by the settlers and appear stark. This stripping of native vegetation along with the massed housing, smoking chimneys and muddy streets evokes the feeling that the Europeans imposed themselves upon their new country in an uncompromising way. The photos taken in the 1920s show tramcars and an increasing number of cars and trucks, but these streets of the old photos seem strangely empty of traffic and people compared with what is seen in these streets today. A visitor to the area today would see the environment for the students as a dynamic community, rich in its variety and contrasts of many cultures and ethnicities. An obvious feature that contrasts with many other New Zealand suburbs is that there are not so many Pākehā to be seen.

Several of the photos taken by the students reveal distinctive features of the suburb which are portrayed in these early photos. The students' photos show that the hills have been softened by a century of regenerating forest, a green belt of trees and playing fields which are accessible and a recreational asset to the community. The suburb as the students know it retains a combination of high density housing, both old and new, and larger traditional residential sections which are more typical of a New Zealand city. It is mainly a residential area with some light industry and the large hospital. For recreation there are many parks and sports grounds which are familiar to the students.

Some of the houses shown in the historic photos can be identified in the students' photos, a row of houses near the school looking rather shabby as rental properties. Their future might be to be smartened up and sold as expensive character homes or to be replaced by townhouses such as those a little further along the street. They are more likely to be sold to the professionals who are moving into the suburb rather than to the students' families who generally live in rental properties. Like many other New Zealand city suburbs, this one has been through a process of "gentrification" as the older suburbs close to the city centre became more attractive. The working class cottages which are comparatively close to the city centre have become desirable and quite expensive. Over the years some have been demolished to be replaced by large housing estates which are owned and operated by the City Council to provide less expensive rental accommodation for people with low incomes or special housing needs. Some of the older estates are multi-storeyed and 
their size and functional appearance detract from the quaintness of the suburb. The scale and designs of the more modern ones are less obtrusive and have more the appearance of townhouses. These City Council estates are where most of the students in this study live.

An initial impression is that some features seem to have changed little over the years and the photographer of a hundred years ago could probably recognise many of the scenes in the students' photos. The old photos show the wooden shop buildings along the main street as being one or two storied, gabled, and with false fronts, reminiscent of sets in a western movie. Several of the students' photos show these buildings which seem little changed in a hundred years. While the buildings from this era in the central city have long been demolished and replaced with concrete and glass, the observer walking through the shopping centre of this community will see that it retains the scale and appearance of a colonial town and many shop and other commercial buildings can be recognised in the photos that were taken a century ago. The shopping centre, which fortunately missed out on $20^{\text {th }}$ century modernisation, retains its colonial character and has been enhanced with trees, attractive seating and lighting.

The shops and businesses in the main shopping area suggest the cosmopolitan nature of the suburb and give an insight into the type of people who live in this community. Most of the writing is in English and this is seen on the shop fronts, the business advertising on commercial buildings, posters which advertise upcoming events, and on street signs. There are many sandwich boards along the footpaths in the shopping centre which advertise restaurants, bookshops and other businesses. These signs are written in English. However, the shop signs and the goods for sale in the shops indicate the cosmopolitan nature of the neighbourhood. The colourful outdoor displays of the fruit and vegetable shops include produce that may not be seen in most New Zealand shopping centres and specialist shops offer exotic foods which are staples for many immigrants. For example, a butcher's shop displays a sign advertising Halal meat, a shop advertises Indian women's clothing, and a sign on a takeaway shop advertises "Authentic Polynesian Cuisine". There are some written examples of languages other than English in the neighbourhood. Chinese writing is seen on a restaurant and a shop front, a finance company sign is written in Samoan, and the sign outside the Salvation Army greets visitors with "Welcome, Haere mai, 
Afio Mai". A shop selling memorial gravestones has an example in the window with its inscription written in Samoan. Other shops sell a huge variety of bright artificial flowers, and leis (garlands) and wreathes made of plastic flowers. Several shops sell second-hand furniture and household goods, and others sell inexpensive clothing. These are the shops that the students are familiar with and which are represented in several of their photos.

Along the main street are the international brands of American fast food restaurants as well as other restaurants and takeaway shops which represent the Chinese, Indian and South East Asian cuisine, which are found in many other suburbs but here there seems to be a greater variety. Near the centre of the main commercial area of the suburb is the community library. Many of the students go there after school and several of their photos were taken in the library. The notices and posters on the large public notice board in the library foyer offer a quick overview of the diversity of the peoples and the various groups that meet in this area.

The library itself, which provides a bright and attractive atmosphere, appears to represent well the community it serves. An example of this is the selection of newspapers that represent the diversity of people in the suburb. The newspapers are in Samoan, Cook Islands Māori and Tongan as well as Arabic, Indian and Chinese. Another example is seen in the children's section where in addition to books in English and Māori, there are books in five Pasifika languages. These are Samoan, Cook Islands Māori, Tongan, Tokelauan, and Niuean. Many of these books are from the Tupu series published by Learning Media. Some of the books appear to have been made by, and for, a local A'oga Amata so they are suited to preschool children while others are for children of primary school age. In the library there is also a selection of books for people learning English in recognition of the considerable number of new immigrants in the community who are new learners of English. Next to the library is a venue with signs advertising free English language classes for adults as well as adult education and job support for refugees and migrants whose first language is not English.

Data from the 2001 census (stats.govt.nz) reveal the distinctive characteristics and the contrasts of this community. Fewer younger and older people live here than are in 
the general New Zealand population. There are more people in the age group between 15 and 64 years who live here.

More people had a post-school qualification than in the general population. One of the more interesting facts and one that makes it a useful community for this study is that the ethnic percentages of the people are not representative of the general population of New Zealand, with fewer people identifying as European and more as Pacific peoples. Only 60 percent of the community said they belonged to the European ethnic group compared with 80 percent in the New Zealand population. After European, the most common group is "Pacific peoples" with almost one in five people belonging to this group. This is significantly higher than for most other New Zealand communities, as only 6.5 percent of New Zealand's population at the time of the census identified as Pacific peoples. The next most populous group is Asian, followed by Māori.

The rate of unemployment here is higher than for the rest of New Zealand. The median income for people in this community is slightly lower than that for the New Zealand population, and in light of this it seems a little surprising that the most common occupational group in the suburb is professionals with a quarter of employed people in this group. In comparison, professionals were the largest occupation group in the main urban centres with 16.5 percent of the employed population.

Fewer households in this suburb have access to a telephone, while almost the same number has access to the Internet as the New Zealand population. In this community considerably fewer households have access to a motor vehicle than in the general population. The high number of rental properties in this community is reflected in the fact that only one third of dwellings here are owned, with or without a mortgage, compared with approximately two thirds for all of New Zealand. The average annual spending for households in this area was slightly lower than for the whole of New Zealand.

A distinctive feature of this community is the large number of churches which represent the cosmopolitan mix of residents who live here. There are churches that represent the denominations found in most New Zealand communities but a notable 
feature is the churches which have large Pasifika congregations, some of these having preschool centres attached to them. There are also Islamic and other churches representing peoples from Europe and Asia. Some of these churches serve congregations which come from a wider area than this community. Associated with the churches are groups which have been established to support the various ethnic communities within the wider community, such as those for early childhood education and to supply social services to families.

\section{The school}

The school attended by the students has a pleasant environment. It is a comparatively small area but trees, shrubs and a grass field provide an attractive green area in this suburb of high density housing and commercial premises. This school was established in the late $19^{\text {th }}$ century and since then the school roll has reflected the changing patterns of immigration to the area. From an examination of photos taken in the early $20^{\text {th }}$ century of this school's children, it appears that all the children attending at that time were Pākehā. In an interview the principal related how the school has always reflected national immigration patterns, initially European and from the 1970s migrants from Polynesian countries. In recent years there have been many more immigrants from Asia sending their children to the school, while the number of Polynesian students attending the school has almost halved over the past decade.

While there are many professionals living in the area surrounding the school, they either do not have children or they send their children to other schools. The majority of the students who attend this school live in the suburb, with most living in the City Council housing estates. Most of the parents work in the community as cleaners, in the laundry or in the kitchen of the hospital, which is the main employer in the community. Many fathers work on the night shift at a large local bread factory.

\section{Ethnic composition of the student roll}

The school is an interesting example of one with a high concentration of students who represent minority ethnic groups, while the Pākehā students in the school are very much in the minority. The most obvious feature of the ethnic composition of the school is that it has many more Pasifika students and far fewer Pākehā and Māori students than the national average. As stated in Chapter 1, Pasifika peoples make up 
relatively small numbers in New Zealand but there are concentrations of various Pasifika groups in particular suburbs and schools and this suburb and school are examples of that. Over the whole of New Zealand Pasifika students in primary schools comprise 9.1 percent of the school population but in this school Samoan students alone comprise 60 percent of the total. There are also students from other Pasifika groups including Tongan and, while these are small numbers, they are also above the national averages. There are also slightly more South East Asian and Indian students in the school than in the national average. While European students make up approximately 59 percent of students in New Zealand schools, in 2004 in this school they comprised only 8 percent. Students of Māori background make up 21 percent of the national school population but comprised just over three percent in this school. (National statistics from Education Counts

...educationcounts.edcentre.govt.nz/statistics/schooling/student-numbers

Accessed on July 2, 2007)

This school could be considered typical of those attended by Pasifika students in that it is ranked by the Ministry of Education as decile 2. Most Pasifika students are enrolled in lower decile schools and the reading and writing achievement in these schools tends to be lower than that in higher decile schools. In 2003, 68 percent of Pasifika students of school age were enrolled in decile 1, 2 or 3 schools compared to only 26 percent of the total school population.

www.minedu.govt.nz/print_doc.cfm?layout=document\&documentid=4712\&ind...

\section{Accessed on 12 July, 2006}

The results from NEMP in literacy indicate that students in lower decile schools achieve less well than those in higher decile schools. At year 4 and year 8 , students from low decile schools scored lower on reading and speaking tasks than students from high decile schools (with the exception of reading Māori text) (Crooks \& Flockton, 2005). In the results for writing, there was a steady trend of improvement from the lower to higher decile schools for both year 4 and year 8 students (Flockton \& Crooks, 2003). Data collected in the school at the time of this study showed that nearly 80 percent of the students from years 3 to 8 were achieving in reading at or above their chronological age with good comprehension of text. 
This chapter has outlined the distinctive characteristic of the community in which the students live in order to provide a context for the data and discussion in the following chapters. The world of these students is different from that of most New Zealand children of the same age and their environment influences where and how they use literacy. In this study which investigates the social and cultural uses of literacy, many of the students' uses of literacy cannot be separated from the community. This is illustrated in the Chapters 6 to 8 which explore the church, Sunday school, home and community as sites for literacy practice. 


\section{CHAPTER 6}

\section{Family Sites for Literacy}

Chapter 6 has a brief introduction to the three chapters of findings. then discusses family sites for literacy. The sites, curriculum. and teachers of literacy are discussed in six themes relating to family practices.

\section{Introduction to the findings}

This chapter is the first of three interconnected chapters that discuss the themes that emerged from an analysis of the data. The framework for analysis (described in Chapter 3) is based upon Cremin's (1976) premise that there is a multiplicity of institutions that educate and that these relate to one another in what he terms "configurations of education" (p.30). Using Cremin's concept of sites and configurations, it can be seen that the students engaged in literacy practices that are situated in sites outside the school, these being family, church, and neighbourhood sites (See Figure 2: Educative sites for literacy for an overview of the sites, teachers, curriculum and use). Chapter 6 explores the sites of family, Chapter 7 the sites of church, and Chapter 8 the sites of the neighbourhood. Each of the sites has its own goals, curriculum and teachers. The literacy practices for each site are explored in themes through a sociocultural perspective to reflect Street's (1984) ideological paradigm.

The methodology for the study was designed so that the students offer an insider view of their own literacy practices. This enables us to foreground the personal plane (Rogoff, 1995) in order to see through the students' own eyes how they appropriate knowledge about literacy practices in authentic settings, most of which are outside the school. Through the community plane can be considered the practices that they have been apprenticed into by their communities. In contrast to official ways of measuring literacy in schools which impose measures on people, this approach which does not seek to assess student achievement is more grounded and takes the students' views more seriously. This chapter illustrates that the students' literacies reflect their own values and how they interpret their world (Freire's concept of reading the world, Freire \& Macedo, 1987). Their individual participation in the social and cultural practices that are revealed in the data are linked to their 
construction of identity (in reality this may be many identities for each student) and reveal how they align themselves with particular groups in society in communities of practice (Wenger, 2006) and how the values of one group may connect with, or clash with, those of other groups to which they belong. Chapter 3 introduced the concept of individual identity and how this often relates to individuals belonging to various groups in society (Collins \& Blot, 2003; Ferdman, 1990; Gee, 1996; Kenway \& Bullen, 2001) with the consequence that the individual may have many identities. As outlined in Chapter 4, the Ministry of Education wants teachers to consider the backgrounds of students as individuals, but the findings in this study relate more to groups of students rather than to individuals. The data in Chapters 6 to 8 indicate that the individual students identify with many groups through, for example, their involvement with family, church and their interest in fields of popular culture.

These examples in the following chapters were selected by the students to illustrate their uses of literacy in out-of-school settings. The examples illustrate one of the themes introduced earlier in the thesis was that "literacy" can be conceptualised as a social practice rather than consisting simply of skills that are owned by the individual.

The literacy practices in family, church and neighbourhood sites as discussed in Chapters 6, 7 and 8 provide a background for the recommendations in Chapter 9 for teachers to make effective connections to students' backgrounds in school literacy programmes.

\section{The family sites for literacy}

Chapter 3 introduced the idea of the family as an important educative site for literacy (Cairney, 2003; Heath, 1983; McNaughton, 1995; Taylor, 1983). In this study the family sites of the Pasifika students emerged as significant for teaching and using literacy. Cremin (1976) writes that every family has a curriculum which it teaches deliberately and systematically while mediating the learning of its members, and he explains that families not only teach in their own right but they screen and interpret the teachings of other institutions. The family uses of literacy described in this chapter provide examples that these institutions in their various sites do not exist in isolation, but work in a network with others to mediate the life of the students. The family sites have practices that overlap with those of religion, the neighbourhood and 
school and the data indicated that there were mutually supportive values and pedagogies between family and religion and family and school (See Figure 4: Configuration of family with other sites) showing the overlapping literacy uses, curriculum and values which illustrate the consonant relationships between the sites. The configuration of family and religion is discussed further in Chapter 7 while the configuration of family and the neighbourhood is discussed further in Chapter 8 .

The literacy handbooks for New Zealand primary teachers (Ministry of Education, 2003a, 2006a) recommend that teachers plan for continuity between students' home literacy practices and those of school. In this study, many of the students' photos were of family members and many of the discussions concerned their social interactions with family members. All the students except one had siblings. Several students said that they had other adults living with their families, for example, grandparents (two students), adult cousins (three students) and an aunt (one student). One student said there were often seven extra children (cousins) staying with her family and another said sometimes a teenage relative stayed. The students also socialised with other family members such as grandparents, aunts, uncles and cousins who mediated their literacy learning. These relatives are included as part of the family as an educative institution for literacy.

\section{The sites}

Chapter 3 introduced the idea of sites in which people use literacy and the social and cultural practices of literacy within the meaningful contexts of those sites. In this study data from the photos, journals and interviews revealed that the family site for literacy was the students' own homes and the homes of relatives and friends, but it was not restricted to dwellings. The family site was wherever the family happened to be. 


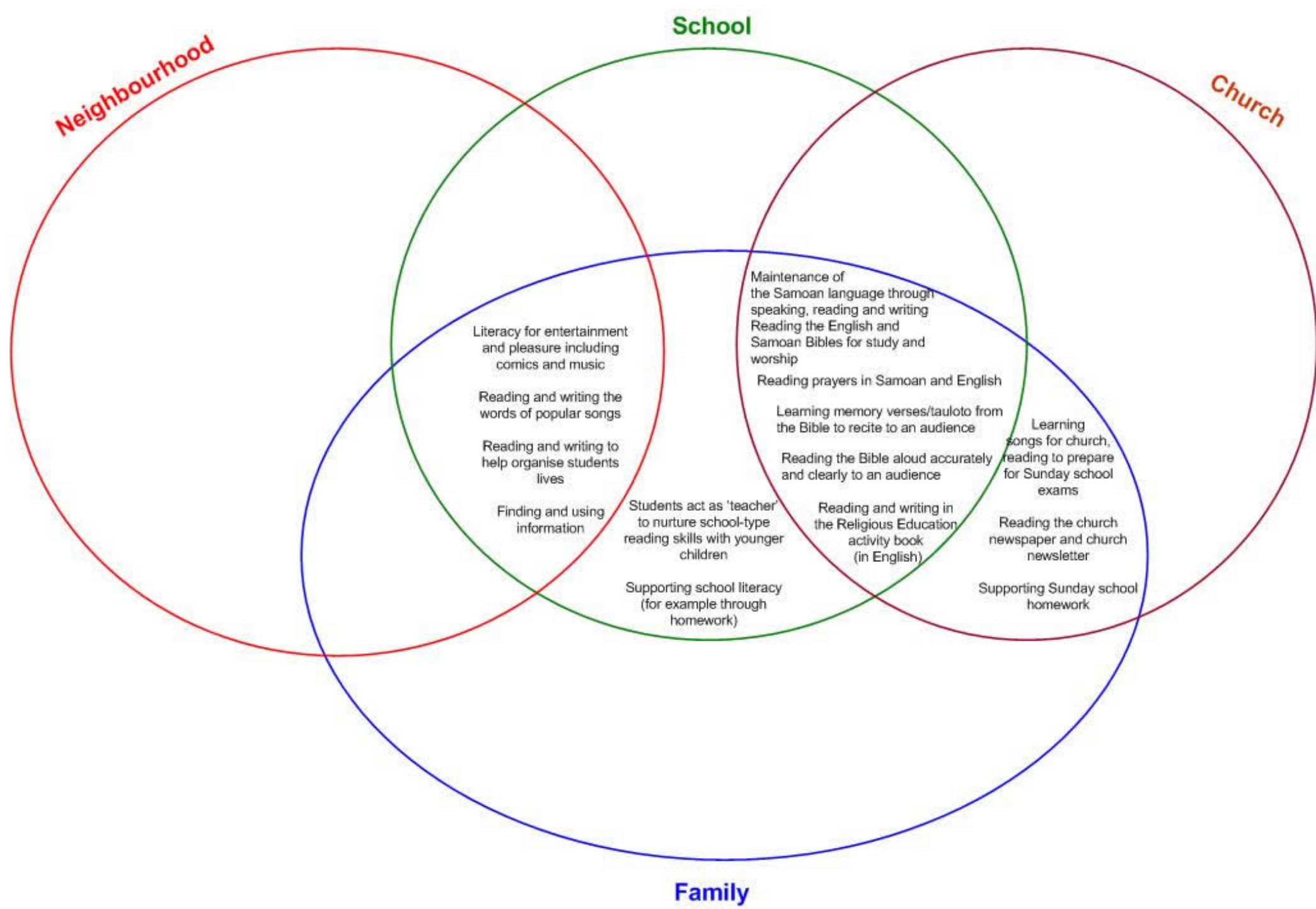

Figure 4: Configuration of family with other sites, showing the overlapping literacy uses which illustrate the consonant relationships 
One hundred and thirty nine of the students' photos were connected to a site for literacy, either through what the photos themselves revealed or through the students' explanations. Of these the most common site presented by the photos was the students' own homes. Forty eight per cent of the photos were taken in or around their homes, usually in the living room, and sometimes in the students' own bedroom. A small number of photos (2.8 percent) were taken in the homes of relatives and friends. An aunt's home and grandparents' home were mentioned by students in interviews. The study did not seek to quantify the literacy uses in various other sites, so there were no questions asked of each student about various sites apart from home, church and Sunday school. This meant that some other sites such as the grandparents' home and aunt's home were spontaneously described by just two or three students.

The photos taken by the students allow us a glimpse into their homes and their family life and they illustrate uses of literacy that are situated in the family. Many of them are taken in the family living room, some of which have woven mats on the floor, framed photos of family groups, individuals and family members in sports teams, with each photo frame surrounded by a brightly coloured plastic lei. Some rooms have decorations hanging on the walls such as woven hats and shell necklaces brought from the Pacific Islands (See Figures 8 and 9). A number of the photos show very large stereo systems, computer consoles and large stacks of CDs. Shelves are stacked with books and some also hold sports trophies, statues of the Virgin Mary and jars of bright flowers.

\section{Teachers and curriculum of the family}

Within the agency of family the teachers who contributed to literacy included parents, grandparents, uncles, aunts, cousins and siblings. Not all were human teachers. The students also learned from resources such as English and Samoan dictionaries, from other books, the Internet and television.

Clearly the details of family curriculum vary from family to family but several common features of curriculum emerged from the data which have strong connections with the educative sites of religion and the school. Because of the school's Catholic special character, its teaching and maintenance of Christian beliefs and values are congruent with those of the church and Sunday school. The family, 
religion and school form a configuration where the values and the pedagogies are mutually supportive (Cremin, 1976). The purpose of the family curriculum that was related to religion was teaching and maintaining Christian beliefs and values, and to support the church and Sunday school pedagogy and values. For a number of the students these practices were in the Samoan language. They are outlined briefly here and are described in detail in Chapter 7.

Examples of family literacy that supported religion included:

- reading the English and Samoan Bibles as part of family and individual worship

- reading family prayers and individual prayers (some families in Samoan and some in English)

- learning memory verses (tauloto) for White Sunday

- practising reading as a performance

- $\quad$ supporting Sunday school homework

- teaching and maintaining the Samoan language which was largely done through reading and studying the Bible

- learning songs for church

- reading to prepare for Sunday school exams

- writing in the church activity book and

- reading the church newspaper and church newsletter.

In addition to the religious uses of literacy that were nurtured by the family there were many other aspects of the family uses of literacy. These included reading books, magazines, circulars, comics, television guide, school newsletter, as well as reading and writing letters, emails, text messages, notes, personal diary, recipes and shopping lists. Families read English and Samoan newspapers and supported students' reading and writing for their school homework. An important feature of family literacy was the students reading to younger children. Within the family setting students read instructions for games, read ingredients on food packaging and read and wrote the lyrics for songs. The data from multiple sources are presented under the following headings which formed themes of the uses or purposes of 
literacy within the curriculum of the family. The sites, curriculum and teachers for each are given under the headings.

1. Maintenance of the Samoan language and culture among family members

2. Students nurturing school type reading skills with younger children in the family

3. Supporting school literacy ( for example through homework)

4. Literacy for entertainment and pleasure including such fields of popular culture of computer games, music, books and magazines

5. Reading and writing to help organise students' lives

6. Finding and using information.

\section{1/ Maintenance of the Samoan language and culture among family members}

In a study that investigates a group's social and cultural uses of literacy the language that is used is a significant factor. A characteristic that distinguishes this group of students from others in New Zealand schools is that many of them are bilingual in that they speak, read and write in Samoan as well as English. There is strong support in their families and community for them to maintain the Samoan language and this is seen particularly in their church-related practices of literacy, which are fostered in the home and Sunday school.

The sites for learning and using the Samoan language included the homes of students and relatives, the church and Sunday school as well as the school. A core part of the curriculum is to speak, read and write in Samoan. For students this included communicating orally with parents and grandparents, peers, Sunday school teachers, priests and ministers. It included reading the Bible and other religious texts such as prayers. It also involved reading and writing for memory verses and for tests and exams at Sunday school.

The teachers of the curriculum are parents and grandparents, other relatives, Sunday school teachers, priests and ministers. Teachers include the Bible and other religious texts. 


\section{Students' own ratings of speaking, reading and writing in Samoan}

In the first interview students were asked questions about their use of the Samoan language and asked to rate themselves on a scale for speaking, reading and writing in Samoan (See Appendix A for the questions). Of the fourteen students, twelve responded that they did speak in Samoan with three responding "never". When they were then asked to record on a Likert scale how often they spoke in Samoan at home, there was a fairly even range of responses from "always or almost always" to speaking "a little". Ten of the twelve students who said they spoke Samoan also said they read in Samoan, and when they were asked to rate themselves on a scale from "extremely good" to "not at all good", their responses were again fairly evenly distributed. When they were asked where they read in Samoan, seven mentioned reading at Sunday school and/or church and six mentioned reading in their homes. Of these, three students said both sites. They said that in the home they read the Samoan Bible, Bible stories, Samoan picture books, Duffy books ${ }^{11}$ and other books.

Fewer of the students said that they could write in Samoan with five students rating themselves fairly evenly between "extremely good" and "not at all good". The student who indicated "not at all good" explained that she could write "a simple sentence" in Samoan. A sixth student indicated that she could write some words in the Niuean language which she did at home. The other writing in Samoan was done at Sunday school.

The interviews with the church representatives also revealed strong support by the church for the maintenance of the Samoan language and this is discussed in Chapter 7. This valuing and working together represents a network of practice to support particular literacy uses and values. The students had varying degrees of proficiency in Samoan, and this is an example of how the individuals' learning is mediated by their own social and cultural environment (Cremin, 1976). Maintenance of the mother tongue was valued by some of the students' grandparents, who were seeking to preserve particular traditions like the immigrant communities described by Cremin (1976). Church Representative C described an issue of language that may be faced by young Samoan people at school and

11 Duffy Books refers to books which have been given to children by the Books in Homes Programme through author Alan Duff's Charitable Foundation which aims to encourage children from lower decile schools to read. Children in participating schools receive five books of their own selection each year and can earn more books through a weekly "Caught being good award". Twice a year special assemblies are held where adult role models, such as sports people and writers, present books to the students and emphasise the connection between success and reading. 
in the community. This concerns a conflict of values between, on the one hand, their peers and, on the other hand, the values of family and church which are supporting the use of the Samoan language. While some families and the church were emphasising the value of maintaining the Samoan language, some young people resist this. Although this came from Church Representative C and not the students in the current study, it may help to explain why some of the students spoke little Samoan. She said "All the children in my class know how to read in Samoan. I say why don't you speak the language when you go to school and they say we are ashamed." They told her that this was because other students made fun of them and when they said something incorrectly, the new arrivals from Samoa laughed at them. She stressed the value of learning the mother tongue as an important part of their identity and to enable them to communicate with family members.

\section{Using Samoan language for family communication}

One of the themes that emerged from the interviews, photos and journals was literacy practices incorporating reading and writing to establish and maintain relationships with friends and family. This study explores literacy as cultural practice and it is therefore necessary to consider what Reder (1994) describes as the cultural transmission or the socialisation of the acquisition of literacy. An essential dimension of this is the passing on of the Samoan language from the older generation to the younger, and this theme is introduced here and explored in more depth in relation to the church literacy practices in Chapter 7. The culturally-patterned activities that demonstrate this in the study included communicating with grandparents and other family members in the Samoan language. In the interviews some of the students revealed that family elders assisted them in learning and practising the Samoan language. As there was no question in the interview schedule for the first meeting that specifically sought this information, it was decided to ask about this in the third meeting with students. In the meeting three interview schedule (Appendix I) students were asked Do you ever talk, read or write in the Samoan language to communicate with your grandparents, other relatives or friends?

Eleven of the thirteen students present replied in the affirmative. Four students described communication with their grandparents, some of whom lived with the students' family. Their written responses included "Yes, read and talk to Grandma and Grandpa," and "I read to my grandma." while other examples included "Yes read and write with family," 
and "Yes, whole family". This communication with family members in Samoan was an important practice in these families and an illustration of a cultural perspective of literacy practice. The students' explanations in the photo elicitation interviews illustrate the apprenticeship of these young people into their community using Rogoff's (1995) community level that explores the cultural values and cultural tools of the community, in this case, the Samoan language being the cultural tool.

One student's description is useful to illustrate the value attributed to language as a cultural tool of some families in this community. Rogoff's (1995) three planes of analysis provide lenses to examine Eseta's explanations of learning the Samoan language with her grandfather. Her grandfather was the teacher in this socially mediated process and while a purpose of the interaction may be to pass on the language to the younger generation, the student's explanation is useful to illustrate how the Samoan language was used by the girl to communicate with her grandparents. Eseta presented a photo to represent this intergenerational communication, and her explanation in the interview describes the practice. The photo is taken in her home in her grandfather's room (Figure 5). Like a number of the photos it appears to be posed, and is not therefore strictly speaking an ethnographic observation, but it does show the student's perception of what is a literacy event.

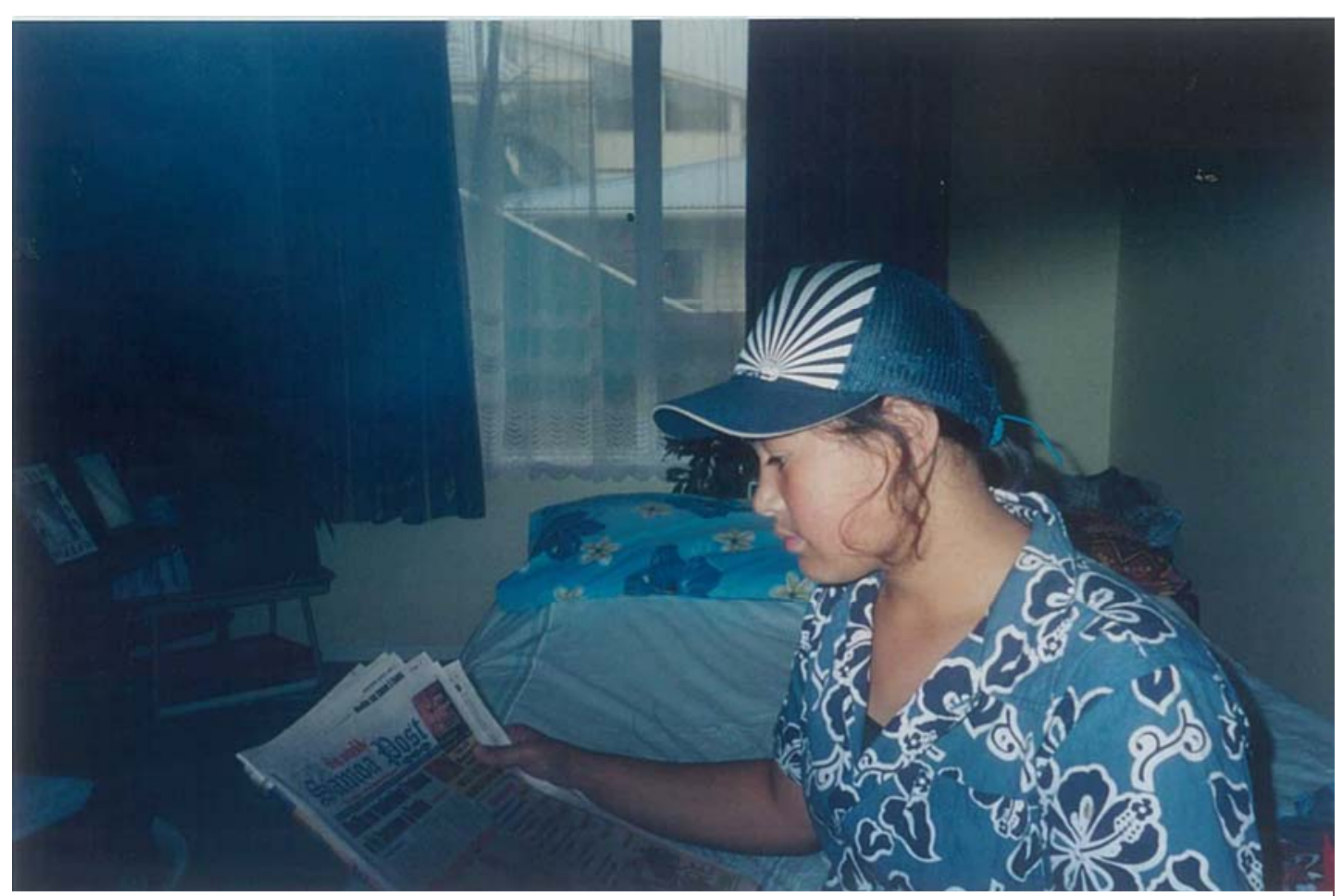

Figure 5: Eseta reading the Samoan language newspaper with her grandfather as teacher Pseudonyms have been used instead of students' own names 
Her words from the interview explain the procedure of the "guided participation" as she and her grandfather engaged in social interaction. Eseta said, "I was reading the Samoa Post. My grandfather was there ...he was helping me read it". She explained that he lives with her family and every week he gets the Samoa Post. It seemed that her grandfather valued this paper which is written in Samoan as he keeps all the old copies. She said she would read... "about sports like David Tua and his boxing." The researcher was interested to find out how her grandfather tutored her, and she explained their interactions: "I read aloud and if I don't know I just ask him. I read it and he tells me what it means." In her journal she recorded that her grandfather was helping her to read it and he was telling her what it was about. A further indication of her family placing value on maintaining the Samoan language was revealed when she said that before she began school she attended the A'oga amata.

Eseta's own comments illustrate her appropriation of knowledge about learning the Samoan language within her family. When the researcher asked her if it was a useful thing to read in Samoan, she said "Yes you learn more." When she was asked what is the advantage of being able to read in Samoan as well as English, she replied, "You get to learn another language and my grandparents always speak with me in Samoan and I don't understand, so that's why he's teaching me so I can understand." Eseta said her grandfather also helps her to memorise verses in Samoan for Sunday school. It seemed that speaking and reading were valued more than writing as Eseta's use of Samoan did not extend to writing. The evidence of Eseta's family valuing maintenance of the Samoan language and the grandfather teaching her illustrate how a cultural tool of the community is passed on to the next generation, representing an important value in this community (seen through Rogoff's community lens).

Language-learning interactions within the family at the interpersonal level were not only to assist children in acquiring and using the Samoan language. The "shared endeavors" described by Rogoff $(1995, \mathrm{p} .147)$ could also be to assist an adult. Paulo's example of helping his father to understand English illustrates this. Paulo explained how he helped his father by translating the television news for him: "Because of at home. Like my dad always used to get me to explain the news to him in Samoan because he doesn't usually understand English. I'd be talking in Samoan to him." This is an example of education being intergenerational with adults teaching children or with children teaching adults. The example is similar to the 
situation described by Cremin (1976) who gives the example in the American context of children in immigrant families, where the children have learned the new culture quickly and act as interpreters to their parents and grandparents.

\section{2/ Students nurturing school-type reading skills with younger children in the family}

A theme that emerged strongly in the photos and discussions and which demonstrates that books and reading are valued in these families was the practice of joint literacy activities of the students with younger children. (For an explanation of joint activities in other settings, see McNaughton, 1995). Some of the discussions elicited from the photos indicated that the students were at times acting like parents or teachers in their interactions with the younger children. This was to support school related literacy, that of teaching and encouraging reading, although this could also be described as family literacy. Although this is not exclusively Samoan it could be considered as an example of the general cultural ways of using written language as described by Barton and Hamilton (2000). It is a useful example to illustrate the values, attitudes and particularly the social relationships that Barton and Hamilton state are reflected in these ways of using literacy. This type of interaction was encouraged in the school site with older students reading to younger children and listening to them read. The teachers stated that in addition to regular buddy reading sessions, older students assisted in the younger children's classrooms on wet lunchtimes and often acted as teacher and read to the younger children. The school also gives information to parents on how they can assist their children with reading at home, and provides specific information on their child's progress and their next learning step. The seven girls produced 12 photos that showed their involvement in literacy events with siblings, relatives and friends who were younger. All seven girls said they read to younger children. Several of the photos showed the girls with their arms around the younger children as they read to them or listened, and some had the younger child on their knee.

The site for these activities was generally the students' homes but some photos were taken in the school grounds after school hours. They are included here in the family site as they are part of family rather than school literacy and together they help to illustrate the configuration of family and school. The curriculum included reading 
easy books to the young children, discussing the written text and pictures, asking questions about the text and pictures and listening and responding to the younger children reading and talking about the books. The teachers were the year 7 and 8 students.

In contrast with the girls, none of the boys produced any photos that illustrated their taking part in joint literacy activities to nurture reading skills with younger children, although Tavita took several photos of his siblings reading independently. However, when they were asked in the extra interview Do you ever read to young children or listen to young children read to you? six of the seven boys said they did. Examples included "I read to my sister and brothers" and "Yes he reads to me." The researcher was interested in why the girls, but not the boys, presented themselves in their photos as fostering literacy in younger children and surmised that maybe the girls, but not the boys, were expected to look after the younger children. Appendix I asked Do you sometimes have to help look after your younger brothers, sisters or relatives? All the girls looked after younger children in combinations of brothers, sisters and cousins while six of the seven boys said they looked after combinations of sisters, brothers, nephews and nieces. These data provide a useful illustration of social practice of literacy that embraces value systems. They show that children as young as one year old are socialised into family literacy practices, in this case reading, long before they enter school. When considering the actions of the students, they are interacting with the younger children in "guided participation" as they share understandings about reading books. They are in fact the teachers of the curriculum assisting the younger children at the interpersonal level. However, when the study foregrounds the younger children whose reading is being fostered, it can be seen how they are involved in "appropriating" (at the personal level) the necessary skills and understandings that will lead to their eventually reading books independently.

The photos of joint literacy activities provide a window into the students' homes and some show the extent of the reading materials in the environment. One photo illustrates Repeka holding her younger brother who is aged one year. Her journal entry stated "I was reading a book to my baby brother". Another of Repeka's photos (Figure 6) shows her younger brother pointing to a picture in a book that is open on the desk in Repeka's room. 


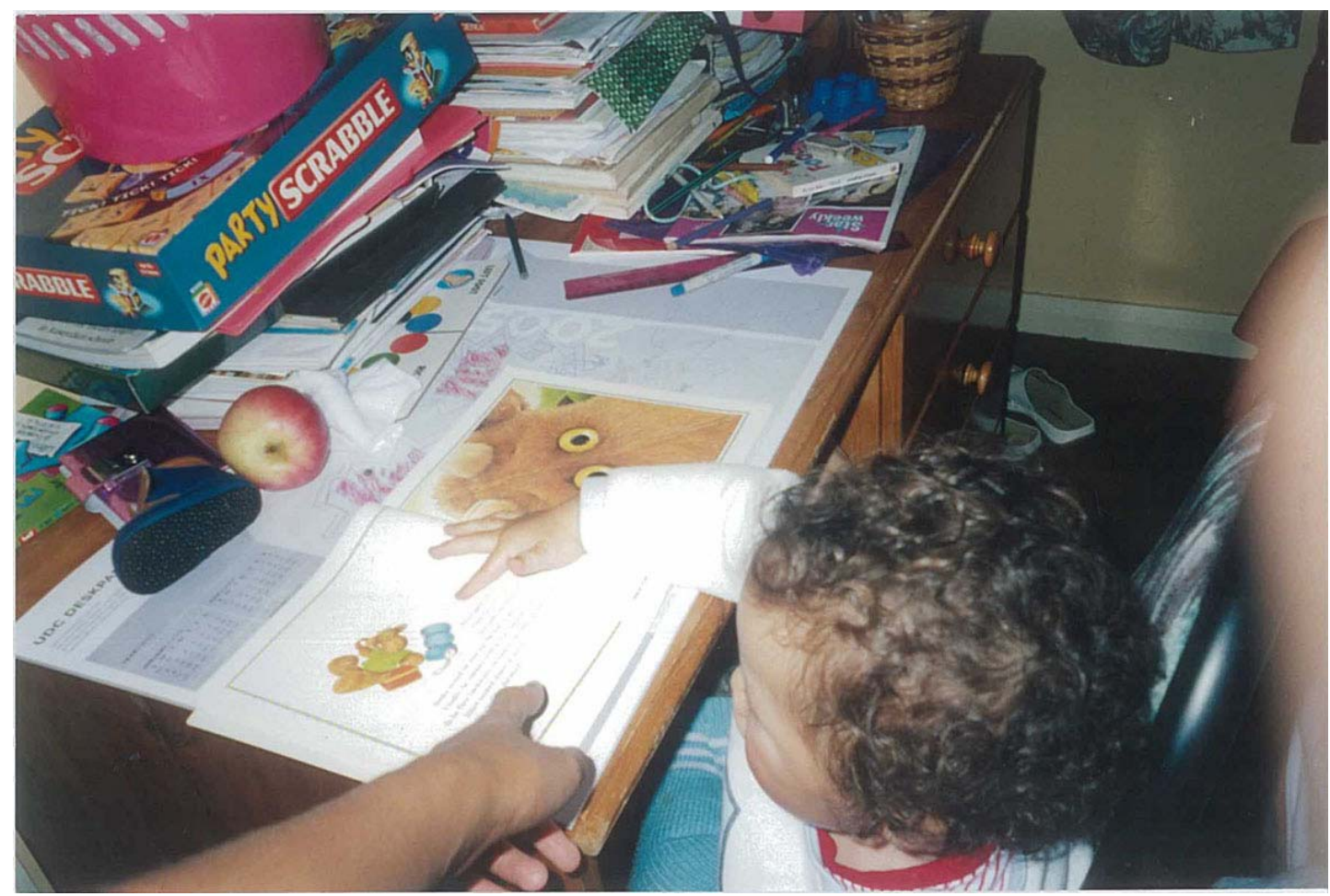

Figure 6: Repeka sharing a picture book with her one-year-old brother (Note the Scrabble set on the desk)

The desk is entirely covered in books and stationery items some of which belong to her mother, an early childhood teacher. Repeka's hand is pointing to the written text on the same page the brother is pointing to. Her eight-year-old cousin is standing behind the one year old brother and was reading the book to him. In response to questioning she said that her brother liked picture books and she read to him often. When she reads to him he points out the pictures and tries to talk about them. For some students reading to younger siblings was a regular practice. For example, Eseta said she would read three times a week to her six-year-old brother while Hana said she read about twice a week to her siblings.

Sara is the eldest child in her family and she presented three photos of her pre-school aged sister involved in reading books. One photo of her little sister looking at a Winnie the Pooh counting book while sitting on a bed at home. Sara explained what was happening here. "I read to her first then she read by herself." Another photo showed her sitting on a sofa with her little sister cradled in her arms as they shared a book. Little sister is holding baby's bottle. Sara explained "I was pointing out what things were and then asking her, like going back to the beginning of the book and asking her." The researcher replied that that was what a teacher does and suggested 
that she was teaching her sister. She agreed. When asked if her little sister liked reading by herself, Sara replied "I think she just likes looking at the pictures."

Another example of engaging young children with books and questioning about the pictures came from Apekaila. The photo is taken in the living room and shows Apekaila sitting on the carpet with her arms around her young two boy cousins who are aged one and two years, with each boy holding and looking at a book. Apekaila says that one was reading his own book which was nursery rhymes. When she was asked if she read anything to them, she replied that she did read and talk with them about the pictures. Apekaila said she would show them the pictures and ask questions such as "What is she doing?" She explained that she does this quite often, when they come to her house. The cousins would choose the book and come and ask her to read it. "There is a shelf at our house and they always come and get which ones ...they judge the book". The role of these students in joint practices with younger children is in some ways similar to the older siblings in the Bangladeshi families studied by Gregory (2004) who played what Gregory describes as "a crucial role as 'teachers', as 'mediators of school practices', as well as 'bridges between languages and cultures" (p.99). She commented that these children had the responsibility of taking on the role of parents as far as teaching in English was concerned and for school subjects while the parents were concerned with educating their children in moral and religious knowledge as they learned in their mothertongue, Bengali. Gregory writes that there were common features in the examples of siblings teaching within the family. These were that the older child demonstrated what the younger should do, they checked up on past learning and directly instructed the younger child, and they provided alternatives if the younger child had difficulty.

\section{3/ Supporting school literacy}

Another dimension to the family practices supporting school literacy is in families valuing school homework and evidence of this was seen in the students helping younger siblings with homework, parents and other family members helping the students, and parents insisting that homework be completed. The students described three sites for this. The community library was a popular site for students to complete their homework, and this is described in Chapter 8. It is included there as a neighbourhood site as the library provided its own resources and teachers to assist 
the students in their learning. Other sites were the students' homes and the school grounds. The examples of doing homework in the school grounds are included in this chapter as "family" practices as they involved family members as teachers after school hours. While the curriculum was that of the school, the teaching was more to do with family than with school. Only a few examples of this literacy use emerged, but they are useful to illustrate a connection between the sites of school, family and neighbourhood where values are shared and common pedagogies are practised.

As with reading, only the girls described helping siblings but as no question was asked about it, boys may also help younger family members with school work. Elisapeta demonstrated that she had a clear understanding of her six year old brother's homework requirements and her explanation sounds like that of a teacher at school. She explained how one of her photos (Figure 7) illustrates how she helps her brother.

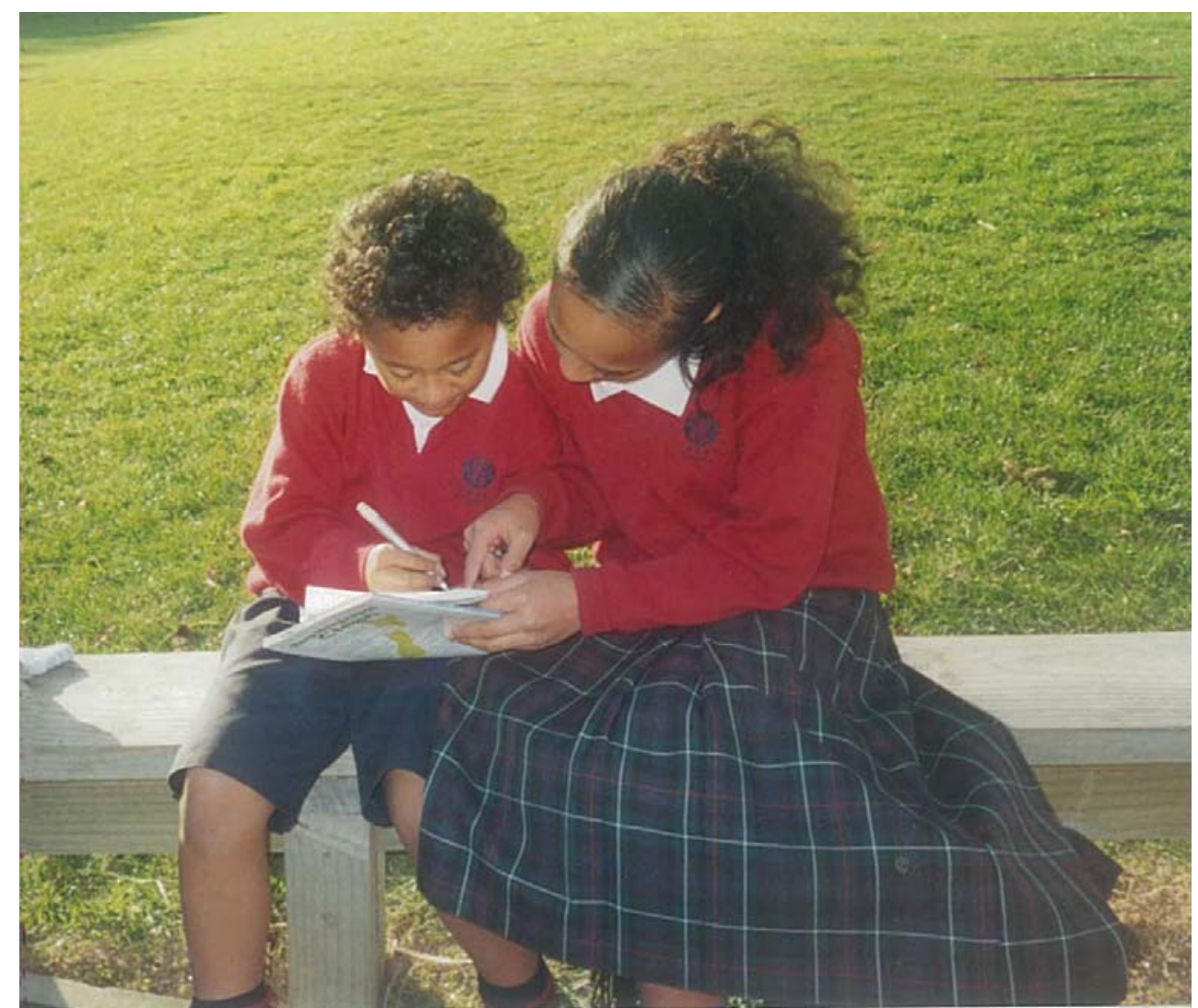

Figure 7: Elisapeta assisting her six-year-old brother with his spelling homework

The photo is taken while waiting for a swimming lesson after school but is included with family sites as it involves a joint activity between family members and it represents how several of the students assisted their younger family members. Elisapeta said "He gets a sheet and they have a blend for a week, a letter for the week and a number for a week. 
For the blends they have all these pictures and which one starts with the letter. Usually they start with the blend and the blend usually starts with the letter of the week." Other students gave examples of helping their younger siblings with homework by reading to them or listening to them read. Eseta listens to her younger brother reading and sometimes he asks her what the word is if he does not know.

Evidence of family support for school literacy was revealed when some of the students said that parents and other family members, such as older siblings or cousins, helped them with homework. Several students also explained that their parents had established guidelines for homework to make sure that it was completed. Both Isaako and Mareko said that their mothers allowed them to play games after they have finished their homework. Paulo enjoyed playing on Playstation but his mother had made it clear that his time for this was restricted. He explained "My mum only likes it when I play in the weekends because she likes me to complete my homework." She had not established a set time to do homework; "No she just says anytime. She just wants us to finish it." Hana described a conflict between the agencies of school and popular culture. She reads at home every day but admitted "I sometimes skip my homework because I can't put the book down".

Some students would use the Internet at home to find information and Elisapeta described doing this for school topics. She said that her father is really good with computers and he and her older sister showed her how to use the Internet.

\section{4/ Literacy for entertainment and pleasure including the fields of popular culture of computer games, music, books and magazines}

One of the major themes of literacy practice that emerged from the student data was the uses of literacy for the purpose of entertainment and pleasure. While the students may have less freedom in regard to some of the other literacy practices, those related to popular culture are particularly interesting as they illustrate what the students have made their own and could be used by teachers to make effective connections in school through what McNaughton (2002) terms "incorporation". Literacy practices related to popular culture are described in this chapter leading to suggestions for incorporation into school literacy in Chapter 9. The data reveal what students have appropriated in ways that are described by Mahiri (2000) as being “...for pleasure, 
identification, and a sense of personal power" (p.382). The students' identification with particular fields of popular culture can result in conflict with institutions such as family, church and school with which they also identity. Coping with this conflict is part of their growing up and developing their own identity.

The uses of literacy for entertainment and pleasure in the family sites are described below under the headings of computer games, music, books and magazines. The curriculum and teachers for each will be described in turn. The use or purpose of the curriculum is to provide entertainment and pleasure and it also assists with the formation of the students' own identity. As well, it concerns acknowledgment of the identity of other people, enabling students to identify and associate with particular groups in society. The data revealed that there were strong connections between the family sites and sites of neighbourhood and school, and these are described in the following sections.

\section{Literacy for entertainment and pleasure (i) Computer games}

The teachers in this field of popular culture included the students' siblings, cousins and friends. Other teachers included the computer games themselves, television, radio, DVDs, music CDs, as well as book based and electronic cheats for computer games. There was considerable curriculum knowledge required for using computer games. This included:

- Knowledge of the individual games including the characters, opponents and what is to be done

- How to navigate onscreen, for example follow the instruction of the menu and other instructions for the games

- Reading the visual symbols, signs and images of the games

- Understanding and using the terminology associated with computer games

- Reading books of instructions

- Knowledge of the different levels of the games and how to achieve higher levels

- Reading cheats for computer games. These are written instructions that are used to attain higher levels in the game. They may be purchased from certain shops or downloaded from the Internet

- Reading DVDs and magazines associated with the games

- Knowledge of where to purchase and hire computer games. 
A field of popular culture which is described in the literature and by the students is games which are played on a computer or a games console. Examples of consoles include Sony's Playstation and Microsoft's X-Box, with Playstation being the common system described by the students in this study. While there were no questions on the interview schedules that asked specifically about computer game use, the topic arose during several interviews and the majority of students said that they enjoyed using Playstation games. In fact, three of the boys indicated in interview one that playing with Playstation was their favourite thing to do in their spare time while a fourth indicated this as his second choice. The three other boys said during the second interview that they played Playstation. Some of the computer games that were mentioned by the students included Rugby 2005, Crash Bandicoot, Need for speed underground, Takedown, Halo 2, and Sonic.

Marsh and Millard (2000) claim that boys are much heavier users of computer games than girls, citing several researchers including Livingstone and Bovill (1999, cited in Marsh \& Millard, 2000) who found 79 percent of boys and 49 percent of girls in their survey played computer games. This matched the findings of this study where all seven boys and four of the girls said they used Playstation, with several boys but no girls describing it as a favourite spare time activity. Both Hana and Eseta said they play Playstation but it is not one of their favourite things to do and they do not have it at home. Kenway and Bullen (2001) describe video games as being strongly gendered, while Marsh and Millard offer reasons for the disparity in use by describing the covers of many games as featuring images of boys and men, and the games magazines are positioned to appeal to the male reader. They write that the publishers seem keen to develop products which reflect "only hegemonic masculinities" (p.121). When some of the boys in this study spoke enthusiastically about their favourite games, they referred to the violent content and this is discussed below. Marsh and Millard (2000) describe also a preponderance of male characters and they are critical of the negative way in which many female characters are presented.

\section{Learning from family members}

The students' descriptions of their computer game use included games played with others. The students explained how they had learned new skills to play the games from other family members including siblings and cousins. Ioane, who was reticent about 
other matters, was enthusiastic about computer games and said that his cousins taught him how to play. These are examples of guided participation at the interpersonal level where the students' learning is mediated by their social partners. Although there may be a negative public perception of computer games as wasting children's time, some writers believe they have benefits. Luke (1997), for example, describes the advantages such as children cooperating with family members and peers, teaching each other new strategies, and discussing the strategies and moves necessary to succeed in the game.

For some students their older siblings and cousins were models for expert computer game use and they mediated the students' learning. Mareko's photo showed his teenage brother playing a Playstation game which he did regularly after school. Mareko said the console is in his brother's room and his brother lets him play on it. When he and Samasoni were asked about the reading or writing that they have to do in the course of the game, Mareko explained the controller that his older brother is holding in both hands in the photo, "You have to read the buttons of the game. $\mathrm{X}$ is for go, $\mathrm{R}$ is burst like fire comes out the back." Isaako said there is a joystick and the analogue is what you press. Mareko explained the menu that appears on the screen. "It says press start. If you want a new game you go new game or load game." Isaako added "It's like a DVD but a DVD has different words on it." Both students said that they often hire games and when they were asked whether they know how to use a new game straightaway or do they have to figure out how to use it, Mareko replied that he knows straightaway.

\section{Skills for playing}

The students explained some of the skills required to play computer games such as reading instructions on the screen. One of Repeka's photos showed a television set in the living room and she explained, "We are playing a game on the Playstation ...Sonic." She said to play the game you have to complete the stages and when she was asked if there was reading involved she replied that you have to read what to do as the instructions come up on the screen. These instructions involved having "a mission, to get the rings, to defeat Robotnik, to pass a level."

Another aspect of the computer game curriculum that the students had learned was how to obtain and use cheats. Four of the students' photos illustrated computer games and four students included entries in their journals which described reading 
information known as "cheats" for their games. Several students' descriptions of cheats demonstrated their understanding of this aspect of the curriculum. Paulo said he downloaded cheats from the Internet while Tavita said he got them from the book which had been purchased. The use of cheats as part of the literacy skill needed to use the games was evident in Tavita's photo which showed his sister reading a Playstation 2 cheat book. He explained that his sister was playing a soccer game and she was reading the cheat to find out how to win it by bringing in new, stronger characters while they are playing a game on the Playstation. The book of cheats was bought at a shop which they named. Both boys explained the products such as used games and movies that could be purchased there. In his journal Tavita wrote "Me and my cousin were looking at PS2 cheats to finish this game at home." Paulo wrote in his journal "My brother reading cheats to a PS2 game. Unlocking weapons, unlimited health and loads more." This entry illustrates his knowledge of the curriculum as the terms he uses will not be obvious to anyone who is not familiar with computer games. For example, when playing a game a score may appear on the screen to indicate the player's "health" as the player is shot by an opponent and there may be an opportunity to pick up more health or ammunition. Prompts will appear on the screen to indicate this. Both Elisapeta and Repeka said they searched for, and downloaded, cheats from the Internet. Repeka was shown how to do this by her cousins. "All my cousins know how to do it. My older cousin he found out and he got all the cheats for this other game."

A clear example of a useful link to a student's interest in popular culture and to his identity construction is the example of Ioane, a year seven boy who was less articulate in the interviews, offering limited responses to the questions and to his photos. However, he spoke quite strongly and confidently about computer games although he was very hesitant and seemed unsure of other matters. He became animated, articulate and motivated when describing the Playstation games which he has at home. Cummins (in Afterword, Pahl \& Rowsell, 2005) describes as 'identity investment' where individuals invest time and energy into literacy practices that are meaningful to them in relation to life goals and interests. This dialogue about Playstation was certainly the most animated for Ioane, particularly when he described his favourite game as Halo 2. When he was asked about any reading that was necessary for Halo 2, he replied, "Just read in the book. It's a book of instructions for the game". His explanation of the games he liked to play and the 
instructions he gave for payment of games at the downtown arcade illustrate his appropriation of the knowledge of the practices that he considers are important to him. Effective teachers are able to motivate and engage learners and this is more likely to occur when the learner's cultural values and knowledge are incorporated into their learning activities (Ministry of Education, 2003a). Teachers can make effective connections for learners in school through "incorporation" where the teacher or student may build on the familiar (McNaughton, 2002) and the enthusiasm of Ioane and the other students for computer games indicates a possible way to achieve this connection.

\section{Conflict with other agencies (family and religion)}

A useful aspect of Cremin's (1976) concept of educational institutions is that it enables consideration of the configurations of the institutions which may include consonance or dissonance between their curricula. The interviews with the students revealed that, in the case of computer use, there was conflict between popular culture on the one hand and family and religion on the other. This is in relation to the violence in some of the computer games and also to the amount of time students spent playing the games. The students' comments foreground the personal level of analysis in revealing something of their personal sense-making in their involvement with popular culture. One aspect of the boys' computer game choices was their preference for violent games, which seems to form an interesting contrast with their religious identity with its strong connections to Sunday school and church. Both Paulo and Tavita indicated that Playstation was their first choice for their spare time activity and agreed that fighting, shooting and sports games were best. This interest in what might be described as violence was an interesting contrast to the way they had presented themselves as Christians. Each boy presented a photo of Bible reading and Paulo also showed himself reading a prayer book and explained how he prayed every day. Another boy also expressed enthusiasm for violent games. Ioane described his favourite game as Halo 2 where "You have to shoot monsters and they are dead and if you throw bombs they die."

However, two boys spoke out strongly against violence. Isaako was critical of the violence and swearing in Playstation games, saying that his favourite game is racing cars but "I don't like games that have violence and swearing. It can damage the child's brain." One of Mareko's photos was of a Playstation game disk of a game 
named "Takedown" and he explained enthusiastically, "It's like a race but you have to crash heaps of cars." When asked if he has Playstation at home, he replied he has a little one, Nintendo. The researcher asked if his parents control the use of it and Mareko said his grandmother does that. "She doesn't like me playing shooting games." Isaako said he has only car racing games ... "because I don't like violence and swearing" but he thought that games like racing, Olympics and rugby were acceptable. Both boys said they go to Timezone, a downtown video arcade, but Isaako assured the researcher that he never looks at the games with violence "cos some games at Timezone have violence."

The church Representative B spoke of a Christian perspective and emphasised that children need to be able to make judgments to separate good from bad. As an example he spoke out against swearing, saying that young people learn this from watching television and videos. He emphasised that children in their culture are not taught to swear. Violence and swearing in computer games and other types of popular culture and the stereotypes of good and bad represent a clash between the values of popular culture and the values of church and family.

Although parents may not fully approve of computer games, it appeared that there was some reconciliation of different practices and values. Some of the students' parents made rules about how much time could be spent on computer games. Students Paulo and Tavita agreed that they would spend half an hour to 45 minute of time on Playstation but this was mostly at weekends. "Heaps of time at weekends." Paulo's mother let him play at weekends so that he completed his homework on week days. Tavita agreed, saying that his mother tells him to do his homework first and the Playstation is like a reward when his homework is done. He plays Playstation four days a week, then at weekends. When Ioane was asked how much time he would spend playing, he replied, "Four games a night, only on the holidays. Not during the week. I'm not allowed to watch TV or games on the week days." He explained that his mother and father made that rule so he does his homework and his chores. While there was recognition by the family that children valued popular culture, their time commitment to this was not to be at the expense of school work. 


\section{Literacy for entertainment and pleasure (ii) Music}

Music also forms part of children's popular culture (Luke, 1997; Mahiri, 2000; Marsh \& Millard, 2000; Morrell, 2000) and popular music is influential in the formation of individual and group identity (Zemke-White, 2001). Music is described by several of these students as an example of their out-of-school literacy practice. This section provides a look through the students' eyes at examples of how they appropriate knowledge about literacy practices that are related to popular music, thus aligning themselves with particular groups. Popular music surrounds children as they grow up. In this study the sites for students enjoying popular music included the family sites of students' own homes and peers' homes as well as the school (and to a small extent, the church). The curriculum relating to popular music includes knowledge of the singers and their music. This involves knowing something of singers' personalities and values and background. An important part of the curriculum was knowing the words of the songs and for the students this involved reading the words on the CD covers and downloading and reading the words of songs from the Internet. It also included writing out the words of songs. The teachers of the curriculum were the students' peers and older relatives as well as the radio, television, and CDs.

Seven of the students' photos and several of their journal entries related to popular music. The singers whom they named included 50 Cent, Michael Jackson, Ciara, Alicia Keyes, Back Street Boys, Jojo, and Decepticons (from New Zealand). When the students were asked in meeting one What do you like doing in your spare time? (Appendix A), Repeka and Eseta identified listening to music as their first choice. Repeka wrote "Watching TV, music videos, C4." (C 4 is the music video channel on television). Another girl, Hana, wrote for her third choice "Play piano and sing" while Samasoni wrote for his third choice, "Dancing to music (make up actions)".

The examples of literacy related to music are useful to show how the learners' environment mediates their learning and to show also how this can vary greatly for each individual. A common writing practice described by the students that illustrates this interest in music was recording the words of the songs that they liked. Evidence of this was provided by their photos, the journals, the interview transcripts and the third interview schedule. The practice of listening to the words of popular songs and writing down the lyrics is a useful example of children's popular culture as it is motivated entirely by the students themselves and thus is a reflection of the developing identity of 
the adolescent. This was a practice described by both girls and boys. When writing song lyrics was described by some girls during the photo elicitation interviews, it was decided to add a question to the meeting three interview schedule (Appendix I), When you listen to the words of songs do you ever write the words down? Three girls replied yes and five boys said they wrote the words of songs "sometimes".

Some of the photos as well as the students' comments illustrate how they have been actively involved in appropriating aspects of popular music. It is interesting to consider the type of music they chose to represent the favourites as there was a marked contrast in the styles and values of the music between the girls and some of the boys. The students were not asked for their favourite artists but those who named singers showed a preference for hip-hop/rap artists (including Ciara, Alicia Keyes, 50 Cent, Baby Bash). Eseta said her first choice of spare time activities was singing hip hop and $\mathrm{R}$ and $\mathrm{B}$. One of her photos showed music CDs which she described as "Michael Jackson, hip hop and stuff".

It seemed that knowing the words of songs was an important aspect of students enjoying the songs and feeling some ownership of them as they could sing along with the music. This recording seemed to be a key part of their appropriation of knowledge of popular music. The individual's selection of music contributes to their construction of identity and aligns the individual with a group of similar interest. The idea was also introduced at the beginning of this chapter that the individual may belong to many different groups in society and have many identities (Gee, 1996) and choosing certain types of music and favourite artists enables the individual to identify with groups of their choice who share common values and interests.

There were several examples of students writing lyrics of favourite songs and the following two examples illustrate the practice from the students' own perspective. The first is from Eseta who showed two photos of her sitting on her bed at home writing down the lyrics of songs as she listened to a recording. She explained that she likes to learn song lyrics from the radio, CDs and the Internet, and she said she might do this about once a fortnight. She recorded in her journal: "I was writing some song lyrics so I can learn the song." In the interview she said, "I like learning song lyrics. I listen to the radio every day and I get a CD and a song that I like. I listen to a couple of words, then pause it and write them down." She described writing the words of the song "One two 
step" by Ciara. She pronounced the name as "Sierra" which confused the researcher when he sought information about this singer, but this serves to illustrate a small aspect of the curriculum knowledge which she possessed and he did not. The words to this song are about dancing to attract boys on the dance floor and contain no swear words or overt sexual references. This seems to be fairly innocent and you would not expect that it would clash with the values of family or religion.

The second example is from Sara who recorded twice in her journal that she read the lyrics of songs. She wrote that she read the lyrics to Jojo's song "Not that kinda girl" and Mariah Carey's song "We belong together". The words of the first song tell of a young woman who is singing to her boyfriend about her independence, and the second song tells of a young woman with a breaking heart asking her boyfriend to come back. The words seem innocent and not unlike the popular songs of many past decades. The content of these songs seems similar to that of the novel Girls in Tears described later in this chapter by Maria.

Ciara was also the singer of interest in Sara's photo of Hana and a friend taken in their classroom at school outside school time. It is included in this chapter as it is connected more closely to the literacy practices of the family sites than the school. The students listened to music often. As Sara said "We almost always know all the words...cos we listen to them all the time" but as they could not always hear the words clearly, they sometimes read the cover. Sara explained that the words were on the inside cover of the CD which they have opened out and are both holding as they read, but if they don't have the words they listen and write them down. In the interview she said, "They are reading the lyrics, cos we had the CD on and they are reading the lyrics."

\section{Conflicting values?}

A close examination of the photo revealed the words "Baby Bash Super Saucy" written on the second CD in the photo. Baby Bash is the name of an American rap artist and his song that the girls had been listening to is titled "Super Saucy". The words of this song which expresses his love for a beautiful woman are full of metaphor and at first reading they seem innocent like the other songs. This song does not seem to have any lyrics that parents would object to or any themes of violence. However, when the words are read more closely, it seems the singer was 
offering "crystal" to his girlfriend, this being a term for crystal methamphetamine which is also known as ice or speed. This is a highly addictive and potentially dangerous drug that is used in clubs to give a high energy rush. It can cause severe health problems and death. It is possible that the songs that the students are listening to and writing down have layers of meaning that may not be obvious to the listener or reader but being able to understand and use the terminology will make the students part of a particular community of practice which may exclude others. Lewis (1998, cited in Alverman \& Heron, 2001) writes that in classrooms and communities popular culture is related to the social and cultural identities of groups as well as to allegiances and to exclusions from the groups. The researcher did not find out how the values of this song might be interpreted by the students but it may be that good presides over bad as the young woman in the song did not want the crystal, preferring a drink of lime and Corona.

As with other forms of popular culture music provides extremely wide choice and the girls' selection of music described above contrasts with that of two boys. Paulo and Tavita each had a photo of a wall poster of the African American rap star 50 Cent and they each said they liked listening to him on the radio. Tavita explained that his photo was taken in his older sister's house. They both said 50 Cent had "Good songs" and Tavita said he liked the way he raps. 50 Cent is well known as a "gangsta rap" singer, "gangsta" being African American vernacular English for the word gangster. Gangsta rap is in the genre of hip-hop music and reflects the violence of American inner city living for young people. Marsh and Millard (2000) write that although gangsta rap has been criticised for the "misogynistic content of some lyrics" (p.167), much other material in popular music promotes the same misogyny.

Some rap music also includes fantasies of violence against white people and policemen (Marsh \& Millard) but may be more fantasy than serious.

It was interesting that these two boys chose such a singer to represent their taste in music as the values of gangsta rap seem to contrast strongly with the values of the educative institutions which mediated their learning. They also each selected Playstation as their favourite spare time activity and they both liked fighting games. Both boys said that they attended church regularly, with Paulo also attending Sunday school each week, and they both read the Bible at home. In particular, Paulo's photos 
and discussions suggested that he accepted the values of his religious education. One photo showed him reading the Samoan Bible because he said he wanted to read it while another showed him reading a prayer book which he said he did so every morning before school. He read his mother's books which had a moral or message in them and he spoke about Biblical teachings. In light of this it seems a strong contrast in values to admire this artist who represents the values of gangsta rap.

While the values of rap culture appear to be in conflict with those of religion, two of the boys in the study offered a positive interpretation. Their explanation in an interview is useful in foregrounding the personal plane. Their joint explanation of why they liked 50 Cent offers us a view through their own eyes of their participatory appropriation (Rogoff, 1995) as they make sense of this genre for themselves. When they were asked if they ever listened carefully to the words of raps and write them down, Tavita replied, "Sometimes, cos he says where he was born and raised. He talks about how he grew up. His dad left him and his mum and he grew up with his mum and his mum suffered. He was rapping about how he was a bad boy." The students were asked if the singer was trying now to be good and Tavita replied "Yes. He is trying to express what he was doing to his mum." The researcher was interested to hear why the boys felt so positively about this singer and they explained that they liked his message and felt that he was trying to be better in a Christian type of way. This explanation seemed to reflect their participation in appropriating aspects of this popular culture, rather than merely receiving a transmission of it (Rogoff, 1995) and it demonstrates Wenger's (2006) concept of community of practice in that the boys seemed to be expressing their original interpretations of the artist rather than simply learning the curriculum of rap.

The first photo is a close-up of 50 Cent with his arms covered in tattoos but the camera has missed his face. In Paulo's photo there are two posters side by side. In one 50 Cent is wearing three chains with crosses around his neck. The impression gained from the posters is one of aggression but the symbols of Christianity appealed to one of the students. When the boys were asked what was it that appealed about the poster, Tavita replied "The cross". Paulo explained the other poster which showed more than twenty faces of African American men as "Old rappers." Both boys knew about these and one simply said "Gang members." When questioned about the wording on the poster, Paulo read out the words, "Parental advisory explicit lyrics" and explained "It's got bad lyrics." He was able to relate this rather technically written warning to his own 
experience. The researcher asked whether that was to warn people or was it to try to make it attractive to people to listen to, and Paulo said it was, "to warn people cos someone might get it for their kids." When asked if he would listen to something like that there was a long pause and when asked if he would be allowed to listen to it at home, Paulo replied "Yep. If my mum thinks it's not good enough she will stop it. If it's got foul language or something." This was a similar attitude to that expressed by teachers in the school who said they would not allow students to play certain music CDs which contained swearing or sexual content.

Both boys agreed that rap stars try to act in a cool way and it may be that they are influenced in their identification with these rap stars by the choices of older members of their families whom they regard as cool in a way that is similar to the younger children described by Dyson (2003). The six-year-old African American children in her study appropriated songs that were experienced in family activities, and which were sometimes aimed at teenagers. She writes that the six-year-olds were learning these songs in various places including in the company of adolescents whom she describes as "cool people whom children admired" (p339). The children knew that these songs were not intended for them and their caregivers expressed concern about the content of certain songs for teenagers, but they identified with these songs.

\section{Literacy for entertainment and pleasure (iii) Books and magazines}

Books and magazines are a field of popular culture which provide entertainment and pleasure for children as they do for adults. The sites where these were read were the home, the community libraries and the school. Their use in the community libraries is discussed in Chapter 8. The data on students reading books and magazines illustrate a connection between the sites of school, family and neighbourhood as they share common values and curriculum. The curriculum included knowledge of authors, as well as knowledge of series of books, their themes and their characters. The teachers include the teachers at school and the librarians who are discussed in Chapter 9. The students took a total of 37 photos of books (apart from school and Sunday school type exercise books) which comprised twenty six percent of all the photos. The majority of photos (25) showed fiction, while only five showed nonfiction with seven showing the Bible or other religious books. 
The data indicated that the students recognised that reading books for pleasure is valued in the sites of school and family. In the interview schedule for meeting one (Appendix A) the students were asked to list three choices for what they most liked to read in their own time with their favourite first. The girls' first choices for reading materials were: Horrible Histories, Baby Sitters Club, Meg Cabot, mystery books, Bible, magazines (for example Dolly), Jacqueline Wilson. The boys' first choices were: Pop-up books, chapter books, Bryce Courtenay, chapter books, Harry Potter, Harry Potter, I Spy. In the interviews the students said they read books from school, Duffy books awarded at school, books from the local library as well as their own books. The interviews added to the information about texts that could be described as popular culture as the students included novels (mentioning series such as Goosebumps, Harry Potter and Gemstones), picture books, comics and magazines aimed at teenage girls.

In the interviews individual students explained their reading preferences which contribute to their construction of identity. For example, a girls' novel that appealed to Maria was seen in her photo of a friend in the classroom reading a novel at a desk. The novel is Girls in Tears. She explained... 'It's by Jacqueline Wilson. It's about, like, if you get like, dumped by your boyfriend. It's about a girl who gets dumped. Every chapter has a different subject about how girls cry when something bad happens". Maria said she likes to read these books too. Iosefa stated that he liked to read books by Bryce Courtenay, "The Power of One. That's my best book" and J.K. Rowling (author of the Harry Potter series) "I'm reading the sixth part now." He also said he had seen the movies based on the novels.

One of Elisapeta's photos (Figure 8) taken in the living room of her home illustrates how books are valued in her family. The photo shows her older sister looking at a book cover and in the background are two bookshelves. Elisapeta seemed to be proud to share information about the number of books in her house and made it clear that books were valued in her family. She described her family having several other bookshelves including those for her cousin who has "her books from uni" and "my mum and dad have a desk and they have most of their books there". The photo also shows her younger brother's reading award from school which is displayed on the windowsill along with Elisapeta's sports trophies. An interesting feature of this photo which was also seen in several of the other students' photos of their homes is 
the display of articles from their Pacific homeland. On the wall are woven hats and shell necklaces and on the bookshelf are woven baskets.

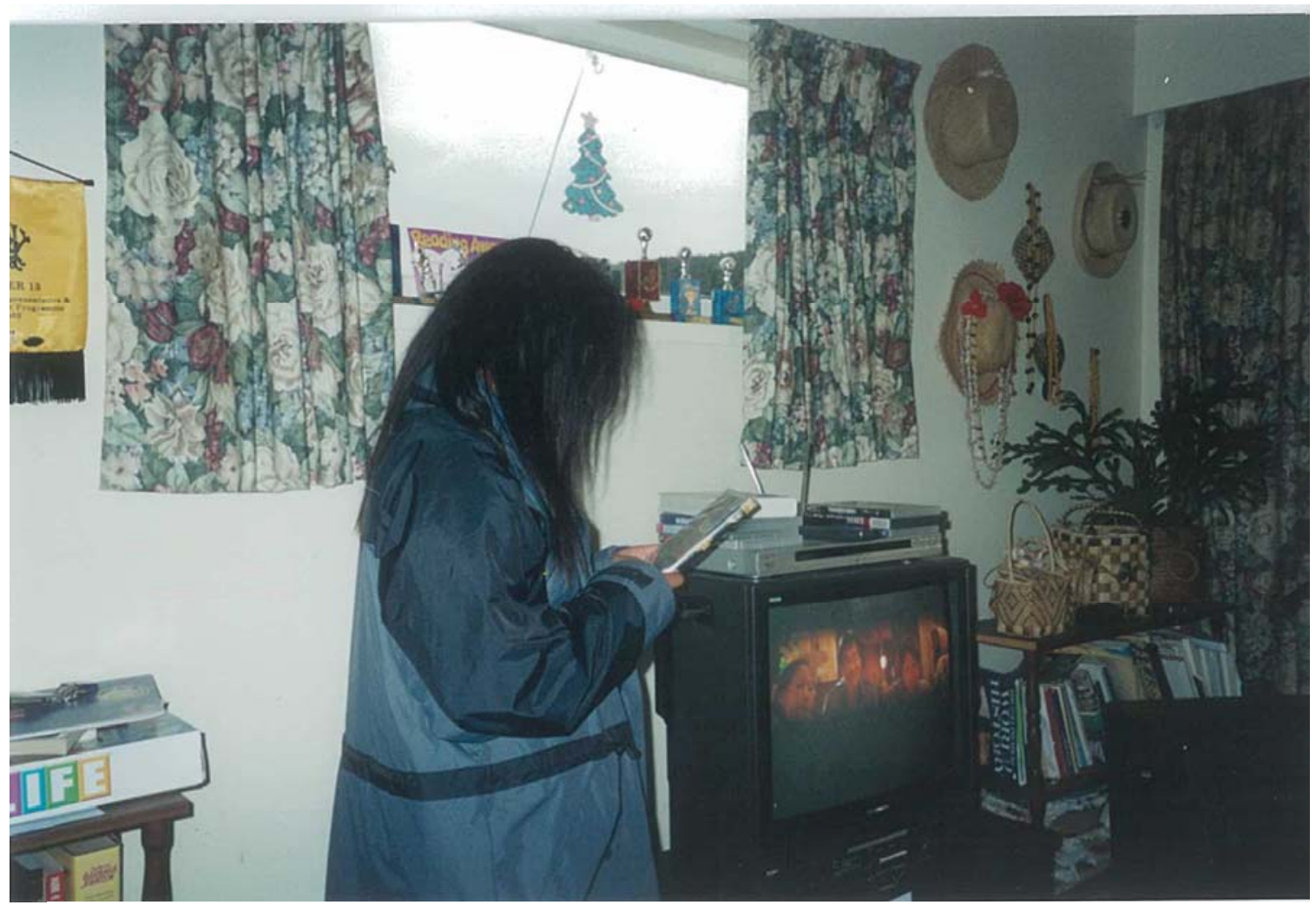

Figure 8: Reading for pleasure at home: Elisapeta's older sister reads a book cover in the living room

The students' comments illustrate that reading for pleasure takes place at home and school and the data suggests that it is valued in both sites. A photo of Eseta reading the book titled The curse of the cheese pyramid was taken at school reading for pleasure in a quiet part of the classroom. "I was reading like how I read daily." She said that reads at home too... "All the time". Hana also said that she reads at home every day. She likes books by Meg Cabot which she gets from the community library. Sara listed the novels Sheena and Her Deadly Games and The Lion, the Witch and the Wardrobe among the books she was reading.

Magazines are a field of popular culture (Marsh \& Millard, 2000) and, along with brand-name fashions and music, are also instantly recognised as codes of identity (Kenway \& Bullen, 2001). Four girls in the study described their favourite magazines and it can be inferred from their comments that they choose to identify with these examples of popular culture for their coolness and sophistication. Some of the magazines are like junior versions of women's fashion magazines and contain 
glossy pages of glamour and fashion. Maria gave her first choice of reading materials as Dolly magazine while Apekaila gave her second as Girl magazine. Two other girls, Eseta and Sara produced photos which showed girls' magazines. Eseta explained that she was reading a Dolly magazine. In her journal she recorded "I was reading an article of food you should be eating every day." The two students explained that it is a magazine which is aimed at teenage girls. When asked what appeals about Dolly, Eseta said she likes the latest fashion and the fun quizzes. In Sara's photo a Total Girl magazine is prominently positioned at one end of the top shelf and looks as if it has been positioned for the photo. She pointed out her CDs, tapes and a large English dictionary. Sara agreed that Total Girl magazine was a favourite of hers and she has many of them. She said she chooses it and her mother buys it every month or so. She said she has other bookshelves of books but the photo shows her favourite. In her journal she wrote that she liked reading magazines such as Girlfriend, Dolly, Creme, Girl Talk, Cosmo and Vogue. In her journal she included a number of entries of reading magazines: Crème, Total Girl, Vogue, Elle, fashion journal and Women's Weekly. A number of these magazines are included in the young adult section of the library and this is discussed in Chapter 8 .

\section{5/ Reading and writing to help organise students' lives}

Some of the literacies that took place within the family sites are those which help students to organise their lives and many of them represent the uses of reading and writing which are required by adults. The examples show how students are being socialised into particular practices which will help them to participate in society as adults. This participation requires more than knowing the skills of reading and writing but involves ways of interacting and valuing (Gee, 1996). The sites for these practices are family, the neighbourhood and the school. The curriculum consists of writing and reading letters and notes, writing in diaries to remind of upcoming events and to plan the use of time, filling in forms, and reading timetables and maps. The teachers are the students' parents, school teachers and sports coaches.

Simple examples of ways the students used reading and writing to help them organise their lives are the shopping lists and reading and notes as reminders such as "take sunhat". Sara's journal recorded many examples of reading and writing to help organise her life within the family. She wrote many texts to each of her parents and 
to her friends and read their replies. She wrote notes to her mother for example, "To say I was going to the library" and she read notes from her mother. She also wrote notes and emails to her friends and received replies. She recorded people's birthdays on the calendar at home and recorded the cell phone numbers for her relatives and friends. Some of these uses are similar to those described by Taylor (1983) in her study of literacy situated in the family where she collected examples of writing such as notes, lists and letters that were used by the families to help with the social organisation of their lives.

Another literacy use that was related to organising life that these students were being apprenticed into was filling in forms and some of them described how adult family members assisted them with this complex task. Being in a sports team and particularly being in a representative team required students to write on documents such as permission forms for trips and to complete forms that were concerned with the team uniforms. The International Adult Literacy Survey (OECD, 2000) describes the knowledge and skills required to find and use information in documents, for example, various types of forms, schedules, maps and tables and refers to this as document literacy. These skills are essential for active participation in society and they are part of the wider curriculum of society, not belonging to any one institution or site.

Several of the students in this study were involved in sport and several examples of reading and writing within the family sites were connected to this. Examples they gave for reading included letters from sports coaches about teams, and reading forms which included information about upcoming trips, future matches and draws for sport. There were also maps to show how to get to matches. For example, Tavita wrote in his journal, "At basketball training we get given a sheet of paper that tells us where it's going to be and what time." Sara who was in a representative team had to fill in permission forms for trips quite frequently. In the interview she said; "I have lots of forms for sports and stuff. Last week we had to go away for an overnight stay for reps and we had to have permission forms and we had stuff about if we had any health problems or if we were taking any medication and that's real important". She explained that she received forms for uniforms too and further information about her team, "We get maps about how to get to the match, and we get draws, like what time our game is." She said that at every training the team members were handed a pack 
of this information. Filling in the form for the trip was not straightforward so her mother assisted her. She explained that both she and her mother filled in the form “Cos I didn't know if I was taking any medication”.

Similar permission forms were required for school camps. Iosefa said he had filled in his one by himself: "When I had to go to school camp last year. Just like when she said how we had to fill in if you are taking any medicines if you have any sickness and if you can swim a hundred or fifty metres". Another context for filling in forms was described by Paulo who wrote in his journal "I write to deposit money for myself."

Students described other uses of literacy to help organise their lives. These included seeking information about their sports teams in the local daily newspaper to find out what time their team's game is and where it is to take place, keeping personal diaries, planner diaries for school, and reading and writing to maintain social contact with family and friends. Some students described reading emails and cellphone text messages. Only three of the students said they used cellphones with two students having their own cellphone. This is a decile 2 school and it may be less likely that 11 and 12 year olds will have cellphones in this setting. Sara recorded in her journal that she used her cellphone frequently for text messaging her parents and friends. Uses of writing in the home included writing notes/messages, letters (overseas), birthday cards and writing text messages. However, there were only a few examples of each of these.

\section{6/ Finding and using information}

Other uses of reading and writing in family sites were related to finding and using information. The sites included the students' homes and the homes of their relatives. The curriculum is similar to that of school in finding and using information from various sources including newspapers, dictionaries, recipe books and the Internet. The teachers included the students' parents and older relatives, as well as resources such as dictionaries, other books, television, written instructions for board games, and the Internet.

A literacy practice that is sited in the family and a part of the culture of many families is that of following recipes. Two girls who enjoyed following recipes to cook mentioned adult family members who modelled the practice. Eseta had a photo 
of herself following a recipe making a chocolate cake in the breadmaker. She said that she likes looking through recipe books and cooking and would cook things with a recipe once a week. Hana also enjoys cooking, especially desserts. She said that sometimes she would follow a recipe in a book but an alternative was to "get my cousin to help me. They will tell me what to do". Neither of these girls said that they would write down a recipe. Hana explained that they do learn about cooking at school but they also had adult models in the family. Eseta said that her aunt made her own recipe book by collecting recipes including those for Samoan food which she wrote down. According to Hana her mother sometimes writes out recipes and cuts them out of magazine and puts them in a book.

One measure of literacy use in families is the reading of newspapers. Newspapers form part of the text environment that many children are socialised into in families and are important as they provide the opportunity on a daily basis for children to see their parents or other family members reading for information and pleasure. For most of the students in this study, their family literacy practices included reading the daily newspaper. A number of them presented data that showed adults reading the paper and sharing information from the paper with the students. Ten of the students included the local daily paper in their photographs or in their discussions arising from the photos and several journals made entries about newspapers. Five of the students said they read the paper, although this might be for only one section such as sport. For example Samasoni said that they get the paper at home "sometimes" and his photo showed his mother reading the daily paper in the community library. Repeka took a picture when she visited her aunt's house of her aunt reading the newspaper, "...reading out an important message to me and my cousin." Not all the newspapers were in English. Eseta's photo showed her reading her grandfather's Samoan newspaper The Samoa Post at home and students described their families reading the church newsletter which is written in Samoan and English, as well as the school newsletter which is written in English.

Several other examples of reading for information in the home were described by the students. They used English, Samoan and Māori dictionaries such as those used at school for finding information in the family site. An example of everyday use is illustrated by Elisapeta's photo of one of her older sisters reading an advertising brochure in the living room at her home (Figure 9). 


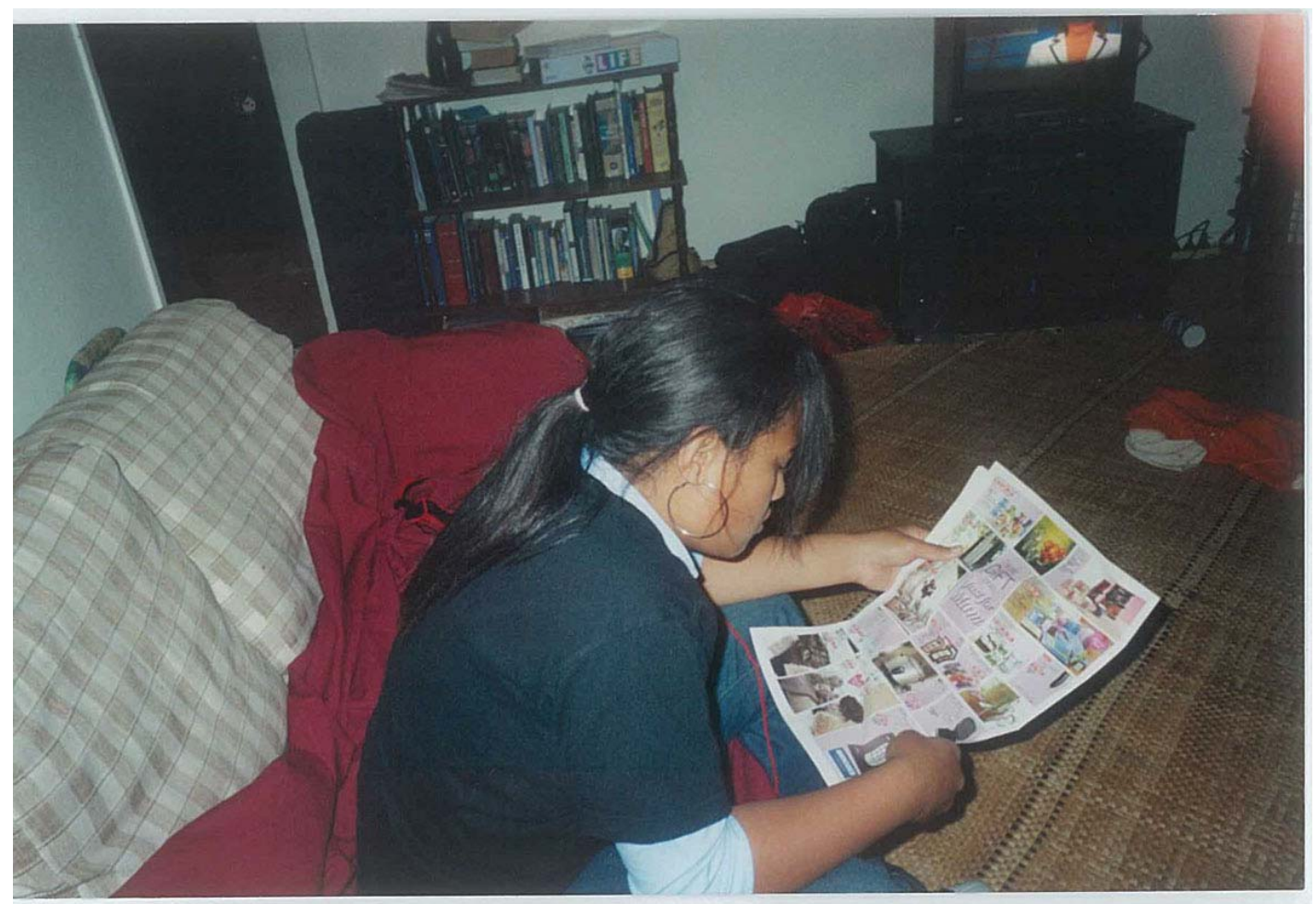

Figure 9: Reading for information in the home: Elisapeta's older sister reads an advertising brochure for Mothers' Day

The photo was taken just before Mothers' Day and the brochure is advertising Mothers' Day gifts from a hardware chain. This prompted Elisapeta to say that she delivered advertising brochures but only read the interesting ones like Rebel sport to look for sports shoes. Like Figure 8 this photo shows one of the bookshelves described by Elisapeta and an interesting cultural feature is the woven mat on the floor.

Other examples were reading information in magazines about good diets, and reading the contents on food packaging. Several of the girls provided examples of their interest in checking for the ingredients of food. Several girls were particularly interested to find out the fat, sugar and salt content of the foods they ate. Elisapeta said that she and her older siblings and her parents do this. When asked what she might be looking to avoid, she replied, "It's not to avoid but not to eat a lot of, like sometimes when I get my money I get a whole lot of junk food but now I know what to get. Basically the ones I look at are fat and sugar, and sodium." She said she also looks at the serving size. When she was asked who taught her to do this, she said she learned this at school and from her mother. It appeared that television was also a teacher of this aspect of literacy curriculum, reading for information in order to make 
good choices over what foods you eat and how much you eat. Apekaila and Maria were trying to avoid eating too much fat and salt and they said they learned about this through watching the television series Eat yourself whole. This was a series fronted by a dietician who went into New Zealand homes to help overweight people change their dietary habits. She focused particularly on reducing fat and salt intake.

\section{Conclusion}

This chapter has introduced the first of the three major sites for students' out-ofschool literacy practices as revealed in the data. The major themes of literacy that emerged in family sites were support for religious uses, the maintenance of Samoan language and culture, nurturing school type reading skills with younger siblings, supporting school literacy, literacy for entertainment and pleasure, literacy to help organise students' lives, and to find and use information. The family sites are described as of great importance in mediating students' literacy acquisition and the chapter has introduced the concept of the family as part of a configuration with the other significant sites of church, neighbourhood and school. The chapter has described how for some practices the values and pedagogy are mutually supportive while for others there is conflict of values between the sites. The examples support Cremin's (1976) claim that curriculum includes not only technical skills but the social skills to carry out the activities with others according to the expectations and routines of the institution.

Chapter 3 introduced the concept that how the individual uses language contributes to construction of identity (Gee, 1996) and how individuals as members of society may have multiple identities which reflect their association with various groups. The insider views of literacy use described in Chapter 6 contribute to our understandings of how the identities of these Pasifika students are constructed in family sites and these are built upon in the following two chapters which explore the sites of church and neighbourhood. 


\section{CHAPTER 7}

\section{Sites for Church Literacy}

\section{Introduction}

This chapter is the second of three interconnected chapters that discuss the students' sites for literacy and focuses on the educative sites for literacy of the church. It describes the goals, curriculum and teachers in sites of church-related literacy practices and provides an insider view through the students' and church representatives' explanations of literacy practices in these sites. Through the students' own eyes it can be seen to what degree they have appropriated knowledge about church-related literacy practices. The data indicate that the church and Sunday school are important educative sites for literacy in the lives of these students, and through their strong connections with the sites of family and school are powerful mediators of students' literacy practices. The findings illustrate the significance to the participants of the Bible, both the Samoan and the English versions, and their community's literacy practices which are linked to the Bible. For people in this Pasifika community, the church is a significant mediator of literacy in their lives, as they attend church frequently and place a strong value on their children's attendance at Sunday school.

This chapter gives firstly a brief description of the church sites, the teachers and the curriculum for church-related literacy (after Cremin, 1976) and then a description of this community's frequent church attendance, which is a value of the community that is reflected in its members' literacy practices. It then describes in turn five areas of cultural practice in literacy which emerged to support the community's values. These practices are described in some detail in relation to Rogoff's (1995) personal, interpersonal and community planes of analysis. The practices are:

1. Studying the Bible to learn the Christian doctrine

2. Accurate oral reading of the Bible for an audience

3. Reading passages of the Bible to memorise and recite them to an audience: Tauloto / memory verses

4. Maintenance of the Samoan language through religious practices

5. Assessment of church curriculum through Sunday school tests and exams. 


\section{Sites}

The data gathered from the students' photographs and interviews and the interviews with the church representatives show that church and Sunday school are important sites for literacy for many of these students. Twelve of the fourteen students attend Sunday school and of these, half attend the Sunday school associated with the church. As well, for many students the home is a site where church-connected literacy takes place and a very strong connection exists between these family sites and the sites of church and Sunday school. In Cremin's (1976) terms these sites work together in a configuration to support the literacy practices of the community. Examples of family literacy that support religion were outlined in Chapter 6 under the heading Teachers and curriculum of the family but generally these practices are described in more detail in this chapter. Descriptions of family situated practices are also included in this chapter alongside church and Sunday school situated practices as they are closely interconnected, and have similar values and pedagogy. Figure 4, which illustrates the configuration of family with other sites, shows the overlapping literacy uses and curriculum of the church with family and school sites.

\section{Teachers}

Many teachers guided the students in these valued church-related literacy practices in various sites. The students learned from Sunday school teachers in six different Sunday schools. In the churches they learned from their priests and ministers. In the family sites the teachers were their parents and in some cases their grandparents and other family members. In the school, they learned from their teachers and in all of the sites the teachers were also the written texts that they used. These consisted of the Samoan and English Bibles, prayer books and other texts such as activity books and books with a religious theme.

\section{Curriculum}

The data gathered from the students and church representatives indicated that the curriculum of church and Sunday school is powerful in supporting some practices and disallowing others. Rogoff's (1995) community plane of analysis allows an examination of how students advance their skill through apprenticeship in culturally organised activities that are supported by both church and family and, to a certain extent, the school. The relationship between these institutions which support each other through similar pedagogy and values illustrates Cremin's (1976) concept of 
configuration where the relationships between institutions is consonant. Although this study did not investigate school literacy, the school is part of the configuration and the overlapping practices are included here. The curriculum in the sites of church, Sunday school and home is offered in both English and Samoan, although this is not for all students. (The Niuean, Tongan and Tokelauan languages were listed by individual students as being used too, although to a much lesser degree.) Samoan was also taught in the school to some classes and students used Samoan in the playground. Students across the school were taught to read prayers in Samoan and the other languages that represented the different cultures. At school, students studied passages of the Bible in English to learn the Christian doctrine, and at times read the Bible to others. The key text for the curriculum in all the sites was different versions of the Bible with data from the students revealing that both English and Samoan Bibles were used in the church, Sunday school and family sites. The principal of the school explained that the Sunday school had purchased the same Religious Education support books as the school (in English) and while these were used in English at school, they were discussed in Samoan as well as English at Sunday school.

The church promotion of literacy (for example in protestant Sweden) described in Chapter 2 provided a background that emphasised how, historically, literacy was used as a tool of social and cultural hegemony with the purpose being to promote social morality and the values of the state religion (Gee, 1996; Graff, 1987b). For many people in modern times, the church is still a powerful institution that transmits its values and mediates learning and the sites for this church learning are still the church and family sites. Included in the ideas about church-related literacy practice which link to the literature and form a valued part of the curriculum of this community are the value of people having access to the Word of God through the written Word being accurately read aloud to them and the value attached to people being able to read the Word of God directly for themselves. A link that this study makes from the past to the present is the great cultural value attached to having God's Word recorded in a book (in this case the Bible) and a feature of this is people being able to have direct access to the Word of God through the book rather than having to rely on another person's interpretation. These are values embedded in the practices that the students are apprenticed into in the sites of Sunday school and home as young members of the community. In considering the concept of literacy it 
appears that reading and writing do not stand alone as an explanation for literacy either in the past or at the present time. The oral mode of language is intertwined with the reading and writing processes of literacy (Graff, 1987b; Street, 1984) and this is the case with the church-related literacy practices described by the Pasifika students and church representatives in this study.

The curriculum for church included reading the Bible aloud to an audience (in Samoan and English) and learning tauloto which is a traditional Samoan practice that involves memorising and reciting Bible passages in Samoan or English. The Samoan word tauloto as a verb means to know by heart or to memorise and as a noun it means poem or poetry (Milner, 1993). Its significance as cultural practice is described later in this chapter. For Sunday school the curriculum included reading and writing Bible stories, singing hymns and songs in English and Samoan, memorising Bible stories and writing them in Samoan, and understanding the Biblical passages. Many of the literacy practices in the Sunday school are similar to school practices of reading and writing although a cultural difference is that some of these practices involve using the Samoan language rather than English.

The following examples of reading and writing in Sunday school and church sites were described by the students and church representatives.

\section{Examples of reading in church sites}

The examples of reading represent the curriculum of this community and illustrate their social practices using both Samoan and English languages, some of which involve the students in guided participation as in a school setting. It seems as if there is some teaching of processing text (described in ELP 1-4 and ELP 5-8 as integrating the sources of information (for example, Ministry of Education, 2003a, p.31) and for comprehending text (also described in the ELP handbooks). Examples included:

- Reading passages from the Bible aloud to an audience (Samoan and English)

- Practising reading to memorise passages of the Bible: tauloto routine (Samoan and English)

- Reading passages and discussing in a group as in guided reading at school (for example Bible stories) 
- $\quad$ Reading prayers (Samoan and English)

- Independent reading as in silent reading time at school

- Reading words of hymns and songs on a screen and in books

- Reading journals with stories about Jesus and about families

- Reading and writing in Religious Education books. This book is given to the Sunday school teacher by the priest.

\section{Examples of writing in church sites}

Like the reading uses, these writing uses illustrate particular social practices within meaningful contexts and used both English and Samoan languages. While some of these are independent writing activities, most of them involve guided participation through interaction with a teacher. Writing activities that are taught in the Sunday school included the following:

- Writing stories. These are like the stories written at school. Some are related to the Bible but not all are on Biblical topics (Samoan and English)

- Writing answers to questions "About the Bible and Jesus" (Samoan and English)

- Cloze exercises where a word is missed out of a sentence and the students select an appropriate word to insert. These tasks are in some Sunday school exams

- Graphic organizers where students take information and put it in a diagram, to demonstrate their ability to classify the information. These are used in exams and in teaching at Sunday school

- Writing dictation: as the teacher reads sentences from the Bible the students write it down

- Writing synonyms and antonyms in Samoan

- Writing a summary and note taking. The teacher reads a verse from the Bible and the students write a summary

- Answering written questions in exams and tests (Samoan and English)

- Writing a poem/a solo (Samoan and English)

- Writing definitions of words (such as Trinity) 
- Writing in Religious Education books in English and Samoan. The students have tasks with questions to answer

- Copying passages from the blackboard.

\section{The purpose of the curriculum}

The sites of church, family and school share aspects of curriculum as well as related values and pedagogies, and a key purpose of the curriculum was to keep the community identity strong. The overlapping of sites is an illustration of a consonant relationship in the configuration of these educative institutions as described by Cremin (1976). The data revealed two aspects of the shared aim of teaching the Christian doctrine which illustrate how teachers in these sites mediate the students' learning. The first aspect is that religion, strongly supported by the family, seeks to maintain the use of Samoan language in worship through reading, writing and speaking in Samoan. Speaking is included in this study of literacy as reading aloud of written texts and recitation of memorised texts are valued practices in the community and are linked to the written word. There is a strong value placed on individuals reading the Bible to enable them to have direct access to the Word of God and on reading to the congregation in order to proclaim and share the Word with others. The students were asked, "If you write in Samoan, where do you do this and what sort of things do you write? Several of the students stated that they wrote in Samoan in church-related literacy, this being in the sites of Sunday schools (five students) and the home (one student). One student wrote in Niuean at home. Repeka said the teachers at Sunday school taught her to write in Samoan at the age of 6 or 7 years. The use of writing was often connected with exams at Sunday school or recording memory verse.

The second distinctive aspect of church sites for literacy is the maintenance of traditional cultural pedagogy which is supported by the family. The most common example of this is the practice of tauloto or memory verse which involves memorisation then recitation as a performance for the congregation in the church. The practice of reading the Bible aloud clearly and with perfect accuracy to the listeners is also valued and supported by both family and church. These connections of similar values and practice between church, family and school are an example of what Barton and Hamilton (1998, p.10) describe as literacy practices which are patterned by social institutions and power relationships. The descriptions of using 
Samoan language provide examples within the context of the church literacy of individuals aligning themselves with a particular community of practice as described by Wenger (2006). They describe dominant practices which can be seen as part of institutionalised configurations of power and knowledge, and which are embodied in social relationships. While these practices are not dominant in New Zealand society, it appears that they are influential over the Samoan people of this community.

These literacy practices help to illustrate that the students' cognitive development is embedded within the context of social relationships and sociocultural tools and practices as described by Rogoff (1990). The examples from the students and church representatives help us to see what Rogoff refers to as cultural variations in the goals of children's development and the means by which they achieve a shared understanding with others in their community in guided participation as these "guides and companions" mediate their learning “...through explanation, discussion, provision of expert models, joint participation, active observation, and arrangement of children's roles" (p.8). Chapter 6 which described family sites for literacy practices, this chapter which is concerned with church sites, and the following chapter which describes neighbourhood sites, present data that provide evidence that the community's tools of literacy practice are situated culturally, institutionally and historically as described by Wertsch (1998).

\section{Church attendance}

In this explanation of social and cultural practice it is appropriate to focus initially on the community plane of analysis (Rogoff, 1995) in order to consider the values of the community to which the students belong and to describe the cultural tools that mediate the learning of its members. The participants in this case study are part of a community whose dominant values include regular church attendance, and many of this Pasifika community's cultural practices relate to the church which provides a significant social context in their lives. An illustration of this is their more frequent attendance at church and the weaving into church practices of traditional cultural values. There is also evidence of family support for church attendance, their children's attendance at Sunday school, and the church-related practices which occur in the home. 
The time commitment to church by most of the students in this study (whether they had choice about this or not) was considerable. Data from the interviews suggested that church and Sunday school are a significant part of these students' lives and represents a large commitment by the families. They were asked How often do you go to church? and twelve of the thirteen students present indicated every Sunday with some attending more than once a week. Replies included "Every Sunday, sometimes Tuesdays, every Friday," "Every week Friday and Sunday" and "Saturdays and Sunday". One student explained that he attends a morning service and an afternoon service at church as well as morning Sunday school. Of the fourteen students in the study twelve attend Sunday school with six of them attending the Sunday school which is associated with the school church. When they were asked How often do you go to Sunday school? some indicated that they attended less frequently than church with four attending most or every session and seven indicating not always or sometimes. Because of this regular church attendance the church and Sunday school emerge as important sites of literacy use by the Pasifika students in the study, providing many examples of the distinctive social and cultural practices of the community into which the students are apprenticed (Rogoff, 1995). The connection between the institutions of church and family demonstrates that literacy as a tool of cultural knowledge of the church is also valued by the family, and the following examples help to illustrate some of the values and structures that the students are apprenticed into by their community.

Almost a century before the Pasifika peoples arrived in the community in which the present study is based, there had been a pattern of Irish immigrants settling here and their children attended the same school as these Samoan students. Lineham (2003) points out that "In the Catholic church, where once Catholicism played such a role in a strongly Protestant culture to maintain Irish values, new ethnicities now use this structure, even in the absence of particular endorsement from the church" (p.202). As outlined in Chapter 5, the many churches in this community play an important role in supporting the various peoples who are immigrants or descendants of immigrants. This reflects Cremin's (1988) description of immigrant communities in New York whose churches, synagogues, temples and mosques each brought together clusters of families who aimed to preserve a particular way of life. They formed configurations of education that became "teaching arms" which were "seeking to preserve particular traditions at the same time that they mediated the influence of the 
dominant American culture" (p.576-7). Many of the immigrants of different cultures who came to live in this community had the same idea, including the Pasifika people.

As Chapter 2 outlined, church going has been in decline in New Zealand (Ward, 2004) but for the participants in this study, religious belonging seems to be a key aspect of their social and cultural identity and regular church attendance is part of this. Church-going has been in decline in western countries particularly since the 1960s and New Zealand reflects this trend. The 2001 census indicates that almost 40 percent of New Zealanders did not specify a religious affiliation, although the census did not collect data on church attendance. According to Ward (2004), in 1960 about 20 percent of the population in New Zealand attended church every week and 40 percent attended once a month. However, by 2000 attendance had been halved to 10 percent once a week and 20 percent attending church once a month. For many of the students in this study, involvement with the church was a significant part of their lives, with the church being a powerful mediator of their learning. Lineham (2003) describes the development of ethnically-based churches where "particular forms of religion are associated with the family in the maintenance of traditional culture" (p.202). This is because immigrants often feel isolated from the mainstream New Zealand community which they regard as a threat to the survival of their traditional cultures. For some, the maintenance in the church of the traditional languages is very important. Lineham writes that among Pasifika people the church involvement is not based on the nuclear family but rather on the extended Polynesian family structure, with grandparents playing a critical role in the maintenance of religion. The comments from some of the students in the study supported this view.

\section{Literacy practices related to the Bible}

The five areas of cultural practice related to the church sites for literacy are discussed in turn in the remainder of this chapter. The first section discusses examples of the students studying the Bible to learn the Christian doctrine. This is followed by discussion of accurate oral reading of the Bible for an audience, recitation of Biblical text, and the use of the Samoan language for religious studies. The final section discusses how tests and exams are used to assess the curriculum. This chapter explores each of these as they provide background to the values and expectations of the community into which these students are apprenticed and also provide evidence of connections between the institutions of church and family (and school). 


\section{1/ Studying the Bible to learn the Christian doctrine}

Studying the Bible represents an important shared value of this community and it is an appropriate one to introduce the other areas of cultural practice which follow this section. Reading the Bible was described by participants as an individual activity, joint activity and group activity and it can be analysed through each of Rogoff's three planes of analysis. Great significance is attached to reading and hearing God's Word as it is recorded in the Bible. The findings in this study support Zinsser's (1985) description of an important message about literacy being that the text (the Bible) has an authority of its own, and Tagoilelagi's (1995) description of the Bible holding an authoritative position in the beliefs of Samoan people. All the students in this study had ready access to the Bible at home. Five students said they had their own Samoan Bibles, five had English Bibles and three had both Samoan and English Bibles. As well, comments from several students indicated that their families had multiple copies of the Bible. For example, Repeka said she had three Samoan Bibles which had been presented to her for her success in exams at Sunday school, when she was 8, 9, and 10 years old. Ioane said he has a Samoan Bible when he visits his grandfather and grandmother's house and he has an English Bible too, while Mareko commented, "My dad keeps heaps of Bibles." (These are Samoan Bibles). In this aspect of the church curriculum, clearly the families supported the church.

When the students were asked to represent their own interpretations of literacy, reading and studying the Bible emerged strongly in the structured interviews, in the written answers to interview questions, in journals and in the photos. Eight of the students' photos showed people reading the Bible while two photos showed a Bible by itself. Some of the photos seemed to be posed to represent what the students valued. For example, Maria set up a photo of four girls reading Bibles at school after class and when asked why they would choose the Bible as the subject for the photo, her partner Apekaila replied that it was set up as an example of what they do read.

Several students represented Bible reading as an individual activity and one which was practised regularly in their lives. Their comments about this and their descriptions of having their own Bibles help to foreground the individuals through the personal plane (Rogoff, 1995). For example, Sara recorded five entries in her journal that she had read a chapter of the Bible at home. Paulo illustrated that he read the Bible at home by explaining the photo of himself reading, "I just read it 
because I want to read it." He said that his parents taught him to read in Samoan. Another example which appears to be posed for the camera is Tavita's photo of his sister holding the Samoan Bible close to her face as she reads it. He said: "My sister was just reading the Bible because she goes to Sunday school and she has probably got like, stuff, like homework." He said that his sister would read the Bible often at home but he would not read it that often. Two of the students' photos related to prayer books and Paulo described reading prayers by himself in the morning before going to school. He also wrote a journal entry "I was reading the Bible before I go to sleep".

\section{Guided participation in Bible reading and family prayers}

However, the majority of the data concerning church sites for literacy is appropriately analysed through the interpersonal and community planes. Most of the literacy practices which were connected to religion revealed the students participating with others in sociocultural activities. In most cases the individual generally tends to remain in the background of the analysis with the community influences being extremely strong, and the guided participation by teachers (in a wide sense) also being foregrounded. Guided participation in Bible reading occurred in the sites of students' homes and the Sunday school. During the interviews several students described their family practices of sharing the Bible and saying prayers together. These are examples of guided participation where there is mutual involvement of the students and their social partners with the interactions of others helping to set the task and guide the students (Rogoff, 1995) with the teachers in these interactions consisting of the students' parents, their siblings, grandparents and other relatives as well as the Bible. At times the students themselves were the teachers who were guiding younger children. Examples of joint Bible reading activities included reading to younger siblings and listening to them while they read. Eseta presented a photo taken in the dining room at home which shows her listening to her six-year-old brother who is reading a children's version of the Bible. She explained that he was reading his favourite story about his namesake (Figure 10). She said as well as listening to him read she also reads the Bible and other books to her brother. This photo is useful to represent the sharing of books with younger children that several of the students' photos illustrated and which was also described by the majority of the students. 


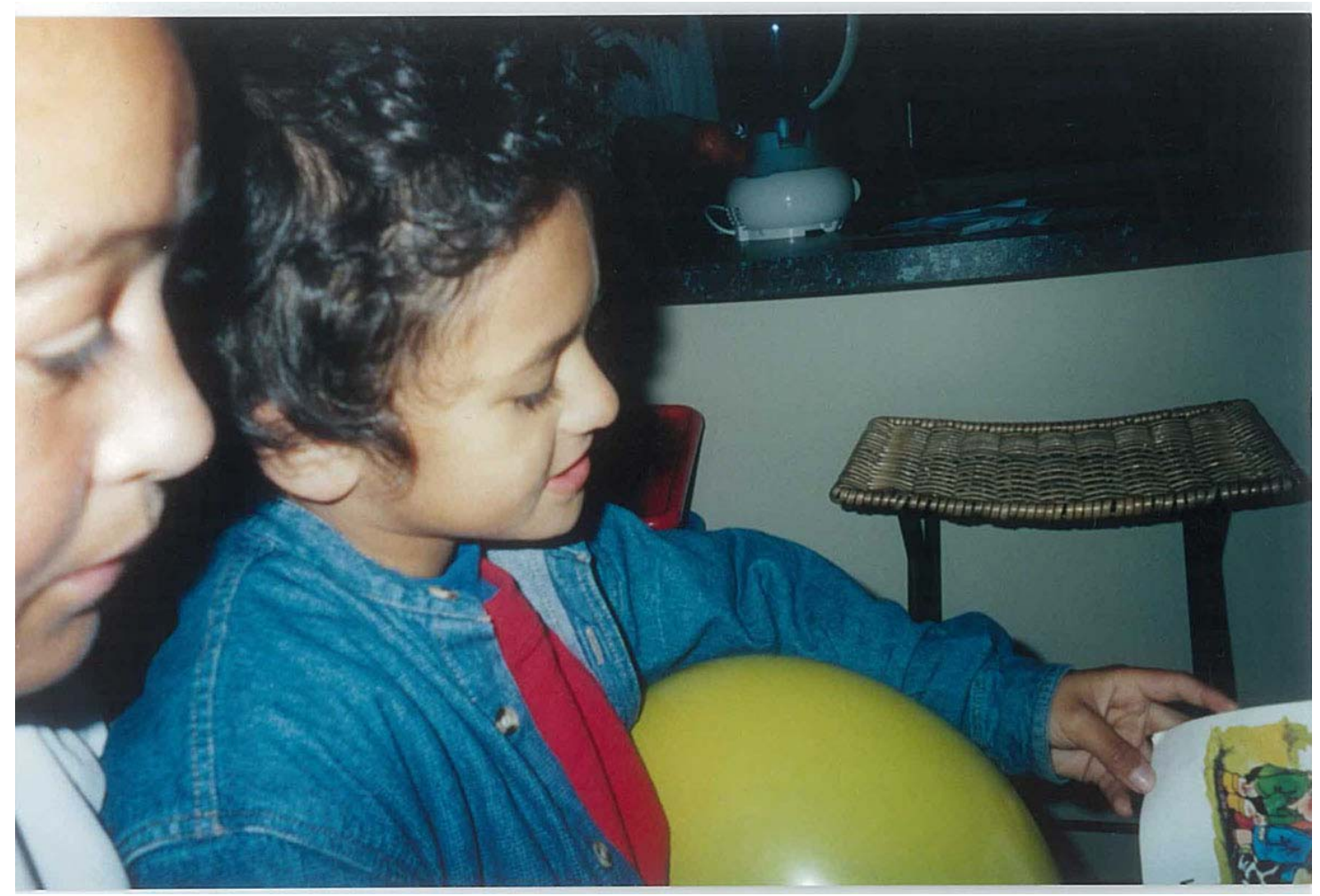

Figure 10: Eseta listens as her six-year-old brother reads a favourite story from the children's version of the Bible

Some of the students offered evidence of joining with other family members to say prayers. Iosefa explained that his family reads the Bible "At home when we do our night prayers" while Paulo wrote in his journal, "9 pm just finished our night prayer, whole family reading the Bible." Samasoni also talked about his family prayers. "Some nights we say an evening prayer. We say one set of prayers in English, one set of prayers in Samoan, one set of prayers in Tokelauan and one set of prayers in Latin." He explained that this activity takes place with his brother and his mother. His brother says a prayer in Latin which he learnt from a book his mother obtained at church, which appears to be a continuation of a traditional church ritual. After the prayer his mother says tomorrow's reading and they read it together from the Bible in English. Ioane said that he reads in Samoan at home to participate in prayers with his grandparents, godmothers and aunties. He said that his grandparents teach him in Samoan. They speak to him in Samoan and when he visits them he has a Samoan Bible which they help him to read "a little bit."

\section{Sharing the community's values}

These examples help to illustrate some of the shared values of the community to which the students belong. The social and cultural practices of literacy related to the church are imbued with the values of Christian doctrine and these values are shared 
within the families. They are examples of the social and cultural hegemony of the church described by Graff (1987b) in Chapter 2. Literacy is seen as a tool of hegemony used to promote the values of the church and is willingly and strongly supported by the families. The social networks such as Pasifika church connections are described by Biddulph, Biddulph and Biddulph (2003) as providing important opportunities for children's learning in the development of their cultural identity and the sense of belonging that contributes to their sense of wellbeing (p. v). A better understanding of these social networks, their values and of student identity by teachers could contribute to improved learning for Pasifika students in schools (discussed in Chapter 9).

It seemed that one of the values of the community was the act of belonging to, and participating in, the community and this was emphasised as being important by Church Representative B. When asked for his views on the contribution of the church to the literacy of church members he replied that it was very important, saying, "It's where we come together and become a community, a congregation. That is a family kind of thing to keep intact the family understanding." He spoke of the aim of "betterment of the community as a whole" and mentioned several groups that were part of the wider Samoan community which were associated with the church such as the choir, the youth group and the Mothers' League. The community's value in the Bible as a guide to living is represented in Maria's description of her grandmother's reading of the Samoan Bible. Here literacy is being used as a vehicle in an attempt to maintain community norms and values. Maria said: "She reads it every night and at six o'clock in the morning." Maria explained that her grandmother wakes up early, does some housework then she sits down and reads the Bible. When the researcher asked if her grandmother ever read the Bible to her, Maria replied "Sometimes when we are behaving bad, she says like you should come and read the Bible... if we are like, behaving bad, and she is reading a scripture that's about good children, and then she'll say come and read the Bible about good children".

I asked "To teach you how to behave?"

"Yes"

When asked “And would you do that?" Maria shook her head. 
These examples of Bible-related literacy illustrate the common value of the community's curriculum that is shared among the various sites for literacy in the community, being in a sense like glue that helps hold the community together. Although the students' homes were the most commonly mentioned sites for reading the Bible, the Sunday school was also described by several students. As in the home site, for some students this reading was in Samoan and for some in English. Eseta said they would have a topic and would read some of the verses, for example about Paul, with some children volunteering to read and some being chosen. Apekaila said at Sunday school she reads the Bible and some journals which contain stories about families and about Jesus. Church Representative A explained that in the Sunday school:

There is an emphasis on learning the Christian doctrine. The reading is very important as all the teachings very much strongly emphasise the sacred scriptures, the Bible. The readings themselves are very important and they start fairly early... The Bible is the main text but there are other books prepared by different agencies of the church.

The values of the community were also reflected in Representative B's comments that it was important for young people to learn to make judgements about the correct way to behave in society. He gave the example of swearing heard on television and videos, saying that sometimes:

\footnotetext{
They learn from the English side of things how to swear, so when they see a swear word written down in graffiti they know it and they should be taught to understand how to separate those words from their normal everyday language, because our children are not taught to swear. It's very important for our culture not to swear. I know there's a lot of children when they think that you're not hearing and you hear them talk amongst themselves and they do swear. It's not part of our language to swear.
}

This value expressed by the church representative is supported by some of the parents according to the students' comments, and is in direct conflict with the language of the raps described by some of the students.

\section{2/ Accurate oral reading of the Bible for an audience}

Two of this Pasifika community's valued uses of literacy that are strongly embedded within religious social settings are concerned with oral presentation which does not appear to be so valued by the wider (papalagi) community. Part of the purpose of the skills that are valued and taught in Sunday school and home is to give the reader and 
hearer direct access to the Word of God. Because His Word is recorded in a written source (the Bible), the oral delivery of the message must be an entirely accurate rendition of the text. This was revealed in the interviews with the church representatives and the students where it emerged that two language skills are highly valued as part of this community's literacy practice. The first, which is described in this section, is the skill of reading aloud with accuracy and clarity to an audience. The second skill is that of reciting memorised passages from the Bible (tauloto), and this is described in the following section of the chapter. These practices which are situated in the church, Sunday school and home form a key part of the community's conceptualisation of literacy and students learn these through guided participation with their social partners. These current practices which emphasise oral reading are reminiscent of historical practices described by Graff (1987b) and discussed in Chapter 2 where the Bible was propagated mainly by oral preaching and teaching.

As discussed in Chapter 2 it seems that, in the past, individual skill in oral language was more highly valued than it is today. This applied to societies that did not have a written language (such as the forebears of this Pasifika community), and societies that might be termed literate but where few people could read and write (such as the forebears of many in New Zealand's papalagi community). These people successfully handed on their essential knowledge from generation to generation without using the written word. Graff (1987b) describes how, before the development of the printing press, the Bible was propagated by oral teaching which was often collective and not the private and silent activity thought of today. It is interesting to consider that some churches and Sunday schools are sites where this collective and oral practice continues today and, while it is not exclusive to Pasifika peoples, this community provides a clear example of how this oral practice is still greatly valued. However, there is a major point of difference with the modern practice. Whereas Graff's audience required the Bible to be read aloud as the majority could not read it for themselves, it is likely that today's congregation in this community is sufficiently literate to read the text for themselves if they choose to do so. Oral reading has been appropriated by the community to become a valued cultural practice rather than existing as a necessity of communication, a practice that is supported by the institutions of church and family. 
Investigating these culturally and socially situated uses of literacy from an ideological perspective may allow us to recognise benefits of literacy that could be acknowledged by teachers in the compulsory education sector, and which could be built on as strengths in the classroom. The church representatives stressed the value placed by the community on students being able to read the Bible aloud accurately and clearly for the congregation. The interviews with the three church representatives provide a view through the community lens at how the students' learning is mediated through the church and Sunday school to meet the cultural expectations of the community. When asked if any particular skill in reading is emphasised, church Representative A replied, "To pronounce words clearly and correctly and how to phrase it as you are reading it aloud and to convey the message." The audience is the congregation in the church and the reader needs to "know how to pause so the people who are listening can understand and follow."

\section{Correct pronunciation then interpretation}

When asked how important it is that children are completely accurate when reading aloud, Representative A replied "The audience in the church is a big one so it is important to stress clarity." Clear enunciation and correct pronunciation are crucial aspects of this social practice as the church representatives explained. They described the importance of correct pronunciation in both Samoan and English. Representative C explained that an aspect of reading that she taught in Sunday school is the correct pronunciation of vowels, explaining that in the Samoan language the vowels are particularly important. Her description of her activities shows her in the role of the expert with greater knowledge as she mediates the learning of novices in their apprenticeship. She teaches the correct vowel sounds and then adds letters onto the vowels. "If children are struggling with a word I put it on the board and I split it up into letters and they practise it until they finally get the word." She also emphasises to the students the importance of understanding and reading the glottal stops. This was hard for the students and she explained her strategy "I always had different words with the same sign so they can practise." She then illustrated a connection between the sites of family and church. She considered that the teachers in the home and Sunday school were working towards a common goal when she acknowledged the role of parents in preparing students to read successfully in church: "When the families have their turn at reading the scriptures during the Mass, I am so proud that a lot of our kids are reading well. That's where it shows that the parents are behind the education of the child." 
This cultural practice emphasises complete accuracy in reading and an explanation that help us understand it is given by Tagoilelagi (1995) who writes that "the reading of the Bible has to be done in the most correct pronunciation" (p.74) although the readers can later share their interpretations of what they have read. However, while the emphasis on accurate oral reading and recitation in the Sunday school and church may help explain the children's skill in oral reading, it leaves questions about their comprehension of the text they are reading.

\section{Comprehension is taught}

The study sought to find out if in the Sunday school teaching oral reading was privileged over understanding what was read as the researcher had the impression from hearing primary teachers' comments that reading as a performance by Pasifika students was recognised, but that good oral performance often seemed to be at the expense of comprehending the text. In mind was the question of whether this correct oral reading might be under valued by New Zealand teachers and whether it might be a skill that could be used better in the classroom. The data for this small group revealed that their practice consists of more than performance to a receptive audience, because it involves children being taught to understand the text they are reading. The three church representatives were very clear that although correct oral reading as a performance is highly valued, the students must understand what they are reading. The church representatives' comments allow an exploration of this practice through the community lens as they, the teachers, explain how this part of the curriculum is addressed.

Representative B stated that when children are doing the memory verses they do understand what it is about, emphasising "I think it's very important to us for our young people to read and to understand, it's very, very important. To read aloud and to understand." He gave an example of agreement between sites towards a common goal when he stated that students may discuss the content of their memory verses with the priest, the Sunday school teacher or their parents. When asked if the students would discuss what the verse was about and understand it, his reply indicated that a teaching strategy in the Sunday school was to develop background knowledge in the students. He stated: 
That is part of their learning from the Sunday school and learning the Bible, so they are not just speaking out from something they don't understand. They speak out from something that has been taught. They are shown pictures of Jesus doing healing and Jesus raising a person from the dead and when they speak on those verses it's already been taught.

The importance of understanding what was read was also stressed by Representative $\mathrm{C}$ who said that although accurate pronunciation was important, she believed that it was more important for the child to understand the meaning of what was read. Other strategies were explained by Representative A who said that the Sunday school teacher might help to develop understanding by reading through and explaining the meaning while relating correct intonation to understanding: "They read through, then they explain what it means. Especially how to phrase it, where to pause, and the intonation of the voice. The teacher will focus on comprehension of the passage and ask questions." Representative A's comments indicated that the teacher's skill in phrasing questions was valued, "especially open questions rather than closed questions." Drama was another strategy used by some teachers to achieve this as students acted out Bible stories. As Representative B explained, the story would be related to the students' own lives: 'Its part of their proclaiming the gospel, sometimes we will bring out the Bible stories and relate it to the way of everyday living, so we act it out in today's modern times." It was an important aspect of the Bible teachings for students to be able to relate them to their everyday lives.

It seemed that a key purpose of these culturally patterned activities of oral reading that were described in the interviews was to enable the people to have direct access to God's Word. Similar values were described in Chapter 2 where Graff (1987b) outlined the influence of the church on literacy as it was seen in Sweden in the wake of the Lutheran Reformation, where near universal levels of literacy were attained without formal schooling. Graff (1987b) describes how under the sponsorship of the Lutheran church and the state, reading literacy was required under the law for all people from the 17th century. In order to receive the sacraments or to marry, citizens had to be able to read the Word of God directly. Sweden's Church Law of 1686 advocated the need for all to have direct access to God's Word when it stated that children, farm-hands and maidservants should "...learn to read and see with their own eyes what God bids and commands in His Holy Word" (Graff, 1987b, p. 150). Having direct and very accurate access to the Word of God is still valued in the present time in some communities and it 
emerged in this study of one Pasifika community that accurate and clear oral reading is highly valued by the church and Sunday school as a way to communicate God's Word to the congregation.

\section{3/ Reading passages of the Bible to memorise and recite them to an audience: Tauloto / memory verses}

The cultural practice of tauloto is a further example of literacy practice that brings the Word of God directly to the people in this community. The interviews with the students and church representatives revealed tauloto to be a valued part of their community's curriculum and it is an example of literacy practice where the evidence from the participants can be examined through each of Rogoff's three planes of analysis. Five of the seven girls and four of the seven boys said they learn tauloto for Sunday school, with five saying they learn in the Samoan language, one in Niuean and the others in English. As well, three of the four students in the pilot study indicated that they learned memory verses, with two saying they learned verses in Samoan. Tauloto is described by McNaughton (1994) as performance routine and Tagoilelagi (1995) offers a useful description and explanation of the practice. In her study, Tagoilelagi found that the Samoan families in New Zealand maintained their cultural beliefs in acquiring literacy, and she describes the tauloto routine as the most significant strategy that they used. She explains that the routine emerged from the early encounters between the Samoan people and the missionaries. Tagoilelagi suggests that the pedagogy in Sunday schools has been influenced by the traditional pastors' schools where the tauloto routine is a common form of verbal interaction between the teacher and the children in Bible reading, where the children imitate what the teacher reads. The experience of tauloto facilitates the development of an extensive recitation memory, as the teacher reads a single word, a phrase or sentence and the child duplicates this. Memory verses are usually associated with church activities in which children are involved such as White Sunday ${ }^{12}$ when children

12 White Sunday is an important church day which is generally the second Sunday in October and is sometimes referred to as "Children's Sunday". It is celebrated as a public holiday in Samoa and is a special day for children and young people who are dressed in white clothes and lead the worship at church. They recite their memory verses, sing and perform religious drama. When they eat they are served by the adults. Church Representative $\mathrm{C}$ explained how White Sunday is a highlight for the year for children. She said there is Mothers' Day and Fathers' Day, and White Sunday is like Children's Day. "They get special treatment. They get a special breakfast in the morning like mum and dad, they have new clothes, white, and they are served on that day." 
quote verses from the Bible. According to Tagoilelagi (1995), the performance routine was seen by families in New Zealand and Samoa as a traditional way of learning to read the Bible which had been passed on through many generations.

The data describing tauloto are useful to illustrate how teachers work in Sunday school, church and family sites with common values and purpose to mediate students' learning as the students are apprenticed into this cultural practice. Through the three planes of analysis (Rogoff, 1995), each level of mediation can be foregrounded in turn. At the personal level, some of the students described how they practised their tauloto by themselves and they explained their feelings about doing this. A photo taken by Repeka of her Samoan Bible (Figure 11) represents this practice and led to Repeka's description of learning memory verses in Samoan for Sunday school.

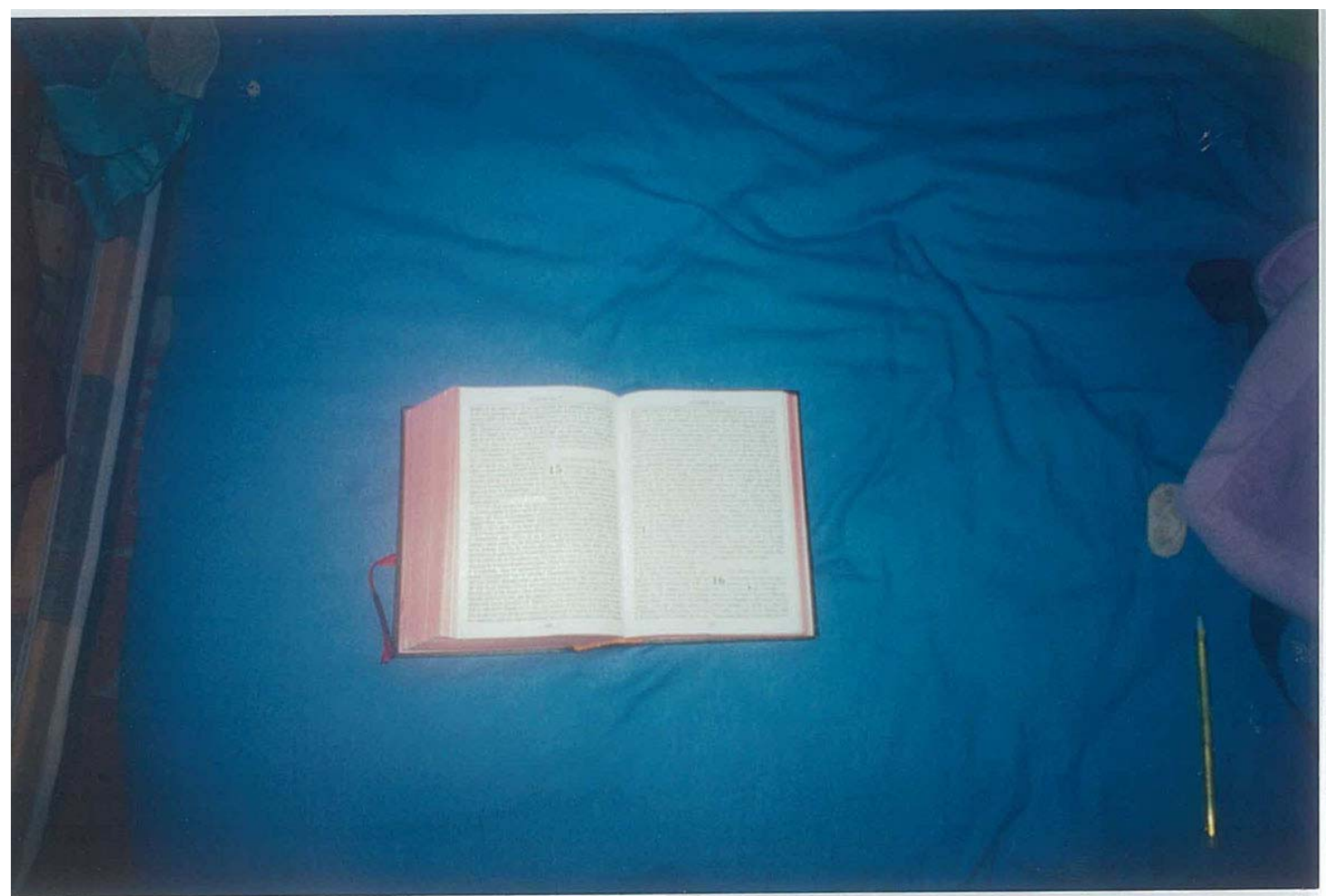

Figure 11: Repeka's photo of her Samoan bible, taken to represent how she practices memory verses every day for the Sunday School exams. 
She explained, "I was trying to learn two verses for the exam." She said she practises every day for three or four weeks and the exams are held once a year. She wrote in her journal, "I was reading the verses that I had to learn from the Bible." She said that it was not difficult and that nobody helped her to do this. However, another student found the tauloto a challenge. Ioane learned memory verses in Samoan for Sunday school saying that it was hard and he had to practise by himself. Paulo recorded in his journal "24/09 at Sunday school we all received our White Sunday speeches. We all read them, some difficult, some easy." When the personal plane is considered the solitary individual is foregrounded and their description is of being alone in learning their tauloto, but they are very much part of their community as their learning is mediated by the community values and by their teachers at Sunday school and in their homes. The practice of tauloto consists of more than the skills of reading and memorising; it requires an understanding of tauloto's cultural value and its role in community practice. The students understand that they are not learning the memory verse for themselves but are involved in a social practice where the audience will be parents, peers and other people in the congregation.

\section{Guided participation in learning tauloto}

The discussions about the practice of learning and reciting the tauloto revealed evidence of guided participation for the learners. There were several examples of how teachers helped to set the task and guide the students in memorising the verses. The teachers of this practice included Sunday school teachers, parents and other family members. Church Representative $\mathrm{C}$ described how she and other Sunday school teachers create the tauloto for the younger children for White Sunday.

\footnotetext{
We get the verse of the Psalms, the simple ones, for White Sunday. The children aged 5, 6, 7 have about two lines that they memorise. The teacher will read the story and create the tauloto for the children.
}

One student's description of learning memory verses in English illustrates a connection between sites of church and neighbourhood and is an example of her teacher's innovation in guiding student participation. Her Sunday school teacher's strategy for helping the students to learn memory verses was to tap into children's interest in popular culture. Elisapeta explained that the memory verses were written on pieces of paper shaped like a starfish or a character from the movie Finding Nemo. The children learn the verses and then are awarded a star. The students had been shown sections of the movie at Sunday school and Elisapeta made the analogy 
to God finding his son. Elisapeta explained that in the movie, Nemo's father Marlin sets out to find his lost son. Also, in the movie, Marlin was swallowed by a whale, as was Jonah in the Bible story. She explained that when people get lost, Jesus is the only one who can save them. The church representatives had emphasised the importance of making links from the Bible to children's own lives, and the use of popular culture as described by Elisapeta is a way to help young people to understand the values and appreciate the relevance of the Bible to their lives. It seemed that the analogy was designed to promote a literal understanding of the Bible as although the students may be encouraged to form judgments about good and bad, the message is that there are rules which provide guidelines for living and it is important to follow these rather than question them.

Several students described the support and guidance they they received from family members in learning the tauloto. Hana explained that her cousin helped her to learn memory verses in Niuean, while Eseta's grandfather helped her to learn them in Samoan. Samasoni explained that when he was four or five years old he used to go to a Catholic club and he would have to memorise a verse from the Bible in order to win a prize. He said "I memorised a verse and got myself a children's Bible." His family supported the religious curriculum. He said "My mother made me practise every day". The examples of family support in learning tauloto are evidence of a strong connection between family and church (including the Sunday school) such as that described by McNaughton (1995). He writes that the churches attended by the Samoan families in his study took an active role in promoting particular literacies and had similar activities and pedagogies to the families. He writes "The connections between the home and the church, especially at the level of complementary literacy activities, were very strong in these families" (p.182) and this appears to be the case with some of the students' families in this study. Tagoilelagi (1995) also describes how the children in her study were scaffolded in learning tauloto by the teacher at Sunday School and by the family at home.

\section{Tauloto as part of the community's curriculum}

Church Representative B explained tauloto as part of the community's curriculum and his comments add to our understanding of the tauloto as cultural and social practice. He emphasised the importance of children understanding their (Samoan) language and being able to speak it. He emphasised the social nature of the practice 
of tauloto, of sharing the tauloto with others, of the special day when the tauloto was shared in the church, and sharing the Christian message. He said:

Every child will be given a verse from the Bible to take home or to learn at Sunday school and then there will be a time they will come together and say their tauloto. Mainly on White Sunday the children will talk from their tauloto. They are proclaiming the good news for their parents.

The emphasis on accurate memorisation can be explained as part of the pedagogy that is valued in learning the mother tongue. Representative B explained:

It's very important for them to speak their language and to learn it by looking at what was given they will memorise it and also have the understanding. When they memorise that they will speak from it and they will be able to learn how to talk their language.

The tauloto is a further example of literacy practice that these students are involved in where participation requires more than knowing the skills of reading and writing but involves ways of interacting and valuing (Gee, 1996). The data indicate that this traditional practice embodies the important church (and community) values such as teaching the Christian doctrine, facilitating direct access to the Word of God, sharing the Word with others, and maintaining the use of Samoan language in worship. Memorisation of religious texts is not unique to this group. Listening, memorising and repeating were emphasised in the fundamentalist Christian churches studied by Zinsser (1985), and students in the "Maktab" religious schools in Iran described by Street (1984) memorised text using their strong oral tradition.

It appears that traditional Samoan influence similar to that described by Tagoilelagi (1995) continues to have an effect on literacy practices in New Zealand Sunday schools such as the one attended by the majority of the students in this study. Tagoilelagi writes that it is clear from the language practices in pastors' school and Sunday school that the pedagogical patterns used during literacy activities of each are similar and complement socialisation in the home. The sites use the same procedures to teach tauloto, plays and Bible reading and it appears that similar practices are continued in the community in this study. Tagoilelagi's Samoan families in New Zealand maintained their cultural beliefs in acquiring literacy rather than being transformed by the dominant culture. The church related methodologies of teaching and learning were influential as they were for some of the participants in this study. 


\section{4/ Maintenance of the Samoan language through religious practices}

The culturally patterned activities described in this chapter show that it is not just the uses of English that are distinctive to this community, but also their valuing and uses of the Samoan language. When exploring literacy as cultural practice a critical issue for understanding the acquisition and development of literacy is to consider "what processes underlie the cultural transmission or socialization of the process" (Reder, 1994, pp. 35-36, italics in original). The use of the Samoan language is a distinct characteristic of this Pasifika community's cultural transmission in their literacy practices in church and family sites, and forms a contrast to other communities in New Zealand.

For a number of students in this study the church and Sunday school were sites where the Samoan language was nurtured, and this fostering of the language through church-related reading and writing was supported in their homes. In describing a sociocultural approach to analysis, Wertsch $(1998$, p.74) refers to language being a cultural tool which mediates action, and the following section of this chapter offers examples of language mediating action in the students' lives. In four of the six Sunday schools attended by these students, Samoan as well as English was used. Some of the reading and writing related to religious practices was taught in English, some was taught in Samoan and at times teachers and students were switching between the two languages. For nine of the fourteen students, church-related reading was wholly or partly in the Samoan language in the sites of the Sunday school, church and home. Some students said that they used both Samoan and English while one student used Niuean. When they were asked where they read in Samoan and what they read, the site of Sunday school was mentioned seven times, the church three times and the home eight times. The most commonly mentioned reading material was the Bible with seven students stating this. Reading the Bible to an audience and the tauloto routine emerged as two important practices where the Samoan language was used and these have been described earlier in this chapter. Other examples of reading and writing uses are listed in the curriculum section at the beginning of this chapter.

One student's comments help us to see how her learning was mediated in different sites by many teachers, providing an example of overlapping support between the institutions of family and church. In the social practice of literacy described here, the 
"ways with words", which Heath (1983) refers to, are similar for family and church. Apekaila's strength in Samoan was not the result of one institution or site working in isolation but rather of teachers in both family and church sites working together in a network to support common practices (Cremin, 1976) with the Samoan language forming part of the curriculum of each. Her discussion revealed her guided participation (Rogoff, 1995) in religious study as she learned to use the Samoan language with the support of her teachers, these being the Sunday school teacher, priest, members of her family and her Bible. Apekaila was a student who described herself as speaking Samoan at home "quite a lot" and "extremely good" at reading Samoan. She stated that she has her own Samoan Bible which she reads at home and she also reads prayers in Samoan at home. In answering what she most liked to read in her own time, she wrote the Bible. She gave herself 4 out of 5 on the scale for writing in Samoan (with 5 being "extremely good").

At Sunday school she writes in both Samoan and English, being encouraged by the teacher to use English if she does not know the Samoan word. When asked about writing in Samoan, Apekaila explained that at Sunday school the teacher will read a sentence from the Bible and then say "full stop," "comma," and the students will write it down. The teacher then marks the work and gives the marks to the students and then to the parents. She said that Sunday school exams are coming up and to study for these she would "Read the Bible as that's where all the information is." She considered that this was a way to learn the Samoan language and her parents supported her in this. Her description of the support in her home shows us how her family saw the relevance of these practices within their own social context. She explained that her parents helped her by "reading the Bible with us and asking questions" as well as helping with the answers and with correct pronunciation of Samoan.

Her ability to understand and speak in Samoan was demonstrated in the public setting of the church, and her description of Samoan being used in the church service illustrates how she and other young people are immersed in distinctive uses of language as a cultural tool. The priest would tell a Bible related story in Samoan and then ask questions for the children in the congregation to answer. The students were expected to answer in Samoan and when she does this she feels a bit scared as there are a lot of people in the congregation. This student's examples illustrate the social institutions of family and church are working together to achieve the same literacy goal. 


\section{Maintaining traditional community values}

The church representatives' arguments for Samoan to be used by the students illustrates their beliefs on how young Samoans in New Zealand should be apprenticed into the community (Rogoff, 1995) as they show strong support for the cultural practice which is nurtured in the institutions of church and family. All the students in this study were born in New Zealand. Chapters 6 and 8 provide evidence that suggests that they may have different values from their parents' and grandparents' generations, but in a sense the practices of using the Samoan language could be compared to the moral values referred to at the beginning of this chapter in that it is like a glue helping to hold the community together with traditional values. Representative B agreed that students should know the Samoan language, saying "It is very important. We do have an understanding that if they speak Samoan they will be able to speak other languages too and write other languages too". The language was seen as a vital component of culture. He said "It's part of looking at the second and third generation and even though they were born here and brought up in New Zealand which they call their country but at the same time they are Samoan children so they have what they should be proud of, a culture and a language."

In the interview with church representatives all three agreed that it was important for Samoan people in New Zealand to maintain the Samoan language and for the students to use it. Two of them said that it was a very important part of the worship that children could read in their mother tongue. The students were being apprenticed into becoming skilled participants in their community through "guided participation in ongoing cultural activities as they observe and participate with others in culturally organized practices" (Rogoff, 1990, p.16). Church Representative A said that it was very important for the children to be able to read in Samoan at Mass. The children's contribution was valued and placed alongside adults who were expert models of the language. "They might do the first reading, a young child for the first reading and then an older person for another reading." He said that some parishes have the children's mass every month while others may have it once a year. When questioned if this would be something that parents would value he replied, "They are very very proud of it. They have a justifiable pride to see their son or daughter reading out in the church" and his reply illustrated the practice as a cultural tool of that community. He stressed that accuracy in reading was paramount: "It is important that the person 
who is to read is briefed properly so they can clearly proclaim the word, so that everybody could hear and understand."

Representative C, who taught in the Sunday school, believed that it is important that young Samoans in New Zealand retain the Samoan language as a key component of their identity and she passed this message on to the parents of her Sunday school students. She told the students in her class, "English is your second language. Samoan is your first language and it's part of your identity."

\section{Christian doctrine taught in Samoan and English}

Although the Samoan language is a vital part of culture, the teaching in Sunday schools must necessarily be in English as well. The conversations with the church representatives revealed that that although the church practice had previously been to teach the children the Samoan language through Sunday school this had been discouraged by the church hierarchy. Church Representative A explained that there is a policy in the Archdiocese from the Cardinal that the Christian doctrine must not be used as a way of teaching or passing on the Samoan language as many children born here are not fluent. For those teaching the Christian doctrine they have to be fluent in both English and Samoan. If children are fluent in Samoan they can learn the doctrine in Samoan, otherwise it is in English. This was confirmed by Representative $\mathrm{C}$ who said that in the past the Sunday school had a separate time for teaching language but they were then told by the cardinal that they could teach in Samoan, but Sunday school was not to be used for teaching Samoan language. She agreed with this policy, saying that the purpose of the Sunday school was to nurture the faith of the children. "We don't teach reading and writing in Sunday school. We teach them the Catholic faith through Samoan language with the papalagi language so our way of teaching is bilingual."

Representative B agreed that Sunday school teaching must be in both Samoan and English because not all the children understand Samoan. This was supported by a comment from Isaako who said he spoke Samoan at home, "Always or almost always". He said that at Sunday school "The teachers talk English to us because when they talk Samoan to us we don't really understand. We have some little kids who were born in New Zealand and they don't understand". Both languages were also used in church services. Church Representative B described how both Samoan 
and English are used at church to reinforce the message to the congregation. "Half the time the preacher will speak in English as well as in Samoan," in referring to a particular text and explaining the text and saying the same thing in both languages.

\section{5/ Assessment of church curriculum through Sunday school tests and exams}

Through the interviews with students and adults it became clear that integrated with the study of Christian doctrine in the Sunday schools was an official assessment of student learning which was supported by family, church and Sunday school and which reflected the values and expectations of the community. It emerged that this is a practice that is similar to the formal assessment of curriculum in compulsory schooling. Although the students were not asked if they did exams or tests, about half of them who attended three different Sunday schools offered this information in the interviews. The church representatives described the tests and exams which were used to assess learning in Sunday school and the procedures they described represent the influence of the church over certain literacy practices. An individual requires more than literacy skills in order to participate in social practices. Willingness to participate in tests and exams signifies recognition of the power of the church in a way that parallels acknowledgement of testing in schools as recognition of the "official" curriculum of schools. In order to succeed as members of the community the students (and parents) need to know how to participate within the social contexts of the community and participation in these tests and exams is an illustration of their acceptance of the community values.

Representative B explained that although Samoan is used, it is also necessary to use English as some of the students are second and third generation New Zealanders. Representative C explained that the exams did not aim to test the students' knowledge of the Samoan language but they provided an option with about ten percent of children in the region choosing to sit the tests in Samoan. She said:

There are some children living with their grandparents and they are carrying on the language and they prefer to have the Samoan paper rather than the English one. If they struggle with the English word put Samoan if they know it. If they struggle with the Samoan word put the English word. 
In the Sunday school described by Representative B, the younger children of three and four years old would have an oral test based on pictures, and each older age group would have written tests up to the young adults who are aged from 17 to 20 years. The students offered explanations of what was learned for the exams. Repeka described writing exam stories at Sunday school based on Bible stories from the New and Old Testaments. "We write it in Samoan. We get two stories to learn and we have to remember it and then we write about it. The teacher tells us the story and we just go over and over and over it". Isaako explained that in exams: "You have questions about the Bible, the days of Jesus, about the New Testament, the Old Testament." Apekaila said that for exams the students are split into classes and they need to answer questions without looking at the book. She said she would use both English and Samoan at Sunday school, using English if she didn't know the Samoan word. Maria mentioned that in her Sunday school they also do small tests and the students with the highest scores will get chocolate as a prize. After the exams were marked there would be a prize giving and they would receive prizes including Bibles, stationery and sweets.

Church Representative A described how at the end of each term the students have a test but the main test is at the end of the year when there is a competition for the whole district with students from many parishes competing. The students can choose whether to answer in Samoan or English. He explained that "The purpose is to see how much the children learned about the topics they have been taught, for example the sacraments, what is the purpose and what is involved." Representative B explained that the questions were based on the scripture and also from the church teaching. The purpose of the tests was not so much to find who came first in the class but to ensure that everybody should achieve the standard to pass "to make sure the child knows his religion and his faith, what his faith does for him, what does a Catholic believe, in the way of communicating and relating to other people."

\section{Conclusion}

This chapter has described some of the church-related literacy practices that Pasifika students are apprenticed into by their communities. In summary, five areas of cultural practice emerged from the data. These were studying the Bible to learn the Christian doctrine, oral reading of the Bible for an audience, the practice of tauloto or 
memory verse, maintenance of the Samoan language through religious practices, and assessment of church curriculum through Sunday school tests and exams.

Each of the three findings chapters adds to our understanding of student identity and how the individual makes sense of his or her world. These data help to demonstrate that the study is not looking at individuals learning reading or writing skills in isolation from others, but at individuals who are interacting in many authentic social and cultural settings for literacy within a community. The literacy practices described in this chapter help to provide an insider view of some of the values and beliefs of the community as the students are apprenticed into the ways of church and family as their identities are constructed in this and the wider community. The data have illustrated the significance of the church, Sunday school and family as sites for church-related literacy and explained the significance of the connections between these sites. Chapter 9 discusses the implications of these practices for helping teachers to make effective connections for these students in school. 


\section{CHAPTER 8}

\section{Neighbourhood Sites for Literacy}

\section{Introduction}

The first four chapters of the thesis argue that literacy can be conceptualised as social and cultural practice and because of this there are many sites and many literacies apart from the official ones of the school. This chapter adds to the debate by providing an insider view of how the students negotiate and construct their own literacy practices in neighbourhood sites. These constructions are linked to their identities as adolescents and this aspect of their identities, the mediation of their learning, is through peers and advertising rather than the more conservative institutions of family and church where it can be assumed that there was control, or at least a strong influence exerted, by their parents and church members. Chapter 8 builds on knowledge of these students by describing their literacy practices in a new context. Later the thesis uses this knowledge in discussing incorporation of practices into school settings.

In a study such as this which takes a sociocultural perspective of how adolescents use literacy in their social and cultural environment, the neighbourhood sites are significant. The students' descriptions of their literacy uses in the neighbourhood sites are essential in helping to build a more complete picture of their out-of-school literacies to add to our understanding of the configurations between sites for literacy and to provide a more complete view of the students' education (Cremin, 1976). While the neighbourhood encompasses the sites of family and church which have been described in the previous two chapters and also the site of the school, in this chapter the neighbourhood is the other sites in geographical proximity that are interconnected with the sites of family, church and school.

Chapter 3 introduced the concepts of literacy practices being closely linked to identity (for example, Heath, 1983; Pahl \& Rowsell, 2005; Street, 1995) and of the individual's identity linking them to various groups in society (Collins \& Blot, 2003; Ferdman, 1990; Gee, 1996) with the consequence being that an individual may have many identities and belong to many groups. This chapter, which describes many uses of literacy, adds to the previous two chapters in illustrating that these students may have multiple identities (Gee, 1999; Pahl \& Rowsell, 2005). Some of their 
literacy uses are not unique to individuals but will be shared with other adolescents in New Zealand and elsewhere. What is unique is the combination of literacy practices for each individual as their identity is constructed in relation to literacy use.

\section{The sites in the neighbourhood}

The term "neighbourhood" is used in this thesis to describe the physical environment of the community (profiled in Chapter 5) in which the students attend school and where the majority live and attend Sunday school. The students took twenty percent of their photos in neighbourhood sites and these show the physical environment of their community that was described in the contextual chapter. Of these photos, eight percent were taken in the libraries, eight percent taken of the streets and shops, and four percent elsewhere in the community. However, many of the discussions in the photo elicitation interviews went beyond the sites depicted in the photos and made reference to neighbourhood sites. The sites include the community libraries in this suburb and the adjoining suburb where some of the students live. Libraries are particularly important sites to consider as they represent the reading interests of the whole community, and because of this they help to illustrate what Cremin (1976) refers to as the consonance and dissonance between the curricula of the institutions which are represented in the library collections. The different types of texts represent the differing values of the various institutions and individuals that the library serves, and examples of these are discussed later in this chapter. Some literacy practices in the neighbourhood reflect the curriculum and values of school and family, illustrated in Figure 12: Configuration of neighbourhood with other sites. This shows the overlapping literacy uses that illustrate the consonant relationships between sites. However, other uses may be in conflict with those values. The sites in the neighbourhood also include the many and varied shops in the suburban shopping centre where the students and their families make purchases, the streets with their signs and advertisements, the buses the students catch, the sports grounds and the sports clubs they attend. The interpretation of neighbourhood is extended to include the shops and arcades of the nearby city centre. The neighbourhood sites for literacy offer unique opportunities as an "apprenticeship" (Rogoff, 1995) for acquiring necessary literacy skills for participating in society. 


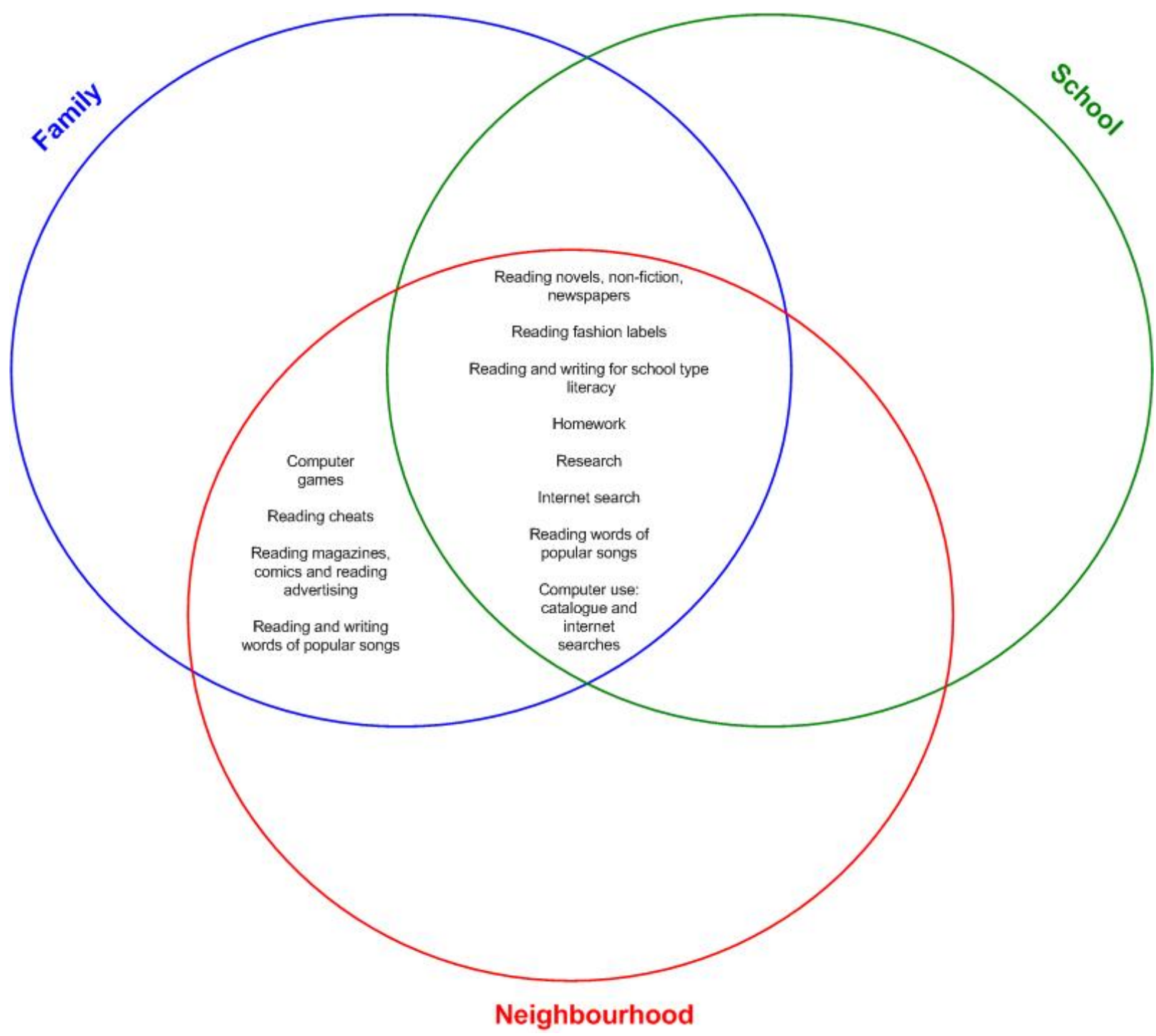

Figure 12: Configuration of neighbourhood with other sites, showing the overlapping literacy uses which illustrate the consonant relationships 
The students' descriptions illustrate how they need to learn to navigate their way in this neighbourhood and in the world beyond.

\section{The teachers and curriculum of the neighbourhood}

The teachers in the neighbourhood sites included the students' parents, siblings, relatives, friends, peers, sports coaches and librarians. They also included libraries, shops, street signs, advertisements, bus timetables, the Internet, computer games, DVDs, music CDs, book-based and electronic cheats for computer games, books, magazines, comics, and corporations (for fashion). The teachers in each site are described for the themes in the following sections of the chapter. The curriculum for the neighbourhood sites includes literacy for pleasure and for finding information, for finding goods and services and purchasing them, and for navigating in the community. The curriculum is also connected with the formation and acknowledgement of identity with particular groups and individuals.

\section{Structure of the chapter}

Four themes of literacy practice emerged from the students' data in relation to neighbourhood sites and these combine to show the students' positive view of themselves in their growing competence in literacy practices. In this chapter each theme is discussed in turn with reference to its sites. The majority of literacy practices related to aspects of popular culture. The other themes were support for school type literacy, literacy for finding and purchasing goods and services and literacy for navigating one's way in the neighbourhood. As each theme is introduced, the sites are named, the curriculum outlined, and the teachers of the curriculum are described. The discussion also describes the neighbourhood in configuration with other sites for literacy. The structure of the rest of the chapter is as follows:

1. Literacy related to popular culture

2. Support for "school-type" literacy in the neighbourhood site of the library

3. Literacy for finding and purchasing goods and services

4. Literacy for navigating one's way in the neighbourhood 


\section{1/ Literacy related to popular culture}

The major theme of literacy practice in the neighbourhood that emerged from the data and the first to be discussed in this chapter is that of less conventional literacies which are described as popular culture (Biddulph, Biddulph \& Biddulph, 2003; Luke, 1997; Mahiri, 2000; Marsh \& Millard, 2000; Morrell, 2000). Popular culture forms an important part of many people's experiences of literacy, and it emerged as a significant use of literacy for the Pasifika students in this study. It is an example where the users have more personal choice and individual interpretation than would be possible in, for example, the agency of religion where the values and pedagogies are defined and controlled by the church. With popular culture, students can, to a certain extent, choose their own curriculum.

The majority of the data and discussion on popular culture were sited in the homes of the students as well as peers' and relatives' homes. The home site is described in Chapter 6 in relation to family literacy. The school was also a site. The students explained many examples of popular culture that are intrinsic to their social practices of literacy. Popular culture is also an intrinsic part of the students' establishment of identity. While other agencies influence their identities, they have less influence over those than of popular culture. The practices relating to popular culture in the neighbourhood included reading fashion labels, using computer games and reading popular fiction and comics. The sites, curriculum and teachers are discussed for each in turn below.

Two important aspects of curriculum apply to all these practices of popular culture. One is to provide entertainment and pleasure while another is the formation and acknowledgement of identity. Being involved with popular culture enables people to identify particular groups and to associate with them. As with adults, popular culture affects many aspects of adolescents' lives and this is seen in the many examples the students offer, and the connections between the sites where these practices occur. Many of the literacy practices that are situated in the neighbourhood are associated with popular culture. These are through the books, magazines and DVDs the students get from the local library and the visits to the downtown shops and arcades to buy computer games, to play games and to search for, and buy, clothes. If teachers in schools have knowledge of these practices, they may provide opportunities for what McNaughton (2002) describes as "incorporation" where the teacher or student may make effective connections between out-of-school and school literacies. 


\section{Reading fashion labels}

A literacy use which seems simple and obvious but which is of great interest to young people is that of attaching value to certain clothing labels. Clothing and sports accessories form part of children's popular culture (Marsh \& Millard, 2000), and several students in this study selected brand name fashion labels as descriptions of their out-of-school literacy use. Seven of the students' photos and two journals contained entries related to items of clothing or labels on clothing and the topic of clothing or labels arose during the course of the second interview with several students.

The sites for this practice included family and school sites where the students read labels and discussed brands. However, the data on reading labels is written in this chapter on neighbourhood sites as the students were aware of this practice connecting them to others in the more public arena of the neighbourhood and beyond that to a wider global community. Some of them described going to shops in the city where they looked at clothes and purchased clothes. The teachers were their peers and family members including older siblings and cousins. Teachers also included celebrities such as singers and sports stars and the magazine advertisements of international corporates such as clothing manufacturers.

The students who gave their views on fashion labels seemed to be very interested in the topic and were quite clear in their opinions of the desirable brands. At the personal level the students' comments revealed their thoughts as participants in social settings influenced by popular culture. The following examples also illustrate how the students have been apprenticed into a community sharing common values (Rogoff's 1995 community plane) and contributing to their identity. The students' own comments during the photo elicitation interviews foreground them as participants in social practices. Their openness and enthusiasm as they offer their views on fashion labels enables them to be seen as individual participants. At the same time, it can be seen in the background the context of the group that they have chosen to be part of, that is, the group that identifies with and shares the values of these fashion labels. The students demonstrated knowledge of the popular culture curriculum in relation to fashion. This was seen in their explanations of details of the different styles of clothing, the variety of products for each label, the prices, where they could be purchased and their identification of celebrities who were associated with particular labels. 
For example, two pairs of girls indicated their strong interest in fashion labels although none had recorded information about this in their journals. Maria described a photo of her cousin wearing Maria's jersey with "Quicksilver" written in a band around the base in very large letters. She explained her preferred labels. “... there's Roxy, Billabong, Dickies and Quicksilver. They're the best brands. Apekaila agreed. In addition to the popular culture curriculum which is outlined above, the students accepted the values of what could be termed the corporate curriculum. In other words they accepted that these clothes had certain desirable qualities that made them worth buying. The students present themselves as being part of the consumer market. These girls and Hana and Eseta considered that Dickies are good because they have the latest fashion. When they were invited to elaborate on this, the researcher was unable to separate their replies: "Cos they're like good styles. They design their clothes nice. They're really good." They both agreed that it was cool to wear these brands and told me the names of three shops where they can be bought. They also described in positive terms the bags made by Kathmandu (a manufacturer of outdoor clothing and camping equipment). Apekaila said "Those are good ones because they last longer." The two girls said that other members of their families have these brands too.

Sara had taken a photo of the logo on the uniform of the school and said she always reads the logos on people's uniforms. This simple photo was the opening for her to explain that she took it because she likes clothing and her preferred brands are Dickies, Converse and Billabong. She explained that she liked these brands "Because they are stylish". Sara agreed with the researcher's suggestion that all the students seemed to be interested in the labels. When Iosefa was asked what did he think are some good labels, he seemed less interested than the girls. He said "The same as hers but I don't really buy them that much."

By selecting these brands the students are identifying with their peers and relatives who also value the brands. Through their comments of support for certain brands they illustrate how they have been apprenticed by peers, relatives and advertising into particular groups and sharing the values of those groups. Wearing and having knowledge of particular fashion labels allows individuals to achieve acceptance and status in the group (Kenway \& Bullen, 2001). The strong influences of consumer culture and media culture on the development of children's identities are described by Kenway and Bullen (2001) in their book entitled Consuming Children. They 
recommend that the social and cultural understandings of children should inform how teachers teach and what teachers teach. Kenway and Bullen write that consumer-media culture is a central feature of children's lives in ways that are complex and contradictory. In the 10-12 year age group there is more likely to be a marked gender differentiation with girls favouring fashion and boys favouring sporting brands. They write that this age group is highly subject to pressure from their peers to differentiate themselves from others. Brand clothing can mark the students' position in their peer culture and earn approval and status. Kenway and Bullen describe the older children aged $12-14$ as valuing brands for their iconic associations with people such as sporting heroes, actors, and pop culture idols, and the identities which they can construct as a result. Identity is a big issue for this age group also, who are becoming increasingly focused on creating their sexual identity. The data in this study was consistent with this with the girls describing a range of fashion clothing and the boys mainly describing sporting brands, particularly shoes.

Although the boys spoke in an animated way about the fashion labels that interested them, not one of them had annotated any of their photos of clothing in their journals. Samasoni said he liked Adidas and Nike. One boy (Mareko) chose to take a photo which showed a single white sports shoe on a stool. He said that it was his own brand new "Airwalks" shoe and he explained his choice, "I chose those shoes because I like wearing it to church or outside." Isaako's photo (Figure 13) is representative of several photos taken of logos by the students. He took this photo of a friend's Canterbury school bag showing the Canterbury logo, "Because I know that Canterbury is really popular." He said it was a good brand. Like the girl students, he knew and liked the labels. When he was asked what makes it a good brand (perhaps misunderstanding the question), he pointed to the logo. When asked again what makes the product good, he said he could not really explain. He just knew that they are popular. 


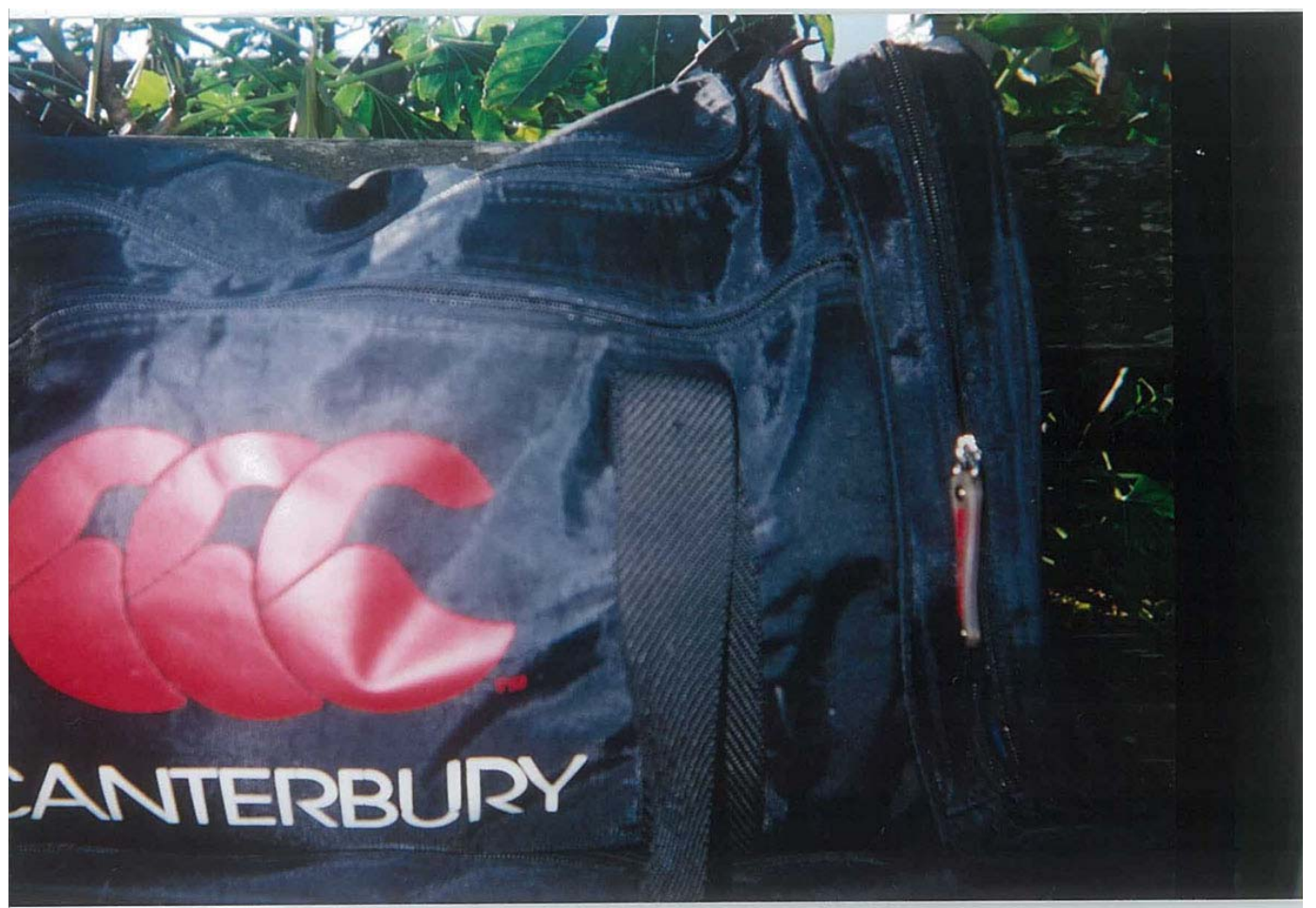

Figure 13: Isaako's photo of his friend's Canterbury school bag, showing the logo that he valued

\section{Identifying with the most popular brand: Chuck Taylor shoes}

According to Kenway and Bullen, (2001) brand-name fashions are instantly recognised by young people as codes of identity. An example of this that came from the interviews was the number of references made by the students to one brand of shoes. No other label was mentioned as often or with such enthusiasm as "Chucks". Their comments about these shoes demonstrate their knowledge of an aspect of the curriculum of children's popular culture. They are also evidence of the students wishing to belong to a particular group which shares a code of identity through the common values of certain fashion labels.

The following examples of individual voices illustrate the individual student's participation in gaining this cultural knowledge. Rather than gaining transmitted knowledge, the student is actively involved and "appropriates" in Rogoff's (1995) terms what they wish to learn and use. Following the discussion about the Quicksilver tee shirt, Apekaila and Maria asked the researcher if he knew about Chucks, explaining that they are shoes designed by an American named Chuck Taylor. During subsequent interviews, several other students discussed Chucks shoes and demonstrated quite a detailed knowledge of this aspect of popular culture curriculum. It is useful as an example of how these students who have many 
different interests and identify with many groups share a common identity through this interest in an American fashion label. The conversations with a total of eight students when they explained their knowledge of this brand of shoes foreground the personal plane (Rogoff, 1995), and allow us to see them as individuals with elements of their own constructions of identity. The focus of the analysis here is what they reveal from their thoughts as they describe their understandings of the brand, and why they value it as a code of identity. The comments from all of them indicate that they accept the value of this component of popular culture.

The shoes known as Chuck Taylor All-Stars are produced by Converse and originated early in the twentieth century as All-Stars which were designed as basketball shoes. American basketball player Chuck Taylor suggested some design changes and promoted the shoes with more colours and styles being added to the range. They are now produced in a wide range of colours with a variety of patterns on the canvas top. They have become symbols of popular culture as they have been worn by musicians and fans of rock and hip hop bands, and have been seen in many movies. The company targets the teenage market and it is easy to see how the bright colours and patterns of the shoes appeal to young people, offering a large range of styles that suggest individuality, this being one of the values that the company markets. On the company's website ${ }^{13}$ is the statement: "Converse. From the court, to the field, to the street, Converse continues to embody the spirit of individuality and creativity for generations of heroes and innovators."

Apekaila and Maria were quite animated during this conversation and they described Chuck Taylor in some detail. When they were asked how they knew about Chuck Taylor, they answered together that when you buy the shoes you get a picture of him on the label. They described how he is standing like this...with an "olden day background". The girls said that Chucks were cool, a description that indicates they were won over by this particular fashion brand and are happy to identify with it. Kenway and Bullen (2001) write that the key idea for marketing is to be cool and in referring to the age group of these students, they write that brand clothing can mark their position in the culture of their peers and win them status. Both Apekaila and

\footnotetext{
${ }^{13}$ Converse website: http://www.converse.com/main.asp?mode=noflash\&bhcp=1
} 
Maria commented that many of the students at school had Chucks (although a pair of boys disagreed) “... and the brand And 1. They are like slippers. For boys and girls”.

When talking about fashion labels these two girls were more animated with raised voices and more talkative than at any other stage of the interview. They often spoke at the same time which had not been the case earlier, and it was difficult to hear the individual voices. Maria wrote that when she leaves school she would like to be a hairdresser or a fashion designer and Apekaila also said hairdresser, perhaps hence their interest in the clothing labels and knowledge of them. A few days later the researcher went into a shoe shop that had been named by these students and had a look at a box of Chucks shoes. It contained a small label with a picture of Chuck with a brief description of his good work in inspiring young people in athletics. The students had obviously read this information carefully.

\section{Creating identity through fashion}

The explanations of some students suggests that they were apprenticed into their understandings about fashion labels by their older relatives (of their generation) with whom they strongly identified. These people who have expertise and experience of the curriculum offer support to enable the students to participate in the community that shares these values about particular fashion labels. When Apekaila and Maria were asked how they know about the fashions, they said that they learn from their bigger sisters and cousins. It seemed that other students also learned about fashion from older relatives as well as from peers and from advertising.

Kenway and Bullen (2001) describe how children buy image when they buy products, and brands of the products are inextricably tied to children's identity building. Brand-name fashions, music and magazines are instantly recognised as codes of identity. During the conversations, it seemed to the researcher as an outsider that the pairs of students had shared knowledge of the labels that are currently fashionable with their age cohort and, as with their selections of music and other aspects of popular culture, this contributed to their construction of identity as part of a group with similar interests. They have clear ideas about what they like in fashion brands and this creation of their identity is through their being able to select or appropriate (Rogoff, 1995) what they like for its own value or to participate in the group. 
Two other girls also showed their interest in fashion labels during the second interview.

Hana and Eseta were interested in Chucks too, being animated and answering at the same time when asked about this brand: "Chucks, that's Converse." They said they are good but expensive. "They're like really old shoes. They had them in the eighties. They used to be really ugly but now everyone wears them." Another girl agreed that Chucks were ugly. Sara said that she has Chucks “...but I don't wear them any more because they are ugly". All of these students who were speaking positively about Chuck Taylors are revealing how they are choosing to align themselves with their social partners in sharing the values of this brand and what it offers. The dialogue from the interviews foregrounds the personal plane and shows their individual thoughts. Their positive comments suggest that they believe in and want to identify with the brand's "coolness", and this lets us see a little of how they go about constructing their identities by associating with the brand. When the researcher inquired if Isaako had special shoes, he showed the Chuck Taylors he was wearing. He pointed out the round label on the ankle which had Converse and Allstars written on it and Chuck Taylor written as a signature. Isaako commented that he thought that a new brand had just come in and Mareko immediately said "Vans" in an excited voice. They claimed that this brand was popular and "real good". They demonstrated knowledge of the brand's features explaining that in Chucks there is long cut or low cut which meant high or low at the ankle and they knew the price. Mareko was particularly animated when talking about the shoes and he seemed quite knowledgeable about them. When asked how he knew about these, Mareko replied "Because I've seen heaps of people wearing it downtown."

Part of the curriculum of popular culture involves knowing how much the desirable items cost and the students' conversations revealed that they knew the prices of items they admired. Iosefa and Sara were aware of the prices for Chuck shoes. Sara said, "Chuck Taylors are from a hundred to a hundred and fifty. Converse clothing, that's fifty bucks for a tee shirt". However, sometimes the high prices put the students in conflict with their parents. An example of this was offered by Isaako who explained that a family friend bought his Chucks for him. He said, "I told my mum I wanted some Chucks and she didn't even bother to listen to me". The reason for this was that the shoes were so expensive at $\$ 99.99$. 
Although they were popular, it seemed as if few of their classmates owned Chucks. They counted only three in the class including themselves.

It is interesting to consider the form of literacy that is concerned with fashion labels and famous brands. While the label such as that on Chucks shoes which was described by several students may contain one or two words and perhaps a logo, it is what is signified that is important. Wearing clothing that displays a particular label is about sharing identity and being part of a particular community. An analogy could be to consider what is signified by the "label" on a car. What is signified by the name "Toyota" will be different from what is signified by the name "Maserati" and its connotations of wealth and belonging to an exclusive group. Individuals belong to communities of practice in different sites including their homes, work and schools, and these communities each have their own values and requirements (Wenger, 2006). This thesis has described some of the communities that the Pasifika students identify with, and their comments about fashion labels help us to see some of the learning required to become a member of one of those communities of like-minded people.

Much of the students' interest was in fashion that was connected to American sports teams' names and American Sports stars. They were clear in their own views of which labels were "cool". Chuck Taylor All-Stars are now manufactured by the Nike company and Kenway and Bullen (2001) write that:

Nike is preeminent among brands that have appropriated the vernacular cultural styles, forms and discourses of African-Americans and Latinos and packaged and sold them back to them. These young consumers have a colossal emotional stake in the identities they have been invited to construct around corporate logos. (p. 171)

During the conversations about fashion labels, the students had expressed clearly that they had chosen certain corporate logos, illustrating how they align themselves with the cultural interpretations of particular groups. Peers and advertising are powerful mediators of this learning. Kenway and Bullen (2001) describe a corporate curriculum and claim that corporates have become successful teachers to young people. Kenway and Bullen write of a blurring between education, entertainment and advertising, and they describe consumer-media culture as offering young people both positives and negatives as they construct their identities. There may be feelings of being connected and also feelings of being inadequate, so the culture can both empower and disempower 
young people. The discussions with the students in this study revealed positive attitudes, but the students were largely selecting their own topics to discuss, so it is less likely they would raise issues where they felt negative about certain products.

Kenway and Bullen (2001) stress that the key idea is to be cool, and describe the marketing concept which is known as cool-hunting, to discover what is considered to be cool. Reading and discussing fashion labels on clothing and accessories may seem like a tentative link to students' out-of-school literacy use because the amount of reading required may be minimal. However, it is useful in helping to understand students' own beliefs and values about literacy practices as the students themselves have offered it as part of an insider perspective and it is clearly of high interest to them. There are possibilities for teachers to link this interest in labels and fashion into literacy learning at school.

\section{Computer games}

The students' literacy related to computer games provided further examples of practice that contributed to building identity and participating in a community, with these practices being mediated through family and neighbourhood sites. They occurred mainly in the family sites, and most of the discussion related to computer games is in Chapter 6. However, literacy related to computer games was also situated in neighbourhood sites where students learned some of the necessary skills and where they bought and hired games. These sites included the downtown arcades and shops, and the community library. The teachers of computer game literacy in these sites were the same as in the family sites, namely older relatives of their own generation, peers, the games instructions appearing on the screen and cheats. As in the family sites the students sometimes learned new skills by watching older siblings and cousins playing games.

To participate in computer games requires particular curriculum knowledge. The student interviews revealed the students being apprenticed (Rogoff, 1995) into the curriculum of computer games, with its requirements of navigating onscreen, reading the signs and images, reading instructions and cheats, as well as the social requirements for playing the games. A menu may appear on the screen giving the player the choice of a multi player game to be played with one or more others or a single player game to play alone against the computer opponents. The students' 
descriptions of how they practised the literacies of popular culture such as these required for computer games reveal literacy as a tool of cultural knowledge and social power, with aspects of the inside knowledge required in order to be successful in these literacy practices emerging from their conversations. The students who described the games were well aware of where to get information to help them to succeed. For example, the interviews with six of the boys revealed that they were aware of businesses in the city where video games could be played, hired or purchased. Boys and girls knew about the rules of the games and what they had to do in order to achieve the next level of the game being played.

Four boys mentioned going into the city to the video arcade named Timezone in order to play computer games. Their explanations demonstrate that they had been apprenticed into some of the practices required to be part of this community of game players. Both Samasoni and Ioane explained that they go to a large video arcade in the central city. Being part of the community included knowledge of how to pay for the games that they played, and in this case it was different from a regular shop. Ioane immediately contradicted Samasoni about payment and reminded him: "It's not on coins. It's on cards. You pay for a card. It's twenty dollars and you just swipe it on the thing." Ioane knew about handling money for the video games and volunteered this information though he did not have much to say about the photos or in answering other questions. Two more boys, Isaako and Mareko, said they went to the video arcade in the city, while another pair of boys, Paulo and Tavita, explained that the book of cheats they used was bought at a shop which they named. Both boys described this shop in the city and explained that you could buy used games, movies, and books of cheats there.

This knowledge about computer games is an example of what Biddulph, Biddulph and Biddulph (2003) refer to as "shared scripts". They write that it is the shared understandings about literacy that are possessed by individuals and groups of people that make literacy practices possible, and describe popular culture leading to the development of "shared scripts across the cultures" of New Zealand (p.v). It is this sharing and being part of the "in group" that enables individuals to identify with the group and participate in particular literacy practices. Individuals are able to participate in these identity groups through being apprenticed into the curriculum of popular culture, by learning the values, and the cultural tools of the community. This 
is another of several communities of practice that they belong to as described by Wenger (2006) where they learn the routines and conventions. This is achieved not simply by learning the curriculum of the community but, as Wenger indicates, through their direct participation in the practices of the community.

Chapter 6 discussed how students' learning about computer games was mediated in family sites by relatives such as older siblings and cousins. This family-mediated learning was extended to neighbourhood sites as well. For example, Samasoni said he had learned the skills to play games in the arcade downtown by watching his cousin play. The local community library was a site for literacy related to computer games and sometimes cheats were downloaded from the Internet in the community library. For example, Elisapeta and Repeka said they printed off the cheats at the local community library for 20 cents a page.

\section{Popular culture texts in the community library}

The community library which was described in the earlier chapter on the suburb was another site in the neighbourhood that fostered literacy, and was mentioned as a site by students more than any other site in the neighbourhood. Fifteen of the students' photos were taken in the community libraries and fifteen journal entries related to the libraries as sites. One student visited the library in the next suburb and where this is the site, this library is specified. Clearly they enjoyed the library and what it had to offer. This positive attitude correlates with the 2004 NEMP assessment for reading (Crooks \& Flockton, 2005) where 81 percent of the year 8 students answered positively when they were asked how did they feel about going to a library. Unlike some of their other sites for literacy practice for the Pasifika students, the library was one where they could choose to go or not, and they chose to go there frequently. The types of literacy practices described by the students that took place in the library consisted of those related both to popular culture and to school related literacy. The following section describes practices related to popular culture.

The teachers in this site include the librarians, the students' peers and the students' teachers from school on their regular visits to the library with their class. The teachers also include the resources of the library such as books, magazines, comics, DVDs, newspapers, the catalogue, and the Internet. The literacy practices in this site described by the students included reading for pleasure and information fiction and 
non-fiction texts, magazines, and comics. The practices also contributed to the formation of identity and students identifying with particular groups.

It emerged from the interviews that a number of students went to the local library after school and this seemed to be a social time when they read books for pleasure, played games and did their homework. This library, which is sited close to the school in this study, has established relationships with the schools in its area. Students from two schools come on regular visits to exchange books and a librarian visits another school to promote the library. Students' art work and research displays from the local schools are put on display on the walls of the library. The researcher arranged brief informal meetings with two librarians who had worked with the students during school visits and after school. The first librarian said that one area of the library was sometimes full of students from the school. There might be 5 to 10 but sometimes there were none. There were times when they came regularly, for example every day for a month, and other times when the librarian did not see them for a while. He said that there were fairly even numbers of boys and girls visiting the library after school. The students browsed through books and looked at the young adult magazines such as Girlfriend and Sugar and also the Simpsons comics. The second librarian commented that they borrow Simpsons comics, but that they tended to browse through the magazines rather than borrow them. She said they gather, chat and share magazines but did not borrow books very often.

\section{Values of popular culture may clash with those of family and school}

Cremin (1976) describes libraries as one of a multiplicity of institutions that educate, and one that has a curriculum. He writes that there are going to be disagreements among people over education, but what is important about public education is that people are able to work to agreement about values and policies. He states that people decide on common ground in public schools and public libraries because they agree on the kind of society they want for the future. He writes:

It's not that we're going to do away with different life-styles and different beliefs, or with the educational institutions - both public and private - that keep those different lifestyles and beliefs alive. It's that we must practice those different life-styles and beliefs within a common framework of mutual respect and understanding. (p.75) 
Popular culture texts in the library may conflict with the values of family and church, so this is a site where some mutual respect and understanding may be required. Whereas in the past libraries were often specialized and restricted to certain members, a modern community library is expected to cater for all in its community. This catering for very wide tastes and values means that it is likely that at times there will be a clash of values. When Isaako returned to the library from secondary school, the researcher asked him if he read the computer magazines and comics and he said no, he preferred to read novels. In the first interview he had spoken out strongly against violence in computer games but he thought that certain sports games were acceptable.

The young adults' section of the library has a large collection of magazines and comics including the Simpsons comics, and many superhero comics such as Batman, Superman and Flash. Some of these have movies, television series and toys based on them. While many of the magazines and comics are full of fighting images, generally the violence is not portrayed as realistic and it is presented in cartoon images. However, on the same shelves are Playstation 2 and $X$ Box magazines which are accompanied by games disks. In contrast to the superhero comics these magazines have more aggressive and realistic images which seem to be aimed at an older audience. One of the librarians said that the boys liked to borrow these Playstation magazines and disks. The images and words of these magazines are evidence of what Marsh and Millard (2000) describe as the hegemonic masculinity of computer magazines that is designed to appeal to male readers. The magazines contain many images of men holding very large guns and scenes of explosions, smashed vehicles, destruction, and war. The games generally seem to involve killing enemies and offer such advice as aim for the head as enemies often wear bullet proof vests. In addition to realistic human figures, animals and fantasy figures are portrayed as aggressive.

While it may seem surprising to see such violent images in a public library, these magazines represent the values of a section of society that the library serves. It could be argued too that a close examination of classic literature would reveal many violent images and themes. Popular culture is successful in presenting its stories in ways that emphasise the visual aspects. Situated close to these magazines in the young adult section of the library are texts that perhaps provide some evidence of the role of the 
modern library in meeting the requirements of many sections of the community. What the librarian described as texts on values are provided to inform young adults on topics such as teenage pregnancy, alcohol, solvent and cannabis abuse, eating disorders, HIV and AIDS. Also in contrast to the violent magazines is a collection of girls' magazines such as those described by Sara, Eseta and Maria including Dolly, Girlfriend, Sugar and Creme. Creme and Dolly are like a junior version of a popular magazine for women with many advertisements for makeup, particularly skin care. There are many photos of young celebrities and young models wearing fashion garments.

\section{Reading novels}

The data that describe students reading novels illustrate strong links in the configuration between the sites of neighbourhood, school and family. The students' learning about novels is mediated in the various sites of these agencies by peers, family members, school teachers, as well as by the texts themselves, movies associated with the texts, and advertising. The students had been asked to take photos of their uses of literacy outside the school, but a number were taken in the classroom. Perhaps it is a reflection of the strength of the agreement in values and curriculum between the agencies of school and popular culture that so many of the students' photos were taken in the school, mostly during silent reading time when the students were reading novels. Certainly reading of novels and enjoyment of reading are encouraged in the school (as part of the English curriculum), and this was also supported by the students' families. Primary schools in New Zealand place considerable emphasis on reading for enjoyment, and enjoyment of English is emphasised in each of the two curriculum documents English in the New Zealand Curriculum (Ministry of Education, 1992b, p.16) and The New Zealand Curriculum Draft for Consultation 2006 (Ministry of Education, 2006b, p.15). In the students' school a time for independent reading is included in the class programme, as well as time for visits to the school library and local community libraries. There was evidence of the value attached to children's novels on one of the researcher's visits to the school when the students and all the teachers were dressed up for the day as favourite characters from books. The teacher of the participants was dressed as a character from a novel in large goblin ears, a long wig, big boots and cloak, and had paraded through the main streets of the community with her class. This could be seen as a very public acknowledgement by the school staff of one aspect of children's popular culture being part of the school curriculum. 
The photos taken in the community library of students reading for pleasure are similar to several taken at school. Groups of students were close together, enjoying and sharing books. There were photos taken of students reading for their own pleasure at home too but these showed individual students reading rather than sharing a social experience with peers. Some of the photos showed the students in school uniform sitting on cushions in the library. Apekaila explained two photos both of which showed three girls reading in the library after school: "After school we always go to the library every day." In one photo Apekaila is reading a Tintin book as is one of her friends. The third girl is reading a 'game book'. Hana also presented a photo taken in the library of her and two girls reading Tintin and Asterix books. When asked about Tintin and Asterix they said they like these books as they like fun and adventures. The first librarian said that the girls reserve books, especially fiction series such as Jacqueline Wilson, while the boys tend to reserve DVDs from the young adult section.

One boy, Samasoni, presented four photos taken in another nearby community library after school. He explained that he went to this library because his family went to church in that suburb. He said they went to a Mass on Saturday and, "When we all go together to church and I want to go to the library they all come with me". One photo shows Samasoni seated at a table reading a comic in the series Justice League, which features ten superheroes such as Batman together. The JLA or Justice League of America consists of several well known superheroes such as Batman, Wonderwoman and Superman fighting together against the forces of evil with other less well known heroes. These comics were also available in the community library near the school. Although they contain fighting, the violence in these comics is less graphic than that in many computer games and computer game magazines. The values of the stories are those of good characters winning over the bad, so they do not represent a conflict with the values of religion as do some of the other texts. Samasoni also took a photo of his fifteen year old brother reading a book about the Titanic in the same community library. Samasoni explained that his family has the video of the Titanic movie at home and they watch it. This provides an example of how students are motivated by one type of text into enjoying another in what Marsh and Millard (2000) refer to as the intertextual world of related products, such as books, comics, magazines and films which provides rich opportunities for reading experiences by children. 
Sara was a frequent visitor to the library after school. In her journal she recorded that she read magazines, books and posters at the library. Hana also said that she and Eseta go to the library every day after school for an hour and fifteen minutes. She said that as well as reading, they play writing games such as scattergories. "It's a really really old game...name, animal, time, you have to fill in as many as you can and the first one that finishes ..." This practice was similar to another writing game that was played by the girls at school and illustrated by one of Hana's photos. She explained that they play games in the morning as they come to school really early, an hour before school sometimes, because their parents are off to work. However, it was only the girls who were involved with writing games. The boys did not do this as "They are usually downstairs playing touch".

One girl presented herself as an avid reader, and this was confirmed by comments from other students. Elisapeta had spoken in the second interview of her love of reading. She said she gets out about three books every second day from the library. "This year I found some really good books and I read a 235 page book in less than a day." Iosefa said "Elisapeta, she reads anything, she reads anything that she sees". Sara agreed with this and added "She reads anything that's like on the table".

\section{Appropriation from popular culture}

An example of a configuration of literacy use between sites rose in a discussion with Isaako in relation to writing. It is an interesting example in that he makes links to two fields of popular culture when describing a writing task, and although it concerns school literacy it is included here as there is a connection to popular culture practices in the neighbourhood. It is similar to Dyson's (2003) description in Chapter 2 of young African American children using their knowledge of popular culture material to make sense of, and participate in, school literacy when they began school. Dyson writes that although youth cultures have a global reach, the youth in various communities adapt them to their own needs and Isaako's explanation is an example of this. In a similar way to the students described by Dyson, Isaako used his own interest in, and knowledge of, popular culture to enhance his fictional writing at school. Isaako had written in a journal entry: "Reading is something you read to experience your writing so it could be interesting and use a bit of help from it and I am involved in it." When he was asked what he meant by this, his explanation illustrated how he appropriated material from a popular culture text in order to 
improve his writing at school. This example shows through the personal plane his participatory appropriation (Rogoff, 1995) of aspects of popular culture. His own words illustrate how he made sense of his teacher's challenge to improve his writing through linking to what is familiar in out-of-school practice.

He said:

What I meant is that when you read a book you could get some ideas from out of the book to make your writing interesting and a bit more active ... so people could understand your writing so that they know that there's something that tells us here that you are reading and bringing your ideas to your writing.

Although he did not say so, this idea seemed to be one that may have been suggested by his teacher. However, his decision was to use a text from popular culture rather than a more traditional school type of text to add this extra information. $\mathrm{He}$ explained the sort of information that he would get from comic books to add to his writing:

\footnotetext{
Now I'm reading Spiderman, so let's say that Spiderman was an intelligent person and you bring that idea into your writing ...but you change Spiderman into another word. One thing is expression...like when you are reading there has to be a lot of expression inside your book so they know what's really happening in the book.
}

When asked if he meant description of things, such as the details about characters and how they felt, he agreed "Yep. Something like that". The discussion went on to include expression when reading aloud and Isaako elaborated on this with a clear and original explanation which made a link to another field of popular culture:

What I meant was, if it was a scary book, there's no music, there can't be speakers around your book and stuff to...you've got to read it, there has to be expression inside it. You've got to add your own scary music into it cos there's no speakers...

An explanation such as this of how to enhance writing, offered in a young person's own words to others of his age or younger could be a useful support in school-type literacy. 


\section{2/ Support for "school-type" literacy in the neighbourhood site of the library}

As well as supporting literacy connected to popular culture, the library also supported what could be described as "school-type" literacy. The significance of this is that it demonstrates a connection of sites that nurture similar literacy practices for the students. Cremin's (1976) concept of configuration of settings helps us to understand how the students' literacy practices are mediated by individuals and institutions in their environment and at times these sites share similar goals and literacies. The sites for this school type of literacy represented by homework are the school itself, the library which is discussed in this chapter, and the family which is discussed in Chapter 6. Cremin explains:

Each of the institutions within a configuration interacts with the others and with the larger society that sustains it and that is in turn affected by it. Configurations of education also interact, as configurations, with the society of which they are part. (p.30)

The configuration of library, family and school is an example of a complementary relationship as in school type literacy for homework they have similar values and similar curriculum.

\section{Homework}

There was evidence of this relationship in several students' descriptions of doing their school homework in the library where they completed the regular tasks set by the teacher which sometimes involved research. It appeared that the teachers of this literacy in the library site were most commonly the resources of books, catalogue and Internet, although at times there might be assistance from adults or peers. The curriculum of this school type of literacy included reading books, newspapers, posters and other resources for information and recording from these sources. It also included knowledge of authors, book series, and the characters of popular fiction. As well, the curriculum included knowledge of using the library catalogue and researching and downloading from the Internet. These elements of the curriculum which were practised in the library meet the requirements of the official school curriculum in the Ministry of Education documents for teaching English (Ministry of Education, 1992b, 2006b). The second librarian said that students often settled in the young adult area of the library after school to do their homework, and some 
continued this routine after starting secondary school. This was confirmed for the researcher when on one of his visits to the library eighteen months after the photo elicitation interview with Isaako, he met him in his first year at secondary school. Isaako greeted the researcher in a friendly manner and said he was in the library to do his homework.

The library was seen by the students as a desirable site for doing their homework for several reasons. The students were able to assist each other. Some of the students said that its good resources made it an ideal place to do their homework. For example, Samasoni said that he goes with his friends about three times a week and they help each other with homework. "I do most of the hard homework in the library, because there's lots of resources, then at home I do the easy one". He explained that the resources are the big encyclopedias, other information books, and dictionaries.

Several students described using the computer in the library for researching school projects. The computer skills that the students were using in the community library were similar to those that they used in the library at school. For example, Apekaila said she got assistance from "The Internet. We're allowed to go on the computers. Do a Google search." This was to find information for a project for example. "The library people will help but only if you need it and ask them."

\section{The library's link with the school programme}

The complementary relationship between community library and school is seen in the regular visits by the students to the library with their school teacher and class during school time. During these students' visits to the library, the librarians were clearly the teachers of the skills that were necessary to access the library information. The curriculum taught by librarians and teachers in the library is similar to the curriculum taught in the school library, that is learning how to use the catalogue and locate books and other resources in the various sections of the library. The class teachers and community librarians liaise over the topics being covered in school during the term so they can prepare information to assist the students. The students' class visited the library to exchange books every three weeks through the year and the second librarian commented that what the students borrowed depended on what the teacher was encouraging at the time, for example whether they selected fiction or non-fiction books. If they were doing research for school they used the junior non- 
fiction section of the library rather than the young adult section. She considered that the after-school visits were more the students' own time, and they may not have their card with them and would therefore not take books out.

It appeared that on their after-school visits, the students only occasionally turned to the librarians for assistance. The first librarian said that students sometimes asked a librarian for assistance in researching a subject, but this did not occur often. It seemed as if the students were doing recreational reading more than homework or research for school. The second librarian said that the students had not asked for assistance from her when doing homework, and she considered that this might be because the students had gained the skills they needed to be independent during the teaching sessions when they came to the library with their class.

There was a practical reason for some students to spend time in the library after school as they were filling in time before they could catch their bus home or until adults would be at home.

For example, Iosefa said he went to the library on occasions when his aunt and uncle were to be home a bit later, so he went there to do his homework. Hana and Eseta said that they waited in the library each day before catching their bus home. When considering who are the teachers in this site, it is reasonable to expect that generally students would be given homework tasks by their teacher that they would be able to complete independently, that is without having to rely on expert guidance from a peer or adult. The students' conversations indicated that they had previously been guided in the skills required to complete their homework tasks. However, the following examples from the students indicate that there was some assistance provided by peers and occasionally the librarians. The conversations reflect more strongly Rogoff's (1995) community plane as the students have already been guided into the skills required for homework.

\section{The library as a site for socialisation as well as homework}

Although the community library was described by students as a place to do homework, the conversations in the interviews revealed another purpose for the library visits. Apekaila's photo showed three girls reading in the library after school. She said "After school we always go to the library every day." She explained that 
this was to finish homework and meet friends. When asked if this was like a social place she replied that it was. She said that they sit at tables to do their homework but it seemed that the visit to the library was a relaxing and socialising time as much as a working time. They enjoyed this time for relaxing with their friends and it seemed as if they had made the place their own. Their comments revealed what seemed like a contradiction in their reasons for going to the library, but comments foreground their thoughts on this. It can be interpreted that these young people who are at the start of their teenage years are beginning to face the issue of adult life of having to make decisions about balancing time for work and leisure. The discipline of setting aside time to complete homework becomes increasingly important for students as they approach secondary school age. These students went to the library because they had to meet the school requirement of completing their homework, but they also had the need to relax and socialise with their friends after a day's lessons at school. Apekaila said "After we read and talk we go and do our homework". When they were asked why they go to the library for homework, Apekaila replied "It's like silence. It's a place that we can focus and finish off our homework". Her partner Maria agreed. Two other students mentioned going to the library to do homework but it seemed that for them the library time was more devoted to reading for pleasure and socializing. When Hana said that she and Eseta do homework in the library sometimes, she giggled and added "Hardly ever". This contrasted with a view from Samasoni who went to another library after school. He said that it was easier to do homework at home because some children come to the library and make a noise that is distracting.

\section{3/ Literacy for finding and purchasing goods and services}

The shops in the neighbourhood which form the immediate physical environment for the students are also sites for literacy use. The curriculum that relates to these neighbourhood sites consists of finding and purchasing goods and services, and it is likely that the teachers of this curriculum will include family members. However, as the students made no specific connection between the family and shops and as shops form an obvious part of the students' physical environment, they are included in this chapter of neighbourhood sites.

Other teachers in the practices of literacy related to shopping are the students' peers, the adults who serve in the shops, and advertising. Although twenty percent of the 
students' photos were taken in the neighbourhood, only one boy took photos to represent the shops that he visited. However, his photos which are all taken in the main shopping area of the suburb are useful in representing the type of shops and their connections with literacy in the neighbourhood. They help to illustrate some of the literacies required for day-to-day living in the community.

\section{Reading the shops}

By far the majority of the writing that the students see in the neighbourhood sites is in English as explained in Chapter 5. Isaako's photos of the neighbourhood and his explanations of the photos allow us to foreground the individual as the focus for analysis. This personal level (Rogoff, 1995) reveals something of the social and cultural influences on this individual and is useful to remind us that the learning for each of the students in the study will be mediated by many different factors as their identities develop. The comments from Isaako indicate how he makes sense of his environment. He is representing his own unique view of his world but his explanations reveal how he has been guided through the social and cultural environment of his family.

Isaako, who was aged 11 years and said he spoke and read Samoan, used the photos and interview discussion to represent himself as a Samoan in a Samoan community in New Zealand. Seven of his photos were taken in the main shopping centre of the neighbourhood, which is close to the school and where the community library is sited. During the first interview when the boys were being given their journals and were discussing how they would record sites for literacy use, Isaako said, "I love shopping". His photos are interesting in that they show examples of the written language on the signs and advertisements of the neighbourhood that the students were exposed to every day and his choice of subjects represent the multicultural nature of the neighbourhood. His selection of subjects for his photos and his explanations of them illustrate his uniqueness as an individual in this environment. This foregrounds the personal plane (Rogoff, 1995) as he makes sense of his world and makes his choices in appropriation as he takes part in the social and cultural activities of the neighbourhood sites. Isaako provides a picture of his environment where his selection of neighbourhood businesses provide food, clothing, household goods, reading materials, his haircut, and assistance with family finance. 
Isaako explained why he had taken a photo of the shop sign over the footpath in the main street of the suburb. The sign read "Mr Bun Fried Chicken." He said "This is where I always go and eat. They have fresh as meats, they have stuff for you, every morning I come here and buy my lunch. I was trying to show you in my photos where I am going." This shop was also mentioned by Sara, who recorded twice in her journal that she read the lunch specials here. Food was also represented in the second photo that Isaako presented and was used to represent his family's cultural background (Figure 14).

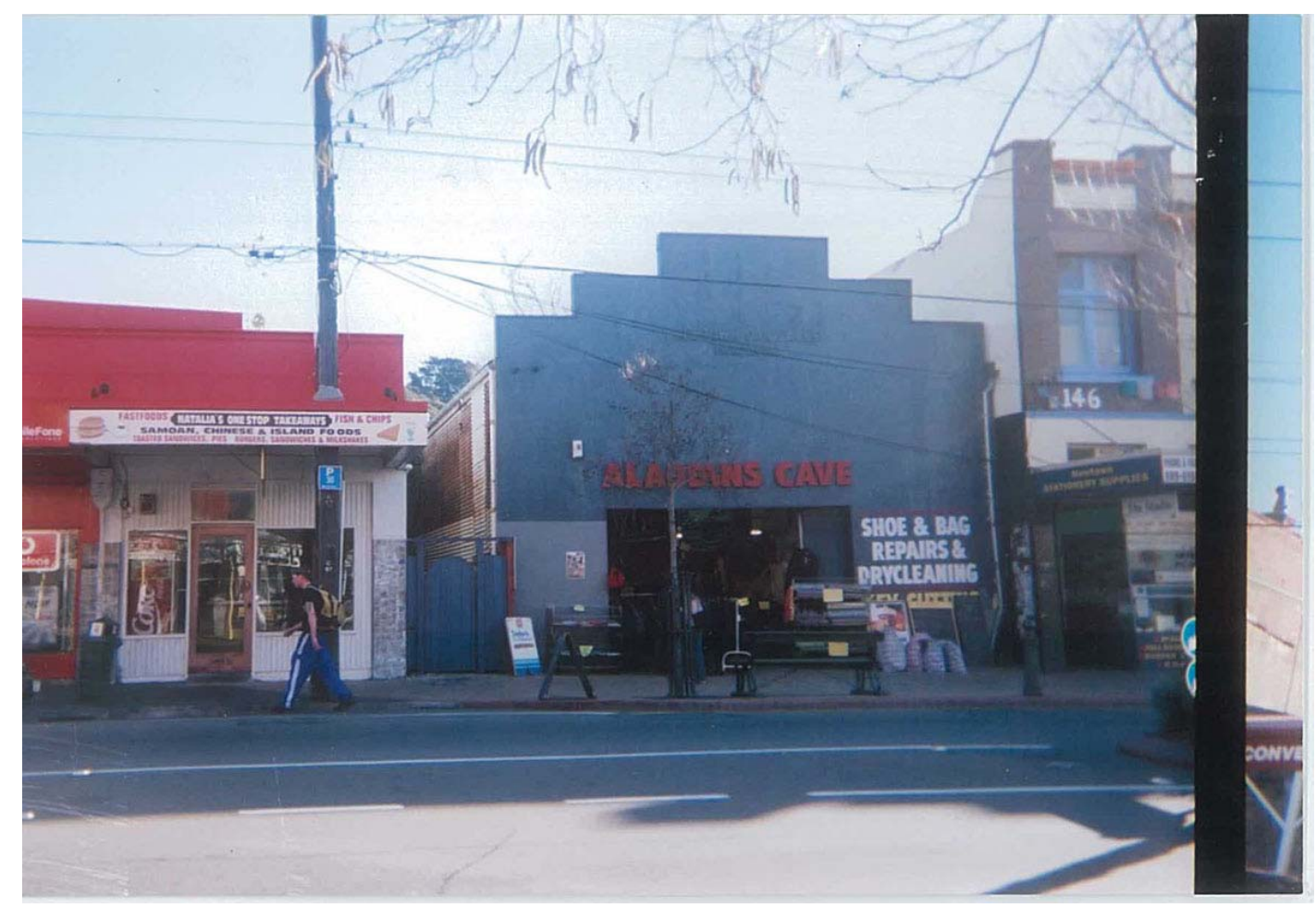

Figure 14: Local shops photographed by Isaako to represent his community and his culture

This photo looked across the main street of the shopping centre to a takeaway food shop selling Samoan and Pasifika food. The shop has a sign written in English advertising fast food such as pies and fish and chips but also Samoan, Chinese and Island foods. He explained that he took the photo as ... "the people who are selling food at this place, are representing our culture, our food that we eat in our own culture." It sells "Chop suey, taro, and there's a thing called pancakes." $\mathrm{He}$ explained in detail how cocoa rice is made with hard Samoan cocoa and rice. He explained that the foods sold in the shop were "...representing our own culture in New Zealand cos there are a lot of Pacific Islanders, Samoans, up in Auckland, Christchurch, Wellington, Dunedin." 
While Isaako has been enthusiastic in presenting these as his own ideas in relation to his identity it seems from his comments that he has been guided into these understandings through the social influence of his family and friends, and he has also learned the values and practices of his community. Another of Isaako's photos was of the local Cash Converters shop (Figure 15).

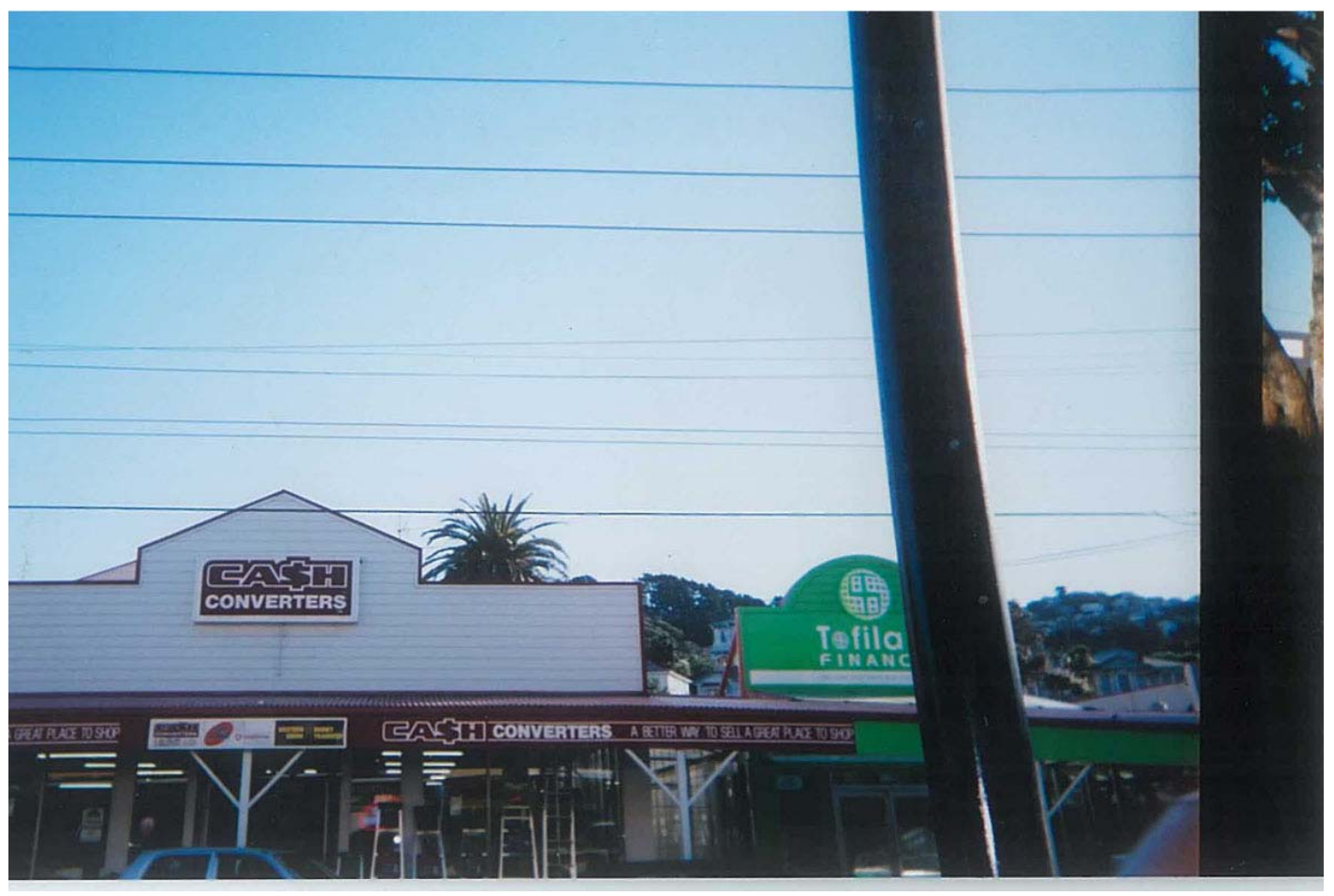

Figure 15: More shops photographed by Isaako to represent his community and his culture

He explained that he took the photo because he goes to the shop frequently and..."This is all about helping families and they are real cheap. People think they are not good and they are dirty but when they get in there they go 'Oh this is nice'. Cash Converters have been really helpful to families". Mareko was also familiar with the stock in this shop and mentioned that it sells Playstations. Mareko and Isaako were asked what stock they would look at when they went in. They each said the first thing they would look at is games.

Isaako's discussion illustrates his growing awareness of adult concerns about money and judgments about what it is appropriate to spend borrowed money on. $\mathrm{He}$ explained a photo he had taken of the premises of a finance company in the neighbourhood shopping centre (Figure 15) saying “...that's another way of representing our culture, helping New Zealand too." He seemed proud that the company is Samoan, saying “... what I was thinking there would never be a Samoan finance but then this showed up." He knew that the company had a branch in 
Auckland and said it helped people "with the money". He explained that in total there were three finance companies in this suburb and he mentioned the names of the other two. His attitude towards the finance companies seemed positive and his comments suggested that he saw that at times they were fulfilling a useful purpose. The researcher inquired what sort of things people might borrow money for and he replied: "If I was in the front of every one that was going to Tofilau Finance, I would just tell them the money is for you to help with your families and to buy furniture, things for your kids, whatever your family needs."

However, he knew that some people used the loans for non-essential items, and did not seem to approve of this saying, "But some people when they get the money they just use it on other stuff like...buying stuff like jewelry". Another of Isaako's photos showed shops in the main street and the premises of one of the other two finance companies. He said he took this photo of the finance company "...because my dad is with them." My first impression was that his father worked for the company, but he explained that his father had borrowed money from the company.

Books were sold in the neighbourhood and the only example of this presented by the students was in one of Isaako's photos. He discussed a photo of a book about cats that he had purchased explaining he chose it because "I like the pictures. I like reading those kind of little books. And I love reading easy novel books". He also had a photo to represent where he bought the book, the photo showing a sandwich board on the footpath outside the shop. He said he goes in there to look at books because "I love looking at books". When the researcher looked for the shop later he found it was a second-hand book shop, but Isaako was not able to describe it as such.

Other photos taken by Isaako helped to complete his presentation of his environment. One of his photos showed a clothing shop where Isaako said he went to buy his clothes. His partner Mareko also said that he bought his shoes there. Another photo taken by Isaako showed the premises where he gets his hair cut.

Some of the girl students said they looked carefully at labels when they were in shops as they were very interested in reading the ingredients of the foods they ate. Elisapeta recorded in her journal, "I use literacy when I want to buy something from the shop. I read the price tag, what it's called e.g. minties and what kind it is e.g. sour lollies." 


\section{4/ Literacy for navigating one's way in the neighbourhood}

This study shows how children make sense of their world and this chapter has presented several sites for literacy in the students' neighbourhood. By this age of 11 or 12 years the students are becoming independent in their movements as they go to and from school, the library, shops and other sites in the neighbourhood and into the central city. One of the practical uses of literacy which can be described as navigation is for people to find their way around the neighbourhood and beyond. The students were sufficiently mature to be allowed by their parents to travel on buses into the city centre to go shopping and to movies, and some of them regularly caught buses to and from school. The curriculum for navigating the neighbourhood includes reading signs on shops and public buildings, reading bus timetables and telling the time, reading notices, price tags and labels, advertisements, and street signs. These are skills that are nurtured largely by families, and the teachers of this are the students' parents and other adults including teachers at school and their peers. This curriculum is included here as most of the students' comments were concerned with using the skills of navigation rather than learning them.

The most common examples of reading in the neighbourhood for the purpose of navigation were reading the bus timetable and reading bus tickets. This was important to many of the students as they caught buses to and from school, once a week to technology classes in a nearby suburb, and sometimes into the city. Several of the students' photos were concerned with using the buses to move around the neighbourhood. Sara and Iosefa discussed using buses and Sara presented a photo of Apekaila at the bus stop on her way home, checking her bus ticket to see how many rides she had left. Iosefa said he caught two buses while Sara said she sometimes goes to town on the bus on Fridays. They both read bus timetables and they conceded that they are rather difficult to read, with Sara commenting that she always got her mother to help her. Hana explained a photo of her reading the timetable at a bus stop in the school suburb, "We were at the bus stop trying to figure out what bus to catch" in order to go to the next suburb for the technology class. Reading various timetables can be challenging so the researcher asked her what she thought about reading bus timetables and she replied, “At first it's confusing ...but then you get used to it after a while". 
Hana was asked if she read bus timetables very often or did she just know when to catch the bus. She answered "When no one else is there I read the bus timetables but if there's a huge group I'll just follow them." She meant that she would follow her peers who were going to the same destination as she was. Each week all of the students caught the bus to technology class which is at a secondary school in the next suburb. They make their own way over there but usually travel with somebody. Hana also took a photo to represent their use of buses in the neighbourhood of her friend at the bus stop counting her change. She represented counting of money as a literacy use. Four photos taken in the pilot study photos were connected with bus travel, including signs that were read on the bus and a bus timetable at a bus stop. A number of the pilot study photos represented the reading required for finding the way around the neighbourhood, including street signs.

\section{Conclusion}

In conclusion, the findings indicated that the majority of literacy practices in neighbourhood sites were those related to popular culture. Others included "schooltype" literacy which took place in the community libraries, literacy for finding and purchasing goods and services, and literacy used by the students to navigate their way in the neighbourhood. The examples in this chapter from neighbourhood sites for literacy help us to build on our understandings of how the literacy learning of these students is mediated through their family, religion and school, and how participatory appropriation (Rogoff, 1995) transforms their understandings of literacy. As Rogoff suggests they are not simply gaining understanding through transmitted knowledge but they are active participants in social and cultural activities as they make sense of their world and create identity. The examples offered by the students in Chapters 6 to 8 illustrate apparent confidence in their growing competence as they negotiate and construct literacy practices in sites outside the school. They also illustrate the students' growing ability to successfully navigate the conflicting values of the various sites for literacy, and these points are dicussed in the following chapter in relation to school literacy. 


\section{CHAPTER 9}

\section{Discussion}

\section{Introduction}

The previous three chapters have offered examples of actual out-of-school uses of literacy selected by the Pasifika students which they had chosen to represent their interests and values. These examples might be interpreted as contributing towards our understanding of how their learning is mediated in different sites and how their identity as literacy learners is constructed in relation to the literacy practices evident in each of these. This work challenges deficit views of Pasifika students, and illustrates the uniqueness of the individuals who took part in this study and their many interpretations of literacy use and practice. Their practices in various sites suggest that literacy may also be one of the tools by which students make the transition between cultures. The perspective which has been used in this study focuses on how individuals learn particular social practices and the studies described in Chapter 3 (Heath, 1983; Scribner \& Cole, 1981; Street, 1984) illustrate the complexity of literacy as practice. Each of these studies also illustrates how it is crucial when exploring literacy to recognise that skills are not decontextualised but are learned within a meaningful context in the social setting. Chapters 6 to 8 have offered examples of such contextualised skills from the Pasifika students and Chapter 9 discusses the results of the study.

The first research question was:

What are the uses of literacy associated with the sites such as family, church and neighbourhood?

The most usual definitions of literacy are associated with school; that is, forms of literacy which Street $(1984,1995)$ calls autonomous. The study, however, based on a framework derived from the work of Cremin (1976), identified a range of uses for literacy which varied according to site. Nevertheless there were connections between and across sites and school type practices were found in both family and church. The photographs taken by the Samoan students in the sample, and their use to facilitate discussion, provided an insider's view of the diverse literacy practices in these sites. While the study began with an expectation that literacy would be identified in family, 
church and neighbourhood, the insiders' view showed literacy uses in popular culture. The library also emerged as an important site. The literacies that have positive value for the students can be considered in Street's $(1984,1995)$ terms as ideological, a term which was explained in Chapter 3.

The second research question was:

Where and how is the literacy learning of year 7 and 8 Pasifika students mediated in out-of-school sites?

Cremin's (1976) framework reveals the sites where the students' learning is mediated and where there is overlapping support or conflict between the sites of family, church, neighbourhood and school. The interviews with students and adults revealed that these sites have their own curriculum, values and teachers who mediate literacy learning in different ways. The study identified that for some literacies, such as religious practices relating to the Bible, the sites work together in a network to mediate the students' learning. The teachers who were the mediators, initiating students into new skills and practices, included the students' adult relatives, their Sunday school teachers, peers, non-adult relatives, siblings, as well as various types of texts.

Rogoff's $(1976,1995)$ description of three planes of analysis revealed the students' interactions with these teachers as their learning was mediated in various communities of practice. For many of the students the church was a significant mediator of learning. Rogoff's planes of analysis revealed how each level of mediation could be identified in relation to a particular literacy practice such as learning tauloto. The interviews with students and adults revealed through the community plane how students' literacy learning is mediated into the practices of the community. For example, the shared cultural values of the community led to the fostering of the Samoan language in family and church sites and the teaching of tauloto. Rogoff's level of guided participation revealed how adult family members and Sunday school teachers guided students in their learning of tauloto while the interpersonal plane illustrated from the individual student's perspective how they practised and learned this. 
While the neighbourhood sites shared some common values with family and school, it seemed that in neighbourhood sites the mediation of students' learning was mainly through peers, young relatives and advertising. This was in contrast to family and church sites where there was a more conservative influence from adult relatives and church members. Rogoff's interpersonal plane revealed that students were active participants in appropriating the less conventional literacies of popular culture in neighbourhood and family sites and it emerged that the values of these literacies were most likely to clash with those of family, church and school.

The third research question was:

What are the implications of the practices across the configurations of sites for students' literacy learning in school?

The breadth of opportunities for becoming literate should make teachers and others wary of judging the literacy of individuals by reference only to their literacy in school. The results provide an understanding that opportunities for becoming literate exist throughout a literate culture but the role of different sites may vary. In the culture experienced by the Samoan students the church was responsible both for specific practices of literacy and the values associated with its use. In the second place the students reported experiences such as those associated with popular culture which might serve teachers as topics for exploration with students. While traditionally school literacies may differ considerably from the range of literacies experienced by students in out-of-school sites, it seems that at present teachers are free to interpret the official school curriculum in a sufficiently broad way to incorporate students' expertise and interest in out-of-school literacies into school programmes. This requires teacher knowledge of those literacies and acceptance of them as valid. These issues will be discussed further later in this chapter.

As Chapter 1 outlined, literacy learning takes place in sites in addition to the school. When all the sites that mediate student learning are considered, the relationships between the values of institutions in the configuration are made clear as consonant or dissonant (Cremin, 1976). Where there are differences, individual students have to reconcile these somehow as they make sense of their world. 
Chapter 9 is structured in two parts.

- Part One discusses the configurations of students' sites for literacy learning and the complementary and conflicting features of these. It is of value for teachers to be aware of how literacy practices in these sites work in a complementary way to mediate the students' learning. It therefore describes the overlap of values, curriculum and pedagogy between the sites. It is also essential that teachers are aware of possible conflicts that the students may face between the values, curriculum and pedagogy of their sites for learning as these may impede learning at school.

- Part Two discusses what can be learned from these results for school practice. This is a response to the demand outlined at the beginning of this thesis for teachers to have a better understanding of students' out-of-school literacy practices and of their cultural backgrounds in order to support students to achieve success in school literacy (Ministry of Education, 2003a, 2006a). Part Two has two main sections. The first (Section A) includes discussion of issues related to the conflicts and complementarities in literacy practices which were outlined in Part One. Teachers need to know of the possible complementary and conflicting values and aims that their students face in different sites and their implications for learning. They also need to be able to assist students to make links between sites. Section B discusses how out-of-school practices and expertise can be linked to school practice to enhance learning. Chapter 2 described how success is enhanced when effective connections can be made for learners in school through what McNaughton (2002) describes as "incorporation" where the teacher or student may build on the familiar or may unlock what is unfamiliar. $\mathrm{Au}$ (1980), Amituanai-Toloa (2005) and McNaughton (2002) describe examples of this strategy.

Many of these points do not apply exclusively to Pasifika students but an understanding of students' individual and group identity and their out-of-school practices will reveal the uniqueness of ways with words (Heath, 1983) of class members and suggest many opportunities for incorporation into classroom practice. This teacher knowledge is not derived from skills testing but from an understanding of the students' cultural and social environment. 


\section{PART ONE: The CONFIgurations With THE CONSONANT AND DISSONANT FEATURES OF SITES}

Chapters 6 to 8 illustrated how family, church and neighbourhood emerged (in addition to the school) as key sites for literacy practice and how each of these sites has its own values, curriculum and teachers. Chapter 2 described how, historically, literacy has been learned in many sites in addition to schools (for example Barton \& Hamilton, 1998; Cremin, 1976; Graff, 1987b; Laqueur, 1976) and the findings in this study support this. The literacy learning of the Pasifika students is mediated by many teachers in many sites with different values, and it is necessary to look across all the sites to try to gain an understanding of the various elements in their world of which they, as literacy learners, have to make sense. These relationships vary from student to student. They may need to come to terms with conflicting values between sites. Not only do the institutions in each site mediate the students' learning, but they perform a mediating role in relation to the other sites and also to society at large (Cremin, 1976).

The work of Scribner and Cole (1981) outlined in Chapter 3 is relevant to this study in illustrating the complexities of the socially organised practices into which people are apprenticed. Their work demonstrates how skills are located within these practices, and the knowledge of the skills is for very specific uses in particular contexts. The work of Street (1984) outlined in Chapter 3 is also pertinent to this study in emphasising the utmost importance of social settings for skill use and considering literacy skills as integral to specific practices. Street's view that these practices are related to the ideology and infrastructure of a community and can be explored as a process of socialisation rather than a technical process is useful in interpreting the configurations of sites in this study.

Earlier this thesis presented Cremin's (1976) argument that institutions which educate demonstrate literacy as a tool of cultural knowledge of the groups who participate in them and who have social power. The previous three chapters have illustrated how in the various sites of family, church, neighbourhood and school, which mediate the students' learning, the social power is held by different groups including parents and other adults in the family, as well as church officials and corporates who control popular culture. The schools, however, are essentially controlled by papalagi who are the dominant group in New Zealand society. 


\section{Section A: The complementary relationships: The overlaps between sites}

\section{The configuration of family with other sites}

The families in which the students were nurtured were very important sites for mediating their literacy practices, and the formation of their identity. The relationships where the values implicit in the literacy practices in the configuration of family and other sites appear to be complementary are illustrated in Figure 4. These sites included the church, school and the neighbourhood and this has been discussed in the results in Chapter 6. The family is a significant site for literacy learning and families are powerful mediators of their young people's learning. Many parents want a better education and life for their children. One of the main functions of the family is to socialise its children into ways of thinking and acting that are appropriate for the community to which it belongs and one of the goals of socialisation is to become literate (McNaughton, 1995). The students' explanations provide an opportunity to explore how the sites mediate their learning and help them in forming their individual and group identities. They provide an insider glimpse into the pathways the students choose as they operate in different sites and different cultural settings.

The data from this study show where the values of the family overlap with the values of other institutions and the relationship of family and church emerged as significant. There was a strong emphasis on family literacy practices to support religion. An indication of the power of the church is seen in the ways the students' families actively supported the values of the church through their literacy practices.

The content of the curriculum was largely centred on the Samoan and English Bibles, but the pedagogy was also important with its emphasis on traditional Samoan ways of memorisation and performance as described by Tagoilelagi (1995).

These strong links between the family and church, which emerged from the data, demonstrate the continuing influence of the church in literacy and are a link to the historical influence of the church described in Chapter 2. The strong configuration of family and church was emphasised by Cremin (1976), and the findings in Chapters 6 and 7 offer examples of these two sites having a shared curriculum which, as Cremin puts it, is taught "...deliberately and systematically over time" (p.22). The complementary practices as described by the students demonstrate that more than reading and writing skill is required to participate in the practices. Cultural and 
social knowledge are also needed. As Cremin states, the curriculum includes not only the technical skills of the institutions in the various sites, but also the required social skills for carrying out the activities with others according to the expectations and routines of the institutions.

This complementary relationship of values included the family and school and, to an extent, it included the family with school and neighbourhood sites. Chapter 4 introduced Bourdieu's (1974) notion of how families transmit cultural capital to their children and how schools continue inequality of opportunity for all by adopting the cultural capital of the middle classes with the assumption that all children have equal access to this. Bourdieu's theory was concerned mainly with the reproduction of class inequalities in the schooling system and is an explanation for lower achievement by non-mainstream students. However, in spite of the reported underachievement in literacy of many Pasifika students in New Zealand (outlined in Chapter 1), the data from this study revealed connections between the cultural capital of the families and that of the school. The practices discussed in Chapters 6 and 8 included students nurturing school type reading skills with younger children in the family, families supporting school literacy (for example through homework) and students reading and writing the words of popular songs. These practices reflected overlapping values between the sites, but there were also conflicting values where it might be said that the cultural capital of the families did not match that of the school and these are discussed later in Part One.

\section{The configuration of church with other sites}

The practices situated in church and other sites that shared common values and pedagogies have been discussed in Chapter 7. Most of the literacy practices that were described by the students as being for church and Sunday school were also situated in the family sites, and some were situated in the school. This configuration of sites illustrates a sharing of community values and is a modern representation of the power of literacy in the church, illustrating what Luke (1994) terms as cultural knowledge and social power. The examples of literacy practice in the findings chapters illustrate how the church exercises considerable influence over the educational practices, cultural practices and language uses of the students and their families in this community. The concept of particular communities having universal values, which contribute to social cooperation, is described by Schweigert (1999) in 
the context of restorative justice. The individual is held accountable to a community and to an understanding of right and wrong, with the restorative practices helping the miscreant back into the traditional values of the community. In a sense, the moral values are part of the glue that holds the community together, and in a similar way, the values related to Bible literacy contribute to the Pasifika community in this study being held together. The students' insider views of literacy practices reveal family, church and school ways of doing things which conform to certain common values that the community holds dear. In a parallel way, Schweigert's (1999) offenders "are held accountable not only to the procedural values of the state but to family commitments to standards of behavior, good character, religious norms, cultural expectations, interpersonal trust, and familial loyalty and reputation" (p.32). He concedes that while there may not be consensus on these communal values in the larger society or the restorative justice conference:

\footnotetext{
...but they are part of the moral fabric of each person's life as a member of a family and of overlapping networks of community support. These are values that arise from a comprehensive view of the right and good, rooted in familial and cultural and religious traditions. (p.32)
}

This type of social cooperation is reflected in the data from the students and church representatives in this study. These complementary relationships in the configuration of church and other sites are illustrated in Figure 4.

\section{The configuration of the neighbourhood with other sites}

The literacy practices situated in neighbourhood sites have already been discussed in Chapter 8. The majority of the literacy practices that the students described as situated in these sites were related to uses of popular culture, and this curriculum was also shared with the family and school. It may be that the students selected so many aspects of popular culture to illustrate their literacy practices because popular culture is such an intrinsic part of the students establishing their individual and group identities over which they have control. The data in Chapter 8 illustrated how the students appropriated aspects of popular culture for their own, and they built identity with particular fashions, music and magazines, for example providing instantly recognised codes of identity (Kenway \& Bullen, 2001). Chapter 3 discussed how the individual's identity links them to various groups in society (Collins \& Blot, 2003; 
Ferdman, 1990; Gee, 1996) meaning that the individual may have many identities and their codes of identity may link them to different groups.

The complementary relationships of values in the configuration of neighbourhood and other sites are illustrated in Figure 12. Many literacy practices were included in the configuration that encompassed neighbourhood, family and school sites. These are examples of communities of practice described by Wenger (2006) who writes that people engage in different practices and behave differently in the different communities of practice to which they belong. Having multiple identities means that our participation in different practices "can interact, influence each other, and require coordination" (p.159). Wenger uses the term "trajectory" (p.154) as a concept to suggest the paths that people's identities take within and across communities of practice. This study has shown that the use of the Samoan language was a strong mediating factor on the identity of the Pasifika students, and this is reflected in their literacy practices across their communities of practice. Wenger describes identity as "more than just a single trajectory" but "should be viewed as a nexus of multimembership" (p.159). This concept is useful in raising an awareness of the complexities faced by these young people who are choosing paths through very different communities of practice, their learning mediated by parents, grandparents, priests and ministers, Sunday school teachers, as well as peers and the texts of popular culture. The complexity is revealed through Cremin's (1988) explanation:

\footnotetext{
We have a theory of education whereby each of the major educative agencies performs a mediative role with respect to the others and with respect to society at large. The family mediates the culture, and it also mediates the ways in which religious organizations, television broadcasters, schools and employers mediate the culture. Families not only teach in their own right, they also screen and interpret the teaching of churches, synagogues, television broadcasters, schools, and employers. One could go on and work out all the permutations and combinations. (p.23)
}

All of these relationships between sites for literacy acquisition and use have been complementary and share common aims, values and pedagogy. For example, the teachers in family and church sites have a common curriculum and pedagogy in teaching the tauloto, and share the aim of maintaining Samoan language and culture through literacy practices. It is likely that the learning of these students is mediated in a powerful way when the educational institutions that play a significant role in their lives share common curriculum and pedagogies. The following section 
discusses the relationships between sites where there is a conflict of values. As with the relationships in the configuration where there are complementary values, this will vary from student to student.

\section{Section B: Contradictory values: The conflicts between sites}

It appeared that there were three broad areas where the relationships were contradictory and might result in conflict within sites or between sites for some students. It would be helpful for teachers in schools to be aware of these possible conflicts faced by Pasifika students as the students operate across sites, which may have different values that may at times be in conflict, and these may present barriers to teachers and students being able to make effective connections (McNaughton, 2002) to school learning for the students. These areas of conflict are described in the following section of this chapter in turn under the following headings:

1. Cultural and social perspectives on popular culture

2. Cultural perspectives on reading

3. Cultural and social uses of language: Mother tongue or dominant language.

\section{Cultural and social perspectives on popular culture}

The interviews revealed for some students a clear conflict of values between family members in family sites over the literacy curriculum of popular culture. The data also revealed conflict between the values implicit in the literacy practices of neighbourhood sites on the one hand, and family, church and school values on the other. These contradictory values in the configuration of family, neighbourhood, church and school are illustrated in Figure 16: Cultural and social perspectives on popular culture: Conflicts between sites and within family sites. The issues of conflict arose in the popular culture fields of computer games, magazines, comics and music where at times there was swearing and images of violence. The themes of violence are part of the curriculum of popular culture which may clash with the values of family and church, illustrating Marsh and Millard's (2000) point that the most concern for parents and teachers about computer games is the amount of violence in the games, with most of the popular games involving some level of violence such as fighting and killing opponents. 


\section{In family and neighbourhood sites}

In family and school sites

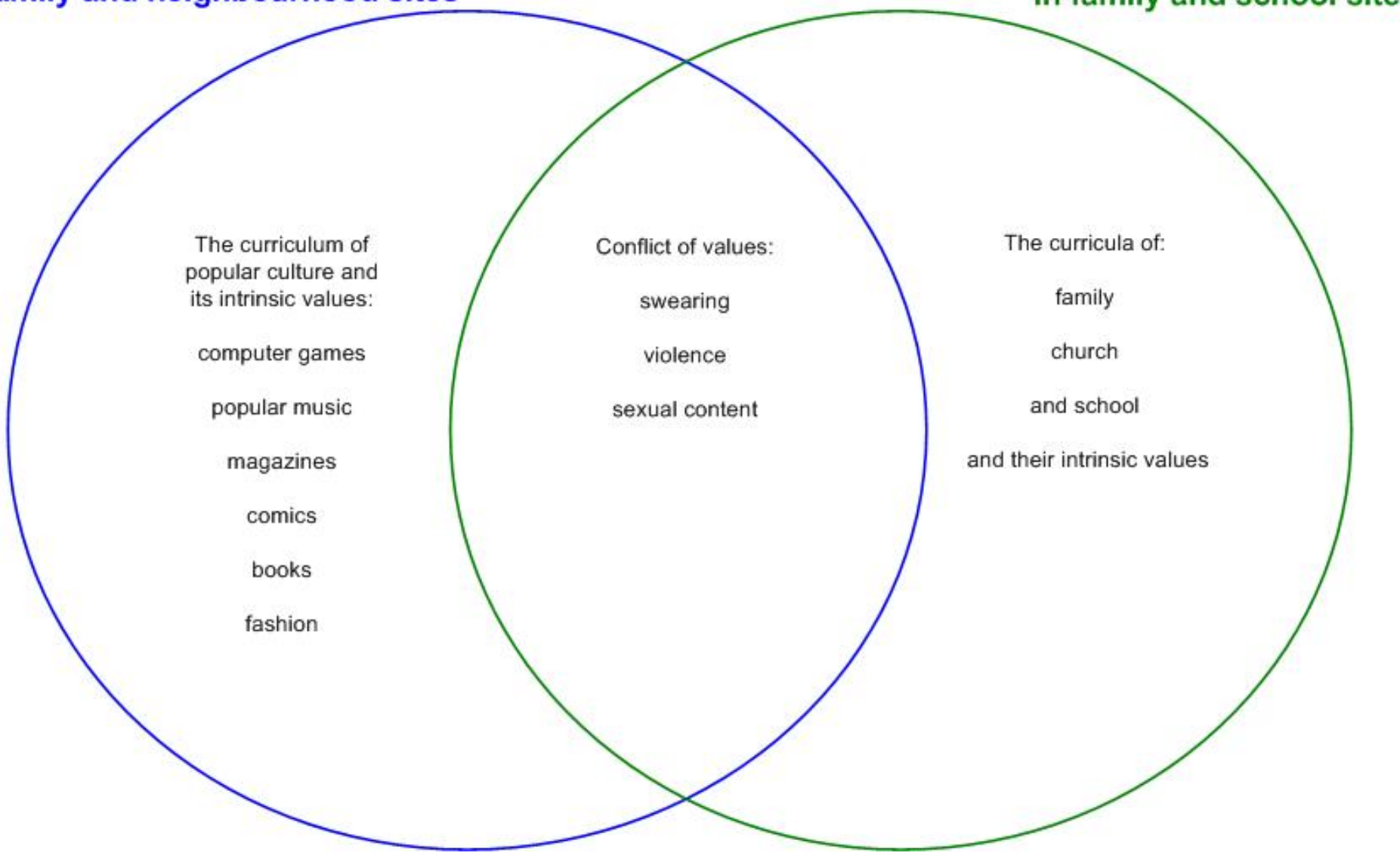

Figure 16: Cultural and social perspectives on popular culture. Conflicts between sites and within family sites 
Chapter 6 describes how some of the boys expressed an interest in violent computer games in relation to the family site while another spoke out against violence and swearing. Some boys enjoyed rap music and described how their parents did not approve of the swearing in the music. Teachers in their school were also critical of the language in some music CDs, and would not allow the children to play them at school. The themes of violent images and actions seem to be in direct contrast to the Christian message taught in their homes, the church, Sunday school, and the school, and perhaps exemplified by Isaako's comment in Chapter 7 that at Sunday school they always seemed to copy out the Ten Commandments. One of the church representatives (B) stressed the need for young people to be able to make judgments to separate good from bad, and spoke out strongly against swearing as an example of something bad they learned from television and videos and which they saw in graffiti. This is a transmission of values and on the basis of the evidence of what they said, it was the encouragement of a literal understanding of the Bible and an interpretation of life against the given truth in the Bible.

Although the violence in the computer games as the boys described in Chapter 6 may represent a clash of values, children can learn to make critical judgements about good and bad from these games. Luke (1997) writes that as children are immersed in the texts of popular culture, they develop understandings of good versus evil as well as heroes and heroines, and although many parents and educators find youth culture objectionable, not all texts should be seen as morally bankrupt or socially corrupting. The students in this study were aged 11 and 12 years, and at this stage of their development the conflict may not be as great as might be found with older children. However, a point to consider is that if popular culture grows in relevance for these students as they grow older, it might bring them into greater conflict with the values of the church.

\section{Cultural perspectives on reading}

The possible conflict of values and pedagogy in relation to reading practice is the most complex of the issues discussed under the heading of contradictory values. The aspects of reading pedagogy that may be considered contradictory between sites of church and school are intertwined with those that are complementary, so they are necessarily discussed together in this section. The configuration of church, family and school share a common belief in highly valuing the ability to read accurately, 
and this was seen in the practices of reading to study the Bible, reading aloud accurately to an audience, and reading to learn the tauloto. Chapters 6 and 7 described the practices and pedagogies in relation to reading in the family and church sites. This overlapping illustrates the common curriculum and values that are shared in these sites. It seems that an area of dissonance is that the pedagogical and practical focus in church and family sites was more on emphasising reading for a literal understanding of text rather than reading to foster a critical thinking approach to text. See Figure 17: Differing cultural perspectives on reading processes: the need for mutual understanding. Caution is required in assuming that only a literal interpretation was fostered in the church and family sites. An emphasis on literal interpretation is what would be expected because the aim of the practices which involve Biblical teachings is to transmit the cultural values of the community which accepts the authority of the Bible. This means that reading God's Word must be entirely accurate and understood in a literal sense. The authority of the Bible is not to be challenged in a critical literacy sense where it would be interpreted in relation to power, but the individual reader or hearer of God's Word is able to interpret the writings and apply them to their own world. However, where there are different cultural perspectives on reading, it would be useful for teachers in schools to develop an understanding and respect for the church perspective and for teachers in church sites to understand that schools are required to teach children to critique texts.

This literal reading and interpretation at higher levels is explained by Tagoilelagi (1995) who writes that the Bible holds an authoritative position in the beliefs of Samoan people, and to question the contents of the Bible would be regarded as a disturbance of the peace which the teachings convey. This represents a literal interpretation of the text. However, she argues that Samoan people do question the Bible and interpret it, "but the original writings remain pure and untouched" (p. 74). Tagoilelagi gives the example of her church youth group conducting a Bible session where the members read the chosen passage before analysing its content: "They can later share interpretations of what was read, but the reading of the Bible has to be done in the most correct pronunciation" (p.74). This places great emphasis on accurate reading as a performance, which was experienced by the students in this study. 


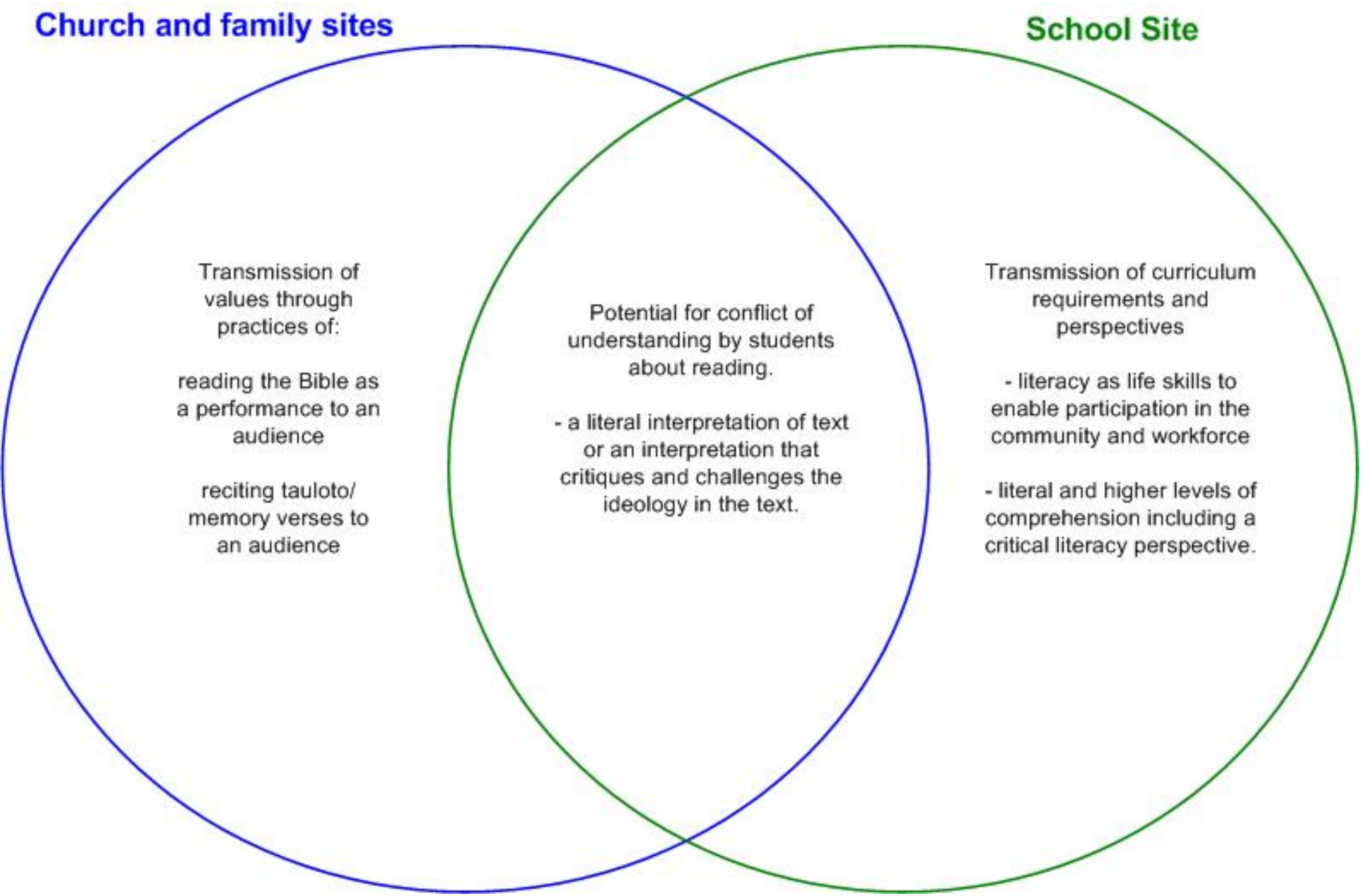

Figure 17: Differing cultural perspectives on reading processes: the need for mutual understanding 
Although the three church representatives stressed the need for very accurate oral reading of the Bible, they also stressed the need for students to be able to relate the content to their everyday lives. Two examples from the Sunday school teaching illustrate this. Representative B explained that the students acted out Bible stories "It's part of their proclaiming the gospel, a Bible story for them to act out. Sometimes we will bring out the Bible stories and relate it to the way of everyday living, so we act it out in today's modern times." Representative C spoke of the need for students to be able to explain in written tests Biblical terms such as Trinity in their own words. She stressed that more than memorisation of definitions was expected with students offering their own explanations of what it meant to them. The purpose of the learning was "that they relate it to their own world and everyday life." Although this could be interpreted as going beyond a literal level of comprehension, the interpretations will remain within the accepted interpretations of the church curriculum.

It would be expected that the reading practices of church sites with their emphasis on accurate decoding and literal understanding are consistent with the practices of the school in relation to religious teaching and with teaching students a literal level of comprehension on a variety of texts (described in Ministry of Education, 2003a) and going beyond this information in the text to use comprehension strategies such as those described by the Ministry of Education (2006a, p.36), for example, making connections with prior knowledge, making inferences, and identifying themes. It may be that these practices represent a different way with words from that of school for some Pasifika students, in a way similar to that described by Heath for children from her Trackton and Roadville communities. Some children acquired what Heath refers to as "linguistic and cultural capital," and this matched that of the school.

In considering these different ways of looking at reading where some appear to be complementary between sites and some contradictory, it should not be assumed that the curriculum and values of one site are "correct", and those of another site "incorrect". The point is that the social and cultural values are different and because the students operate in all these sites, there may be conflict for some students.

Clearly, the purpose of the church curriculum is not to foster a critical literacy perspective as described by Freire and Macedo (1987) in Chapter 2. They argue for 
literacy to be analysed in ways to see if it serves to maintain existing social formations or to promote emancipatory change. Their argument for critical literacy is to inform individuals of the power relationships in society with the purpose of changing these structures.

Other writers (for example Au, 1995; Au \& Raphael, 2000; Lankshear, 1997; Luke, 1997; Marsh \& Millard, 2000; Morrell, 2002) argue for critical literacy to be included in school literacy programmes, and this is discussed further in Part Two of this chapter with implications for teaching practice. Critical literacy enables readers to consider the ideology of various texts through the analysis of language, and how this relates to power relationships in society. This view of literacy fits with Street's ideological paradigm of socially constructed practices described in Chapter 3 (Street, 1984, 1993, 1995, 1997, 2003).

Arguably this is similar to Heath's (1983) description of different groups of people having different ways with words. Heath describes school as not being a neutral and objective place for all the children in her study with only some having the linguistic and cultural capital that matched that of the school. Chapter 3 explains how the pedagogical practices and cultural assumptions of the Townspeople's homes matched those they later found at school. It may be that for some Pasifika students there is an element of this mismatching of cultural capital in relation to reading and interpreting texts. The school curriculum places a strong emphasis on critical thinking (Ministry of Education, 1992b, 2006b) and teachers need to be aware of differing cultural interpretations of reading that may be faced by the students.

The English curriculum statement (Ministry of Education, 1992b) strongly emphasises "thinking critically" as an achievement objective at each level of the curriculum for compulsory schooling. The new draft English curriculum (Ministry of Education, 2006b) also includes critical thinking at each level and introduces a critical literacy perspective. For example, at levels three and four (the approximate levels of the students in this study), students are to show an understanding of how texts are shaped for different purposes and audiences, and to identify particular points of view and evaluate the reliability and usefulness of texts. 
Educators need to consider if there is a mismatch between students' home literacy practices and those of the school. The issue is not raised in relation to the students in this study but generally of Pasifika students in New Zealand schools, as it is possible that some students may have a different perception of reading which is appropriate in their own cultural setting, but not in the school. The teachers who criticise the lack of comprehension by Pasifika children are referring to oral reading rather than silent reading. In considering their overrepresentation in negative educational statistics, the students are described as Pasifika and when teachers discuss them they are described as Pasifika or perhaps Samoan, and it may be assumed by some that this "difference" in ethnicity is an explanation for lower scores. However, it is useful to remember Heath's explanation that the differences in educational achievement in her study were not explained by race. She writes that the place of language in the cultural life of each of the groups she studied was interdependent with the habits and values of that group. This study has also focused on how behaviour is mediated through culture and how language practices are part of the group's shared learning as a way to explain the Pasifika students' literacy practices.

Literacy is culturally defined and, therefore, has close links to cultural identity (Ferdman, 1990). When there is a mismatch between literacy as it is represented and valued in a person's cultural identity and in the learning situation, the individual has to make a choice that has implications for their own literacy acquisition and for their relationship to particular texts.

As Ferdman explains "the student must either adopt the perspective of the school, at the risk of developing a negative component to his or her cultural identity, or else resist these externally imposed activities and meanings, at the risk of becoming alienated from the school" (p.195). Ferdman comments that for children from the majority culture, the perspective of the school is likely to parallel their cultural identity; this is less likely for children from ethnic minorities. This can be explained by the students considering certain experiences as "owned" or "not owned" by their group (Ferdman, 1990), and is analogous to McNaughton's (2002) description of "incorporation". Ferdman writes that "When a child perceives a writing task or a text and its symbolic contents as belonging to, and reaffirming, his or her cultural identity, it is more likely that he or she will become engaged, and individual meaning will be transmitted or derived. In contrast, those tasks and symbols that serve to 
deny or to devalue aspects of the individual's cultural identity, or even those that are neutral in relation to it, may be approached differently and with less personal involvement" (p.195).

As an example he writes that "a child who, for cultural reasons, is accustomed to reading aloud with a group, may approach reading assignments at school differently from a classmate who thinks of reading as something that is done alone and silently" (pp.195-196). The Samoan teacher of the majority of the students in this study demonstrated her knowledge of the concept of incorporation by explaining that for a group of Pasifika students' reading she carefully selected text with a Pasifika focus. When introducing the text she linked it to their experiences of home, of Samoa, of Tonga adding that she can hook them in as they have prior knowledge of a cultural perspective.

\section{Cultural and social uses of language: Mother tongue or dominant language}

The configuration of sites of literacy practice illustrates a complementary relationship between family and church in the use of Samoan language, which was mainly used for speaking and reading. However, it appeared that there were contradictory values between the sites in relation to the use of Samoan. See Figure 18: Cultural and social uses of language: Mother tongue or dominant language? It might be expected that children growing up in New Zealand would be immersed in the English language for much of the time, even if Samoan is spoken in the home by family members. This is partly because English is pervasive as the main language of television, radio, newspapers, movies, popular music, video games and conversation. 


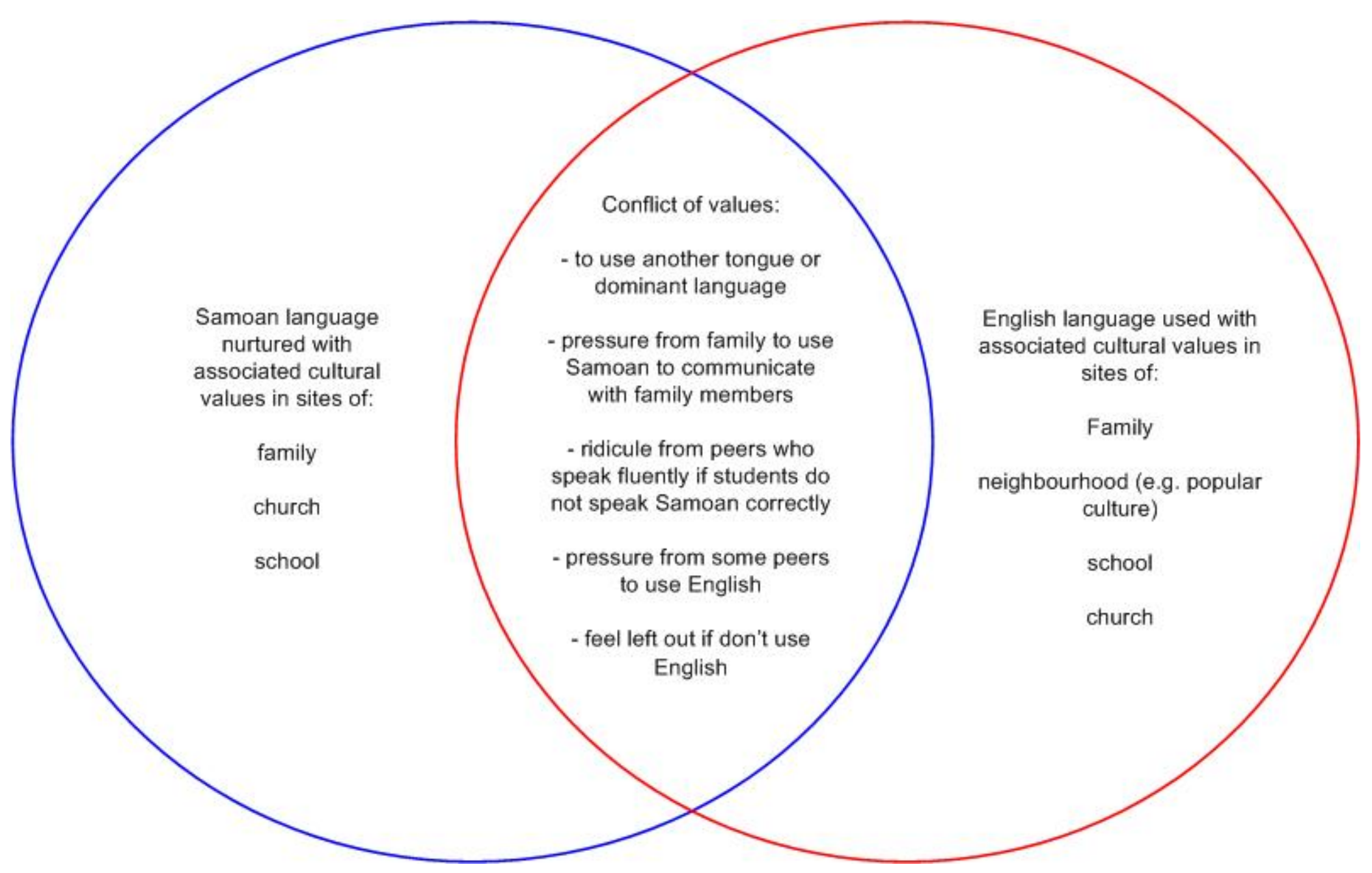

Figure 18: Cultural and social uses of language: mother tongue or dominant language? 
Maintenance of the Samoan language was valued by many adults in this Pasifika community and distinguishes their literacy practices, particularly in church and family sites. It was used for literacy practices in the church and Sunday school and a number of the students were supported by parents and other adult family members in using Samoan for church-related practices in Samoan at home. The principal of the school attended by the students said that the school recommended to parents that they encourage the mother tongue at home. Although the data focus on the Sunday school attached to the school in this study, the students attended a total of six Sunday schools, and Samoan (as well as English) was used in four of these. For some students, Samoan was used to communicate with their grandparents. The church representatives stressed the importance of these young people retaining and using the Samoan language which was seen as an integral component of their Samoan culture. They emphasised that whether they were second or third generation New Zealanders, they were still Samoans. The students themselves identify as Samoan and Representative C made the point that papalagi always say that these people are Samoan.

However, as well as support for using Samoan in the family and church sites, young people sometimes face pressure from their peers to use only English. Representative C explained that all the children in her Sunday school class knew how to read in Samoan, and when she asked them why they did not speak in Samoan at school they replied that they were ashamed to do this. Although she was not speaking exclusively about the students in this study, it may be that they faced the same issues. Criticism for their speaking Samoan came not only from students whose first language was English, but also from those whose first language was Samoan. Representative C's students told her they were reluctant to speak, "Because other students make fun of us and not only that, when we say something incorrect, the new people from Samoa laugh." One of the Samoan teachers in the school commented that by the time children reached the middle school (aged about eight years) they tend to speak in English all the time saying they feel left out if they speak in Samoan. She encouraged them to use their own language.

A conversation in an interview with two students offered an insider view of their attitudes towards language use. One girl said she used English at Sunday school and referred to the priest as a "fob". When the researcher asked what this meant she replied that he was a Samoan who "couldn't speak English properly." The two girls 
explained that students would call each other a fob if they did not use English properly. Their parents would occasionally use this term too, and the researcher realised after the interview the word is a term derived from "fresh off the boat". The girl who used this expression to describe the priest said she spoke Samoan a little at school, but never at home. She did not read or write in Samoan.

\section{PART TWO: IMPLICATIONS FOR CLASSROOM PRACTICE}

Part Two contains two sections. The first section includes discussion related to the complementary and conflicting values and aims that students face in the different sites for literacy which were outlined in Part One. This section acts as background to inform the discussion in Section B, which considers how students' out-of-school literacy practices and expertise can be linked to school practice to enhance learning in what is described by McNaughton (2002) as incorporation.

\section{Section A: Discussion of complementary and conflicting values and aims}

\section{Complementary values, aims, curriculum and pedagogy}

This thesis has explored the argument that teachers need to be aware of students' backgrounds, including their cultural and social practices, in order to make effective connections to learning in school with the aim of raising student achievement. The findings in Chapters 6 to 8 offer a view through the students' own eyes of how they appropriate knowledge about literacy practices in out-of-school settings. In school sites for learning, the teachers, peers and resources mediate students' learning but, as this thesis has argued, schools are only one of many sites for literacy learning. These uses which include descriptions of the settings support Street's (1984) argument that literacy is not a neutral technology which is detached from specific social contexts. If it is accepted that it is important that teachers have knowledge of how students' learning is mediated in out-of-school sites and there is a need for teachers to be aware of the various communities of practice of which their students are members (Wenger, 2006) and which mediate their learning. Associated with this is the need to understand how individual and group identity develops. As outlined in Chapter 3, identity is strongly linked to literacy practices (Heath, 1983; Pahl \& Rowsell, 2005; Street, 1995). Knowledge of the complementary and conflicting values that arise as students operate in different sites is helpful for teachers in understanding how students' identity is constructed. 
Because school is but one site for literacy acquisition, it is useful for teachers to understand the overlap of values, curriculum and pedagogy between students' various sites for literacy as it is likely that these sites combine to be powerful joint mediators of learning for the students. With this knowledge, teachers in schools can capitalise on these overlaps as strengths which are valued by the school, and they can communicate this acknowledgement of value to students' families. Teachers can then positively reinforce the common values of out-of-school sites where they match those of the school curriculum. They can also continue to make meaningful links between the out-of-school and school sites in order to facilitate students' learning. Young people's appropriation of aspects of popular culture in different sites illustrates the complementary relationship of values and curriculum, and is a significant factor in their construction of individual and group identity. Popular culture also illustrates contradictory values which are discussed in the following section. Teacher awareness of young people's involvement in popular culture seems to be an essential element for making connections to school literacy, and this is discussed later under the heading Implications for classroom practice.

Improved understandings such as this are a response to the demand from the Ministry of Education (2003a, 2006a) for teachers to have a better understanding of students' out-of-school literacy practices and of students' cultural backgrounds in order for them to achieve success in school literacy. The students' families have influenced the students' values through what Bourdieu (1974) describes as cultural capital which is transmitted by families to their younger members. In considering this concept it should be remembered that institutions and sites outside the family setting, including church and neighbourhood, also mediate the students' learning and contribute to the students' total cultural capital that they bring to school. The students themselves are not necessarily passive recipients of their elders' values.

This thesis has argued that a definition of literacy is at times restricted to skills, and that a more suitable definition to explore how people actually use literacy in their everyday lives is one that embeds literacy within social and cultural practices (Street, 1984). This interpretation serves better to explain how similar values, aims and pedagogy are shared across sites. Examples of this were the uses of literacy in family and church sites of practising reading as a performance and learning tauloto. It is likely that these practices will be valued by teachers when they recognise them 
as important in the Pasifika community. For this, teachers need to acknowledge that the students' participation in these practices involves particular cultural and social knowledge of their community in addition to skills.

An issue which is not directly related to literacy but is useful for teachers' overall knowledge of students' backgrounds is understanding the students' increasing role as active participants in their "communities of practice" (Wenger, 2006), and the overlapping networks of community support for the students. Associated with this is the fact that knowledge by teachers of the complementary values, aims, curriculum and pedagogy in the literacy sites raises teacher awareness of the values holding the community together (Schweigert, 1999) which is essential knowledge for teachers and administrators in the school community.

An example of complementary pedagogy, curriculum and values which is illustrated in the configuration of family and school is the example of students acting as teachers in joint literacy activities where they helped their younger siblings in reading. This illustrates the values, attitudes and the social relationships that are reflected in cultural ways of using literacy (Barton \& Hamilton, 2000) in showing how families socialise younger members into family literacy practices before they enter school. These practices were discussed in Chapter 6 and data in this study, albeit limited, indicated that the practices of the students as teachers seemed consistent with those of primary schools. If teachers are aware of these family practices which are similar in value, curriculum and pedagogy to school new entrant practices, then they can offer encouragement for them to continue at home and they can also be nurtured in the school site with older students working with younger children as has been the experience in schools in which the researcher has worked as a teacher.

Chapter 6 discussed how many of the students read books to younger children or listen to them reading while some of the students described the emergent understandings about reading that they fostered. This complementary curriculum and pedagogy between school and family sites is a valuable link and should be encouraged in both sites. The social interactions and emergent understandings centred on reading books with younger children that are described by the students are similar to those of parents and of teachers in early childhood and new entrant primary school settings. They are important in guiding the learners into achieving the 
requirements of both family and school curriculum, and as such they represent a connection between the agencies of family and school. The practice described by some students in Chapter 6 seems similar to the practices of Heath's (1983) Mainstream people in the way they prepared their children for school. These families taught children to label items and describe their features. There were ritualised uses of language by Mainstream people such as assigning labels to objects, with the children responding to questions where the questioners already knew the answer. These are the ways with words that Heath's children met in school and it is likely that the young brothers and sisters in this study will meet similar ways with words when they begin school in New Zealand. While the pedagogy relates to beginning school strategies in teaching reading, it is essential that teachers of older students are familiar with them in order to continue this complementary relationship. They can achieve this by reinforcing the students who are helping younger children at home and in supporting younger children in the school.

In Chapter 6 the data revealed that the girls in the study volunteered information about reading with younger children, whereas the boys agreed they were also involved once they were asked. This may be because in the family site there are more models of women than men reading to young children, and boys may not see the practice as an important role for males. While the students did not volunteer any information about conflicting values on this subject, it may be that the boys did not consider reading with younger children to be a desirable role for males. If teachers are aware of resistance to this role, then they can work for schools to develop a culture where it is seen as cool and socially acceptable among their peers for boys to be involved in reading with younger children, and a way to achieve this may be to seek the boys' own views on how this can be achieved. If teachers are aware of these practices which are situated in the family, they can be valued in the school and reinforced in the school practices. Teachers can also communicate their value to parents to foster continuation of these overlapping values, curriculum and pedagogy between school and home. Much has been reported about the underachievement of Pasifika students, but teacher awareness of the students' strengths in literacy gained through the overlapping of values and curriculum in these different sites helps to provide a balanced picture and avoid a deficit view. 


\section{Conflicting values and aims}

It is important for teachers to be aware of where students may face conflict within sites or between sites, and three areas of possible conflict were described in Part One of this chapter. Conflict may prevent students and teachers from being able to make effective connections between out-of-school practices and the practices of school as described by McNaughton (2002).

The most obvious conflict apparent to those outside the students' community is that related to popular culture as the images of violence and "bad" language are available to all. The major issues of conflict that emerged from the discussion on popular culture were the violence and swearing in computer games, magazines and some popular music, notably "gangsta rap". Although the family supported some fields of popular culture, the values of family and church clashed with the values that were represented in some popular culture that the students enjoyed. These differences are representative of the various communities of practice (Wenger, 2006) that the students are involved in and through which they have to find their pathway.

A second area of possible conflict was the different cultural interpretations of reading. In the church sites there was a literal interpretation of the text read (the Bible), and though this will be related to students' everyday lives and open to interpretation, the authority of the text will not be challenged. By contrast, in the school setting text is challenged through a critical literacy perspective required by the curriculum (Ministry of Education, 2006b).

The third area of conflict faced by students was in the use of Samoan language which was encouraged for some in their family and church sites. However, the students are living in a country where the dominant language is English. The popular culture texts they read and the songs they listened to were in English, and young people face some pressure from peers to speak in English rather than Samoan.

Teachers need to be aware of how the curricula, values and literacy practices may be different in the various sites. These sites represent what Wenger (2006) describes as communities of practice and as they are involved in different practices it can mean that the individual student may have to reconcile the different forms of membership among the communities. Wenger gives the example of different communities 
requiring different responses for the same circumstances and what is acceptable in one community may be "inappropriate, incomprehensible, or even offensive in another community" (p.160). Knowledge of these differences is particularly useful to teachers because it helps them to understand how their students are finding their pathway through two (or more) cultures to make their own way in the world in the communities of practice. They achieve this by appropriating certain practices and understandings and in the process, create their individual and group identity. This may have similarities to that of their parents, and also differences. If teachers are aware of the multiple identities and different practices and behaviours for the different communities of practice to which the students belong, they have more opportunities to make connections between out-of-school and school practices and encourage students to make meaningful connections themselves.

Being a member of different communities of practice may mean that the individual has to reconcile differences in practice (Wenger, 2006) such as those described previously for the Samoan students. Reconciliation requires more than learning sets of rules for different communities, and Wenger considers that reconciliation may be the biggest challenge faced by learners moving between communities of practice. He gives examples which are relevant to the students in this study of a child moving from family to classroom and immigrants moving from one culture to another, and claims that learning involves more than the appropriation of new information. Wenger writes "learners must often deal with conflicting forms of individuality and competence as defined in different communities" (p.160). This means that there may be tensions that are not resolved and he explains his selection of the term "reconciliation" to describe this formation of identity "to suggest that proceeding with life - with actions and interactions - entails finding ways to make our various forms of membership coexist, whether the process of reconciliation leads to successful resolutions or is a constant struggle" (p.160). An example of this might be the families who wished their children to maintain the Samoan language to communicate with family members such as grandparents, but whose children were under pressure to use English in their everyday lives.

While Cremin's (1988) explanation that families mediate the culture and screen and interpret the teaching of other institutions is correct, young people are not totally under the domination of their families. The students in this study were aged 11 and 
12 years, and at the start of adolescence with its major physiological and identity developments. During adolescence the period of identity versus role confusion is a very important stage in the development of self-identity (McInerney \& McInerney, 1998). This is when young people "integrate what they have learnt about themselves and begin to test their identity out in the wider world" (p.349). Essential components of this identity formation are the development of a philosophy that includes moral values, an orientation to religion, and developing a sense of self in relation to social issues (McInerney \& McInerney, 1998). Teachers need to be aware that their students have these many influences in their lives which are helping to shape their identity.

McInerney and McInerney (1998) write that for children in New Zealand who come from ethnic minority groups there may be a strong clash of forces which orients the development of their sense of identity. They write that while Pākehā children are socialised into a world where their families and peer groups share values and traditions, children from other groups may find themselves influenced by conflicting forces. "These children, therefore, receive conflicting messages from the wider society, school, peers and their cultural community" (p.350). They write that there is potential for conflicting messages and identity conflict on many issues, and give the example of moral values.

\section{Section B: Incorporation of out-of-school literacy practices to enhance school learning}

This second section of Chapter 9 builds on the previous discussion of complementary and conflicting features across the students' sites for learning. It suggests ways to improve literacy learning in schools by creating effective connections between outof-school and school literacies described by McNaughton (2002) as "incorporation". This seeks to address the issue raised in Chapter 4 which described how official literacy, as promulgated by the Ministry of Education (2003a, 2006a), makes an attempt to incorporate cultural and social perspectives into school literacy, but does not sufficiently explain to teachers how this can be achieved. Chapter 2 introduced Freire and Macedo's (1987) concept of reading the world before reading the word. It is crucial for teachers of Pasifika students to be aware of what the world of their students is. 
Literacy cannot be reduced simply to technical skills of learning words and letters, but as Freire and Macedo argue, the words need to be linked to the experience of the learner rather than the experience of the teacher. The strategy of incorporation outlined in this chapter provides a way to see literacy as the relationship of the Pasifika learners to their world. Chapter 3 describes how the NLS value out-ofschool contexts for literacy learning, and suggests that people who may not appear to be so literate in formal educational settings may succeed in literacy outside the classroom. Again, incorporation provides a means to link these strengths into the school curriculum. Goodridge (1995) found in her study which included Samoan children at transition to school that some teachers considered that Māori and Pasifika children did little or no writing in their families and that the children lacked experiences. The teachers had a narrower range of goals in writing than the children brought from their experiences at home. Goodridge describes (p.255) "a relatively weak match with the teachers' expectations for the Samoan children and with their emergent expertise at home. Despite the children coming to school with a relatively broad range of emergent writing expertise their teachers focused on a relatively narrow range of expertise." This restriction on children's writing by teachers at transition to school is described by McNaughton (2002) as a narrow funneling of expertise which has the effect of narrowing the delivery of the curriculum and not recognising the variety of genres the child may be familiar with from their out-ofschool experiences. Whereas Goodridge's observations in Samoan families showed that a broad range of writing expertise had been taught and learned in everyday family activities through sociocultural processes, her observations in five classrooms in three schools showed that most teachers taught children to develop a narrower range of expertise. However, some teachers did make relatively strong connections to the writing systems of families, and took into account the role of culture in the children's literacy development.

As Chapter 1 outlined, the long tail of underachievement in literacy in New Zealand includes disproportionate numbers of students from Pasifika backgrounds. To improve learning for these students, teachers need to be informed more about students' own out-of-school literacy practices in family and community (Ministry of Education, 2003a, 2006a), including the multiple sites for these practices and the possible connections and conflicts between practices in different sites (Cremin, 1976). Literacy is a contested term, as the early chapters in this thesis suggest, and 
schools are part of this contention. The discussion and suggestions that emerge are a response to the demand for a better understanding of students' out-of-school literacy practices and of their cultural backgrounds (Ministry of Education, 2003a, 2006a). Effective connections can be made for learners in school through what McNaughton (2002) describes as "incorporation" where the teacher or student may build on the familiar or may unlock what is unfamiliar. The students' explanations of their outof-school literacy practices demonstrate that these are valid literacies. For example, even in computer games, many messages are conveyed in writing.

While the Ministry of Education $(2003,2006)$ handbooks acknowledge students' outof-school literacies, the statements are aspirational rather than concrete advice to teachers. This study provides examples that teachers may be able to use to make effective connections for their students. This is not a straightforward issue. It is a moot point that just knowing about a child's background will make a difference; it is not that simple. However, this study may help to open teachers' minds to the richness of literacy practices that students may experience in their homes and communities and bring recognition of how much they may miss if they do not know their students and communities sufficiently well.

If teachers have an understanding of students' backgrounds and can make links to these in school, learning outcomes may be improved. Teachers can encourage students to share their prior experiences with peers and, as the Ministry of Education (2003a) states, "in a classroom that is a true community of learners, diversity offers tremendous potential for the learning of both the teacher and all the students" (p.46). Teachers may also be able to utilise other people who are experienced in, and understand, the literacy practices of the students so that they can mediate the students' understandings of literacy in the school. To achieve this, it is essential to explore closely the literacy practices that students have made their own and those that they choose to be involved with.

Research has already been conducted by a member of the Pasifika community in building on McNaughton's (2002) idea of incorporation by making connections of Samoan students' out-of-school knowledge and expertise to school programmes in order to improve literacy learning for them. Amituanai-Toloa's (2005) study of incorporation of familiar expertise of Samoan students' out-of-school activities into 
school literacies was discussed in Chapter 2 where she argued that its success depends on teachers having awareness of cultural linkages and connections that can be made between home and school. The instruments used in primary schools for assessing literacy do not directly link to Pasifika cultural settings. However, the writing exemplars (Ministry of Education, 2003b) for example, can be a useful tool when combined with teacher knowledge of how to teach writing and knowledge of Pasifika students' culture. Teachers can select exemplars representing themes that students can relate to, and select other texts to support these themes.

The following section of this chapter discusses the implications of the findings for classroom practice through three themes:

- Popular culture linked to school literacy

- Matching family and school practices: words and books

- Supporting Samoan language in schools

- Need for flexibility in assessing and teaching.

\section{Popular culture linked to school literacy}

There are two reasons why it is important for teachers to have knowledge of popular culture and its role in young people's construction of identity, and these are strong arguments for including studies of popular culture in the classroom. These arguments do not apply only to Pasifika students, but to all students. The first, which was outlined in Chapter 3, is that teachers need to be able to make links to students' cultural backgrounds in order to ensure engagement in learning and to help promote equitable opportunities in the classroom (Ministry of Education, 2003a, 2006a). This is the incorporation described by McNaughton (2002) where the teacher or student builds on the familiar in order to make effective connections between out-of-school literacies and school, and popular culture provides rich opportunities to achieve this. The second reason, outlined in Chapter 4, is that there is a call in the English curriculum (Ministry of Education, 2006b) for teaching critical literacy in the school literacy programmes (and for example by Au, 1995; Lankshear, 1997; Luke, 1997) and this is discussed later in this section of Chapter 9.

There is a common feature of curriculum that applies to all the popular culture uses discussed in this chapter. Cremin's (1976) concept of educational institutions, such as family and church having their own curricula which they teach deliberately and 
systematically, applies also to popular culture. Young people, such as the students in this study, are surrounded by peers, family, and other powerful mediators of their understandings of popular culture, and if teachers have knowledge of this curriculum and its significance to students, they can work with students to incorporate valued aspects of it into the school site. Fashions in clothing, computer games, music, books, magazines (all of which were described by students in this study) and other forms of children's popular culture are produced by adults for profit and are extensively promoted, and the texts described in the previous chapters are examples of how these are commercially motivated (Mahiri, 2000; Marsh \& Millard, 2000). Marsh and Millard write that if the ways that children's popular cultural icons are produced and consumed are examined, it is clear that significant market forces are involved. Extensive market research takes place, television programmes feature the characters, the toy industry makes the figures, and fast-food chains market their meals to children with related toys. The students' identification with some of these texts indicates that they are buying into the values of this market, although they do have some choices over what they will appropriate as their own. Young people, like adults, do not necessarily passively accept what is offered by the marketers. Like adults, "...children are agents in the construction of their own culture at the same time as being subject to hegemonic discourses of profit and consumerism. They both accept and reject the products offered to them" (Marsh \& Millard, 2000, p.21). This concept can be linked to Rogoff's concept of participatory appropriation where children are not merely recipients of transmitted knowledge, but are actively making choices. The examples from the students in Chapter 9 illustrate how they made their selections of popular culture which contributed to their individual and group identity.

\section{Music as popular culture}

Music forms part of children's popular culture (Luke, 1997; Mahiri, 2000; Marsh \& Millard, 2000; Morrell, 2000) and is described as an example of out-of-school literacy by a number of the students in this study. Music is closely linked to the building of identity, and is an instantly recognised code of identity for young people (Kenway \& Bullen, 2001). Young Pasifika people in New Zealand have appropriated rap music and, according to Zemke-White (2001), they “.... are making a racialised choice that, while perhaps based on aesthetic preferences, is also possibly connected to a perceived political, racial and cultural alliance with African Americans" (p.230). She argues that young people are using the rap genre in the way 
it was intended as a political and aggrieved voice of those who are sometimes voiceless. Zemke-White (2001) suggests that rap music and hip hop culture are used by some young people in New Zealand to construct local identities which are attempting to resist a dominant European culture. However, she rejects the concept that rap with its American origins is a threat to indigenous culture or formation of identity in New Zealand. Rather, she argues rappers in New Zealand are using hip hop culture and rap to create new identities incorporating their local issues of class, ethnicity and cultural heritage. While none of the students in this study raised these political issues, they expressed a clear interest in hip hop and rap and this provides a link for incorporation into classroom practices where critical thinking on issues such as these could be fostered and be linked into the new culture.

Delpit's (2006) argument for teachers to celebrate diversity in their classrooms is consistent with the message in the Ministry of Education (2003a, 2006a) handbooks, and she provides a practical example of how a teacher may achieve this. Delpit (2006) writes that many of the teachers of black children in the American city where she worked "have their roots in other communities and do not often have the opportunity to hear the full range of their students' voices" (p.17). She queries how much the teachers know about the verbal creativity and fluency of their students outside the classroom and whether they know that the students are prolific and fluent writers of rap. Delpit provides an example of incorporation (as described by McNaughton, 2002) where a secondary school teacher acknowledged her students' own expert knowledge in getting the students who were classified as slow learners to analyse rap songs to discover their patterns. She writes, "the students became the experts in explaining to the teacher the rules for creating a new rap song. The teacher then used the patterns the students identified as a base to begin an explanation of the structure of grammar" (p.33). This knowledge was then used as a base by the teacher to discuss the rules used by Shakespeare in constructing his plays or rules used by poets in developing sonnets. Delpit writes "both student and teacher are expert at what they know best" (p.33), a comment which acknowledges the contribution of school teachers as teachers and students as teachers working together to connect the curricula of school and out-of-school sites. Their joint contribution serves to enhance literacy learning in the classroom, and the analysis described by Delpit would be suitable for primary students of the same age as the Pasifika students in this study. 
Rap music is also the subject for incorporation in a strategy described by Gregory (2004) who reveals a twofold connection to children's out-of-school literacies. Gregory describes how the teacher of one class in a Bangladeshi community in East London was teaching about rap as a poetic form, and she was able to make a connection to children's memory skills when practising a poem together in English. Like the students in this study, Gregory's participants were accustomed to reciting and practising prayers and other texts in their mother tongue, and the teacher who was aware of these skills was able to incorporate these in the classroom programme.

\section{Acknowledging students' own expertise in out-of-school literacies}

There needs to be caution in making the assumption that teachers do not already understand students' out-of-school literacies as some teachers are making links to their interests through, for example, podcasting students' work at school. When teachers acknowledge students' expertise and interest in a diversity of out-of-school literacies, it opens an opportunity for incorporation. These socially and culturally embedded ways with words may differ considerably from those of the school, and the music of popular culture provides many opportunities for meaningful connections to be made in the school. The Ministry of Education's literacy handbooks state that "in a class that is a true community of learners, cultural and linguistic diversity offers potential for valuable learning by the teacher and all the students" (Ministry of Education, 2006a, p.50). However, translating this ideal into classroom practice needs some explanation, and the following provides a practical suggestion.

Data from the Pasifika students demonstrate that they participate in diverse language practices, some in both English and Samoan, and while for some their uses of language may be similar, some will contrast with those of the adults in their family and church sites and with those generally associated with school literacy. Their literacy practices illustrated considerable interest in fields of popular culture. Delpit suggests that teachers can "celebrate diversity by making language diversity a part of the curriculum" (p.67) by asking the students to teach the teacher and other students about their own language. She writes 'they can 'translate' songs, poems, and stories into their own dialect or into 'book language' and compare the differences across the cultural groups represented in the classroom" (p.67). This specialised use of language which is understood by those who identify with this genre of music is an example of what Gee (2000) calls social languages. Gee writes that people create sublanguages from the grammatical resources 
of a language such as English sometimes drawing on other languages as well. This concept of social languages is seen in the terminology of hip hop and the ways in which words are used. Gee writes: "social languages are distinctive in that they are used to enact, recognize, and negotiate different socially situated identities and to carry out different socially situated activities" (p.413). However, he cautions that for this to occur, ways with words are integrated with ways of thinking, valuing and interacting. Marsh and Millard (2000) are in agreement that hip hop and rap offer many opportunities for the analysis of linguistic forms in the classroom. A motivating factor in using these forms of popular culture for incorporation is that the students' own expertise is recognised and the participation is a joint one between teacher and students.

A further example from Dyson (2003) describes how young African American children beginning school appropriate familiar material from popular culture and reframe and adapt it into the literacy practices of school, thus making these new school experiences meaningful for them. For example, they drew upon their knowledge of songs, movies and cartoons when they were writing at school. Students may be innovative as they appropriate aspects of literacy knowledge from different sources and make them their own, and this is represented in the cultural and linguistic syncretism described by Gregory (2005) which represents a transformation rather than just a blending. It is a creative process where the students reinvent culture.

\section{Computer games}

Chapter 6 revealed that a number of students in the study were familiar with computer or video games, and spent much of their spare time playing games, some identifying it as a favourite pastime. The chapter outlined some of the distinctive curriculum knowledge required for participation in these games. They are an important component of popular culture in this study as students' involvement with them contributes to their identity formation, and informs the discussion of complementary and conflicting values between sites. Computer games offer many opportunities for teachers and students to make connections to school literacy, particularly in teaching critical literacy which is discussed in the following section.

Rowsell (2006) suggests practical ideas for incorporation such as creating video games from movies and recording successful strategies for navigation in cheats which the students write for others. Another idea is to analyse the visual depiction of 
characters and setting in a video game and compare this with the book it is based on. When some responsibility for learning is given to the students, such as in the reciprocal teaching strategy, the students may be able to assist their peers in ways that are not available to their teacher. Reciprocal teaching is a group procedure to develop comprehension and critical thinking where students take over responsibility to take turns to lead the group as they interpret the text (Ministry of Education, 2006a). Palincsar and Herrenkohl (2002) describe how in this collaborative learning experience students provide assistance to each other by referring to popular culture. They write "...in the process of helping a peer address a confusion in the text, students construct metaphors drawing upon action heroes, computer games, song lyrics, and other contemporary popular media about which adults may know very little." When teachers are knowledgeable about students' out-of-school literacies and their associated values and conflicts, they can assist students to make meaningful connections to school.

\section{Using popular culture in teaching critical literacy}

Many writers call for critical literacy to be included in school programmes (for example Au, 1995; Au \& Raphael, 2000; Lankshear, 1997; Luke, 1997; Marsh \& Millard, 2000; Morrell, 2002) with $\mathrm{Au}$ and Raphael (2000) commenting that opportunities to develop critical literacy are often less available to students of diverse backgrounds. Texts of popular culture provide useful opportunities for teachers to develop this, as they are an important part of the students' literacy experiences outside the school (Luke, 1997; Morrell, 2002; Stevens, 2001). An advantage of this is that the students may see the texts such as computer games and popular music as more motivating and meaningful than texts that might be used traditionally in schools. Teachers need to be cautious in their selection of texts, with Marsh and Millard (2000) arguing against a narrow view of what "quality" literature should be taught in schools. They describe teachers' unease about including popular culture in the school curriculum with one reason being that these texts are more transient than what is considered to be more literary.

However, taking a critical literacy perspective creates challenges for teachers. Morrell (2002) describes the struggle for educators as their classrooms become increasingly diverse, to find teaching strategies and curricula that are inclusive and affirmative for the students yet allow academic and critical literacies to develop. $\mathrm{He}$ 
describes the NLS view that the failure of some students stems from the inaccessibility of the school curriculum to students who are not in the dominant culture and whose literacies may have little connection with those taught in schools. Morrell argues for the teaching of critical literacy in order to help students understand the socially constructed meanings in text as well as the political and economic contexts in which they are embedded, this ultimately having a possible emancipatory effect on the users. It is interesting to consider the cultural interpretation to reading the Bible taken in the church and family sites of the Pasifika community in this study.

Lankshear (1997) argues for teachers to develop students as critical readers and writers who are able to detect and handle the ideological dimension of literacy and the role that literacy plays in enacting and producing power. Carmen Luke (1997) argues for the teaching of a critical social literacy which examines "how the public texts of everyday life construct our understandings of the world, and position persons to take up various social, political, and cultural identities" (pp.20-21), and she suggests that a cultural studies approach needs to be incorporated into teacher education programmes to include media and popular culture and the cultures of childhood and adolescence. Critical literacy can be approached through incorporating students' interest in music into the literacy programme. Marsh and Millard (2000) make suggestions for this, stating that popular songs could be used in the classroom to explore themes such as threats to the environment like global warming, and social issues such as poverty. Marsh and Millard also offer the example of analysing a song to identify ways in which the text has been framed to position the listener, for example in relation to gender roles and the values being promoted in the song.

\section{Cautions about using popular culture in the classroom}

Although there are advantages in incorporating popular culture into the school literacy programme, there is a potential problem with this and caution is urged so that what is valued by students is not degraded by an adult perspective (Luke, 1997; Marsh \& Millard, 2000; Stevens, 2001). Marsh and Millard (2000) caution of the danger of teachers appropriating children's culture for educational purposes and suggest that analysis of children's popular songs must be managed carefully so that children's pleasures are not diminished or ridiculed, or one group's taste rejected. 
Luke (1997) argues for critical discourse analysis of popular texts, but not to do this through the narrow views of the educator as there is a danger that an adults-only perspective could spoil what is positive for students. Luke (1997) cautions against using children's popular culture in the classroom in ways where the teacher is the objective knower and correct interpreter, and where children are not able to see through the text with the result that the pedagogy becomes a tool leveled against the pleasure that children derive from popular culture such as television programmes and music. She explains that teachers need to give up their usually negative attitudes towards popular youth culture and develop interest in the cultural texts and practices that appeal to the age group they teach. The idea is not to ruin the pleasure that children derive from their popular culture. Scrutinising these texts in the classroom may belittle them but there is much that can be used in a positive way. This does not mean that anything from popular culture is acceptable as the teachers in the school in the current study explained. They did not allow students to play popular music which contained swear words.

There is another potential problem for teachers in selecting song lyrics for analysis. Marsh and Millard (2000) write that many lyrics contain gender, racial and class stereotypes and teachers may be seen to endorse these values, but the issue should not be one of censorship to exclude much of popular culture from the classroom or to explore ideologies in a confrontational way, but rather to create opportunities for dialogue.

A third potential difficulty for teachers is outlined by Au and Raphael (2000) who caution that teachers' efforts to bring popular culture and peer or community literacies into the classroom may not be seen favourably by parents of students who are not from the majority culture. They may consider that this is a sign that their children are not learning what the mainstream children learn, and that they are being held to a lower standard. Obviously, it is advantageous if teachers are able to communicate their intention clearly to parents to prevent this being a concern.

Three examples of how teachers can bring popular culture into the classroom are suggested by Stevens (2001) through lessons in physics, poetry and social studies, which fit into the existing curricula and promote students' critical thinking. 


\section{Valuing students' individual and group identity}

Data from the family, church and neighbourhood sites discussed in Chapters 6 to 8 provided an insider view of how individual and group identity is constructed. The students must operate successfully in several sites each of which has its own curriculum and values, meaning that rather than having a single identity, the individual student may identify with many groups. The influence of the social groups the students are involved in can be seen in the more formal settings of the church and Sunday school as well the less formal settings in family and neighbourhood sites. The students operate in all these sites and may need to reconcile conflicting values as their identities are constructed through their selections of literacy uses which reflect current adolescent taste in areas such as fashion, music and their reading materials. This was described in Chapter 8 where Pahl and Rowsell (2005) argue that the NLS raise awareness of learners in relation to their identities. Knowledge and acceptance of these identities provides a means for teachers to incorporate relevant out-of-school experiences into the classroom. There has been evidence in the data from students of what Cummins (cited in Pahl \& Rowsell, 2005) describes as 'identity investment' where individuals invest time and energy into literacy practices that are meaningful to them in relation to life goals and interests. Students who are considered to have low levels of literacy by school measures may have skill in reading sports statistics or navigating complex videogames and may be able to discuss these areas of interest in articulate and critical ways. Cummins writes "we all invest our identities minimally in some spheres of literacy practice while in others the investment of identity is enormous" (p. 141).

This aligns with the Ministry of Education requirement that teachers in New Zealand schools will foster accepting attitudes in the classroom. Values that schools are expected to model and foster include valuing "diversity, as found in our different cultures, languages, and heritages" and exploring with empathy, the values of other people (Ministry of Education, 2006b, p.10). Heath (1983) and Pahl and Rowsell (2005) link literacy closely to the individual's identity. Pahl and Rowsell (p.98) describe identity as "the most important ingredient in teaching and learning literacy." It is expressed through people's use of language, the clothes they wear, artifacts they have around them, and how they talk. People create their identity through social practices in the different sites of the homes and communities they live in. It links people to each other in their communities and to their shared histories (Pahl \& 
Rowsell, 2005). In order to investigate and understand these students' literacy practices and what they have made their own, their identities in relation to literacy use must be considered. Chapter 3 explained how the Effective Literacy Practice handbooks for teachers (Ministry of Education, 2003a, 2006a) demonstrate an increasing emphasis on the need for teachers to make effective links to children's cultural backgrounds. Both texts state that teachers need to consider cultural engagement as every learner views literacy tasks through a cultural 'lens' which is influenced by their prior knowledge, experiences, and values. A clear directive is given that effective teachers need to motivate and engage students in learning by making connections to students" "interests, experiences, and sense of identity" (Ministry of Education, 2006a, p.22), and this chapter has offered some possibilities for achieving that.

\section{Matching family and school practices: words and books}

Matching ways with reading

For students of primary school age reading practices play an important role in creating a complementary relationship between school and family sites in relation to some aspects of curriculum and pedagogy. The understandings about books that children gain from their interactions with adults and siblings in their preschool years may influence their success at school. The examples in Chapter 6 from the girl students illustrate that they understand what is required for reading at school. They demonstrate values and attitudes towards reading in the site of the family which are similar to the values and attitudes of the school. These students were acting in a similar way to those described by Gregory (2004) as mediators of school practices in their homes. They may at times act as a bridge between languages and cultures as Gregory outlines.

Tagoilelagi (1995) challenges the pedagogical patterns in the state schooling system in New Zealand that create a mismatch between the Samoan child's learning environment at home and school. She draws a parallel with Heath's (1983) study in which the black working class community of Trackton practised similar patterns to ways in which Samoan families in Samoa socialised their children into reading (Duranti \& Ochs, 1988). Tagoilelagi states that the Trackton community had similar conversational patterns to the Samoan families in that they tended not to see babies or young children as partners for regular conversation. People tended to talk about 
the baby rather than to the baby (Heath, 1983). Tagoilelagi writes, "the low amount of routines which were initiated by the children in the two groups of families (Samoa and New Zealand) could be an aspect of the Samoan people's cultural model in handling literacy activities" (p.79). It appears that the situation for some Pasifika students in New Zealand may be similar to that of Heath's Roadville and Trackton children when they attended school. However, a difference with this study is that these students are adolescents and are asserting their own ideas about literacy. They are influenced by their families and community literacies as at Sunday school, but also create their own uses which are part of their own identities as young people.

Heath (1983) claimed that school is not a neutral objective place. Her study showed that children learned different ways of using language in their homes and their communities and these different ways influenced their success at school. Heath's (1983) description of the success of the Townspeople's children can be likened to the success of the majority culture children in New Zealand who share what Heath describes as the linguistic and cultural capital of the school. Each of these two studies is useful when considering how best to make connections for Pasifika students in New Zealand schools. Heath's study informs of the mismatching of cultural capital between some family and school sites and the need to inform families of "school ways" with literacy. It is also a useful reminder that people are literate in different ways, some of which are more valued by "official" literacy than others.

The emergent understandings about reading that are learned in some families and in school include the conventions of discussing the pictures and story, such as labeling items and answering questions (the ritual where the questioner already knows the answer but expects the child to respond), handling books correctly, controlling directional movement, and learning that the written text rather than the picture is to be read. (For a list of understandings about reading that children may exhibit at entry to school at age five, see Effective Literacy Practice, Ministry of Education, 2003a, p.70.)

\section{Using tauloto and reading skills in the classroom}

One of the common literacy practices that was distinctive to these students was that of memorising Bible passages to be recited to the congregation in church. What is valued in the church and Sunday school can also be valued in the school, particularly 
oral reading and memorisation of written text. This skill of recitation memory may provide a useful connection for young children in learning to decode text (McNaughton, 2002). The students themselves may transfer the memorisation skill of tauloto to new learning situations as the researcher discovered when he visited a homework centre for secondary students. In this centre, which ran for one evening every week, students were assisted in their various subjects' homework by adults. When the researcher asked students if they ever used the skill of tauloto at school a year 13 boy replied that he used it for learning quotes for English classes. A year 10 girl also said she has used the tauloto technique for memorising notes in order to remember the main ideas in English lessons. The out-of-school experience of Pasifika children in recitation of texts can be used in classroom activities to assist reading with young children (McNaughton, 2002). Teachers in the school attended by the participants in this study offered examples of how they tapped into students' strength in memorising when they required them to learn a greeting by heart for a meeting with parents, and the morning karakia ${ }^{14}$ for the class (both in Māori). At times, children's memory verses would be used at school if they were appropriate to the religious unit being studied.

Given the evidence in the data which shows the importance of memorisation of text and reading clearly and accurately to an audience as an integral part of their literacy practices in the church, it is reasonable to suggest that they assume a greater importance in the church sites than in the school site. It would seem to be quite straightforward to incorporate these into meaningful contexts for children in school programmes, affirming their out-of-school uses and building on them in a useful way. For example teachers could incorporate these skills through students learning text by heart to share with an audience as in reading poetry or prose as a performance. Another example would be remembering the key points of a story in order to share it orally with an audience as in storytelling (see Pedersen, 1995).

A number of reading and writing uses which were situated in church literacy sites were listed in Chapter 7. The writing uses are similar to those in school literacy programmes and it would be of interest to teachers to be aware of the variety and extent of these in order to make effective connections to school literacy. The students themselves could be

\footnotetext{
14 The teachers described the karakia as a prayer to welcome the children to school in the morning.
} 
active contributors and help teachers to make appropriate choices from their repertoire of practices which may be more extensive than their teachers realise. Students used both English and Samoan languages and examples included cloze exercises, creating graphic organisers, writing dictation, writing summaries, and note taking.

\section{Comprehension of text}

This chapter earlier raised the issue that there may be more emphasis on exploring texts at a literal level for Pasifika students through their church-related literacy practices. In the researcher's experience, some teachers have emphasised Pasifika students' skill at oral reading but have been critical of their lack of comprehension. This is an important aspect of school literacy where teachers can incorporate students' background knowledge in ways that students see as relevant as a way to build up expertise in comprehension of a variety of texts as described by AmituanaiToloa (2005). She suggests that teachers build on Samoan students skills of observation and listening in order to enhance their reading comprehension. Students have already been apprenticed (Rogoff, 1995) into these skills by their communities, so it makes sense to continue with the same pedagogy within the classroom where possible. Amituanai-Toloa recomments that to use this strength, teachers should demonstrate concepts in texts rather than just explaining them.

\section{Supporting Samoan language in schools}

A distinguishing feature of the students in the study is their cultural background and an integral part of this being their ability to use a Pasifika language, which for the majority was Samoan. The mother tongue was valued by family members and church representatives in family and church sites, and is seen as an important community value. This section of Chapter 9 argues that schools should also be sites for teaching Samoan (and other Pasifika languages), and that the incorporation of Samoan language will help to match the cultural capital of home and school for many students. A strong argument in support of teaching Pasifika languages in New Zealand schools was made in Chapter 4 (Hunkin-Tuiletufuga, 1996, 2001; Irwin, 1988; May, Hill \& Tiakiwai, 2004; Spolsky, 1988; Taumoefolau, Starks, Bell \& Davis, 2004).

The data from this study and the literature indicate that language use is integral to the identity of the individual and the groups to which they belong. This is one of the key cultural features that is shared among the group that defines and characterises the 
group's cultural identity as described by Ferdman (1990). The use of Samoan was associated closely with reading and writing practices connected with church sites for literacy. Two strong values of the community are intertwined in the literacy practices of religion and in using the Samoan language. The sites where the students use Samoan language, whether they are family, church, community or school sites, are examples of the different communities of practice to which they belong (Wenger, 2006) and where they engage in different practices, behave differently and illustrate multiple identities. A useful strategy described by the teachers in the school in this study was the use of Samoan (and other languages) to assist a student when a concept in English was puzzling for them. A peer who had expertise in Samoan would help the student to understand the concept in order to be able to express it in English.

\section{Official support for Pasifika languages}

The overview and critique of the New Zealand curriculum in Chapter 4 discussed the issue of whose cultural knowledge and social power influence the official requirements for literacy teaching in New Zealand schools. It can be seen from the Ministry documents discussed in Chapter 4 that the intention of "official" literacy is to make it more relevant to Pasifika (and other minority) students. The Ministry of Education documents, which are critiqued in Chapter 4, promote an ideal which is for education to be relevant and inclusive for Pasifika peoples. This is illustrated by the New Zealand Curriculum Framework assertion that students could learn in their Pasifika languages (Ministry of Education, 1993) and be supported by the Literacy Experts Group (Ministry of Education, 1999a) who recommended that Pasifika languages be used in schools. They wrote that literacy instruction in years 1 to 4 in a Pasifika language could have benefits for the child's learning both their first language and English, as well as helping to maintain and protect minority languages in a dominant English context.

The Ministry of Education has responded to the need for a Pasifika dimension in curriculum delivery with the production of the Samoan curriculum for New Zealand schools (Ministry of Education, 1996c). This curriculum states that speaking Samoan will enable students to take part more effectively in family, church and community activities and, as they become parents, they will have a special role in passing on the language to their children. It also states "For children and students whose home language is Samoan, maintaining that language will enhance their learning of 
English. For all children, there are cognitive benefits in learning two languages" (p.7, italics in original). Resources to support the teaching of Pasifika languages in schools and early childhood centres have been produced for the Ministry of Education by Learning Media. These include the Tupu series of books which are written in Samoan and four other Pasifika languages and come with teachers' notes and audio recordings. Other resources are the Samoan language journal Folauga which is designed for year 1 to 8 students learning the Samoan language and Folauga Ualoa 2 which is a Samoan language magazine for secondary students. In addition, draft curriculum statements in the languages of Tonga, Niue and Tokelau are currently being developed.

Hunkin-Tuiletufuga (1996) provides useful suggestions for future education policy. He acknowledges that some are implemented in certain areas (at his time of writing), but these need to be more widespread to cater for the children entering school from Pasifika preschool centres. His recommendations include the setting up of bilingual classes where there are Pasifika preschools so children have continuity in their first language, the establishment of total immersion schools on Pasifika languages and cultures, and training of more Pasifika teachers in order to implement the languages and cultural programmes into schools. Teachers of these students will need to be particularly skilled. As McInerney and McInerney (1998) state, it is inevitable that for students who are operating in two cultural settings there will be culture clashes. They write "and your primary task as an educator will be to assist the child in resolving the conflict" (p.351).

Earlier this chapter introduced Wenger's (2006) concept of trajectory to indicate the paths that people's identities form within and across the communities of practice to which they belong. Because the use of language is integral to identity, which can be seen through people's social and cultural uses of language, Wenger's metaphor of multiple trajectories which may clash with each other or reinforce each other is useful to raise awareness of the complexities of identity faced by the Pasifika students. He writes that:

\footnotetext{
...a nexus does not merge the specific trajectories we form in our various communities of practice into one; but neither does it decompose our identity into distinct trajectories in each community. In a nexus, multiple trajectories become part of each other, whether they clash or reinforce each other. They are, at the same time, one and multiple. (p.159)
} 


\section{Need for flexibility in assessing and teaching}

Chapter 4 reviewed the curriculum changes in New Zealand, pointing out that the curriculum now makes literacy requirements explicit to teachers and others. The question remains though, whether there is enough flexibility in the curriculum to ensure that learning is appropriate for all students, or whether the curriculum represents hegemonic practice by the majority which will restrict the learning of some students or force them to assimilate. While it is true that the Effective Literacy Practice textbooks recommend that teachers make links to students' cultural and social practice, the guidelines in these texts, the English exemplars and other documents are making increasingly detailed demands for attainment and assessment in literacy. With the curriculum appearing to be more prescribed, the 'official' view of reading and writing may restrict other forms of literacy. However, it appears that the curriculum is broad enough to include the interpretations of literacy described in Chapters 2 and 3. The out-of-school literacy practices such as those valued by church and family and those of popular culture can be encompassed by the curriculum, and surely an intention of the curriculum is to enlighten or emancipate the learner (Ministry of Education, 2006b). However, recognition and incorporation of these literacies depends on how schools interpret the curriculum, and it needs to be remembered that the Effective Literacy Practice handbooks are guidelines to pedagogy rather than explanations of how to achieve effective connections for students.

Recognition that there are valid out-of-school literacies that are different from those of school raises the question whether students may be experiencing a hidden curriculum in that they may have literacy skills that teachers are failing to measure. The assessment needs to be flexible enough to encompass these literacies. While teachers have a substantial amount of information on student achievement in literacy skills, the question needs to be raised whether the factors that make people literate are really understood. In considering the apparent underachievement in literacy of Pasifika students in New Zealand, the question can be asked whose knowledge is represented. If the curriculum is to be appropriate for students from diverse backgrounds, then there is a need for teachers in New Zealand to retain a degree of autonomy in interpreting and teaching the curriculum. Flexibility will enable them to take into account the differences of students rather than expect all to assimilate into the values of the majority culture as they might be exemplified by the school. Hull and Schultz (2002) write that there has been a big swing to the right in the education pendulum in the United States, Britain and Australia, 
halting and reversing many of the conceptual and practical steps forward in teaching literacy. Taylor (in the foreword of Barton, Hamilton \& Ivanic, 2000) criticises what she describes as inflammatory newspaper reporting about literacy teaching in the United Kingdom and the United States. She is critical of mandatory phonics teaching in the UK and claims that in the USA, "there are cities in which every child in a particular grade is supposed to be working on the same page, in the same way, at the same time, on any given day" (p.xiii). The politicians and publishers of the basal readers are blamed for the loss of teachers' freedom to be professional and the replacement of essentials such as guided reading and research projects with reading programmes on highly controlled basal readers.

\section{Culturally responsive instruction to reflect home culture}

Several studies provide useful examples of making links between students' out-ofschool literacies and the school curriculum. One study of incorporation that links into children's cultural backgrounds and which has successfully enhanced reading practice is described by $\mathrm{Au}$ (1980). To address some of the barriers that children from minority cultures may experience in classrooms, Au argues that the ultimate goal "is to be able to create culturally appropriate instructional events for minority children" (p.93). She gives the example of the success of the Kamehameha Early Education Programme (KEEP) which improved the reading success of 5 to 8 yearold indigenous Hawaiian students. One difference of this programme from the one the children would normally receive was that the small group lessons were largely devoted to teaching comprehension rather than decoding the text by learning phonics (See also Rickford (1999) for an emphasis on comprehension rather than decoding for students from a minority culture). The lessons were similar to "talk story" with its rules governing speaking and turntaking which Au describes as "a major speech event in Hawaiian culture" (p.95) and in this article she outlines the procedures of the lessons. In talk story there was much interaction among the children who build on each other's responses and a weaving of information from the text and children's personal experiences. Unlike the conventional lesson where the teacher asks a question of one student, then evaluates their response, in the lessons based on talk story the children are encouraged to make cooperative responses with their peers. $\mathrm{Au}$ (2002) writes: "usually two or three students will answer at once, using overlapping speech. Gradually, other students join in. In effect, the students collaborate to answer the teacher's question and to interpret the text" (p.404). 
$\mathrm{Au}(2002)$ writes that many teachers are aware of the distance separating them from their students and want to show respect for the students' cultures in their teaching. She refers to "culturally responsive instruction" (2002, p.404, italics in original) to refer to "teaching that reflects the values and standards for behaviour of students' home cultures" (p.404). She argues that when teachers used the talk story practices with Hawaiian children, the children paid better attention, discussed more ideas in the text, and made better inferences from the text. The implications of Au's work for the current study are twofold. In the first instance, teachers need to be aware that there may be a distance separating them from their students and their cultures, and they need to acknowledge and respect those cultures. Secondly, they need to be aware of strategies to help address this. Many of the literacy uses described by the Pasifika students offer teachers opportunities to be more aware of social and cultural differences, and they provide opportunities for instruction that is culturally responsive as described by Au.

In Gregory's (2004) study the teaching by older children of their younger siblings in London reflected the learning styles of the Bengali and Qur'anic classes that the children attended. These links between the children's homes and school may also be seen as collusion between the school teacher and the child. Gregory states that the children took school practices home, but the teacher also linked literacy teaching into the children's learning styles from their community practice. This contrasts with the situation described by Heath (1983) where children in three different communities were socialised into language use with one group having more successful transfer to the literacy practices of the school. The Mainstream children who were the most successful had learned the rules for talking about books and had been socialised into ritualised uses of language.

The success of incorporation, according to Amituanai-Toloa (2005), depends on teachers having awareness of cultural linkages and connections that can be made between home and school. She writes "simply put, successful incorporation depends largely on how teachers are aware of students' out-of-school activities and current levels of competence that can build that bridge in order for transfer of learning to occur" (p.32). She gives the example of Lee's (2003) study of African American students learning English literature through concept of 'signifying'. Students were able to have a better understanding of new concepts in English when their teachers incorporated signifying. Amituanai-Toloa (2005) considers that in spite of the 
differences between Samoan and African American students "...the concept of incorporation can be seen as a generalisable principle for effective instruction across cultures" (p.162).

\section{Appropriation of out-of-school literacy to school context}

An example of appropriation is given by Dyson (2003) who describes how young African American children use their knowledge of popular culture to help them relate to school literacy when they begin school. She writes "the observed children did not approach official literacy activities in their first-grade classroom as though they had nothing to do with their own childhoods" (p.330). Dyson describes this as appropriation where the children used complex recontexualising processes, borrowing, translating, and reframing the material that they were familiar with and thus aiding their entry into the literacies of school. The young children in Dyson's study used material and practices from popular culture that they were familiar with "...to take intellectual and social action in the official school world" (p.330). Dyson comments how youth appropriate these cultures "... and adapt them to their systems of symbolic meanings and social relations (p.332). Dyson found that one of the practices related to popular culture was the appropriation by young children of voices. For example, they heard singers and rappers as they accompanied their older siblings out of the house, and they played around with this material. The children took what they wanted such as sounds and images from original sources and reframed them within different practices and then used these in school literacy. For example when they were asked to write, they would draw upon songs, films and cartoons. Dyson explains "in this way, they made new kinds of practices meaningful by infusing them with cultural knowledge and comfortable peer relations" (p.333). These connections between out-of-school literacies and school literacies illustrate how a curriculum can be interpreted in a sufficiently flexible way to include understandings that are meaningful to students from their own lived experiences.

\section{Conclusion}

Chapter 9 has drawn together key ideas that emerged in the study about configurations of students' sites for literacy learning and it has explored the overlap of values and curriculum between the sites. It has then discussed the implications of these for school practice in improving literacy for Pasifika students through teacher awareness of possible conflicts between sites and through incorporation of students' expertise into school sites. 


\section{CHAPTER 10}

\section{Summary and Conclusion}

This concluding chapter begins with a brief overall summary of the thesis. It then offers an outline of the strengths and limitations of the study while the concluding section discusses the implications of this study for practice in schools, for education policy and for future research.

\section{Brief summary of the thesis}

With a growing number of Pasifika students in schools who represent the increasing diversity in New Zealand classrooms and who are generally performing less well on school assessments of literacy than Pākehā students, there is an urgent need to seek ways of improving their literacy performance. To address this the Ministry of Education has produced a comprehensive "Pasifika Education Plan" (first released in 2001) and language curriculum statements such as that for Samoan language, and many text and audio resources which have been distributed to schools. As well, the Ministry literacy handbooks require teachers to improve learning for students from diverse backgrounds by making connections to their home literacies and to students' knowledge from their out-of-school experiences.

In recent years modern interpretations including the NLS and sociocultural theory have changed educators' perceptions of the nature of literacy. Whereas previously literacy may have been viewed more as technical skills, it is now acknowledged that in addition to the skills, literacy is embedded within social and cultural practices. There are many literacies (multiliteracies) which differ widely according to culture and context.

This thesis is a case study which sought an insider view of the out-of-school literacy practices of fourteen year 7 and 8 students from a Pasifika background. The findings illustrate the issues they face as they navigate between the two worlds of Pasifika and papalagi cultures. The literacy practices which they described occurred in family, church and neighbourhood sites, and are of value in informing teachers of their outof-school literacies and how some sites worked in a complementary way to mediate students' learning. Of particular interest is where there were common values and 
pedagogy in the configuration of sites as it could be assumed that this overlapping provided more powerful mediation in their learning. These complementarities occurred most strongly between the sites of family and church, and a distinctive feature of the students' practice which was situated in these sites and strongly valued was the use of Samoan language. Of value are the pointers to whom, in the students' backgrounds, teachers might be able to draw on to facilitate further the students' literacy acquisition.

Also of interest is the conflict within the configuration such as that between the values of church and family on one hand, and the values of popular culture on the other. Having a better understanding of these complementary and conflicting aspects of students' learning is useful to teachers who are seeking ways of incorporating outof-school knowledge into school programmes. Because this is so much a part of students creating identity, it is a suitable topic for incorporation. However, care needs to be taken that this is not done through what students might see as the narrow views of the teacher or that the tastes of one group are rejected.

Although this case study is of a small sample, the findings are useful in considering Pasifika literacy as through illustrating some of the complexity and strength of students' actual out-of-school practice they reject a deficit view of literacy. The data reveal the different communities of practice to which the students belong (Wenger, 2006) and where they engage in different practices, behave differently, and illustrate multiple identities. The data illustrate how the curricula, values and literacy practices may be different in the various sites and it would be helpful for teachers to be aware of these differences in the various communities of practice. Associated with this is the important message from Wenger (2006) that the individual student may have to reconcile the different forms of membership among the communities.

\section{Strengths and limitations of the study}

\section{Strengths of the study}

Chapter 1 began by introducing the argument (Ministry of Education, 2003, 2006) that one way to raise the achievement of Pasifika students in New Zealand classrooms is for teachers to have a better understanding of students' out-of-school literacies in order for there to be meaningful connections between out-of-school 
literacies and the school curriculum. The main contribution of this study to understanding how best to support Pasifika students in schools is that it provides examples to teachers of the lived out-of-school literacy experiences of a group of students. The richness of the literacy learning in students' family, church and neighbourhood sites illustrates how much teachers may miss if they do not know their students and communities well.

If teachers know about students' out-of-school literacies through this study, it may open their minds to possibilities that were not obvious to them before. While the kind of information the study reveals may not apply to individual students, it provides useful background information about students' lives and may assist teachers to ask the right questions to enable them to make successful connections to students' lives.

The strength of the thesis is the collection of authentic data. The methodology was designed to include the students as ethnographers to enable them to show an insider's view of their appropriation of knowledge about literacy practices. Students were invited to make their own decisions in taking their own photos, and in the subsequent photo elicitation interviews the researcher was working with students to generate data rather than observing them as an outsider. This helps in part to address two issues in the study, that the researcher as an outsider cannot be an expert on Pasifika culture and that there is an imbalance of power between the researcher and students. The photo elicitation interviews were held with self-chosen pairs of students who seemed to be confident in expressing themselves in this setting with only their peer and the researcher, and the result was detailed qualitative data. The photos were also a source of data in their own right and gave the researcher an insider view of sites and uses which would otherwise not be visible to him. Another strength of the study is that it considers multiple sites of actual literacy use of these students and connections between the sites. It is useful for teachers to be aware of these connections where there may be support for students through complementary values and pedagogy, or difficulties for them because of conflicting values or pedagogy. The study offers an insider perspective of the complex pathways that many students tread between their sites of literacy practice, and between the Pasifika and palagi worlds. The study uses multiple sources of data which enabled the researcher to check the consistency of findings. The data come from the interviews with students, the church representatives and school teachers, and from the photographs. 


\section{Limitations of the study}

A limitation of the study is that it involves a small sample of Pasifika students and is therefore not generalisable to the wider population. The researcher was in a position of power and was seen as a teacher by the student participants, and this may have influenced their responses. The researcher was also a papalagi and researching a cultural group other than his own, and this may make it more difficult to gain a true perspective from the students and adults. A possible limitation of the study is that students may have been influenced in their selection of photos by their perception of what the researcher expected as examples of literacy. This may have restricted their openness to their own ideas and creativity in choosing, and led them to avoid less conventional uses of literacy. Their selections may also have been influenced by peers and family members who wished them to present their family literacy practices in a positive light. A limitation is that the researcher did not go back to the students to ask them about what might better support their literacy acquisition.

A further limitation was in gathering written information from the students. Three students did not return their journals and some journals contained very little written information. The boys seemed reluctant to write and they indicated that they found it boring to write in the journal, so maybe another way for them to record information would have been more successful. Another limitation is that this study did not demonstrate that students' literacy achievement in school would be lifted through incorporation of the students' out-of-school expertise and knowledge in literacy or through increased teacher knowledge of complementary or conflicting values and pedagogies that the students meet in different sites.

\section{Conclusion}

This final section discusses the implications of this study for practice in schools, for education policy, and for future research.

\section{The implications for practice in schools}

The data collected in this study in relation to the Pasifika students appear to show a very rich awareness of the range of literacy use and a competence in literacy use in a range of practices outside the school. If the study improves teachers' understandings of this rich tapestry of practices, it will help challenge notions of deficit where they 
lie. All teachers who are teaching students from a Pasifika background need to have some knowledge of Pasifika cultures. The incorporation of out-of-school knowledge and expertise into school programmes can help teachers to make effective connections for students in literacy learning and to achieve this, teachers need understandings of students' social and cultural uses of literacy in out-of-school sites. Associated with this is the need for understanding by teachers of the overlapping values and pedagogy between the students' sites for literacy, so those that match the school can be reinforced through school programmes. There needs to be an understanding by teachers that incorporation involves both student and teacher input. The students need to feel comfortable that they can build on what is familiar to them, and although the connections they make may not be familiar to the teacher, the teacher can acknowledge the students' expertise in this field.

An important implication to consider is that in order to achieve incorporation, New Zealand teachers, who are largely monocultural and monolingual, need to establish more equitable and focused working relationships with the families and communities of minority language students.

The strategy of incorporation includes making connections to students' interests and knowledge through appropriate selections of topics and texts. It also includes building on students' expertise in ways of learning. Examples of these which emerged in the study are the skill of memorisation to recite to an audience, and reading aloud to an audience. An example from the literature is the traditional Samoan apprenticeship of learning through watching and listening, with AmituanaiToloa (2005) recommending that teachers build on this strength by ensuring that they demonstrate the desired practice rather than merely describing it to students.

There is a need for understanding by teachers of where conflict may exist for students in values, curriculum or pedagogy between their various sites for literacy. This is because students are making choices and at times they are having to reconcile (Wenger, 2006) between the differences of the various communities in which they operate. Understanding the consonant and conflicting values which relate to religion may be more challenging for teachers in schools where there is not a connection between the school and the church, and teachers need to be sensitive to the range of views in their community. 
A common example of out-of-school knowledge which has implications for school practice is popular culture. Because popular culture is an intrinsic aspect of students' individual and group identity, teachers can make effective links to students' out-ofschool knowledge by incorporating aspects of popular culture into school programmes. Innovative uses of literacy are developing rapidly, and teachers may not be aware of some that are important to young people. They need to allow students to share their expertise in these developing literacies and uses of technology. While it is likely that texts from popular culture would be motivating for students, the texts would need to be carefully selected in order that one group's tastes are not ridiculed or rejected and so that the values in the texts did not clash with those of the community.

An important implication for practice in schools is that knowledge of students' outof-school literacies may help teachers to challenge beliefs about how they assess their students' literacy and the tools they use to do this. It may lead to more careful selection of how particular assessment tools are used (for example by assessing students when they read or write about topics that reflect their out-of-school knowledge) or by balancing the more formal assessment with non-standardised and informal assessment procedures. An example of this might be the teacher and students jointly constructing criteria relating to the use of popular culture texts in the classroom and using these criteria for self and peer assessment.

Teachers need to ensure that comprehension skills are emphasised. This is to take students beyond a literal interpretation of text to make inferences, analyse and evaluate texts. They need to include a critical literacy perspective as in this study the church related practices seemed to focus strongly on literal interpretation. The literature supports the view that critical literacy is particularly important for students from diverse backgrounds who may be disadvantaged through being taught mainly literal levels of comprehension (Au \& Raphael, 2000; Rickford, 1999). Critical literacy enables students to consider the ideology of various texts through analysis of language and consider how this relates to power relationships in society.

If the students' parents and the Sunday schools are using the Samoan language it would seem logical to continue the use of Samoan at school. Teachers in the students' school were strongly of the view that Samoan should be taught in the 
school. There is literature to support the view that promoting bilingualism supports literacy learning for students such as these (May, Hill \& Tiakiwai, 2004). This is an important issue that may need to be brought to the fore and discussed at national level. To provide bilingual education, schools need to include fluent speakers of Samoan. (This has important implications for education policy which are outlined below).

It would be worthwhile for schools to provide guidance for students at all levels to enable them to nurture literacy with younger siblings. It emerged in this study that most of the students were acting as teachers of literacy to young children and this is supported by the literature (Gregory, 2004). The school encouraged older students to work with younger children in the school setting and this occurred both on an organised and an informal basis.

\section{The implications for education policy}

It is essential that schools retain autonomy of choice over the tools they use to assess literacy. Education policy needs to ensure that schools are not pressured to use only skills-based and decontextualised assessment of literacy. There needs to be provision for schools to value the home and community literacies of their students and to assess them in sensitive ways.

Research evidence should be provided to parents and educators of the advantages of bilingualism in Pasifika languages and English. There are two aspects to this. The first relates to the draft curriculum (Ministry of Education, 2006b) which increases the profile of second language learning and provides the opportunity for New Zealanders to value more highly the languages that are spoken in the countries of New Zealand's closest neighbours and by increasing numbers of people in New Zealand. The second aspect is in promulgating the message that strength in the home language can have benefits rather than disadvantage the child who is learning English as a second language at school.

There is support (outlined in Chapter 4) from the Pasifika community and Ministry of Education for greater use of Pasifika languages in New Zealand schools. This thesis strongly supports this argument and recommends that there be an increased number of teachers who are able to teach in Pasifika languages and who have 
knowledge of Pasifika cultures. This would enable children who have had preschool experience in a Pasifika language to continue this learning through school (like the continuity from kohanga reo ${ }^{15}$ to immersion and bilingual classes for children learning in Māori). It is worth capitalising on the language resource already in the community by attracting greater numbers of fluent speakers of Pasifika languages into teaching. An appropriate medium-term strategy to encourage those with a Pasifika cultural and language background into teaching would be to sow the seeds early by encouraging students to consider this option when they are beginning secondary school. There is a continuing need to have more teachers from Pasifika backgrounds in New Zealand schools. With over 9 percent of students in schools from a Pasifika background and only 3 percent of teachers, the number of Pasifika teachers needs to reflect better the student population.

For teachers to use the incorporation strategy successfully with Pasifika students, they need to have knowledge of Pasifika cultures, so information on this needs to be included for all teachers in pre-service and in-service teacher education as well as in teacher resources. If teachers are to incorporate students' out-of-school knowledge and expertise into school programmes, it is vitally important that they retain the freedom to interpret the curriculum in ways that are sufficiently flexible to allow them to make these links.

There is a continuing need for more text resources in Pasifika languages for primary and secondary students to support the teaching of Pasifika languages in schools. There is also a need to continue to produce texts by, and about, Pasifika people to enable teachers and students to make effective links.

\section{The implications for future research}

There is a continuing need for more research into the successful incorporation of Pasifika students' out-of-school literacies. This is to investigate how these literacies are recognised by schools and used in literacy programmes. It needs to examine how teachers make effective links to incorporate students' knowledge and out-of-school pedagogies in order to improve students' literacy levels as they are assessed by schools. There is a need for further research into literacy to provide insider views of

\footnotetext{
${ }^{15}$ Kohango reo is a Māori language early childhood centre.
} 
Pasifika participants in various communities of practice in New Zealand. This would involve young people as participants where they have some control over the research process as they illustrate how they make sense of the world. This research could investigate the issues for the students who are immersed in two cultures and who use two languages in different communities of practice. Future research could explore issues of differing values in the students' communities of practice and how students deal with the reconciliation of values between their communities of practice. The research could consider the effect these have on students' learning in school. There is a need to investigate how teachers are successfully using popular culture in the classroom as a way to incorporate Pasifika students' out-of-school literacies. This would explore how teachers successfully link these into the requirements of the official curriculum. 


\section{References}

Abercrombie, N., Hill, S., \& Turner, B. (1994). The penguin dictionary of sociology (3rd ed.). London: Penguin Books.

Alton-Lee, A. (2003). Quality Teaching for Diverse Students in Schooling: Best Evidence Synthesis. Wellington: Ministry of Education.

Alvermann, D., \& Heron, A. (2001). Literacy identity work: Playing to learn with popular media. Journal of Adolescent and Adult Literacy, 45(2), 118-122.

Amituanai-Toloa, M. (2005). Ua Malie Toa Ua Malie Tau. Students with silver tongues whip the tail: Enhanced teaching and learning of reading comprehension in Samoan bilingual classes. Unpublished thesis submitted in fulfillment of the requirements for the degree of Doctor of Philosophy (Education) The University of Auckland, Auckland.

Anae, M., Coxon, E., Mara, D., Wendt-Samu, T., \& Finau, C. (2001). Pasifika Education Research Guidelines Final Report. Wellington: Ministry of Education.

Apple, M. (1990). Ideology and curriculum (2nd ed.). New York: Routledge.

Apple, M. (1999). Power, meaning, and identity: Essays in critical educational studies. New York: Peter Lang Publishing.

$\mathrm{Au}$, K. (1980). Participation structures in a reading lesson. Anthropology and Education Quarterly, 11(2), 91-115.

$\mathrm{Au}$, K. (1995). Multicultural perspectives on literacy research. Journal of Reading Behavior, 27(1), 85-100.

$\mathrm{Au}, \mathrm{K}$. (2002). Multicultural factors and the effective instruction of students of diverse backgrounds. In A.E. Farstrup \& S.J. Samuels (Eds.), What research has to say about reading instruction. Delaware: International Reading Association.

Au, K., \& Raphael, T. (2000). Equity and literacy in the next millenium. Reading Research Quarterly, 35(1), 170-188.

Barton, D. (1994). Literacy: An introduction to the ecology of written language. Oxford: Blackwell.

Barton, D. (2000). Researching literacy practices: Learning from activities with teachers and students. In D. Barton, M. Hamilton \& R. Ivanic (Eds.), Situated literacies: Reading and writing in context (pp. 167-179). London: Routledge.

Barton, D., \& Hamilton, M. (1998). Local literacies:Reading and writing in one community. London: Routledge.

Barton, D., \& Hamilton, M. (2000). Literacy Practices. In D. Barton, M. Hamilton \& R. Ivanic (Eds.), Situated literacies: Reading and writing in context (pp. 7-15). London: Routledge.

Barton, D., Hamilton, M., \& Ivanic, R. (2000). Introduction: Exploring situated literacies. In D. Barton, M. Hamilton \& R. Ivanic (Eds.), Situated literacies: Reading and writing in context (pp. 1-6). London: Routledge.

Biddulph, F., Biddulph, J., \& Biddulph, C. (2003). The complexity of community and family influences on children's achievement in New Zealand: Best evidence synthesis. Wellington: Ministry of Education. 
Bogdan, R., \& Biklen, S. (1992). Qualitative research for education: An introduction to theory and methods. Boston: Allyn and Bacon.

Bourdieu, P. (1974). The school as a conservative force: scholastic and cultural inequalities. In J. Eggleston (Ed.), Contemporary research in the sociology of education. London: Methuen.

Brash, D. (2005, April 28, 2005). A better education for every child. The Dominion Post, p.?

Broadfoot, P. (1996). Education, assessment and society: a sociological analysis. Buckingham: Open University Press.

Bronfenbrenner, U. (1979). The ecology of human development. Cambridge MA: Harvard University Press.

Burnett, C., \& Myers, J. (2002). "Beyond the frame": Exploring children's literacy practices. Reading, 36(2), 56-62.

Burns, R. (2000). Introduction to research methods. London: Sage Publications

Cairney, T. (2003). Literacy within family life. In N. Hall, J. Larson \& J. Marsh (Eds.), Handbook of early childhood literacy (pp. 86-98). London: SAGE Publications Ltd.

Carpenter, V. (2001). Curriculum and the (Re) production of education. In H. D. V. Carpenter, E. Rata, C. Rawlinson (Ed.), Theory in practice for educators. Palmerston North: Dunmore Press.

Carspecken, P. F. (1996). Critical ethnography in educational research: A theoretical and practical guide. New York: Routledge.

Clark, A., \& Moss, P. (2001). Listening to young children: The mosaic approach. London: Natoinal Children's Bureau.

Codd, J., \& Openshaw, R. (2005). The education system in Aotearoa New Zealand. Melbourne: Thomson Dunmore Press.

Cole, M. (2000). Cultural Psychology: A once and future discipline. Cambridge, Mass.: The Belknap Press of Harvard University Press.

Collier, J., \& Collier, M. (1986). Visual Anthropology: Photography as a research method. Albuquerque: University of New Mexico Press.

Collier, M. (2001). Approaches to analysis in visual anthropology. In T. van Leeuwen \& C. Jewitt (Eds.), Handbook of visual analysis (pp. 35-94). London: Sage Publications.

Collins, J., \& Blot, R. (2003). Literacy and literacies: Texts, power and identity. Cambridge: Cambridge University Press.

Coxon, E., Anae, M., Mara, D., Wendt-Samu, T., \& Finau, C. (2002). Literature review on Pacific education isuues:Final report. Auckland: University of Auckland.

Cremin, L. (1976). Public education. New York: Basic Books Inc.

Cremin, L. (1977). Traditions of American education. New York: Basic Books Inc.

Cremin, L. (1988). American Education: The metropolitan experience 1876-1980. New York: Harper \& Row. 
Crooks, T., \& Flockton, L. (2005). Reading and Speaking Assessment Results 2004. Dunedin: Educational Assessment Research Unit, University of Otago

Darling, J., \& Nisbet, J. (2000). Dewey in Britain. In J. Oelkers \& H. Rhyn (Eds.), Dewey and European education. Dordrecht, The Netherlands: Kluwer Academic Publishers.

Davies, C. A. (1999). Reflexive ethnography. A guide to researching selves and others. London: Routledge.

Delpit, L. (2006). Other people's children: Cultural conflict in the classroom. New York: The New Press.

Denscombe, M. (2002). Ground rules for good research: a 10 point guide for social researchers. Buckingham Open University Press

Denzin, N., \& Lincoln, Y. (Eds.). (2000). Handbook of qualitative research (Second ed.). Thousand Oaks Calif.: Sage Publications Ltd.

Department of Education. (1987). The curriculum review. Wellington: Government Printer.

Dewey, J. (1941). Education Today. London: George Allen \& Unwin Ltd.

Dewey, J. (1966). Selected educational writings. London: Heinemann.

Dickie, J. (2000). Pacific nations students in primary teacher training: Investigating their learning needs. Unpublished master's thesis, Victoria University of Wellington, Wellington.

Drury, R. (2004). Samia and Sadaqat play school: Early bilingual literacy at home. In E. Gregory, S. Long \& D. Volk (Eds.), Many pathways to literacy (pp.4051). London: Routledge Falmer.

Duranti, A., \& Ochs, E. (1993). Literacy instruction in a Samoan village. In B. Schieffelin \& P. Gilmore (Eds.), The acquisition of literacy: Ethnographic practices (pp. 213-232). New Jersey: Ablex Publishing Corporation.

Dyson, A. H. (2003). "Welcome to the Jam": Popular culture, school literacy, and the making of childhoods. Harvard Educational Review, 73(3), 328-361.

Education Counts. (n.d.). Student numbers as at 1 July 2006. Retrieved May 16, 2007 from http://educationcounts.edcentre.govt.nz/statistics/schooling/student-numbers/

Education Counts.(n.d.). Pasifika education statistics. Retrieved 16 May, 2007 from: http://educationcounts.edcentre.govt.nz/statistics/schooling/student-numbers-atjuly-2006.

Education Counts. (n.d.). Pasifika-medium education as at 1 July 2006. Retrieved 16 May, 2007 from: http://educationcounts.edcentre.govt.nz/statistics/schooling/pasifikamedium-education

Eisenhardt, K. (2002). Building theories from case study research. In A. M. Huberman \& M. B. Miles (Eds.), The qualitative researcher's companion (pp. 5-35). Thousand Oaks: Sage Publications.

Elley, W. (2001). STAR Supplementary tests of achievement in reading. Wellington: New Zealand Council for Educational Research.

Ferdman, B. (1990). Literacy and cultural identity. Harvard Educational Review, 60(2), 181-204. 
Fleer, M. (2004). The cultural construction of family involvement in early childhood education: Some indigenous Australian perspectives. The Australian Educational Researcher, 31(3), 51-68.

Flick, U. (1998). An introduction to qualitative research. London: Sage Publications.

Flockton, L., \& Crooks, T. (2003). Writing Assessment Results 2002. Dunedin: Educational Assessment Research Unit, University of Otago.

Freire, P. (2000). Pedagogy of the oppressed. New York: Continuum International Publishing group.

Freire, P., \& Macedo, D. (1987). Literacy: Reading the word and the world. London: Routledge and Kegan Paul Limited.

Gaur, A. (1984). A history of writing. London: The British Library.

Gay, G. (1989). Ethnic minorities and educational equality. In J. B. C. M. Banks (Ed.), Multicultural Education issues and perspectives (pp. 167-188). Boston: Allyn and Bacon.

Gee, J. (1992). The social mind: Languager, ideology, and social practice. New York: Bergin \& Garvey.

Gee, J. (1996). Social linguistics and literacies: Ideology in discourses (Second ed.). London: The Falmer Press.

Gee, J. (1997). Foreword: A discourse approach to language and literacy. In Changing literacies (pp. xiii-xix). Buckingham, PA: Open University Press.

Gee, J. (1999). Critical issues: Reading and the new literacy studies: Reframing the National Academy of Sciences report on reading. Journal of Literacy Research, 31(3), 355-375.

Gee, J. (2000). The New Literacy Studies: From 'socially situated' to the work of the social. In D. Barton, M. Hamilton \& R. Ivanic (Eds.), Situated literacies: Reading and writing in context (pp. 180-196). London: Routledge.

Gee, J. (2001a). A sociocultural perspective on early literacy development. In S. Neuman \& D. Dickinson (Eds.), Handbook of early literacy research (Vol. 1, pp. 30-42). New York: The Guilford Press.

Gee, J. (2001b). Reading as situated language: A sociocognitive perspective. Journal of Adolescent and Adult Literacy, 44(8), 714-726.

Goldman-Segall, R. (1998). Points of viewing children's thinking: A digital ethnographer's journey. New Jersey: Lawrence Erlbaum Associates.

Goodridge, MJ. (1995). Activity systems of writing: A co-constructivist analysis of children's emergent writing development at home and in the transition to school in three diverse sociocultural settings. Unpublished doctoral thesis, University of Auckland.

Graff, H. (1987a). The labyrinths of literacy: Reflections on literacy past and present. Philadelphia: The Falmer Press.

Graff, H. (1987b). The legacies of literacy. Bloomington, US: Indiana University Press.

Gregory, E. (2004). 'Invisible" teachers of literacy: collusion between siblings and teachers in creating classroom cultures. Literacy, 97-105. 
Gregory, E. (2005). Playful talk: the interspace between home and school discourse. Early Years, 25(3), 223-235.

Hamilton, M. (2000). Expanding the New Literacy Studies:Using photographs to explore literacy as social practice. In D. Barton, M. Hamilton \& R. Ivanic (Eds.), Situated literacies: Reading and writing in context (pp. 16-34). London: Routledge.

Harper, D. (2002). Talking about pictures: A case for photo elicitation. Visual Studies (17 (1) ), 13-26.

Harris, T., \& Hodges, R. (Ed.). (1995). The literacy dictionary. Newark, Delaware: International Reading Association.

Heath, S. B. (1983). Ways with words. Cambridge: Cambridge University Press.

Hoggart, R. (1957). The uses of literacy. London: Chatto and Windus.

Hull, G., \& Schultz, K. (Eds.). (2002). School's out: Bridging out-of-school literacies with classroom practice. New York: Teachers College Press.

Hunkin-Tuiletufuga, G. (1996). A possible missing factor? The role of Pacific Islands languages in the education of Pacific Islands children in New Zealand. In Proceedings Report: National symposium 1996 Pacific Islands learning: The answers are within us (pp. 65-69), Education Training and Support Agency.

Hunkin-Tuiletufuga, G. (2001). Pasefika languages and Pasefika identities: Contemporary and future challenges. In C. Macpherson, P. Spoonley \& M. Anae (Eds.), Tangata O Te Moana Nui: The evolving identities of Pacific peoples in Aotearoa/New Zealand (pp. 196-211). Palmerston North: Dunmore Press.

Irwin, K. (1988). The needs of Pacific Island students in school. Paper presented at the Proceedings of the First Research into Educational Policy Conference, Wellington.

Kenway, J., \& Bullen, E. (2001). Consuming children. Buckingham: Open University Press.

Kincheloe, J., \& McLaren, P. (2000). Rethinking critical theory and qualitative research. In N. Denzin \& Y. Lincoln (Eds.), Handbook of qualitative research (2nd ed., pp. 279-313). Thousand Oaks Calif.: Sage Publications Limited.

Krause, K., Bochner, S., \& Duchesne, S. (2006). Educational psychology for learning and teaching (2nd ed.). Melbourne: Thomson.

Lankshear, C., Gee, J., Knobel, M., \& Searle, C. (1997). Changing Literacies. Buckingham: Open University Press.

Lankshear, C., \& Knobel, M. (1997). Different worlds? Technology-mediated classroom learning and students' social practices with new technologies in home and community settings. In Changing Literacies (pp. 164-187). Buckingham, Philadelphia: Open University Press.

Lankshear, C., \& Knobel, M. (2003). New Literacies: Changing knowledge and classroom learning. Buckingham PA: Open University Press.

Laqueur, T. (1976). The cultural origins of popular literacy in England 1500-1850. Oxford Review of Education, 2(3), 255-275. 
Lineham, P. (2003). Three types of church. In R. Bodde \& H. Kempster (Eds.), Thinking outside the square: Church in Middle Earth (pp. 199-224). Auckland: St Columba's Press.

Luke, A. (1994). The social construction of literacy in the primary school. Melbourne: MacMillan Education Australia Pty Ltd.

Luke, C. (1997). Media literacy and cultural studies. In S. Muspratt, A. Luke \& P. Freebody (Eds.), Constructing critical literacies: Teaching and learning textual practice (pp.19-49). Cresskill, NJ: Hampton Press.

Mahiri, J. (2000). Pop culture pedagogy and the end(s) of school. Journal of Adolescent and Adult Literacy, 44(4), 382-385.

Market Research Limited. (1995). Māori and Pacific Island demand for educational services: Survey prepared for Ministry of Education. Education Gazette, 75(60), 2-3.

Marsh, J., \& Millard, E. (2000). Literacy and popular culture: Using children's culture in the classroom. London: Paul Chapman Publishing Ltd.

Marshall, G. (Ed.). (1998). Oxford dictionary of sociology. Oxford: Oxford University Press.

May, S., Hill, R., \& Tiakiwai, S. (2004). Bilingual/Immersion education: Indicators of good practice: Final report to the Ministry of Education: Wilf Malcolm Institute of Educational Research, School of Education, University of Waikato.

McDonald, G. (1987). The ownership of literacy. Unpublished manuscript. Invited address, University of Otago.

McDonald, G. (1995, 7-10 December, 1995). Phonics, whole language and standards of literacy: Are they connected? Paper presented at the New Zealand Association for Research in Education, Palmerston North.

McDonald, G. (2006). Literacy and the achievement gap. Curriculum Matters, 2, 2642.

McInerney, D., \& McInerney, V. (1998). Educational psychology ( $2^{\text {nd }}$ ed.). Sydney: Prentice Hall.

McKenzie, D. (1985). Oral culture, literacy and print in early New Zealand: The Treaty of Waitangi. Wellington: Victoria University Press with the Alexander Turnbull Library.

McNaughton, S. (1995). Patterns of emergent literacy: Processes of development and transition. Auckland: Oxford University Press.

McNaughton, S. (2002). Meeting of minds. Wellington: Learning Media.

Miles, M., \& Huberman, A. M. (1994). Qualitative data analysis. Thousand Oaks, CA: Sage Publications

Milner, G. B. (1993). Samoan Dictionary. Auckland: Polynesian Press.

Ministry of Education. (1991b). The national curriculum of New Zealand: A discussion document. Wellington: Learning Media.

Ministry of Education. (1992a). Dancing with the pen. Wellington: Learning Media.

Ministry of Education. (1992b). English in the New Zealand curriculum. Wellington: Learning Media. 
Ministry of Education. (1993). The New Zealand Curriculum Framework. Wellington: Learning Media.

Ministry of Education. (1995). Reading in junior classes. Wellington: Learning Media.

Ministry of Education. (1996a). Ko e Ako 'a e Kakai Pasifika. Wellington: Ministry of Education.

Ministry of Education. (1996b). The learner as a reader. Wellington: Learning Media.

Ministry of Education. (1996c). Samoan in the New Zealand curriculum. Wellington: Learning Media.

Ministry of Education. (1999a). The Literacy Experts Group Report to the Secretary for Education. Wellington.

Ministry of Education. (1999b). Report of the literacy taskforce. Wellington: Ministry of Education.

Ministry of Education. (2001). Pacific education plan. Wellington: author.

Ministry of Education. (2003a). Effective literacy practice in years 1 to 4. Wellington: Learning Media.

Ministry of Education. (2003b). The New Zealand Curriculum Exemplars. Wellington: Learning Media and The Learning Centre Trust of New Zealand.

Ministry of Education. (2005). Education Standards Act. Wellington: Learning Media.

Ministry of Education. (2006a). Effective literacy practice in years 5 to 8. Wellington: Learning Media.

Ministry of Education. (2006b). The New Zealand curriculum: Draft for consultation 2006. Wellington: Learning Media.

Ministry of Education. (2006c). Pasifika education plan 2006-2010. Wellington: Ministry of Education.

Morrell, E. (2002). Toward a critical pedagogy of popular culture: Literacy development among urban youth. Journal of Adolescent and Adult Literacy, 46(1), 72-77.

New London Group. (1996). A pedagogy of multiliteracies: Designing social futures. Harvard Educational Review, 66(1), 60-92.

OECD. (2000). Literacy in the information age: Final report of the international adult literacy survey: OECD and Statistics: Canada.

Pahl, K., \& Rowsell, J. (2005). Literacy and Education: Understanding the New Literacy Studies in the classroom. London: Paul Chapman Publishing.

Palinscar, A., \& Herrenkohl, I.L. (2002). Designing collaborative learning contests. Theory into Practice, 41(1), 26-32.

Patton, M. (2002). Qualitative research and evaluation methods ( $3 \mathrm{rd}$ ed.). Thousand Oaks: Sage Publications.

Pedersen, E. (1995). Storytelling and the art of teaching. English Teaching Forum, 33(1), $2-5$. 
Phillips, G., McNaughton, S., \& MacDonald, S. (2001). Picking up the pace: Effective literacy interventions for accelerated progress over the transition into decile 1 schools. Wellington: Ministry of Education.

Price, H. (2000). Lo! I am on an ox. Wellington: Gondwanaland Press.

Prosser, J., \& Schwartz, D. (1998). Photographs within the sociological research process. In Image based research: A sourcebook for qualitative researchers (pp. 115-130).

Razfar, A., \& Gutierrez, K. (2003). Reconceptualizing early childhood literacy: The sociocultural influence. In N. Hall, J. Larson \& J. Marsh (Eds.), Handbook of early childhood literacy (pp. 34-47). London: SAGE Publications Ltd.

Reder, S. (1994). Practice-Engagement theory: A sociocultural approach to literacy across languages and cultures. In B. Ferdman, R. Weber \& A. Ramirez (Eds.), Literacy across languages and cultures (pp. 33-74). Albany: State University of New York Press.

Rickford, A. (1999). I can fly. Teaching narratives and reading comprehension to African American and other ethnic minority students. Lanham, Maryland: University Press of America.

Robbins, J. (2005). 'Brown paper packages'? A sociocultural perspective on young children's ideas in science. Research in science education, 35, 151-172.

Rogoff, B. (1990). Apprenticeship in thinking: Cognitive development in social context. New York: Oxford University Press.

Rogoff, B. (1995). Observing sociocultural activity on three planes: participatory appropriation, guided participation, and apprenticeship. In J. Wertsch, P. Del Rio \& A. Alvarez (Eds.), Sociocultural studies of mind (pp. 139-164). Cambridge: University of Cambridge.

Rogoff, B. (1998). Cognition as a collaborative process. In W. Damon, D. Kuhn \& R. Siegler (Eds.), Handbook of child psychology (5th ed., Vol. 2, pp. 679-744). New York: John Wiley \& Sons Inc.

Rogoff, B. (2003). The cultural nature of human development. New York: Oxford University Press.

Rowsell, J. (2006). Family literacy experiences: Creating reading and writing opportunities that support classroom learning. Markham, Ontario: Pembroke Publishers.

Schratz, M., \& Steiner-Loffler, U. (1998). Pupils using photographs in school selfevaluation. In J. Prosser (Ed.), Image-based research: A sourcebook for qualitative researchers (pp. 235-251). London: Routledge Falmer.

Schwartz, D. (1989). Visual ethnography: Using photography in qualitative research. Qualitative Sociology, 12(2,), 119-154.

Schweigert, F. (1999). Moral education in victim offender conferencing. Criminal Justice Ethics, Summer/Fall, 29-40.

Scribner, S.A., \& Cole, M. (1981). The psychology of literacy. CAmbridge, Mass.: Harvard University Press.

Silverman, D. (2001). Interpreting qualitative data (Second ed.). London: Sage Publications Ltd. 
Simon, J. (2000). Education policy change: Historical perspectives. In J. Marshall, E. Coxon, K. Jenkins \& A. Jones (Eds.), Politics, policy, pedagogy: Education in Aotearoa/New Zealand. Palmerston North: Dunmore Press.

Smith, J. (2004). Situated literacy: A study of family literacy in Aotearoa/New Zealand. Unpublished A thesis submitted in partial fulfilment of the requirements for the degree of Master of Education, Wellington College of Education, Wellington.

Spolsky, B. (1988). Report on the Samoan language in the New Zealand educational context. Wellington: Department of Education.

Stake, R. (2000). Case studies. In N. Denzin \& Y. Lincoln (Eds.), Handbook of qualitative research. (2nd ed., pp. 435-454). Thousand Oaks: Sage Publications Inc.

Statistics New Zealand. (2002). New Zealand official year book. Wellington: Government Print Publications.

Statistics New Zealand. (2006). New Zealand census. Retrieved 15 August, 2007 from http://www.stats.govt.nz/census/2006-census-data/classification-counts/a.

Statistics New Zealand. (2007). QuickStats about culture and identity. Retrieved 23 May, 2007 from: http://www.stats.govt.nz/census/2006-census-data/quickstatsabout-culture-identity/q.

Stevens, L. (2001). South Park and society: Instructional and curricular implications of popular culture in the classroom. Journal of Adolescent and Adult Literacy, $44(6), 548-555$.

Street, B. (1984). Literacy in theory and practice. Cambridge: Cambridge University Press.

Street, B. (1995). Social literacies: Critical approaches to literacy development, ethnography and education. New York: Longman.

Street, B. (1997). The implications of the 'New Literacy studies' for literacy education. English in Education, 31(3), 45-59.

Street, B. (2003). What's "new" in new literacy studies? Critical approaches to literacy in theory and practice. Current Issues in Comparative Education, 5(2), $1-14$.

Street, B. (Ed.). (1993). Cross-cultural approaches to literacy. Cambridge: Cambridge University Press.

Sturrock, F., \& May, S. (2002). PISA 2000: The New Zealand context. The reading, mathematical and scientific literacy of 15 year olds. Wellington: Learning Media.

Tagoilelagi, F. (1995). The role of the Samoan culture (Fa'asamoa) in the development of its children's literacy skills. Unpublished MA thesis ,, University of Auckland Auckland.

Taumoefolau, M., Starks, D., Bell, A., \& Davis, K. (2004). The role of second language acquisition theory and practice in Pasifika language maintenance in New Zealand. In Language Acquisition Research: Papers presented at a Ministry of Education Forum held in 2003 (pp. 41-55). Wellington: Research and Evaluation Unit, Ministry of Education. 
Taylor, D. (1983). Family Literacy. Young children learning to read and write. Portsmouth NH: Heinemann Educational Books Inc.

Tharp, R., \& Gallimore, R. (1990). Rousing minds to life: Teaching, learning, and schooling in social context. Cambridge: Cambridge University Press.

Thomas, R.M. (1984). American Samoa and Western Samoa. In R.M. Thomas \& T.N. Postlethwaite (Eds.), Schooling in the Pacific Islands: Colonies in transition (pp.203-235). Oxford: Pergamon Press.

Timperley, H., Robinson, V., \& Bullard, T. (1999). Strengthening Education in Mangere and Otara: The First Year Evaluation Report. Wellington: MInistry of Education, Research Division.

Tuafuti, P. (2000). Bridging the dichotomy between modern and traditional literacies in Samoan and English. Many Voices, 15, 10-14.

Timperley, H., Phillips, G., \& Wiseman, J. (2003). The sustainability of professional development in literacy: Parts One and Two. (Report to the Ministry of Education). Wellington: Ministry of Education.

Vidich, A., \& Lyman, S. (2000). Qualitative methods: Their history in sociology and anthropology. In N. Denzin \& Y. Lincoln (Eds.), Handbook of qualitative research (2nd ed., pp. 37-84). Thousand Oaks: Sage Publications Inc.

Vygotsky, L. (1978). Mind in society: The development oh higher psychological processes. Cambridge MA: Harvard University Press.

Ward, K. (2004). Is New Zealand's future churchless? Stimulus: the New Zealand journal of Christian thought and practice, 12(2), 2-12.

Wenger, E. (2006). Communities of practice: Learning, meaning and identity. Cambridge: Cambridge University Press.

Wertsch, J. (1998). Mind as action. New York: Oxford University Press.

Wertsch, J., del Rio, P., \& Alvarez, A. (1995). Sociocultural studies: history, action, and mediation. In J. Wertsch, P. del Rio \& A. Alvarez (Eds.), Sociocultural studies of mind (pp. 1-34). Cambridge: Cambridge University Press.

Wolcott, H. (2001). Ethnographic research in education. In C. Conrad, J. Haworth \& L. Lattuca (Eds.), Qualitative research in higher education: Expanding perspectives (pp. 155-172). Boston: Pearson Custom Publishing.

Zemke-White, K. (2001). Rap music and Pacific identity in Aotearoa: Popular music and the politics of opposition. In C. Macpherson, P. Spoonley \& M. Anae (Eds.), Tangata O Te Moana Nui: The evolving identities of Pacific peoples in Aotearoa/New Zealand (pp. 228-242). Palmerston North: Dunmore Press.

Zinsser, C. (1985). For the Bible tells me so: Teaching children in a fundamentalist church. The Quarterly Newsletter of the Laboratory of Comparative Human Cognition, 7(3), 86-89. 


\section{Appendices}

Appendix A: $\quad$ Interview schedule for meeting one with Year 7 and 8 students

Appendix B: $\quad$ Discussion guide for meeting two with Year 7 and 8 students

Appendix C: Interview schedule for Church representatives

Appendix D: Information sheet for principals, teachers, parents/caregivers and church representatives

Appendix E: $\quad$ Consent form for Church representatives

Appendix F: Consent form for principals of participating schools

Appendix G: $\quad$ Parents/Caregivers consent form for their child (in English)

Appendix H: $\quad$ Pepa mo le maliega o Mātua / Tausi tamaiti

Parents/Caregivers consent form for their child (in Samoan)

Appendix I: $\quad$ Meeting three interview schedule for students

Appendix J: Discussion guide for meeting with school staff

Appendix K: Consent form for using photographs in the thesis 


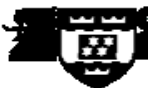

\section{Appendix A: Interview schedule for meeting one with Year 7 and 8 students}

John to read out questions 1 to 9 and record for each student this page as part of an informal conversation.

1. Boy / girl

$$
\text { Name }
$$

2. What is your age?

Date of birth

3. How many children are in your family?

4. What is your place in your family? (for example, the eldest, second youngest etc)

5. Are there other children living in your house? If there are, then how many children?

6. Which Pasifika culture or cultures do you belong to?

7. In which country were you born?

8. In which country or countries have you attended school?

9. Do you ever speak Samoan or another Pasifika language? 
10. If you do speak Samoan, how often do you speak in Samoan at home?

$\begin{array}{ccccc}\begin{array}{c}\text { Always or } \\ \text { almost always }\end{array} & \text { Quite a lot } & \text { Sometimes } & \text { A little } & \text { Never } \\ 5 & 4 & 3 & 2 & 1\end{array}$

11. Do you read in Samoan?

12. If you do read in Samoan, how good are you at this?

\section{Extremely good}

5
Not at all good

2

13. Where do you read in Samoan and what do you read?

14. Do you read in Samoan at Sunday School or Church?

15. Do you ever write in Samoan?

Yes

16. If you do write in Samoan how good are you at this?

Extremely good

5
2
Not at all good

1

17. If you write in Samoan, where do you do this and what sort of things do you write?

18. Do you write in either English or Samoan at Sunday School or Church? If you do then what do you write? 
19. Where do you go to Sunday School or church?

20. What do you like doing in your spare time? Please write your favourite first.

(1)

(2)

(3)

21 What do you most like to read in your own time? Please write your favourite first.

(1)

(2)

(3)

22. How important is it to know the other people in the group before you would speak about these sorts of things? 


\section{Appendix B: Discussion guide for meeting two with Year 7 and 8 students}

1. What sort of job would you like to have when you leave school?

2. How important are reading and writing for that job?

3. Have you heard that sometimes people from a Pasifika background don't get such good results in reading in English as some other students?

4. Have you heard that sometimes people from a Pasifika background don't get such good results in writing in English as some other students?

5. If you say yes, do you think this is fair? How do you feel about this?

6. Do you think that it will be more difficult for Samoan students at secondary school?

7. Do you think that reading and writing is more of a papalagi thing to do than a Pasifika one? What is your view? 


\section{Appendix C: Interview schedule for Church representatives}

1. Could you please describe any reading or writing activities that take place at church or Sunday School?

2. Which language is used?

3. Are the children taught some reading or writing skills at church or Sunday School?

4. What sort of skills are most valued?

5. Do the children do any tests or exams there?

6. Could you tell me what the purpose of these is and what they are testing?

7. Do the children work together on activities or by themselves?

8. When the children are reading, is any particular skill emphasised?

9. How important is it that they are completely accurate if they are reading aloud?

10. Do you think that these skills and activities are useful ones for the children when they go to school?

11. Have you heard that sometimes people from a Pasifika background don't get such good results in reading and writing in English as some other students?

12. Do you have any ideas about this?

13. What are your views on the contribution of the church to the literacy of church members?

14. Some people say that reading and writing is a papalagi value. What is your view? 


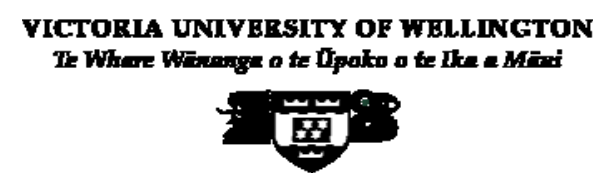

\title{
Appendix D: Information sheet for principals, teachers, parents/caregivers and church representatives
}

\author{
Research Project: \\ A study of the sites and uses of literacy by year 7 and 8 Pasifika students \\ Talofa lava, Malo e lelei, Fakaalofa lahi atu, Kia orana, Taloha ni, \\ Ni sa bula, Namaste, Kia ora.
}

\section{Who am I and why am I doing this research?}

My name is John Dickie and I am a papalagi New Zealander. I have worked in primary education in the Wellington area for 30 years. For 17 years I was a primary teacher and I developed a special interest in the teaching of reading and writing. For five years I worked for Wellington College of Education as adviser in reading and writing, visiting schools, advising and working with teachers and children on language programmes. For the last eight years I have been a lecturer in the English Department at Wellington College of Education working with primary teacher trainees.

This present study which is for a doctorate $(\mathrm{PhD})$ involves Pasifika learners, but focuses on primary students in years 7 and 8 (aged about 11-12 years) and it includes my interest in reading and writing. This is an important area as reading and writing tests show that many students from a Pasifika background do not achieve as well as papalagi students of the same age. I am interested in finding out how these year 7 and 8 students use reading and writing in community settings outside the school and I would like to observe the students in the classroom during their reading and writing instruction, then interview each group of students twice. I will give each group a disposable camera and ask them to take photos of how they use reading and writing in places other than school. They will be asked not to take photos of other people's faces without asking their permission first. I will collect the cameras and bring the photos so we can discuss them at our second interview. If any photographs were to be subsequently placed in my thesis or any other publication or presentation, permission will be sought from the participants. I will also ask them to collect samples of writing from their homes and I will give each student a notebook and ask them to write down their ideas about where they see reading and writing being used.

In addition to interviewing the students, I would like to interview representatives of churches as they may be able to provide useful information. If you have any questions please contact me by telephone (Work: 463 9767) or email john.dickie@vuw.ac.nz

Thank you

Yours sincerely

John Dickie 
YICTORIA UNIY ERSITX OF WELLINGTON

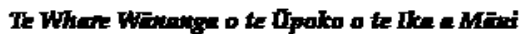

\title{
Appendix E: Consent form for Church representatives
}

\author{
Talofa lava, Malo e lelei, Fakaalofa lahi atu, Kia orana, Taloha ni,
}

Ni sa bula, Namaste, Kia ora

My name is John Dickie and I am a lecturer in the English Department in the College of Education, Victoria University. I am doing doctoral (PhD) study at Victoria University and my research is to explore how students from a Pasifika background use reading and writing outside the school in the home and in the community. I have included a description of my study in the information sheet. I am contacting you as I am particularly interested in the role of the church in encouraging literacy so I would like to talk to you about your views on this.

If you agree to being interviewed your name will remain confidential and you can withdraw from the interview at any time if you wish to do so. The interview will be tape recorded and a written copy of the conversation will be given to you. You can check it to make sure that it is an accurate record of our discussion and you can make changes to it if you wish.

The information that I collect will be seen only by my supervisors, a typist and by me. It will be stored securely in a locked cabinet at the College of Education and will be destroyed after three years. The findings of my research may be published and they will be shared with teachers and other interested people. While I am planning my study and gathering the information, I have sought the approval of a support group of three educators who are from a Pasifika background. They will not be shown any of the information I gather.

I do hope that you will agree to help me with this study.

Yours sincerely

John Dickie

\section{CONSENT TO PARTICIPATE IN RESEARCH}

Title of the project: An Autonomous and Ideological Investigation of Pasifika Children's Literacy at year 7 and 8.

Researcher: John Dickie

I have been given, and have understood an explanation of this project. I have had an opportunity to ask questions about it and to have them answered. I understand that at any time before the collection of data is completed, I may withdraw from the interviews or withdraw any information I have given. I agree to taking part in this research and I agree to the researcher using a tape recorder to record the interviews with me.

Signature:

Name: 
Date:

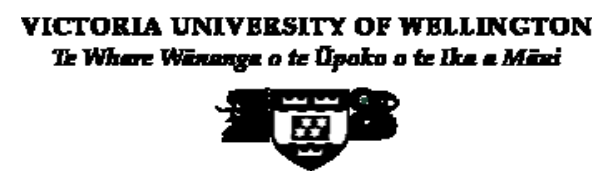

\title{
Appendix F: Consent form for principals of participating schools
}

\author{
Research Project: \\ A study of the sites and uses of literacy by year 8 Pasifika students \\ Researcher: John Dickie \\ Talofa lava, Malo e lelei, Fakaalofa lahi atu, Kia orana, Taloha ni, \\ Ni sa bula, Namaste, Kia ora
}

I have read John Dickie's introductory letter which explains this research project and I agree to year 8 students from this school participating in the project. I understand:

- that written permission will be sought from each student's parents/caregivers

- that the names of the students will remain confidential to the researcher

- that the students do not have to take part in this research and parents / caregivers can choose to withdraw consent for their participation in this research without having to give a reason, up to and including the final point of data collection

- that the students will use disposable cameras and take photographs which will be discussed at the interviews

- that the students will keep a journal and collect samples of writing

- that the conversations of the interviews will be audiotaped and then written

- that data collected will be seen only by the researcher and a typist, will be stored securely in a locked cabinet in a locked room at Wellington College of Education, and will be destroyed after three years

- $\quad$ that the research findings may be published and will be shared with teachers and other interested people

- that useful information from the study will be shared with the school 
- that the researcher seeks the approval for questions and research methodology from a Support Group which contains three Pacific nations educators. The Support Group will not view any data or help the researcher to interpret the data.

Name of Principal

Date

Signature

Name of school

Thank you very much for your assistance.

John Dickie 


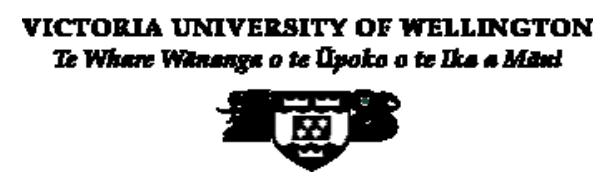

\title{
Appendix G: Parents/Caregivers consent form for their child
}

\author{
Talofa lava, Malo e lelei, Fakaalofa lahi atu, Kia orana, Taloha ni, \\ Ni sa bula, Namaste, Kia ora
}

\section{Dear Parents/Caregivers}

I am a lecturer in the English Department at Victoria University College of Education and I am doing some research to find ways we can improve our teaching of reading and writing for students from a Pacific Islands background. This is explained on the information form. I am interested in finding out how year 7 and 8 students use reading and writing outside the school at home and in the community. The school principal supports this research and has given permission for these interviews. I would like to observe the students in their classroom for approximately one hour during their reading and writing instruction, and interview the groups of students twice (each interview will take about 40 minutes).

I would like to give each group of two students a disposable camera to take photographs of their reading and writing activities outside the school. I will have the photographs developed and the students and I will discuss them at our second meeting. I would also like the students to write in a notebook that I will give them and to collect some examples of writing from their homes. The discussions will be tape recorded and then written down but no students will be identified by their names. The information collected will be seen only by me, my supervisors and a typist and it will be stored securely in a locked cabinet at Victoria University College of Education and destroyed after three years. The findings of the research may be published and will be shared with teachers and other interested people. When the research is completed I will give a short report to the school and request that this is made available to the parents of the students who have taken part in the study.

The students will not be tested or judged in any way. The names of the students will remain confidential and they do not have to take part in this research. If they do take part, you can withdraw your consent at any time without having to give a reason.

I am seeking your permission to interview

If you agree to your son/daughter taking part in this research would you please read and sign this consent form and return it to the school.

I agree for my son/daughter to take part in the above research.

Name of student

Name of Parent/Caregiver Date

Signature

Thank you very much for your assistance John Dickie 


\title{
Appendix H: Parents'/Caregivers' consent form for their child
}

\author{
Pepa mo le maliega o Mātua / Tausi tamaiti
}

Talofa lava, Malo e lelei, Fakaalofa lahi atu, Kia orana, Taloha ni, Ni sa bula,

\author{
Namaste, Kia ora
}

Mo Mātua / Tausi tamaiti

'O a'u 'o se faiā'oga i le Matātā Tau 'Igilisi i le Vāega o A'oa'oga Fa'afaiā'oga o le lunivesitē o Vìtoria, ma 'o lo'o o'u galue nei i le faiga o ni sā'ili'iliga e su'esu'e ai ni 'auala e fa'aleleia ai le a'oa'oina o le faitau tusi ma le tusitusi mo tamaiti ā'oga mai 'āiga Pasefika. 'O lo'o fa'amālamalamaina lenei vāega i le pepa o fa'amatalaga. 'Ou te fiailoaina pē fa'apēfea ona fa'aaogā le faitau tusi ma le tusitusi e tamaiti o le tausaga 7 ma le 8 i fafo o le ā'oga, i le fale fa'apēnā fo'i ma si'osi'omaga o tagata lautele. 'Ua lagolagoina e le pule ā'oga lenei fa'amoemoe ma 'ua ia tu'uina mai fo'i lana fa'atagaga e fai ai nei sā'ili'iliga. 'Ou te fiava'ava'aia aga a tamaiti i totonu o lo lātou potu ā'oga mo se itūlā e tasi 'a'o faia a lātou matā'upu ia o le faitau tusi ma le tusitusi, ma fa'atalanoa se vāega o i lātou ta'i fa'alua (e ta'i 40 mīnute le 'umi o talanoaga ta'itasi).

'Ou te mana'o fo'i 'ina 'ia tofu tamaiti ta'ito'alua ma se mea pu'eata e 'uma ma tia'i, e pu'e ai a lātou faitaugātusi ma le tusitusi i fafo atu o le ā'oga. 'A māe'a ona fa'availā'au nei ata, ona mātou fa'atalanoaina lea i la mātou fonotaga lona lua. 'Ou te mana'o fo'i 'ina 'ia tusitusi tamaiti i totonu o se 'api 'ou te tufaina i ai, 'ina 'ia mafai ona ao mai ai ni tusitusiga e fai ma fa'ata'ita'iga mai o lātou 'āiga. 'O le 'ā pu'eina nei talanoaga ma tamaiti i se lā'au pu'e leo e aunoa ma le fa'ailoaina o o lātou igoa. 'O nei fa'amatalaga 'o le 'ā aoina mai, 'o le 'ā faitau ai lava na'o a'u, 'o lo'u pule, ma ē fautuaina a'u fa'apēnā ma se tama'ita'i lomitusi, ma 'o le 'ā teuina ma le loka puipuia i kāpoti a le Vāega o A'oa'oga Fa'afaiāoga o le lunivesitē o Vìtoria, ma e fa'alēaogāina pe'ā 'uma le tolu tausga. 'O i'uga o nei sa'ili'iliga 'o le 'ā fa'asalalauina ma tufa atu fo'i i faiā'oga ma nisi o tagata e fiafia i ai. 'A 'uma ona faia le sa'ili'iliga, 'ou te tu'uina atu se līpoti pu'upu'u i le ā'oga, ma 'ou te fa'atalosagaina lenei līpoti 'ina 'ia mafai ona faitau ai mātua o tamaiti ā'oga sā 'auai i lenei su'esu'ega.

E leai se su'ega e su'e ai tamaiti ā'oga pe fa'amasinoina fo'i i so'o se itū. 'O igoa 'uma o tamaiti ā'oga 'o le 'ā malu puipuia, ma lātou 'auai i lenei su'esu'ega. 'Āfai e 'auai i lenei su'esu'ega, e mafai ona toe 'ave'eseina lau fa'atanaga i so'o se taimi lava e aunoa ma se mafua'aga e tu'uina mai.

'Ou te mana'omia lau fa'atanaga e fa'atalanoa ai

'Āfai 'ua 'e 'ioeina e 'auai lou alo i lenei su'esu'ega, fa'amolemole e faitau ma saini lenei pepa ona fa'afo'i mai lea i le ā'oga.

'Ua 'ou malie e 'auai la'u tama i le su'esu'ega.

Igoa o le tamaititi ā’oga

Igoa o Mātua/Tausi Tamaitliti Aso

Saini

Fa'afetai lava mo lau fesoasoani

John Dickie 


\section{Appendix I: Meeting three interview schedule for students}

\section{Name}

1/ How much do you like reading in your own time - not at school?

Heaps quite a lot sometimes never

2/ Do you have your own Bible?

If you write yes, then is your Bible in English or Samoan?

3/ Do you ever talk, read or write in the Samoan language to communicate with your grandparents, other relatives or friends?

4/ Do you sometimes have to help look after your younger brothers, sisters or relatives?

5/ Do you ever read to young children or listen to young children read to you?

6/ How often do you go to church? 
7/ How often do you go to Sunday school?

8/ Do you learn memory verses for Sunday school?

If you wrote yes, do you learn memory verses in English or Samoan?

9/ When you listen to the words of songs do you ever write the words down?

10/ How did you feel about writing in the journal?

11/ How did you feel about taking photos?

12/ Who does the writing at home?

13/ Does anybody at home read to you? 


\section{Appendix J: Discussion guide for meeting with school staff}

\section{Questions for discussion at staff meeting (I have put these into broad topics)}

1/ Is Samoan taught in the school?

Is there a connection with the A'oga Amata?

Do students converse in Samoan at school?

2/ Saying prayers and reading the Bible in Samoan and English were important outof-school literacy practices for the students. I am interested to find out if these were also part of their school literacy.

- Is the Samoan language ever be used for religious practices at school?

- Do the students study the Bible at school to learn the Christian doctrine?

- Do the students take part in prayers at school.?

- Do they read the Bible to others or hear the Bible read at school?

- Do students ever practise or recite memory verses at school?

- Would the school attend services in the church?

3/ What sort of comprehension skills are taught to students? Are they taught critical thinking?

If they are, what sort of issues might they be discussing in relation to critical thinking?

4/ Are aspects of popular culture incorporated into school lessons?

(e.g.Children's novels are.) Would links be made to music or movies or other aspects of children's popular culture?)

Do they read comics and magazines at school, for example in the school library? 
5/ Do teachers make links into students' cultural backgrounds?

6/ I have been learning about the community values in relation to literacy practices. One mentioned was "no swearing". Would this be stressed at school? Would other values such as those stressed in church and Sunday school be learned at school too? (Maybe based on Biblical teachings).

7/ Would the older students ever be working with younger students in the school, for example in hearing them read or in reading to them? If they do, are particular skills or behaviours emphasised?

Are parents informed about how they might help with reading at home?

8/ Students used computer skills in the Newtown library (catalogue and Internet searches). Did they learn these at school?

Did they use them in the school library?

Is there liaison between the school teacher and the librarians over what is taught in the library?

9/ What sort of employment are the parents in?

10/ Would students read newspapers at school?

11/ What sort of reading/writing homework would the year 7 and 8 students have?

(For example they mentioned doing research in the library.)

12/ What are the most effective ways of communicating with parents? 


\title{
Appendix K: Consent form for using photographs in the thesis
}

\author{
17 May, 2007
}

Dear

When you were a student at St Anne's School you assisted me with my research into Year 7 and 8 students' uses of literacy in their homes and community by taking photos and meeting with me to explain the uses of literacy that were shown in your photos.

Since we met I have been writing the results of this research which will be recorded in my thesis which is a book that will be placed in the university library. I would very much like to include in the book some of the photographs you took as they will add interest to the book and help to explain your uses of reading and writing. This letter is to ask your permission for using the photographs which are enclosed with this letter.

In future I may be talking about this research at conferences and I would like your permission please to show your photos to people there. As well, it is possible that I may want to use them in another book.

If you do agree to this would you please sign the form attached to this letter and return it to me in the enclosed stamped envelope.

Thank you for your assistance. Best wishes for your studies at college.

Yours sincerely

\section{John Dickie}

If you agree to your photographs being included in John Dickie's thesis would you please sign this form and return it in the enclosed stamped envelope.

Yes I agree to my photographs being included in John Dickie's thesis.

Name of student

Signature

If you also agree to the photographs being shown to other people at a conference or in another book would you please sign this section.

Signature

Thank you very much for your assistance

John Dickie 